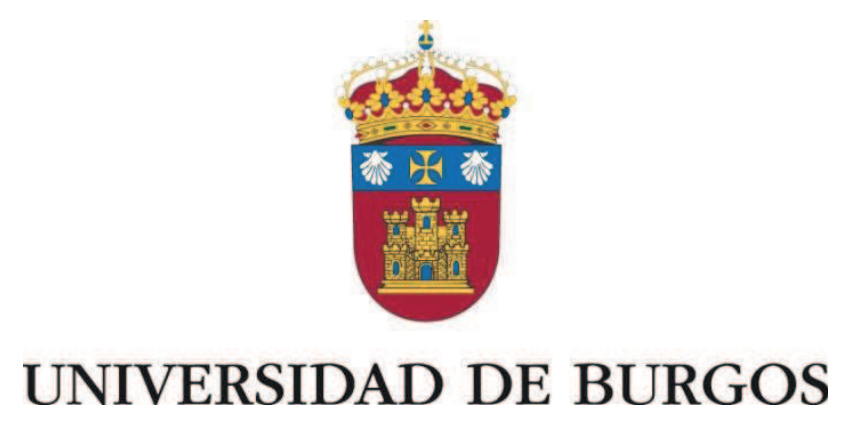

\title{
Morteros aligerados con residuos de espumas rígidas de poliuretano Obtención, caracterización y puesta en obra
}

TESIS DOCTORAL

AUTOR:

DIRECTORA:

CODIRECTOR:
Carlos Junco Petrement

Dra. Verónica Calderón Carpintero

Dr. Ángel Rodríguez Sáiz 


$$
!
$$




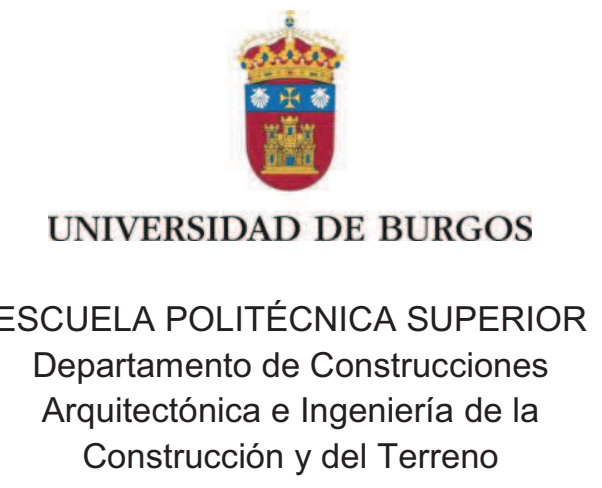




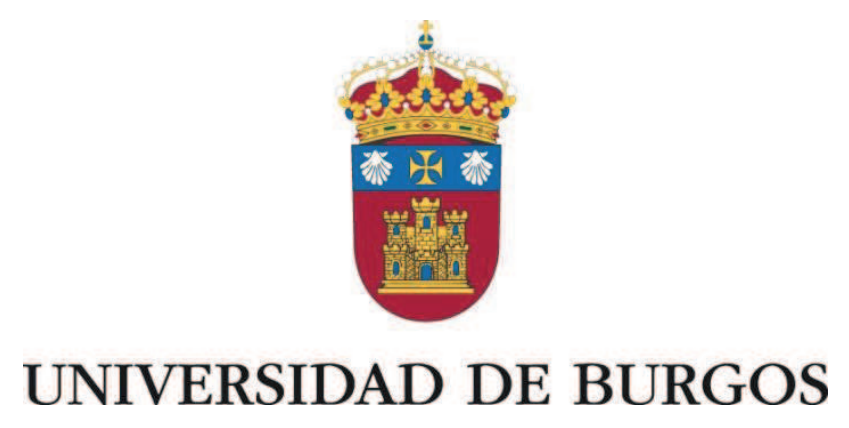

\section{Morteros aligerados con residuos de espumas rígidas de poliuretano Obtención, caracterización y puesta en obra}

TESIS DOCTORAL

AUTOR:

DIRECTORA:

CODIRECTOR:
Carlos Junco Petrement

Dra. Verónica Calderón Carpintero

Dr. Ángel Rodríguez Sáiz 



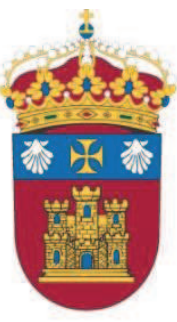

Dña. Verónica Calderón Carpintero, Profesora Titular Doctora y D. Ángel Rodríguez Sáiz, Profesor Titular Doctor, del Área de Construcciones Arquitectónicas del Departamento de Construcciones Arquitectónicas e Ingeniería de la Construcción y del Terreno de la Escuela Politécnica Superior de la Universidad de Burgos,

I N F O R M A N :

Que la presente Memoria titulada "Morteros aligerados con residuos de espumas rígidas de poliuretano. Obtención, caracterización y puesta en obra" se ha realizado en el Departamento de Construcciones Arquitectónicas e Ingeniería de la Construcción y del Terreno de la Universidad de Burgos, bajo su dirección, por el Arquitecto Técnico D. Carlos Junco Petrement y autorizan su presentación para que sea calificada como TESIS DOCTORAL

Burgos, 9 de noviembre de 2012

Fdo: Dra. Verónica Calderón Carpintero Fdo: Dr. Ángel Rodríguez Sáiz 

A Ana y nuestros hijos

\section{Agradecimientos}

Mi más sincero agradecimiento a Jesús Gadea Sáinz, compañero y mentor desde mi incorporación a esta Universidad.

A mis directores de Tesis, Verónica Calderón Carpintero y Ángel Rodríguez Sáiz, amigo. Sus experiencias investigadoras y su apoyo permanente han sido decisivos desde el inicio de este trabajo. En momentos me he sentido abrumado por la dedicación de Verónica al buen fin de esta Tesis.

A Sara Gutiérrez González, hemos compartido lealmente intendencia y optimismo.

A mis compañeros del laboratorio, José Luis Díez del Campo y Pablo Luis Campos de la Fuente

Muy especialmente a Yésica Pardo Delgado, por su interés, tenacidad y buen carácter.

A todo el grupo de materiales, al que afortunadamente pertenezco. 



\section{Resumen}

La utilización de residuos de espumas rígidas de poliuretano generados en la industria, como sustitutivo de la arena en los morteros para albañilería, tiene un doble efecto beneficioso para la preservación del medio ambiente. Por un lado se reciclan unos desechos que generalmente acaban en vertederos y por otro se disminuye el consumo de áridos que se extraen de la naturaleza.

La caracterización física y química de los morteros confeccionados con los residuos de espuma de poliuretano, nos muestra que las mezclas obtenidas tienen propiedades que los pueden hacer aptos para su utilización en obras de construcción.

Por ello se han diseñado distintas mezclas con varias clases de cemento, arena y dos tipos de espuma, empleando diferentes dosificaciones con el objeto de comprobar la viabilidad de los morteros.

Para la fase experimental del estudio de las propiedades de los morteros se han seguido las normas UNE-EN aplicables a los morteros para albañilería, y a falta de normativa concreta, se han utilizado aquéllas que se refieren a materiales similares como la piedra natural.

La consistencia, densidad y aire ocluido en estado fresco y la densidad y resistencias mecánicas a flexión y compresión en estado endurecido han indicado que la mayoría de los morteros estudiados cumplen con las especificaciones de la normativa de aplicación. El principal inconveniente encontrado ha sido la elevada cantidad de cemento por metro cúbico de mortero en las mezclas con resistencias mecánicas altas, lo que ha obligado a seleccionar las dosificaciones con mejor ratio de resistencia por cantidad de cemento, primando especialmente los morteros con mayor contenido de espuma.

Se han estudiado las modificaciones que producen el empleo de dos tipos de aditivos en los morteros seleccionados y además se ha profundizado en el conocimiento de otras propiedades tales como la trabajabilidad y retención de agua, resistencia a la adhesión y a la abrasión, realizando por último, ensayos de envejecimiento acelerado para comprobar la durabilidad. 
Los resultados obtenidos en la fase de experimentación han sido similares a los de los morteros de uso habitual en albañilería, destacando fundamentalmente la mejor trabajabilidad, menor densidad del mortero endurecido, mayor elasticidad y un importante incremento de la permeabilidad al vapor en todas las dosificaciones estudiadas.

Para determinar la viabilidad de los morteros fabricados en este trabajo de investigación se ha realizado una pequeña construcción en el complejo de la "Cúpula de la Energía", en la localidad de Garray, provincia de Soria, dentro del Proyecto "CONPOL" de investigación CDTI-MEC, llevado a cabo entre nuestro equipo de investigación de la Universidad de Burgos y la empresa VIAS S.A., en la que se han empleado distintas dosificaciones en unidades de obra tales como fábrica de ladrillo, enfoscado interior y exterior y solera de nivelación de piso. La aptitud se ha contrastado con la ejecución de revestimientos cerámicos y de resinas epoxi y con acabado de pintura plástica, comprobándose en todos los casos, la idoneidad de los productos para recibir revestimientos tradicionales.

La baja densidad de las mezclas repercute directamente en la evaluación de las cargas sobre la estructura de los edificios, habiéndose realizado un estudio sobre un edificio tipo de viviendas, en el que se ha calculado que el empleo de los morteros aligerados puede llegar a reducir hasta en un 7,7\% el peso total del edificio.

La evaluación final de los morteros se ha completado con el estudio económico en función de la distancia de generación del residuo a la obra, destacando algunas mezclas cuyo coste de elaboración ha resultado igual e incluso inferior a los morteros tradicionales. 


\section{Summary}

The use of rigid polyurethane foam waste, from industrial production, as a substitute for sand in masonry mortars has two beneficial consequences for environmental conservation. On the one hand, waste that is often dumped in landfill sites may be recycled and, on the other hand, the use of fines extracted from the natural environment is reduced.

The physical and chemical characterization of mortars manufactured with polyurethane foam waste suggests that the properties of their mixtures could be suitable for use in construction work.

Different mixtures were therefore designed with various types of cement, sand and two types of foam, at different dosages, with the aim of testing the viability of such mortars.

At the experimental stage, the UNE-EN norms applicable to masonry mortars were followed in the study of mortar properties and in the absence of specific regulations, those referring to similar materials such as natural stone were used.

Consistency, density and level of occluded air in the fresh state and the flexural and compressive mechanical strengths and density in the hardened state all indicate that the majority of mortars in the study comply with the normative specifications for their application. The main drawback was the large amount of cement by cubic meter in the mixtures of high mechanical strength, which obliged us to select mixtures with higher strength ratios by percentage of cement, giving special priority to mortars with larger amounts of foam.

The modifications arising from the use of the two types of additives in the selected mortars were studied, as were other properties such as workability and water retention, adherence resistance, and abrasion, followed last of all by accelerated ageing to test durability.

The results obtained in the experimental phase were similar to those of mortars of habitual use in masonry, fundamentally highlighting better workability, lower density of hardened mortar, greater elasticity and an important increase in water vapor permeability for all the dosages under study. 
Various small constructions were built at the "Cúpula de la Energía" complex, at Garray, in the province of Soria, in order to determine the viability of the mortars manufactured in this investigation. These tests formed part of the "CONPOL" CDTI-MEC research project, conducted by the University of Burgos research team and the company VIAS S.A. Different dosages were used in work units such as brick masonry, interior and exterior renderings, and basement floor screed. Their adaptability was tested through the execution of ceramic and epoxy-resin renderings with plastic paint finishes, confirming in all cases the suitability of the products to support traditional renderings.

The low density of the mixtures has a direct impact on the evaluation of the structural loads of the buildings, which was confirmed by a study on a residential building, in which it was calculated that the use of lightweight mortars could reduce the total weight of the building by up to $7.7 \%$.

The final evaluation of the mortars was completed with an economic study that specified the distance from the source of waste generation to the site, highlighting preparatory costs of some mixtures that were on a par with or even less than traditional mortars. 




\section{ÍNDICE}

Capítulo 1.- Justificación y objetivos 1

1.1.- Antecedentes 3

1.2.- Objetivos 17

1.3.- Estado del arte 18

1.3.1.- Morteros ligeros 18

1.3.1.1.- Introducción de aire ocluido en su interior 19

1.3.1.2.- Mediante adición de cargas ligeras 21

1.3.2- Morteros aligerados con materiales tradicionales 22

1.3.2.1.- Arcilla expandida 22

1.3.2.2.- Perlita expandida $\quad 22$

1.3.2.3.- Vermiculita expandida 23

1.3.3- Morteros aligerados con residuos industriales 23

1.3.3.1.- Corcho natural 23

1.3.3.2.- Vidrio celular 24

1.3.3.3.- Papel reciclado 25

1.3.4.- Morteros modificados con polímeros 25

1.3.5.- Morteros aligerados con residuos poliméricos 27

1.3.5.1.- Poliestireno expandido (EPS) 27

1.3.5.2.- Poliereftalato de etilo (PET) 28

1.3.5.3.- Polietilvinilacetato de etilo (copolímero EVA) 29

1.3.6.- Morteros aligerados con residuos de poliuretano espumado $\quad 29$

1.4.- Morteros para albañilería $\quad 31$

1.4.1.- Introducción 31

1.4.2.- Empleo de material reciclado en los morteros.

Breve reseña histórica 34

1.4.3.- Concepto de mortero $\quad 35$

1.4.4.- Componentes del mortero 37

1.4.4.1.- Conglomerantes $\quad 37$

1.4.4.2.- Áridos $\quad 37$

1.4.4.3.- Agua 40

1.4.4.4.- Adiciones $\quad 40$

1.4.4.5.- Aditivos 41

1.4.5.- Propiedades de los morteros $\quad 42$

1.4.5.1.- Propiedades del mortero fresco 42

1.4.5.2.- Propiedades del mortero endurecido 43

1.4.5.2.1.- Características mecánicas $\quad 44$

1.4.5.2.2.- Características físicas $\quad 45$

1.4.5.2.3.- Durabilidad 47 
2.1.- Ensayos físicos 51

2.1.1.- Trituración de los residuos de espuma de poliuretano 51

2.1.2.- Densidad aparente del árido. Porosidad del árido 52

2.1.3.- Densidad aparente de las partículas 53

2.1.4.- Densidad aparente de la espuma conformada 54

2.1.5.- Densidad real de la espuma triturada 55

2.1.6.- Medida de la consistencia del mortero fresco 56

2.1.7.- Densidad aparente del mortero fresco 57

2.1.8.- Contenido de aire del mortero fresco 58

2.1.9.- Período de trabajabilidad del mortero fresco 59

2.1.10.- Capacidad de retención de agua del mortero fresco 60

2.1.11.- Densidad aparente del mortero endurecido 60

2.1.12.- Coeficiente de absorción del mortero endurecido 61

2.1.13.- Permeabilidad al vapor de agua del mortero endurecido 62

2.1.14.- Transmisión acústica a ruido aéreo 63

2.2.- Ensayos químicos 64

2.2.1.- Granulometría por difracción de rayos láser 64

2.2.2.- Difracción de rayos x (DRX) 65

2.2.3.- Análisis elemental 65

2.2.4.- Microscopía electrónica de barrido 66

2.2.5.- Termogravimetría 66

2.2.6.- Tomografía axial computerizada (TAC) 66

2.3.- Ensayos mecánicos $\quad 67$

$\begin{array}{ll}\text { 2.3.1.- Resistencia a flexión } & 67\end{array}$

2.3.2.- Resistencia a compresión 68

2.3.3.- Resistencia a la adhesión 69

2.3.4.- Resistencia a la abrasión 71

2.3.5.- Medición de la capacidad de deformación 72

$\begin{array}{ll}\text { 2.4.- Ensayos de durabilidad } & 73\end{array}$

2.4.1.- Resistencia a la helada 73

2.4.2.- Resistencia al envejecimiento por niebla salina 74

2.4.3.- Resistencia al dióxido de azufre en condensación general $\quad 76$

2.4.4.- Resistencia al envejecimiento acelerado en agua salina $\quad 77$

2.4.5.- Resistencia a la cristalización de sales 78

2.4.6.- Resistencia al envejecimiento por choque térmico $\quad 79$

2.4.7.- Envejecimiento acelerado (materiales poliméricos celulares) 80

Capítulo 3.- Caracterización de las materias primas 81

3.1.- Cementos 83

3.2.- Arena 86

3.2.1.- Requisitos geométricos 87

3.2.1.1.- Forma de las partículas $\quad 87$

3.2.1.2.- Granulometría y finos 87

3.2.2.- Requisitos físicos 90 
3.2.2.1.- Densidad aparente del árido

Densidad aparente de las partículas. Porosidad como árido 90

3.2.3.- Requisitos químicos 91

$\begin{array}{ll}\text { 3.3.- Agua } & 91\end{array}$

3.4.- Residuos de espuma rígida de poliuretano 92

3.4.1.- Características geométricas 93

3.4.1.1.- Forma de las partículas 93

3.4.1.2.- Granulometría y finos 93

3.4.2.- Características físicas $\quad 95$

3.4.2.1.- Densidad de la espuma conformada (antes del triturado) 95

3.4.2.2.- Densidad aparente y real de la espuma triturada 95

3.4.2.3.- Absorción de agua 96

$\begin{array}{ll}\text { 3.4.3.- Características químicas } & 97\end{array}$

3.4.3.1.- Composición química (CHNS) 97

3.4.3.2.- Microscopía electrónica de barrido (SEM)

Microanálisis por energía dispersa de barrido 97

3.5.- Aditivos 99

3.5.1.- Emulsión adhesiva 99

3.5.2.- Aditivo inclusor de aire/plastificante 99

Capítulo 4.- Morteros de referencia y morteros aligerados con residuos de espuma de poliuretano 101

4.1.- Diseño de los morteros 105

4.1.1.- Morteros de referencia 105

4.1.1.1.- Clasificación normalizada 106

4.1.1.2.- Dosificación y resistencia mecánica 106

4.1.2.- Morteros con agregados PUR 112

4.2.- Dosificación y fabricación de los conglomerados 114

4.3.- Resultados obtenidos 119

4.3.1.- Mortero fresco 119

4.3.1.1.- Densidad aparente 119

4.3.1.2.- Contenido de aire ocluido 119

4.3.1.3.- Rendimiento 119

4.3.2.- Mortero endurecido 123

4.3.2.1.- Densidad aparente 124

4.3.2.2.- Resistencias mecánicas 128

4.3.2.2.1.- Resistencia a flexión 128

4.3.2.2.2.- Resistencia a compresión 128

4.3.2.3.- Características químicas 141

4.3.2.3.1.- Microscopía electrónica de barrido (SEM) 141

4.3.2.3.2.- Termogravimetría (TGA) 142 
Capítulo 5.- Fabricación y caracterización de morteros con aditivos

5.1.- Criterios de selección

5.2.- Diseño de los morteros modificados con aditivos

5.3.- Dosificación y fabricación de los conglomerados modificados con aditivos

5.4.- Resultados obtenidos 162

5.4.1.- Mortero fresco 162

5.4.1.1.- Densidad aparente y aire ocluido 162

5.4.1.2.- Período de trabajabilidad 164

5.4.1.3.- Capacidad de retención de agua 168

5.4.2.- Mortero endurecido 169

5.4.2.1.- Características físicas 169

5.4.2.1.1.- Densidad aparente del mortero endurecido 169

5.4.2.1.2.- Absorción de agua 171

5.4.2.1.3.- Permeabilidad al vapor $\quad 174$

5.4.2.1.4.- Transmisión acústica a ruido aéreo 181

5.4.2.2.- Características mecánicas 182

5.4.2.2.1.- Resistencias a flexión y compresión 182

5.4.2.2.2.- Resistencia a la adhesión 187

5.4.2.2.3.- Resistencia a la abrasión 187

5.4.2.2.4.- Capacidad de deformación 189

Capítulo 6.- Durabilidad 197

6.1.- Resultados obtenidos 199

6.1.1.- Heladicidad 199

6.1.2.- Niebla salina 202

6.1.3.- Comportamiento frente al dióxido de azufre (Kesternich) 205

6.1.4.- Agua salina 208

6.1.5.- Cristalización de sales $\quad 210$

6.1.6.- Choque térmico 212

6.1.7.- Envejecimiento acelerado (materiales poliméricos) 214 
Capítulo 7.- Aplicación y puesta en obra 219

7.1.- Amasado en obra 222

7.2.- Aplicación en obra 223

7.2.1.- Mortero M II-4PU50A 223

7.2.2.- Mortero M II-4PU50B 223

7.2.3.- Mortero M IV-4PU50B 224

7.2.4.- Mortero M IV-6PU50A 224

7.2.5.- Mortero M IV-6PU75A 224

7.2.6.- Mortero M IV-6PU75B 225

7.3.- Puesta en obra de los morteros 225

7.3.1.- Ejecución de enfoscado de exteriores 225

7.3.2.- Ejecución de enfoscado de interior 226

7.3.3.- Ejecución de muro con juntas para revestir 226

7.3.4.- Ejecución de muro con juntas vistas 227

7.3.5.- Ejecución de solera de interior 228

7.3.5.1.- Mortero M IV-6PU75A 228

7.3.5.2.- Mortero M IV-6PU75B 229

7.3.6.- Chapado de baldosa cerámica 230

7.3.7.- Solado con baldosa cerámica 231

7.3.8.- Revestimiento con pintura epoxi 232

7.3.9.- Aplicación de pintura plástica 233

7.4.- Resultados de ensayos de muestras recogidas en obra 233

7.4.1.- Ensayos mecánicos 233

7.4.2.- Ensayos de adherencia de los morteros puestos en obra 234

7.5.- Resultados de ensayos sobre unidades de obra 235

7.5.1.- Ensayos organolépticos $\quad 235$

7.5.1.1.- Resultados iniciales 235

7.5.1.2.- Resultados a los 28 días 236

7.5.2.- Pruebas de aptitud $\quad 239$

7.5.2.1.- Adhesión de baldosa cerámica 240

7.5.2.2.- Adhesión sobre soporte de hormigón 242

7.5.2.3.- Pintura plástica sobre paramento enfoscado exterior $\quad 243$

7.5.2.4.- Pintura de acabado sobre soleras 243

7.5.2.5.- Resistencia a la penetración 243

7.5.2.6.- Dureza superficial 244 
Capítulo 8.- Estudio económico 247

8.1.- Valoración cuantitativa de los morteros con agregados de PUR 249

8.1.1.- Precios unitarios de los materiales a pie de obra 250

8.1.2.- Precio del mortero previo al amasado 251

8.2.- Disminución del valor de las acciones permanentes sobre la estructura de los edificios

Capítulo 9.- Conclusiones finales. Líneas de investigación de futuro

9.1.- Conclusiones finales

9.2.- Líneas de investigación de futuro 


$\leftarrow$

O

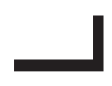

$\supset$

1

1

0

$\longrightarrow$

৩

Justificación y objetivos 



\section{Capítulo 1.- Justificación y Objetivos}

\section{1.- Antecedentes}

La creciente concienciación por la preservación de la naturaleza está contribuyendo de forma decisiva en la búsqueda de soluciones que alivien el impacto que los residuos tienen sobre el medio ambiente y la salud humana, por lo que se impone una eficiente gestión de los residuos. En respuesta a la demanda social y al agravamiento que supone el aumento incesante del volumen de residuos, especialmente en los países más industrializados, los estados han desarrollado su legislación elaborando planes que previenen la acumulación y/o destrucción indiscriminada de estos residuos.

La última Directiva europea sobre residuos, Directiva 2008/98/CE de 19/11 del Parlamento Europeo establece la siguiente definición de Residuo: cualquier sustancia u objeto del cual su poseedor se desprenda o tenga la intención o la obligación de desprenderse ${ }^{1}$ sin necesidad de estar incluido el residuo en ninguna clasificación o categoría previa.

Como objetivos clave de la política en materia de residuos de la Unión Europea, se encuentran

- reducir al mínimo los efectos negativos de la generación y gestión de los residuos para la salud humana y el medio ambiente

- reducir el uso de recursos, incluidos los no renovables

- favorecer la aplicación práctica de la jerarquía de residuos en este orden:

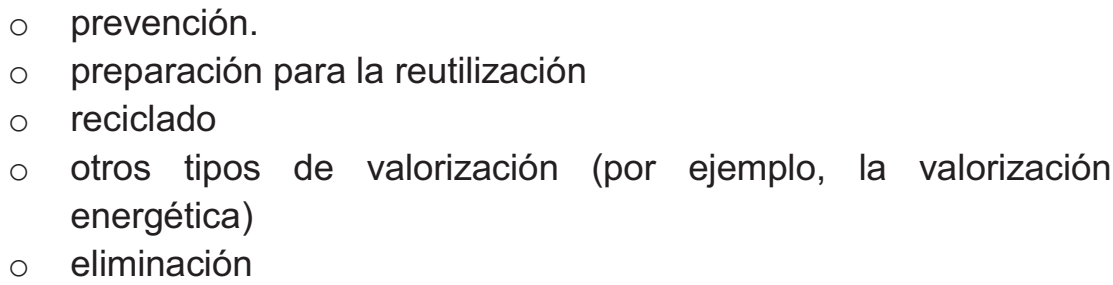

\footnotetext{
1 Directiva 2008/98/CE del Parlamento Europeo y del Consejo, de 19/11/2008, sobre residuos y por la que se derogan determinadas Directivas
} 
En España Ley 10/1998 de 21 de abril de Residuos, ${ }^{2}$ define el Residuo como cualquier sustancia u objeto perteneciente a cualquiera de las categorías que Figuran en el anejo de esta Ley, del cual su poseedor se desprenda o tenga la intención o la obligación de desprenderse. Dicha Ley 10/1998, establece la obligación de elaborar y aprobar Planes Nacionales de Residuos que se confeccionarán por integración de los respectivos Planes autonómicos. En cumplimiento de esa obligación se elaboró y editó el Plan Nacional Integrado de Residuos (PNIR) para el período comprendido entre los años 2008 y 2015 . $^{3}$

Dentro del Plan Nacional Integrado de Residuos (PNIR) (2008-2015), la política de residuos viene dada por un enfoque doble

- Los residuos como problema ambiental

- Los residuos como recursos que pueden contribuir al ahorro de materias primas, a la conservación de recursos naturales, a la preservación del clima y al desarrollo sostenible.

La filosofía que impregna el PNIR, deriva de la necesidad de garantizar que la gestión de los residuos no ponga en peligro la salud humana ni perjudique el medio ambiente, tal y como se señala en las Directivas europeas previas a la redacción del propio PNIR, y se corrobora en la Directiva 2008/98/CE. La aplicación de las medidas del PNIR en su forma más ambiciosa daría como resultado el aumento del conocimiento de los flujos y la gestión actual; la mejora en la eficiencia en la gestión de residuos; el crecimiento del sector empresarial especializado y la creación de empleo.

Para ello sería preciso completar la investigación y el desarrollo de diversos puntos que se citan a continuación:

- modificar la tendencia actual de crecimiento de residuos.

- erradicar el vertido ilegal.

- fomentar la prevención y la reutilización y consolidar el reciclado y la valorización, disminuyendo el vertido.

- completar infraestructuras y mejorar su funcionamiento.

\footnotetext{
2 Ley 10/1998 de 21 de abril de residuos. BOE № 96 de 22/04.

3 Plan Nacional Integrado de Residuos (PNIR) para el período 2008-2015. Resolución de 20 de enero de 2009. Ministerio de Medio Ambiente y Medio Rural y Marino. BOE N ${ }^{\circ}$ 49 de 26/02.
} 
- evaluar instrumentos económicos.

- consolidar programas del I+D+i.

- reducir la contribución de residuos al cambio climático.

Aunque los Programas de $1+D+i$ están empezando a dar resultados tangibles y se ha mejorado el control, la inspección y la vigilancia de la política de residuos, a la hora de realizar un primer análisis de la situación actual en el campo del reciclado y reutilización de materiales, se detectan una serie de carencias y parámetros alarmantes como son:

- déficit de información y de estadísticas.

- poca sensibilización sobre el problema ambiental de los residuos

- alto porcentaje de residuos destinados a vertedero

- legislación compleja y necesidad de articular diferentes modelos de gestión entre las Administraciones para su cumplimiento

- diferente grado de desarrollo y aplicación de la normativa entre distintas Administraciones

- necesaria actualización de normativa o creación de nueva normativa para residuos específicos y nuevos sistemas de gestión.

\section{Clasificación de los residuos}

Los residuos se pueden clasificar en función de dos parámetros que son:

- Según su peligrosidad: Residuos peligrosos (RP), cuya definición de acuerdo con la Ley 10/1998 de 21 de abril, son aquellos que figuran en la lista aprobada en el Real Decreto 952/1997 de 20 de junio, ${ }^{4}$ así como los envases y recipientes que los hayan contenido.

- Según las actividades productivas que los generen

- Residuos urbanos o municipales (RU), que son los generados en los domicilios particulares, comercios, oficinas y servicios, así como todos aquellos que no tengan la calificación de peligrosos y que por su naturaleza o composición puedan asimilarse a los producidos en los anteriores lugares o actividades. Dentro de estos residuos

\footnotetext{
${ }^{4}$ Real Decreto 952/1997 de 20 de junio, por el que se modifica el Reglamento para la ejecución de la Ley 20/1986, básica de residuos tóxicos y peligrosos. Ministerio de Medio Ambiente. BOE No 160 de 05/07. 1997
} 
urbanos están los procedentes de obras menores de construcción y reparación domiciliaria.

- Residuos industriales no peligrosos (RINP). Aquellos residuos producidos en el ejercicio de una actividad industrial productiva 0 de servicios que no estén identificados como peligrosos en la Orden MAM/304/2002 de 8 de febrero. ${ }^{5}$

- Existen además otro tipo de residuos como son los residuos de construcción y demolición (RCD), vehículos fuera de uso (VFU), neumáticos fuera de uso (NFU), pilas y acumuladores usados, plásticos de uso agrario, etc.

\section{Residuos plásticos y poliméricos}

Dentro de la categoría de residuos industriales no peligrosos se incluyen la inmensa mayoría de los generados por la industria de los plásticos, cuya producción a nivel mundial desde el año 1950, muestra un crecimiento sostenido. Un dato de especial relevancia es que la producción de plásticos creció un $167 \%$ en los últimos 20 años, (Figura 1.1).

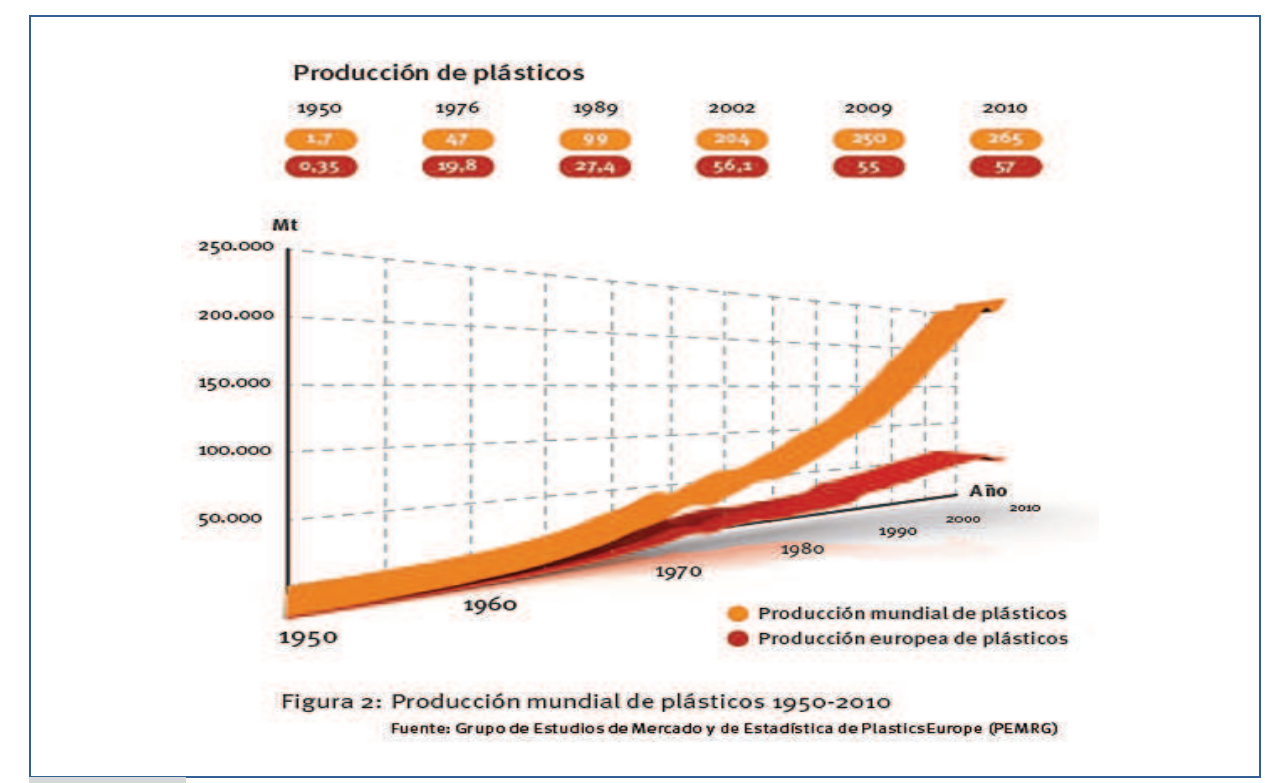

Figura 1.1. Producción mundial de plástico años 1950-2010

5 Orden MAM/304/2002 de 8 de febrero del Ministerio de Medio Ambiente, sobre valorización y eliminación de residuos. BOE № 43 de 19/02. 2002 
Aunque en el año 2009 la producción descendió ligeramente (6,1\%) respecto del año anterior, debido a la continuada ralentización de la economía, en el año 2010 volvió a incrementarse un $6 \%$, con lo que recuperó los niveles del año 2008.

La Unión Europea (considerando la Europa de los 27 países), más Noruega y Suiza (Figura 1.2) produce un total de 57 millones de toneladas de plástico, lo que supone el $21,5 \%$ de la producción mundial de este material del año $2010 .^{6}$

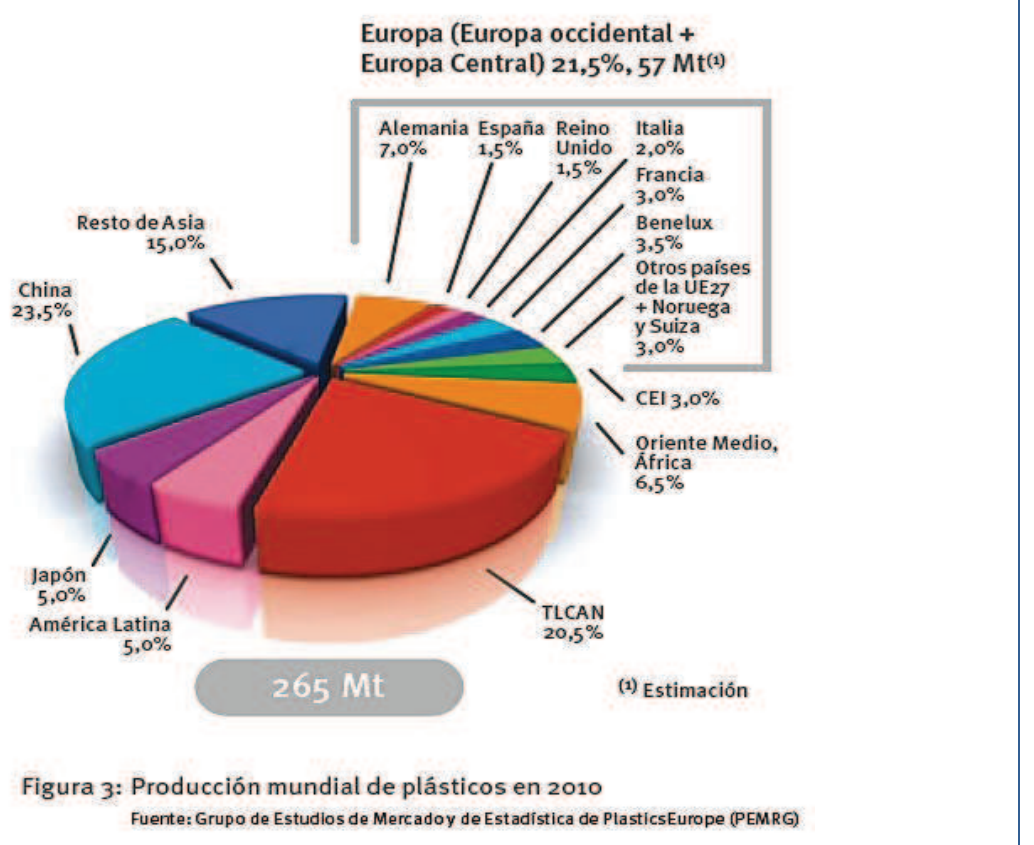

Figura 1.2. Producción mundial de plástico año 2010. Distribución por países

La demanda de plástico en la Unión Europea más Noruega y Suiza en el año 2010, por sectores de producción y por tipo de plástico, se indica en la Figura 1.3. Si centramos el análisis en la demanda de poliuretano éste supone el $7 \%$ de la demanda total de plástico, es decir 3,25 millones de toneladas.

\footnotetext{
${ }^{6}$ Grupo de Estudios de Mercado y Estadística de PlasticsEurope (PEMRG) Plásticos Situación en 2011. http://www. plasticseurope.es/
} 


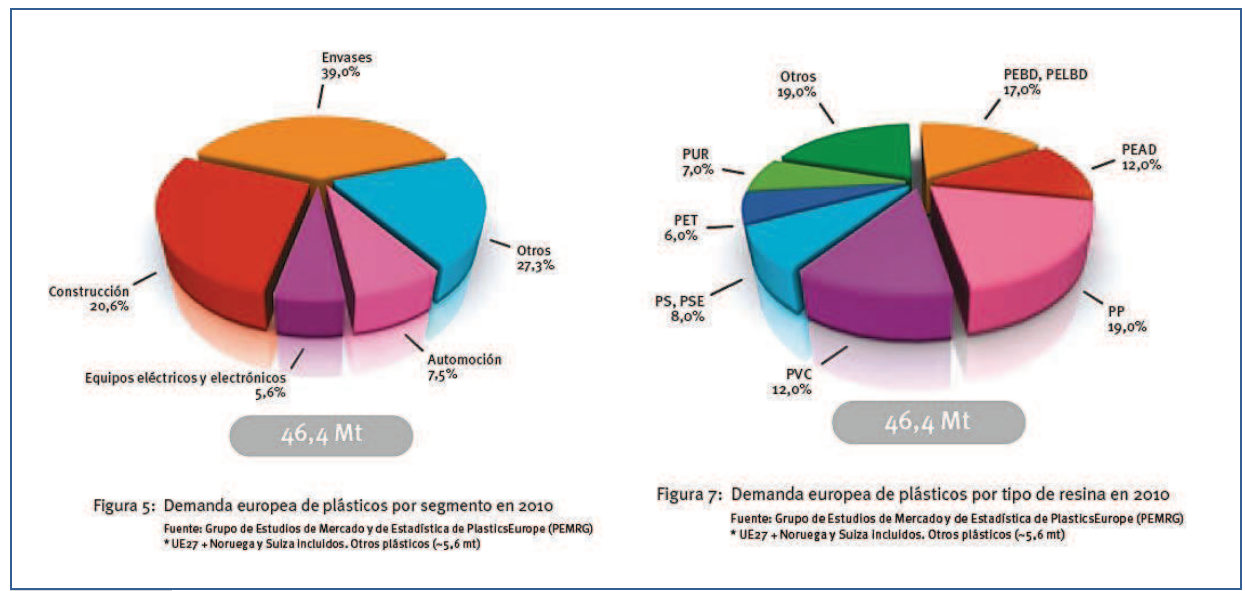

Figura 1.3. Demanda de plástico en la UE por sectores de producción y tipo de plástico del año 2010

Respecto a la vida útil de los plásticos en la UE+Noruega+Suiza, entendiendo por vida útil el tiempo durante el cual el producto cumple su función, es importante reseñar que el $40 \%$ del total de la producción se destina para la fabricación de productos de corta vida tipo embalaje (usar y tirar), y el $60 \%$ para productos de larga vida. Si a los productos de usar y tirar añadimos los residuos que se generan en la fabricación y manufactura de otros productos, se comprende fácilmente que las cifras de generación de residuos, en el uso de los plásticos, lleguen a ser de más del $50 \%$ sobre la producción total.

Esta ingente cantidad de residuos, cifrada en 24,7 millones de toneladas anuales en el año 2010, para la UE+Noruega+Suiza, ocupan un gran volumen y son de difícil gestión, dado que los plásticos son materiales poco degradables a muy largo plazo y su reutilización resulta poco viable por razones de su baja dureza superficial. La Figura 1.4, es un resumen de la demanda de plástico, generación de residuos y tratamiento de los mismos, que nos indica que del total de residuos en la Unión Europea, se almacenan en vertedero el $42,1 \%$, frente a la recuperación energética y reciclado que alcanzan el $57,9 \%$. 


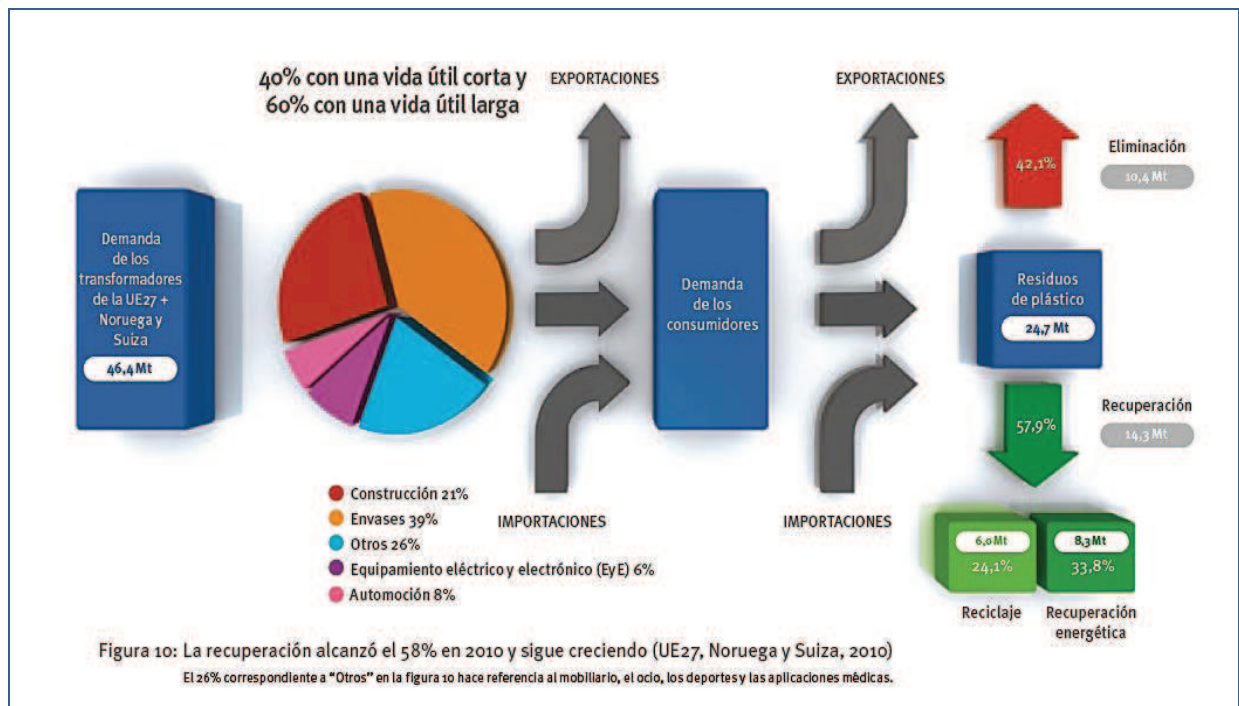

Figura 1.4. Vida útil del plástico en Europa año 2010. (Fuente PEMRG)

A partir del año 2008 la tasa de reciclaje más recuperación energética se sitúa por encima de la eliminación de los residuos en vertedero $(57,9 \%$ frente a $42,1 \%$ en 2010). No obstante, el paralelismo en el crecimiento entre la recuperación energética y el reciclaje de plásticos (Figura 1.5) obliga a replantearse las políticas medioambientales en este campo, buscando alternativas que primen la posibilidad del reciclaje incluso de los residuos menos aptos para ello, de modo que la tasa de reciclaje llegue a superar a la tasa de recuperación energética.

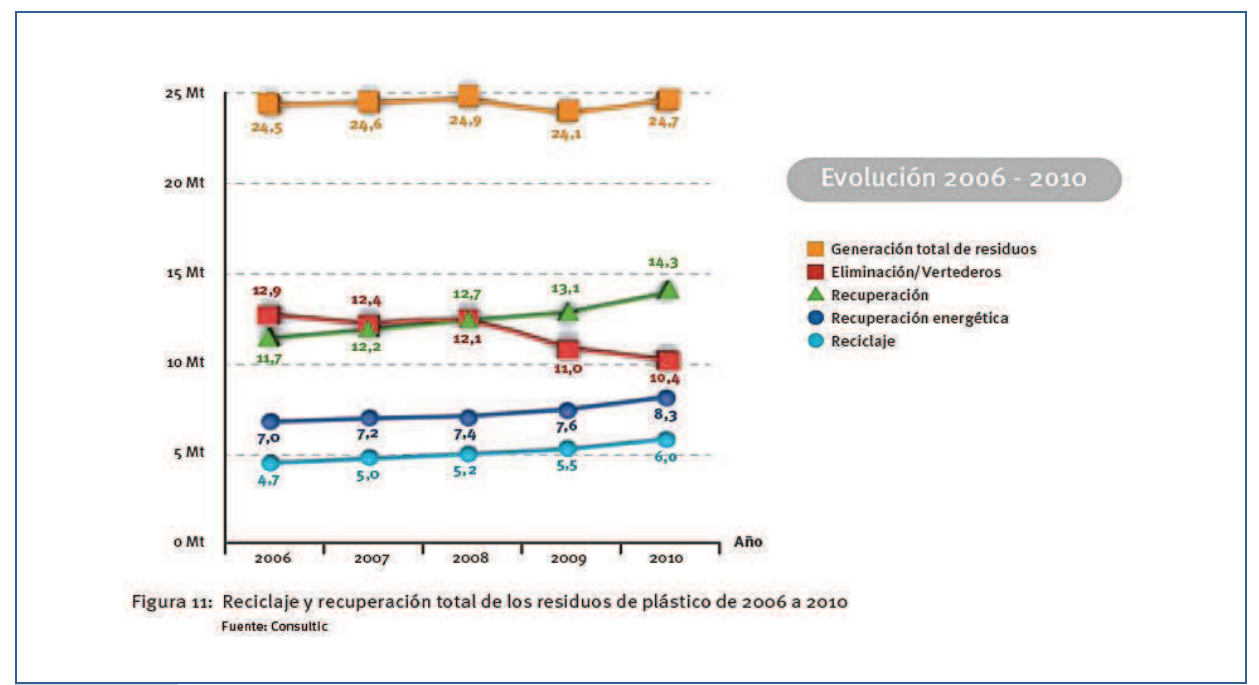

Figura 1.5. Variaciones de las tasas de recuperación y eliminación de residuos plásticos en Europa, años 2006-2010. 
En consecuencia, cualquier estrategia destinada a la mejora de la gestión de residuos debería combinar reciclaje y valoración energética, pero primando el reciclaje para aquellos residuos susceptibles de serlo y emplear como combustible alternativo otros residuos no reciclables. La Figura 1.6 muestra que mientras la tasa de reciclaje en la mayoría de los países se sitúa entre el $15 \%$ y el $30 \%$, los niveles de recuperación energética varían entre un $0 \%$ y un $75 \%$.

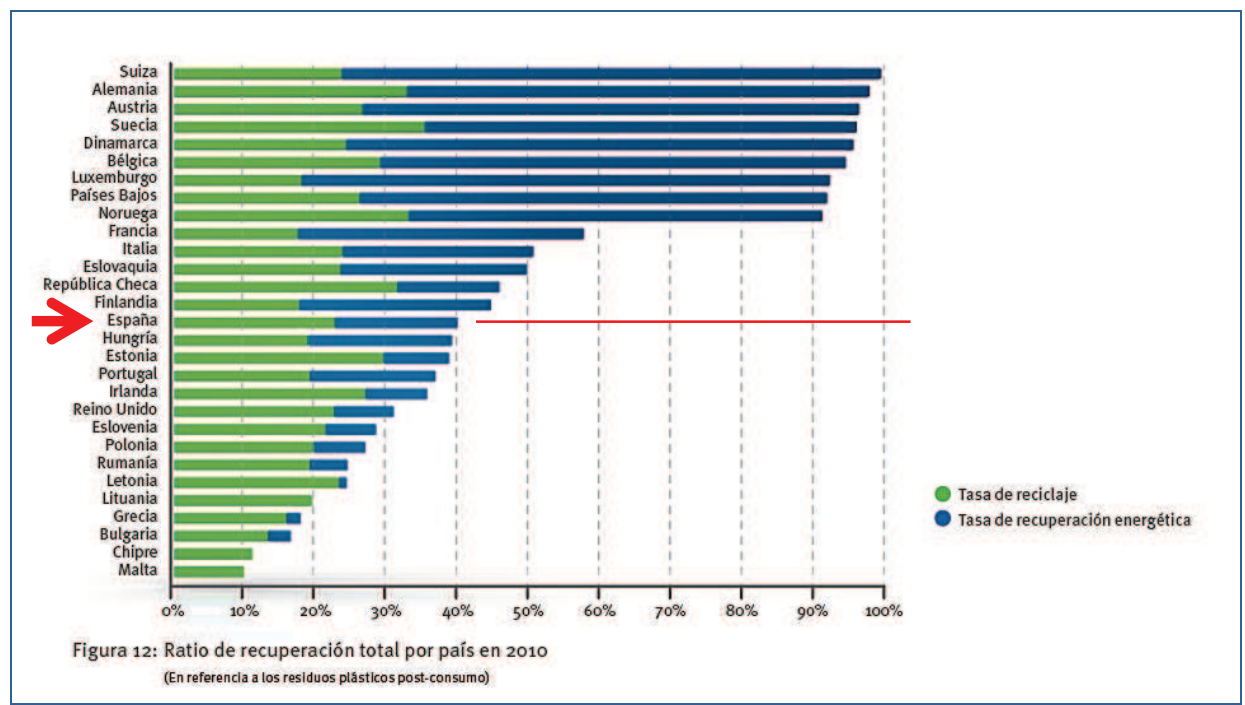

Figura 1.6. Ratio de recuperación y eliminación de residuos plásticos en la UE año 2010. (Fuente PEMRG)

Si se analizan los datos de los países del centro y norte de Europa, se observa que alcanzan tasas de recuperación cercanas al $100 \%$, lo que significa que no depositan residuos plásticos en vertederos. Sin embargo los países de la antigua Europa del Este, junto a otros países mediterráneos, eliminan en vertedero más del $70 \%$ de sus residuos.

Por último la Figura 1.7, nos muestra la evolución de la tasa de recuperación por país en los últimos 5 años. Resulta muy destacable el esfuerzo de algunos países como Estonia y Finlandia, que han aumentado esta tasa en torno al $30 \%$. Además, se pone de manifiesto el incremento del reciclaje frente a la recuperación energética en la mayoría de países, especialmente en países como Dinamarca, Suecia y Suiza, países que además no desechan los plásticos a vertedero. 


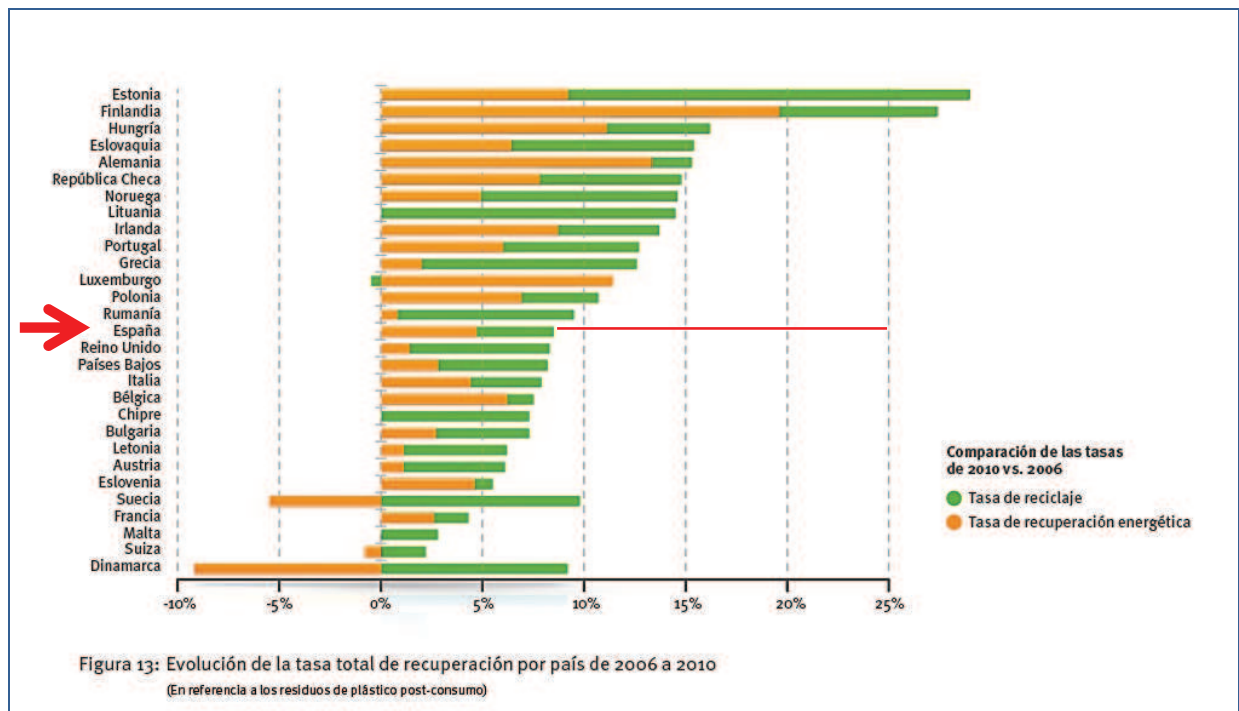

Figura 1.7. Tasa total de recuperación por país años 2006-2010. (Fuente PEMRG)

La situación en España no difiere sustancialmente de la media europea, pues el consumo de plásticos ha mostrado un crecimiento sostenido hasta el año $2007 .^{7}$ La profundidad y duración de la crisis económica se ha manifestado en el decrecimiento continuado de los años 2008 y 2009, volviendo a niveles del año 1999, tal y como se muestra en la Figura 1.8.

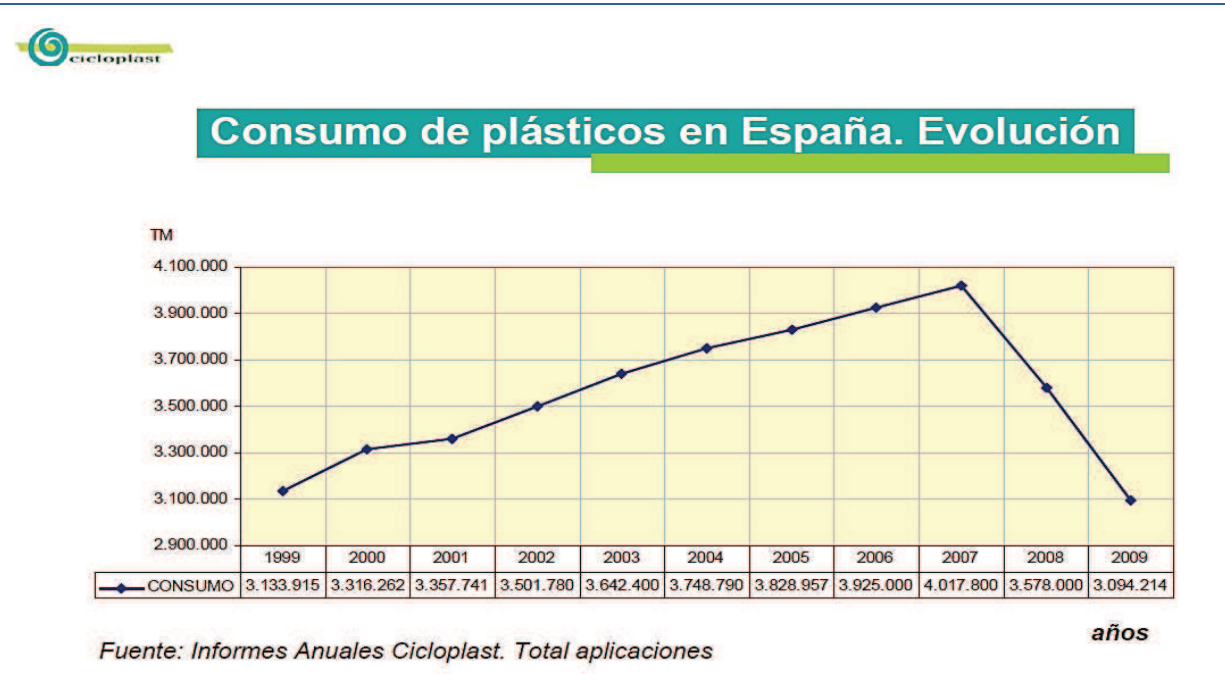

Figura 1.8. Evolución del consumo de plásticos en España años 1999-2009.

\footnotetext{
7 Resultados Informes Anuales Cicloplast Evolución Reciclado plásticos España 19992009. http://www.cicloplast.com/
} 
La generación de residuos respecto del consumo de plásticos es del 72,6\% (Figura 1.9), superior a la de la UE, probablemente debido a una mayor incidencia de los envases plásticos respecto de la demanda total $(46 \%$ en España, 39\% UE).

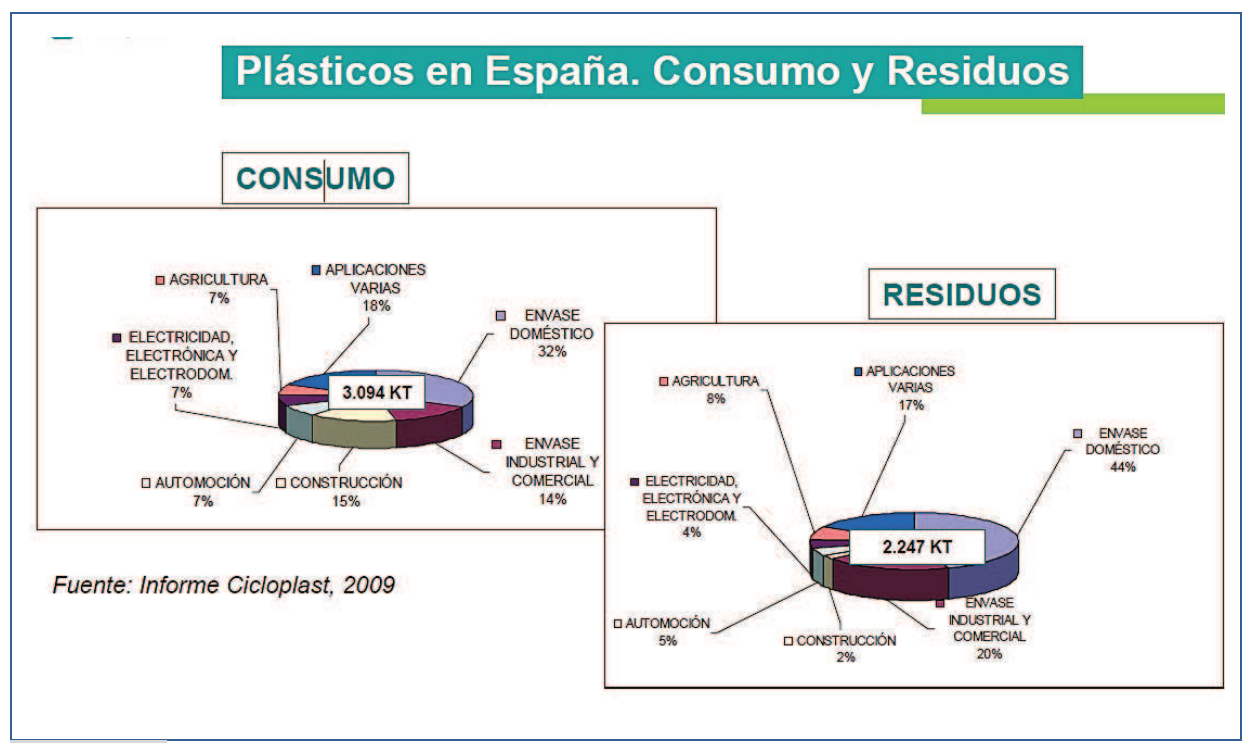

Figura 1.9. Consumo y generación de residuos plásticos en España

El índice de recuperación de residuos para valoración energética o reciclaje en España (Figura 1.10), es del $40 \%$ sobre el consumo, claramente por debajo del de la Unión Europea (57,9\% año 2010), y muy alejado de los países centroeuropeos. España ocupa el puesto $n^{\circ} 15$ entre los 27 países de la UE más Noruega y Suiza.

El reciclado de plásticos en España ha experimentado un crecimiento entre los años 1999 a 2007 (Figura 1.10), si bien el volumen total de producto reciclado ha decrecido sensiblemente en los años 2008 y 2009, por el descenso continuado del consumo en esos dos años. Sin embargo destaca el índice de reciclado de residuos, del orden del $21 \%$ en 2009 sobre el total de residuos, equiparable a países como Suiza y Dinamarca, e incluso por encima de otros como Francia (Figura 1.11). 


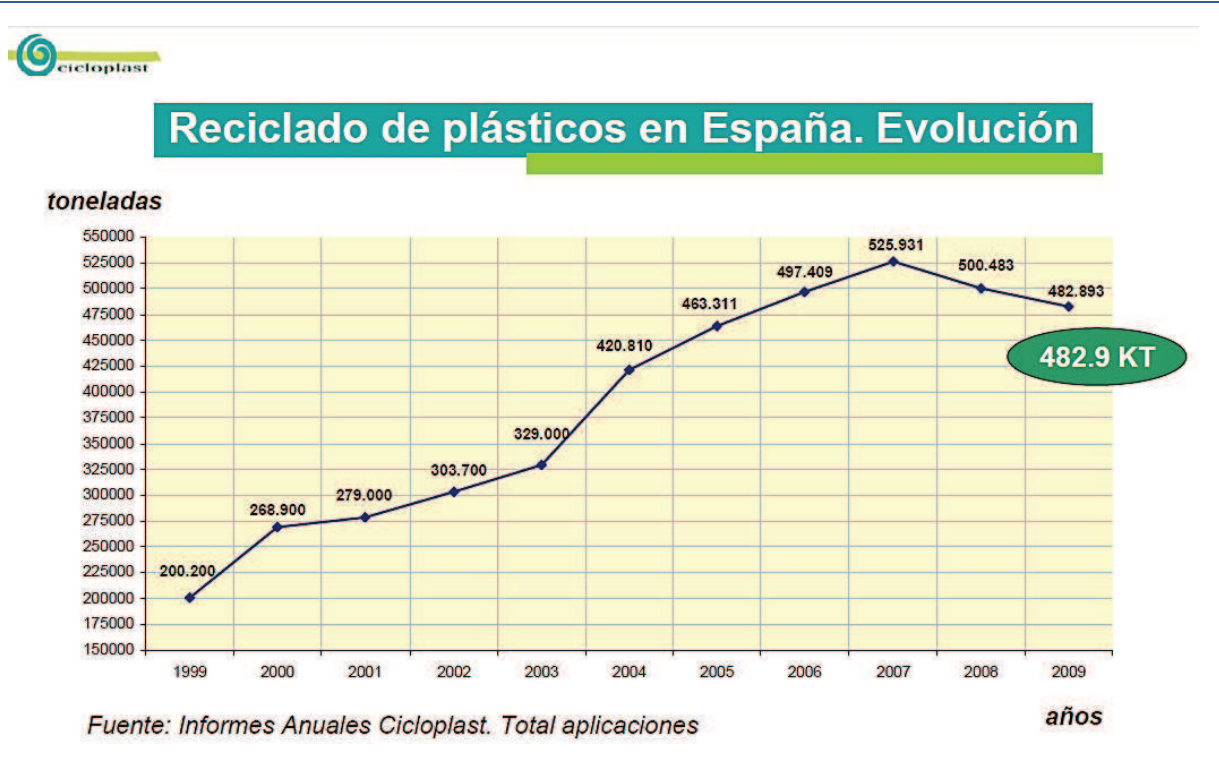

Figura 1.10 Evolución del reciclado de plásticos en España años 1999-2009.

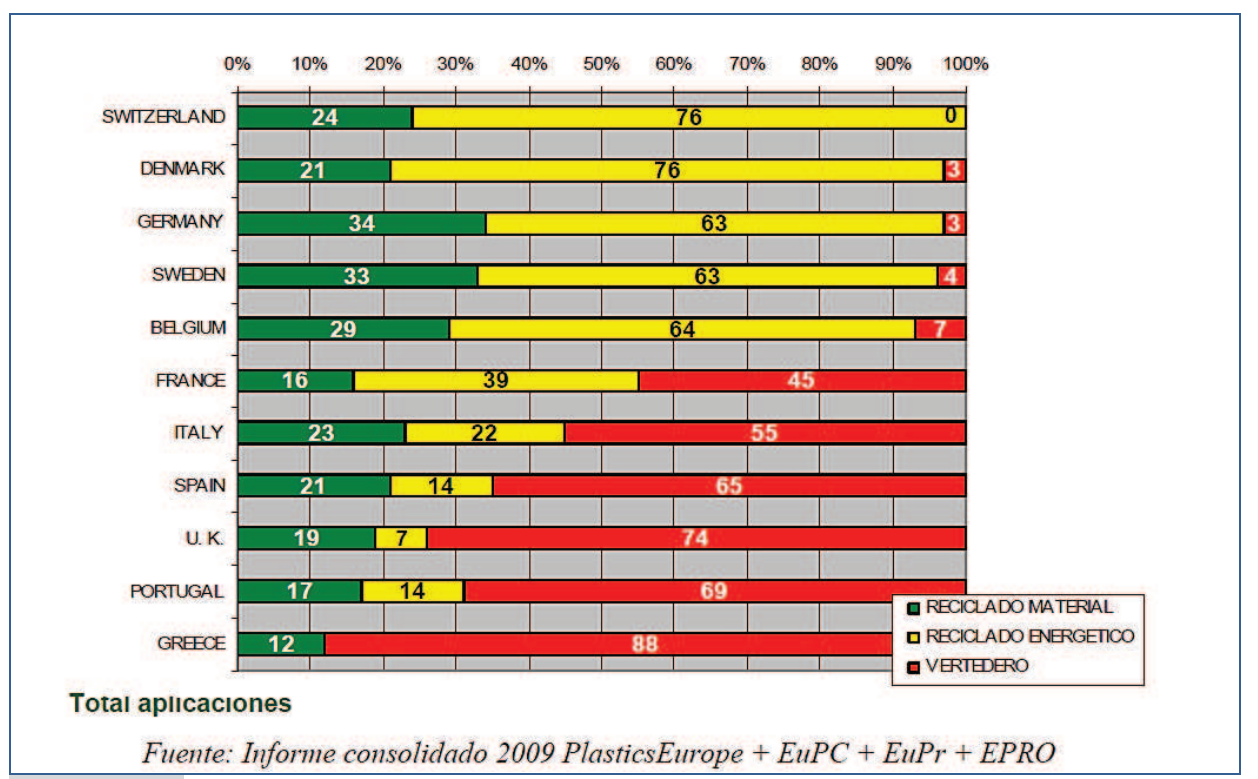

Figura 1.11. Destino de los residuos plásticos en Europa año 2009.

Finalmente, la tasa de reciclaje respecto de la demanda en España en el período 1999-2009 experimentó un crecimiento sostenido, tal y como se refleja en el gráfico de la Figura 1.12. 


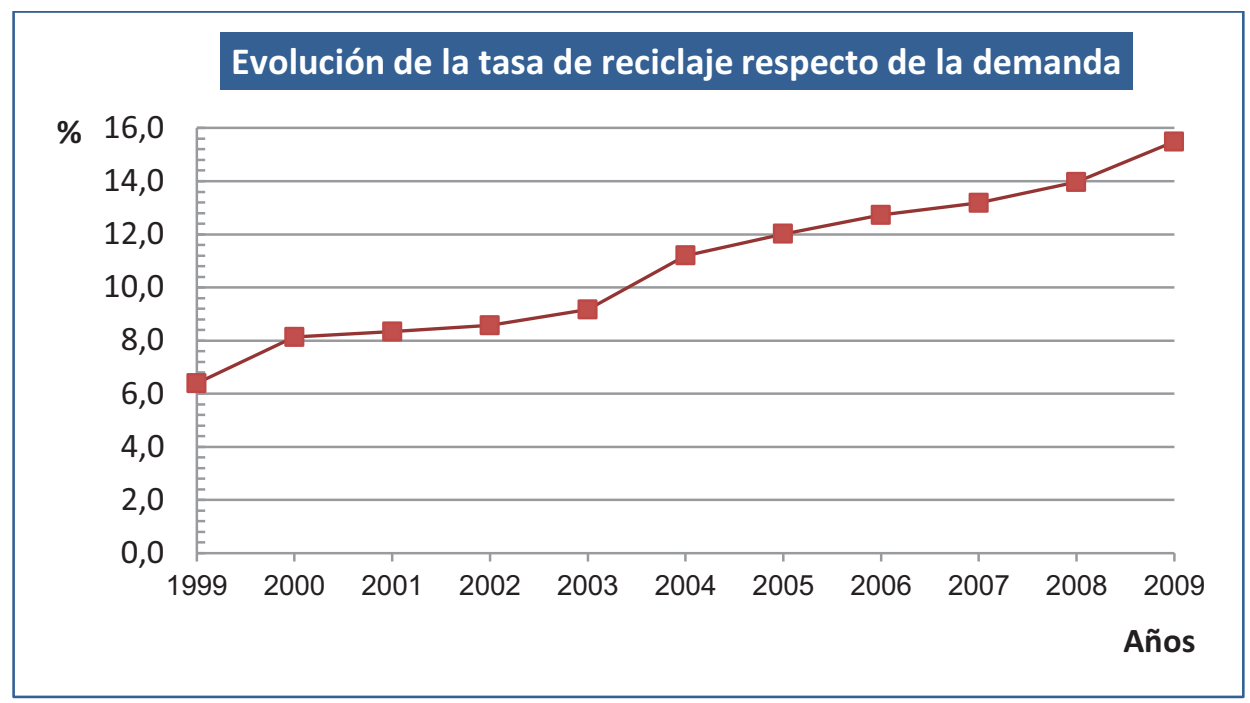

Figura 1.12. Evolución de la tasa de reciclaje de plásticos en España, respecto del consumo. (Fuente: Cicloplast)

\section{Residuos de espumas rígidas de poliuretano}

Un producto polimérico de especial relevancia es el poliuretano, con una demanda en la Unión Europea, más Noruega y Suiza, del 7\% sobre la demanda total de polímero, lo cual supone 3,25 millones de toneladas en el año 2010, como se muestra en la Figura 1.13.

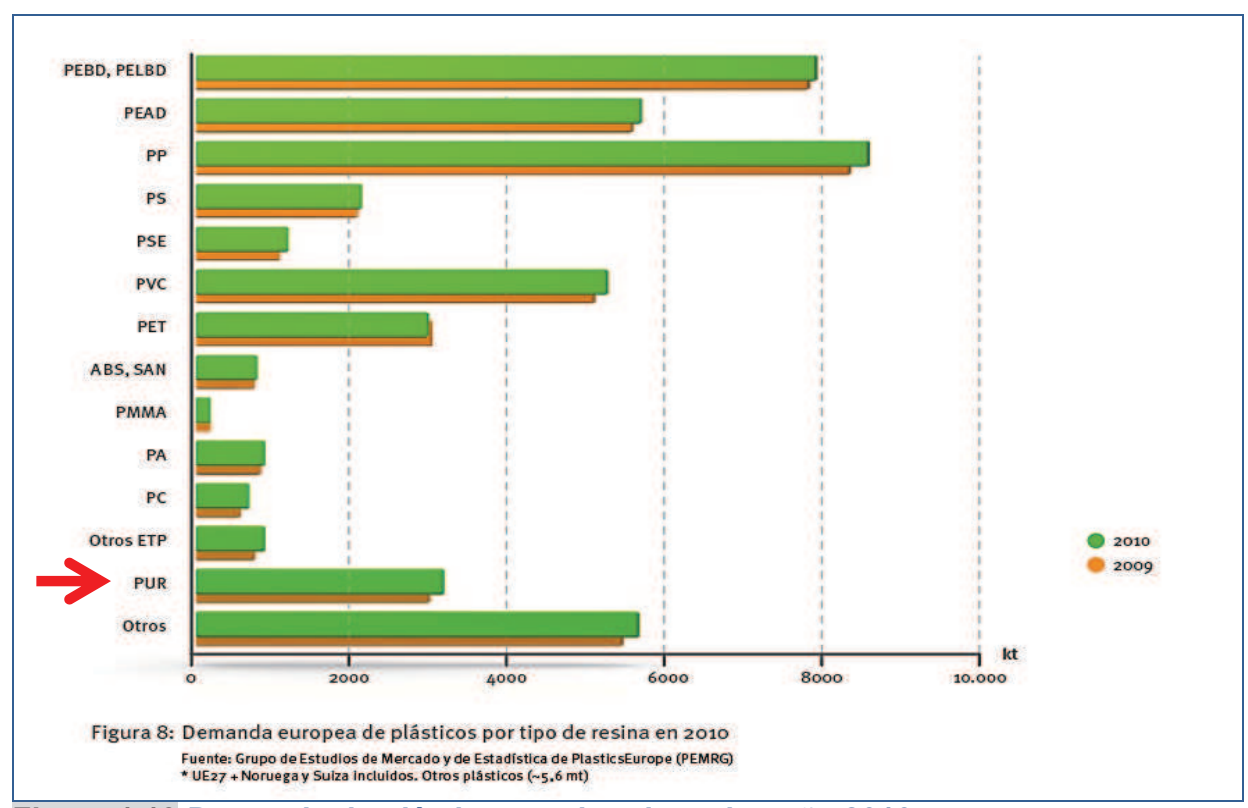

Figura 1.13 Demanda de plástico por tipo de resina año 2010. 
La demanda del poliuretano se centra en la industria del embalaje, la construcción, la automoción, las industrias eléctricas y equipamientos electrónicos y otros tipos de industria, destacando especialmente los sectores de la automoción y la construcción (Figura 1.14).

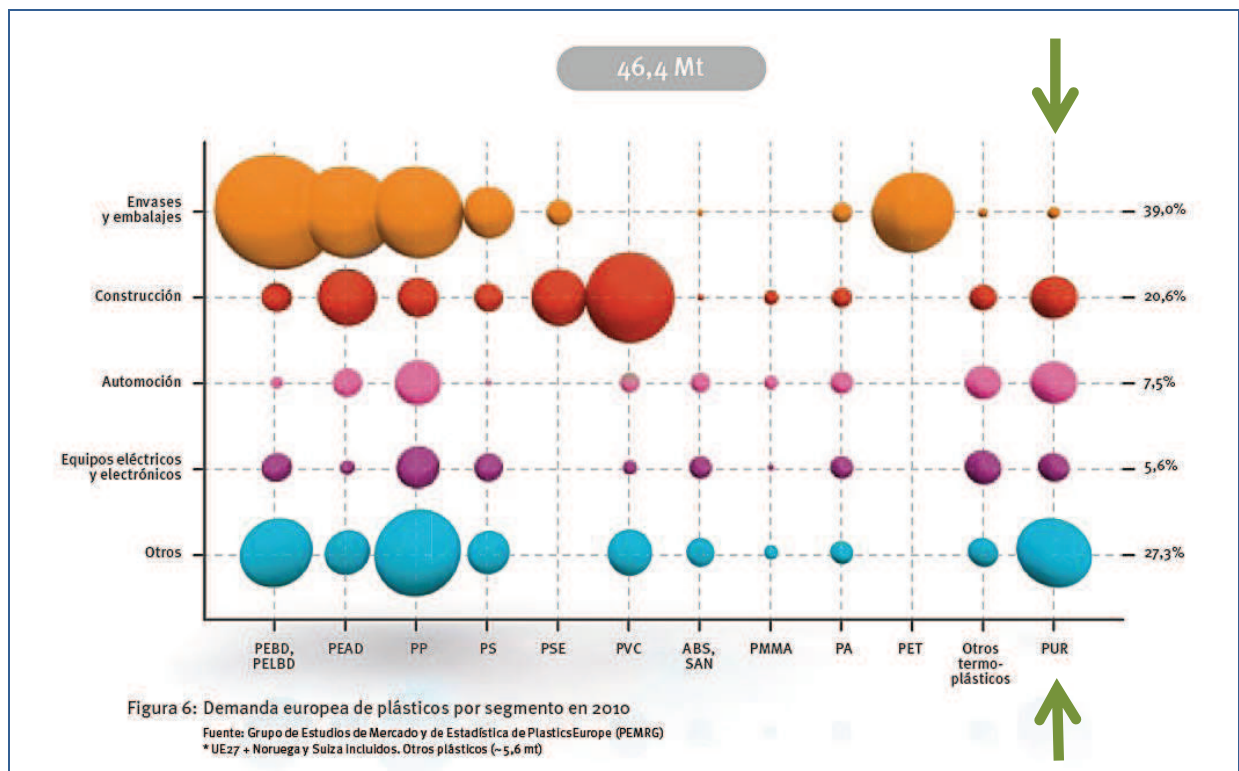

Figura 1.14 Demanda de plástico por segmentos año 2010.

De los 3,25 millones de toneladas anuales de demanda de poliuretanos en la Unión Europea, más Noruega y Suiza, se estima que un $25 \%$ se requiere en forma de espuma rígida, unas 812.500 toneladas al año.

El poliuretano rígido (PUR) tiene importantes aplicaciones en el sector de la construcción, para aislamiento térmico (prefabricados o conformados in situ); industria del automóvil, con productos para guarniciones de las carrocerías e interiores (puertas, techos, asientos); industrias del envasado y embalaje; productos para aislamiento térmico y protección contra los golpes y caídas; industrias del frío; colchonería y derivados, como productos para la conformación del cuerpo de colchones, almohadas, cojines, etc.

Estas industrias, tanto en los procesos intermedios de fabricación como en los procesos de manufactura, generan una importante cantidad de residuos ligeros pero de gran volumen, cuya gestión, debida a su volumen, supone el aporte de recursos de elevado coste económico, derivado en gran parte del coste del transporte, de la escasez de espacio para su depósito y del 
coste ambiental cada vez mayor de los vertederos. Por tanto, resulta obligada la búsqueda de soluciones para la gestión de residuos que cumpliendo con la premisa de preservación del medio ambiente, no supongan un sobrecoste elevado en la gestión.

No existen estadísticas fiables de los residuos procedentes de la producción y manufactura de las espumas rígidas de poliuretano. Sin embargo, en función de la producción de este tipo de materiales, que durante el año 2010 fue de 812.000 toneladas, se puede estimar una cantidad de residuos del $20 \%$ sobre el total, es decir 162.000 tn/año. El volumen que ocupa esta cantidad de residuos debido a su baja densidad se estima en aproximadamente de $4 \mathrm{Hm}^{3}$.

El Plan Nacional Integrado de Residuos 2008-2015 (PNIR), clasifica los residuos procedentes del empleo de las espumas rígidas de poliuretano como Residuos Industriales No Peligrosos (RINP), por lo que su gestión se deberá llevar a cabo de acuerdo con el I Plan Nacional de Residuos Industriales No Peligrosos (2008-2015) (I PNRINP). Este plan basado en la jerarquía establecida en el PNIR, fija los siguientes objetivos:

- Prevención: Para el año 2015 se debe haber alcanzado una reducción del $10 \%$ en la generación de RINP.

- Reutilización: Al menos se deberán reutilizar un 15\% de los RINP producidos, con un objetivo intermedio del $12 \%$ en el año 2010.

- Reciclaje: Posibilidad de alcanzar hasta un 50\% del total de RINP por reciclaje o valorización material, con objetivo intermedio del 30\% de reciclaje en el año 2011.

- Valorización energética: Se pueden reutilizar energéticamente hasta un $15 \%$ de los RINP.

- Eliminación: Nunca deberían llegar a depósito de seguridad más del 10\% de los RINP en el año 2015.

Los residuos de espumas rígidas de poliuretano pueden reciclarse o valorizarse energéticamente, no debiendo llegar nunca a su eliminación en depósito de seguridad, salvo raras excepciones.

EI I PNRINP (2008-2015), en su apartado 8.4., explica que el reciclaje de los RINP es viable mediante la aplicación de diversas tecnologías, y que para ampliar estas tecnologías y mejorar el reciclaje, se deben adoptar, entre otras medidas, la realización de estudios para identificar los RINP que podrían ser valorizados y los medios para promover su reciclado. 
Es en este campo en el que se pretende desarrollar el presente trabajo de investigación, aportando tecnologías y procedimientos sencillos que hagan viable el reciclaje de los residuos de espumas rígidas de poliuretano.

\section{2.- Objetivos}

El objetivo principal de la Tesis Doctoral es la obtención de morteros de cemento para albañilería con sustitución parcial o total de la arena por los residuos de espuma rígida de poliuretano que se generan en las industrias donde se fabrican para conformados, con el fin de conseguir productos viables que mejoren la gestión de estos residuos.

La viabilidad de los morteros de cemento con agregado de residuos de PUR implica:

- Dosificación de distintas mezclas en función de las propiedades que se buscan

- Caracterización de distintas dosificaciones de morteros que cumplan con la normativa específica de aplicación.

- Selección de los morteros que por su composición, contenido de residuos de PUR, propiedades y coste les hagan competitivos frente a los morteros fabricados con materiales tradicionales.

- Puesta en obra de los morteros que garanticen su aptitud.

Para el cumplimiento de los objetivos precedentes se ha establecido la siguiente metodología:

- Conocimiento de la industria que genera residuos de espuma rígida de poliuretano, volumen de residuos y gestión de los mismos.

- Búsqueda de los trabajos de investigación previos en el empleo de los residuos de PUR en morteros y hormigones.

- Caracterización de los materiales componentes de los morteros de cemento prescritos y de las espumas rígidas de poliuretano. 
- Fase experimental de fabricación de las mezclas con sustituciones de arena por residuo de PUR, utilizando distintos tipos de cemento $y$ de PUR.

- Fase experimental de caracterización de todas las dosificaciones en sus propiedades fundamentales, de acuerdo con las especificaciones de las normas UNE-EN.

- Posterior selección de varios tipos de morteros basada en criterios de competitividad por este orden: contenido en PUR; características mecánicas; contenido y tipo de cemento.

- Efectos de diferentes aditivos sobre las características de los morteros seleccionados.

- Determinación de la durabilidad de los morteros en relación con sus homólogos de referencia.

- Realización de pruebas de aptitud con la fabricación y puesta en obra efectiva de los morteros seleccionados.

- Estudio económico cuantitativo de la fabricación y puesta en obra de los morteros investigados y análisis cualitativo de las ventajas que proporciona el empleo de los morteros con agregados de residuos de PUR.

\section{3.- Estado del arte}

En este apartado se engloban los métodos más importantes para aligerar materiales conglomerados a base de cemento que se han desarrollado hasta la actualidad, incluyendo los últimos avances en reciclado de residuos poliméricos utilizados como aligerante, desde el punto de vista de su empleo en materiales conglomerantes de uso en construcción.

\subsection{1.- Morteros ligeros}

La definición amplia del término "mortero", como compuesto homogéneo formado por la unión de conglomerante, árido y agua, que se moldea en estado plástico y que una vez endurecido resulta apto y durable para su 
uso en albañilería, nos permite ordenar el estudio del mortero, en base a sus propiedades en estado plástico y a sus prestaciones una vez endurecido.

El uso de materias primas e inertes de diferentes densidades para la fabricación de morteros es ampliamente conocido y explotado desde la época de los griegos y romanos. ${ }^{8}$ Sin embargo, el comienzo generalizado del empleo de áridos ligeros en la construcción se produce con el descubrimiento de la expansión de esquisto, un agregado ligero con suficiente fuerza y calidad adecuado para su uso en aplicaciones estructurales de hormigón. El proceso fue desarrollado por Stephen Hayde a principios del siglo XX en Kansas, Missouri. ${ }^{9}$.

A partir de 1950 comienza con éxito la fabricación y comercialización extendida de este tipo de productos ya que, en términos generales, los materiales aligerados presentan una serie de ventajas que los hacen idóneos en cuanto a la facilidad de transporte y puesta en obra. Asimismo, tienen un mejor comportamiento térmico al incluir un volumen controlado de aire ocluido en la matriz conglomerante.

Actualmente, como últimos avances en proceso de desarrollo de este tipo de materiales se encuentran, por ejemplo, el relleno de baja densidad geotécnica y su uso como un medio de filtración biológica. ${ }^{10}$

Existen varios procedimientos para aligerar un material, que se explican con detalle en los siguientes apartados.

\subsubsection{1.- Introducción de aire ocluido en su interior}

De manera general la incorporación de aire en el interior de un mortero se puede realizar mediante la adición de compuestos (aditivos) cuyas propiedades se basan en la inclusión de aire o en propiedades espumantes a partir de la generación de gases de expansión.

\footnotetext{
${ }^{8}$ Cowan H.J.A. History of masonry and concrete domes in building construction. Build Environ (1977); 12, 1-24.

${ }^{9}$ Buildex Inc. Haydite Expanded-Shale Lightweight Aggregate.

http://www.buildex.com/haydite.html (Accessed: September 11, 2012).

${ }^{10}$ Draganović A, Stille H. "Filtration and penetrability of cement-based grout: Study performed with a short slot." Tunnelling Underground Space Technology, 2011, 26 (4), 548-559.
} 
Este tipo de aditivos se emplea por primera vez en el año 1933, cuando por casualidad se añadieron resinas al clinker, observando una mejora en el comportamiento del hormigón ante las heladas y a la impermeabilidad, lo que implicaba a su vez una mayor durabilidad. ${ }^{11,12}$

La función principal de estos aireantes consiste en producir un número elevado de finas burbujas de aire en el mortero, (de 10 a 500 micras de diámetro), de distribución continua de tamaños, separadas y repartidas uniformemente.

Estas microburbujas permanecen durante el endurecimiento e interrumpen la red capilar del material. Debido a su forma esférica actúan como lubrificante del conglomerante en estado fresco, dando lugar a una mejora de la docilidad y a una disminución de la tendencia del mismo a segregar y exudar (Figura 1.15).

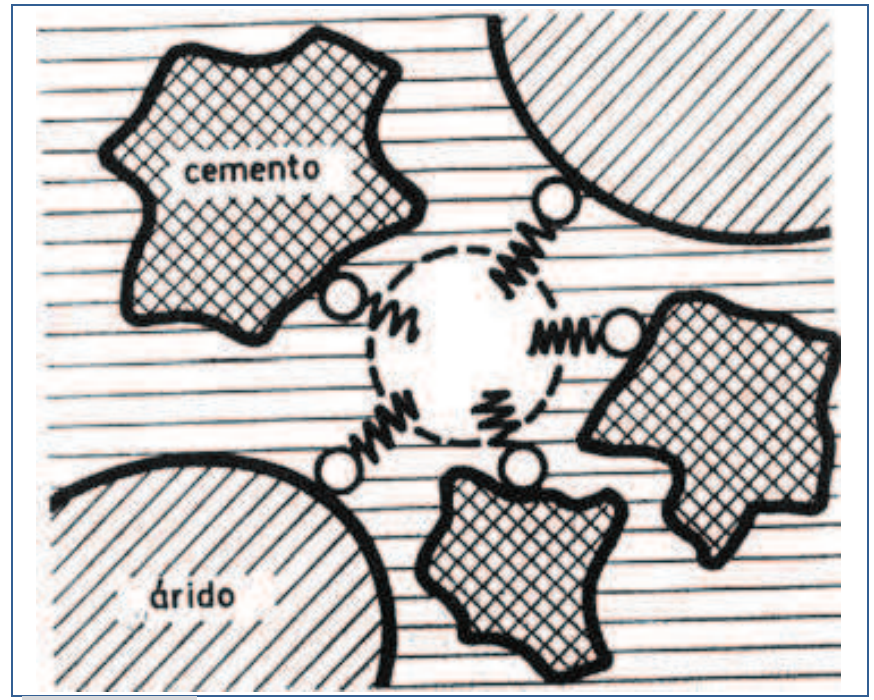

Figura 1.15. Microburbujas de aire

Por otra parte, permiten mantener una consistencia plástica o fluida, disminuyendo la relación agua/cemento con lo que se consigue aumentar la compacidad y la cohesividad interna. Como efecto secundario, determinados aditivos de este grupo pueden producir una disminución de la resistencia mecánica, que es función del contenido de aire.

\footnotetext{
${ }^{11}$ Powers, T. C., 1945, "Working hypothesis for further studies of frost resistance of concrete," ACl Journal, Proceedings, V. 41, No. 4, Feb., pp. 245-272.

${ }^{12}$ Powers, T. C., 1954, "Void spacing as a basis for producing air-entrained concrete," ACl Journal, V. 50, No. 9, Mayo, pp. 741-760.
} 


\subsubsection{2.- Mediante adición de cargas ligeras}

Se puede aligerar un mortero mediante la adición de cargas ligeras, como rellenos o sustitutos de parte de los áridos de la mezcla. Se denomina adición, ya que se incorpora en la masa en pesos superiores al $5 \%$ sobre el peso del conglomerante. Dentro de estos tipos de compuestos, se encuentran los áridos ligeros, tipo arcilla, perlita y vermiculita expandidas, y otros elementos más novedosos reciclados o de productos de desecho de la industria como son el corcho, el vidrio tratado o el papel reciclado.

Estas cargas ligeras suelen denominarse áridos ligeros, entendiendo como árido ligero cuando la densidad real del grano es inferior a $2 \mathrm{~g} / \mathrm{cm}^{3}$ (UNE 83101-90).

Los áridos pueden ser inorgánicos (arcilla expandida; esquisto expandido; pizarra expandida; vermiculita; perlita expandida, etc), orgánicos o industriales.

Los áridos ligeros que se emplean de manera habitual en morteros, hormigones y yesos ${ }^{13}$ también se clasifican como de origen natural, como la piedra pómez, las escorias volcánicas, las cenizas volantes y la toba volcánica, o de síntesis, como la arcilla expandida ${ }^{14}$, la perlita ${ }^{15,16}$ y la vermiculita. ${ }^{17}$

Por otro lado, acorde con una concienciación cada vez mayor en el empleo de materiales sostenibles, existen otros tipos de agregados ligeros no elaborados como son el granulado de corcho, la cáscara de cereal o las virutas de madera ${ }^{18}$, y otros de naturaleza orgánica polimérica como el polietileno $^{19}$, el poliestireno expandido ${ }^{20}$ o el politereftalato de etilo (PET). ${ }^{21}$

\footnotetext{
${ }^{13}$ Mnjit S., Mridul G. Perlite based building materials. A review of current applications. Constr Build Mater (1991), 5, (2), 75-81.

${ }^{14}$ Hall R.D, Blakey F.A. Expanded clay agregate for concrete. Constructional Review. (1953).

${ }_{5}^{5}$ Eckardt P. Fireproof super lightweight concrete. Ger. Offen D.E. 3, 110, 658 (Cl. Co. 4B 15/02), 1982, 11.

${ }^{16}$ Kisari J, Varkonyi G, Szalonki M. Lightweight concrete. Chem Abstr (1986), 105, 28851.

${ }^{17}$ Rosen A. Some use of vermiculite. S.A. Mining and Engineering. 1994.

${ }^{18}$ Gouny F, Fouchal F, Maillard P, Rossignol S. A geopolymer mortar for wood and earth structures. Constr Build Mater 2012, 36, 188-195.

${ }^{19}$ Chen P.W, Chung D.D.L. A comparative study of concretes reinforced with carbon, polyethylene, and steel fibers and their improvement by latex addition. A review. $\mathrm{ACl}$ Mater J 1996, 93 (2), 129-133.
} 


\subsection{2.- Morteros aligerados con agregados ligeros tradicionales}

\subsubsection{1.- Arcilla expandida}

Este agregado se obtiene sometiendo a las arcillas a un proceso de cocción a altas temperaturas $\left(1200^{\circ} \mathrm{C}\right)$, para su transformación en gránulos esféricos, porosos y de baja densidad con interior celular, debido a la formación de microburbujas de aire ocluido. Esta propiedad confiere un gran poder aislante, por lo que es un material idóneo para su aplicación en aislamientos, conglomerados ligeros y prefabricados de uso en edificación. ${ }^{22}$ La arcilla expandida ha sido ampliamente utilizada en la fabricación de hormigones y morteros de cemento aligerados, resolviendo grandes problemas de peso del material y reduciendo considerablemente su conductividad térmica. ${ }^{23,24}$

\subsubsection{2.- Perlita expandida}

Este mineral de origen volcánico formado principalmente por silicatos, se tritura a una granulometría adecuada y se calienta a temperaturas comprendidas entre $900-1200^{\circ} \mathrm{C}$. En este proceso el agua ocluida se transforma en vapor y el silicato se expande aumentando hasta 20 veces su volumen inicial. Se le da este nombre porque tiene la apariencia de una perla al observarse microscópicamente a pocos aumentos.

Esta transformación proporciona unas características muy adecuadas para su uso como agregado ligero en hormigones, morteros y yesos, con propiedades mejoradas de aislamiento térmico y acústico. ${ }^{25}$

\footnotetext{
${ }^{20}$ Cai L. Experimental research on producing thermal insulating bonding mortar by spent polystyrene foam. Cem Concr Compos 2012, 174-177, 1253-1256.

${ }^{21}$ Reis J.M.L , Carneiro E.P. Evaluation of PET waste aggregates in polymer mortars. Constr Build Mater 2012, 27(1), 107-111.

${ }^{22}$ Ozguven A, Gunduz L. Examination of effective parameters for the production of expanded clay aggregate. Cem Concr Compos (2012), 34, 781-787.

${ }^{23}$ Al-Sibahy A, Edwards R,. Thermal behaviour of novel lightweight concrete at ambient and elevated temperatures: Experimental, modelling and parametric studies. Constr Build Mater (2012), 31, 174-187.

${ }^{24}$ Kew H, Donchev T, Petkune N. Behaviour of concrete containing lightweight expanded clay aggregates under high temperatures. Proceedings in Concrete Solutions, 4th International Conference on Concrete Repair (2012), 491-496.

${ }^{25}$ Lanzón M, García-Ruiz P.A. Lightweight cement mortars: Advantages and inconveniences of expanded perlite and its influence on fresh and hardened state and durability. Constr Build Mater 2008, 22 (8), 1798-1806.
} 


\subsubsection{3.- Vermiculita expandida}

La vermiculita es un mineral de la familia de la mica, compuesto principalmente por silicatos hidratados de aluminio y magnesio. Los morteros aligerados más tradicionales incorporan la vermiculita expandida mediante el simple proceso de calentar el mineral en un horno hasta unos $800^{\circ} \mathrm{C}$, temperatura a la cual el mineral se lamina y se expande aumentando entre 20 y 30 veces su volumen al evaporarse el agua contenida en el mineral. Las láminas formadas actúan como diminutos "espejos" que reflejan tanto las radiaciones térmicas como las ondas sonoras, lo que le da al mortero sus propiedades de absorción acústica, la capacidad aislante térmica y de protección contra el fuego. ${ }^{26}$

Por otro lado, se desarrollan en la actualidad nuevas técnicas de mezclado de mortero y vermiculita que, junto con otros aditivos como el ácido cítrico, ácido tartárico, el sulfato de cobre o el citrato potásico o sódico, proporcionan unas características de resistencia, dureza, y aislamiento mejoradas. $^{27}$

\subsection{3.- Morteros aligerados con residuos industriales}

\subsubsection{1.- Corcho natural}

El corcho es un material ligero celular que constituye la corteza del alcornoque y cuya composición química principal incluye suberina (40\%), lignina $(22 \%)$, hemicelulosa $(11 \%)$, celulosa $(9 \%)$ y extracto orgánico $(15 \%$ $20 \%) .{ }^{28}$ Las ventajas asociadas a su baja densidad y a su estructura celular son la baja conductividad térmica, buena absorción acústica y alta impermeabilidad. ${ }^{29}$

En cuanto a la aplicación de este material en compuestos a base de cemento se ha encontrado bibliografía reciente que examina el impacto del

\footnotetext{
${ }^{26}$ Formosa J, Haurie L, Chimenos J.M, Lacasta A.M, Rosell J.R. Comparative study of magnesium by-products and vermiculite formulations to obtain fire resistant mortars. Mater Sci Forum 2008, vol. 587-588, 898-902.

${ }^{27}$ Román Alema B, Torres Zacarías P. Mortero de yeso con vermiculita expandida y aditivado, y procedimiento para su obtencion. Patente de invención 2010 . ES2331043 B1.

${ }^{28}$ Pereira H. Chemical composition and variability of cork from Quercus suber L. Wood Sci Technol (1988), 22, 211-218.

${ }^{29}$ Gibson L.J, Ashby M.F. Cellular solids: structure and properties, $2^{\text {nd }}$ ed. (Paperback). Cambridge University Press, Cambridge (1999), 453-467.
} 
corcho utilizado como remplazo de arena o piedra, donde se comprueba que tanto el tamaño de grano, como la humedad y la edad del corcho influyen en las propiedades mecánicas ${ }^{30}$, de permeabilidad y de resistencia térmica. ${ }^{31,32}$

\subsubsection{2.- Vidrio celular}

Los trabajos de investigación encaminados al empleo del vidrio como añadido a conglomerados de construcción son muchos y muy variados ya que, debido a su composición química (sílice y carbonatos sódico y cálcico que por calentamiento pueden derivar en óxidos de calcio y de sodio), pueden considerarse como adiciones de tipo puzolánico, muy habituales y apropiadas en la fabricación de cementos.

Existe por ejemplo, bibliografía en la que se caracterizan conglomerados con elevada sustitución de cemento (hasta un $20 \%$ ) y tamaño de partícula controlado, obteniendo resultados muy favorables de actividad puzolánica, tiempos de fraguado, absorción de agua, fricción y durabilidad, lo que confirma que el polvo de vidrio puede contribuir a la sostenibilidad en la construcción. ${ }^{33,34}$

Otros artículos se basan en el estudio del reciclado de residuos procedentes del triturado de tubos catódicos de vidrio que suponen un problema medioambiental debido a su alto contenido en plomo. Varios investigadores han aprovechado las propiedades de este tipo de vidrios, consiguiendo morteros con mayores resistencias mecánicas y alto grado de aislamiento a la radiación y apantallamiento de los rayos $\mathrm{X}$, si bien presentan el inconveniente de tener un elevado grado de retracción. ${ }^{35,36}$

30 Nóvoa P.J.R.O, Ribeiro M.C.S, Ferreira A.J.M, Marques A.T. Mechanical characterization of lightweight polymer mortar modified with cork granulates. Compos Sci Technology 2004, 64, 2197-2205.

31 Panesar D.K, Shindman B. The mechanical, transport and thermal properties of mortar and concrete containing waste cork. Cem Concr Compos 2012, 34(9), 982-992.

${ }^{32}$ Gil L. Cork Composites: A review. Materials 2009, 2, 776-789.

33 Matos A.M, Sousa-Coutinho J. Durability of mortar using waste glass powder as cement replacement. Constr Build Mater 2012, 36, 205-215.

${ }^{34}$ Corinaldesi V, Gnappi G, Moriconi G, Montenero A. Reuse of ground waste glass as aggregate for mortars. Waste Management 2005, 25 (2), SPEC. ISS, 197-201.

${ }^{35}$ Zhao $\mathrm{H}$, Sun, W. Effect of cathode ray tubes glass sand as fine aggregate on properties of mortar. Kuei Suan Jen Hsueh Pao/Journal of the Chinese Ceramic Society 2012, 40(2), 240-246.

${ }^{36}$ Ling T.C, Poon C.S, Lam W.S, Chan T.P, Fung K.K.L. Utilization of recycled cathode ray tubes glass in cement mortar for X-ray radiation-shielding applications. J Hazard Mater 2012, 199-200, 321-327. 


\subsubsection{3.- Papel reciclado}

Los éteres de celulosa se utilizan comúnmente como aditivos para mejorar la calidad de los materiales basados en cemento, ya que normalmente mejoran las propiedades de los morteros en estado fresco tales como la retención de agua, capacidad de trabajo, y tiempo abierto. ${ }^{37}$

Con estos antecedentes, se han llevado a cabo varios trabajos que se basan en la inclusión de estos desechos obteniendo materiales ligeros, homogéneos y con una mejora en la estabilidad térmica y mecánica, ${ }^{38} \mathrm{o}$ en la utilización de los residuos de lodos de la industria del papel como sustituto parcial del cemento para obtener hormigones y morteros más trabajables y permeables, contribuyendo a la disminución de la cantidad de agua potable necesaria para el amasado de los materiales. ${ }^{39}$

\subsection{4.- Morteros modificados con polímeros}

El concepto de modificación de conglomerados con polímeros para la obtención de materiales con propiedades mejoradas o adaptadas no es nuevo, ya que la investigación y el desarrollo de estos materiales se ha realizado durante los últimos 70 años. Como resultado, se han desarrollado diversos compuestos aligerados que actualmente son materiales de construcción muy populares debido a su buena relación costerendimiento. ${ }^{40}$

El uso de materiales modificados con polímeros en la construcción de edificios, puentes, instalaciones industriales y otras edificaciones de ingeniería civil ha tenido, en los últimos años, un impacto creciente en la nueva construcción y la reparación de infraestructuras envejecidas. Las aplicaciones van desde las estructuras compuestas o híbridas en

\footnotetext{
37 Patural L, Marchal P, Govin A, Grosseau P, Ruot B, Devès O. Cellulose ethers influence on water retention and consistency in cement-based mortars. Cem Concr Res 2011, 41(1), 46-55.

38 Visakh P.M, Thomas S, Oksman K, Mathew A.P. Crosslinked natural rubber nanocomposites reinforced with cellulose whiskers isolated from bamboo waste: Processing and mechanical/thermal properties. Compos Part A: Appl Sci Manufacturing 2012, 43(4), 735-741.

${ }^{39}$ Yan S, Sagoe-Crentsil K, Shapiro G. Properties of cement mortar incorporating deinking waste-water from waste paper recycling. Constr Build Mater 2012, 29, 51-55.

${ }^{40}$ Guide for structural lightweight aggregate concrete (1987) ACI Manual of Concrete Practice, Part 1

Farmington Hills: American Concrete Institute.
} 
ambientes corrosivos, a las aplicaciones en forma de fibras para la reparación y el refuerzo de las estructuras existentes. ${ }^{41}$

Los morteros de cemento a base de polímeros se denominan habitualmente por las siglas PCM (polymer cement mortar), y se basan por un lado en la incorporación de aditivos poliméricos, que incluyen emulsiones (látex), polvos de polímero redispersable, polímeros solubles en agua, resinas líquidas y monómeros y por otro lado, en la sustitución parcial de los ligantes hidrato del cemento convencional por polímeros de diversa naturaleza. ${ }^{42}$

La búsqueda de materiales de construcción duraderos y sostenibles aplicados al mundo de la construcción es una de razones por las que se busca la sinergia entre la combinación de materiales de construcción clásicos y polímeros. Un mejor conocimiento del comportamiento de los materiales, especialmente en el campo de las mezclas, y una mejor comprensión de los procesos de curado, ha permitido un alto desarrollo apoyado en la investigación básica previa. ${ }^{43}$

Existen varios científicos a nivel internacional que se dedican a determinar las propiedades que los polímeros proporcionan a los diferentes conglomerados para la construcción. Algunas de las personalidades más importantes en este campo de investigación con numerosas publicaciones de ámbito internacional son, entre otros, el profesor japonés Yoshihiko Ohama (alrededor de 130 publicaciones), el profesor David W. Fowler (120 contribuciones), el profesor alemán Dionys Van Gemert (unas 80) y el Dr. Lech Czarnecki del Politécnico de Varsovia (40), que habitualmente se dan cita en el International Congress on Polymers in Concrete (ICPIC), y en el Asian Symposium on Poplymers in Concrete (ASPIC), que suponen los encuentros a nivel mundial más importantes en este campo científico desde hace más de 30 años. Ambos congresos están respaldados por instituciones como el American Concrete Institute ( $\mathrm{ACl})$, el Japan Concrete

\footnotetext{
${ }^{41}$ Hamilton H.R, Benmokrane B, Dolan W, Sprinkel M.M. Polymer materials to enhance performance of concrete in civil infrastructure. J Macromol Sci, Part C: Polymer Reviews $2009,49,1-24$

42 Ohama Y. Concrete-polymer composites-the past, present and future. Key Engineering Mater 2011, 466, 1-14 and International Congress on Polymers in Concrete. ICPIC 2010.Madeira (Portugal).

${ }^{43}$ Ohama, Y. Polymer-based admixtures. Cem Concr Compos 1998, 20(2-3), 189-212.
} 
Institute $(\mathrm{JCl})$ y la Union of Laboratories and Experts in Construction Materials, Systems and Structures (RILEM), entre otras. ${ }^{44}$

A nivel nacional, los grupos de investigación de la Dra. Mercedes del Río Merino de la Escuela de Arquitectura Técnica de Madrid, y de la Dra. Eva García Alcocel de la Universidad de Alicante trabajan en la adición de residuos poliméricos para la obtención de diferentes conglomerados aligerados.

\subsection{5.- Morteros aligerados con residuos poliméricos}

Los morteros y hormigones de peso ligero pueden ser producidos mediante la sustitución de áridos ligeros tradicionales por agregados poliméricos ligeros, ya sea parcial o totalmente dependiendo de los requisitos de densidad y resistencia, con el fin de reducir el problema de eliminación de residuos sólidos, la contaminación del medio ambiente y el consumo de energía. Dentro de este campo, se encuentran como materiales más estudiados el poliestireno expandido, el politereftalato de etilo y el polietilvinilacetato de etilo.

\subsubsection{1.- Poliestireno expandido (EPS)}

El poliestireno expandido es un polímero termoplástico con una estructura celular rígida y cerrada rellena normalmente de aire que proporciona al material una densidad aparente pequeña. Aunque existen numerosos polímeros expandidos en el mercado, el más habitual es el poliestireno expandido, también llamado corcho artificial, conocido internacionalmente por las siglas EPS.

Los primeros estudios científicos publicados de inclusión EPS se remontan a 1980, donde Ohama et al. añadían estireno en disolución impregnando el hormigón en su amasado, que polimerizaba como poliestireno (PS), originando un efecto hidrofugante, transformando el hormigón en un material más resistente. ${ }^{45}$

\footnotetext{
${ }^{44}$ Van Gemert D, Czarnecki L, Maultzsch M, Schorn H, Beeldens A, Łukowski P, Knapen E. Cement concrete and concrete-polymer composites: Two merging worlds: A report from 11th ICPIC Congress in Berlin, 2004. Cem Concr Compos 2005, 27 (9-10), 926-933

${ }^{45}$ Ohama Y, Nishimura T, Hachisuka H. Strength properties of steel fiber reinforced polystyrene-impregnated concrete. Proceedings - Computer Networking Symposium 1980, 3, 151-158.
} 
Los trabajos de composites fabricados mediante la adición de residuos de EPS como agregados ligeros en conglomerados datan de los últimos 10 años. Babu et al. analizan el comportamiento al añadir humo de sílice como material complementario de cemento. ${ }^{46}$ Peng et al. examinan las propiedades de aislamiento térmico y acústico, ${ }^{47}$ y como contribución más reciente Wang et al. fabrican un material estable ante el ataque de productos químicos comunes como las soluciones salinas, los ácidos diluidos y el ataque biológico. ${ }^{48}$

\subsubsection{2.- Politereftalato de etilo (PET)}

EI PET es un poliéster que se obtiene mediante una reacción de policondensación entre los monómeros ácido tereftálico y etilenglicol. Es un polímero termoplástico lineal con un alto grado de cristalinidad que puede ser procesado mediante extrusión, inyección, inyección y soplado, soplado de preforma y termoconformado. Fue producido por primera vez en 1941 por los científicos británicos Whinfield y Dickson, quienes lo patentaron como polímero para la fabricación de fibras. ${ }^{49}$

Alrededor de 1950 se comenzó a emplear en forma de film para envasar y conservar alimentos. Pero la aplicación que supuso su mercado principal fue su utilización en forma de envases rígidos, a partir de 1976, gracias a su impermeabilidad y aptitud para la fabricación de botellas para bebidas poco sensibles al oxígeno, como por ejemplo el agua mineral y los refrescos carbonatados.

Los resultados de la investigación, donde los residuos triturados de botellas de PET se han empleado en una matriz de mortero, se plasman en los trabajos de Reis, ${ }^{50}$ Mahdi $^{51}$ y Rebeiz, ${ }^{52}$ siendo este último uno de los

\footnotetext{
46 Babu K.G, Babu D.S. Behaviour of lightweight expanded polystyrene concrete containing silica fume Cem Concr Res 2003, 33 (5), 755-762.

${ }^{47}$ Peng J.H, Chen M.F, Zhang J.X. Study on waste expanded polystyrene as lightweight aggregate for thermal insulating mortar. Jianzhu Cailiao Xuebao/J Build Mater 2002, 5 (2), 166.

${ }^{48}$ Wang R, Meyer C. Performance of cement mortar made with recycled high impact polystyrene. Cem Concr Compos 2012, 34 (9), 975-981.

${ }^{49}$ Whinfield and Dickson. Improvements Relating to the Manufacture of Highly Polymeric Substances, British Patent 578,079, 1941; Polymeric Linear Terephthalic Esters, U.S. Patent 2,465,319, 1949.

${ }^{50}$ Reis J.M.L, Carneiro E.P. Evaluation of PET waste aggregates in polymer mortars. Constr Build Mater 2012, 27 (1), 107-111.
} 
primeros científicos en utilizar estos compuestos como sustitutos de los áridos. Los resultados obtenidos indican que al incrementar la proporción de PET añadido se disminuye la densidad, aumenta el aislamiento térmico y se reduce la resistencia mecánica a flexión.

\subsubsection{3.- Polietilvinilacetato de etilo (copolímero EVA)}

Es un polímero resultado de la copolimerización de etileno y acetato de vinilo a través de una reacción de activación mediante la formación de radicales libres, a presión y temperaturas elevadas.

Los estudios que emplean el copolímero EVA como agregado en materiales de construcción son muy recientes y comienzan en el año 2009, cuando Saoula et al. consiguen una mejora de las prestaciones del hormigón bituminoso. ${ }^{53}$ Posteriormente, Tutikian mide el aislamiento acústico del hormigón ligero con residuos de EVA en suelos, comprobando que este árido reciclado reduce los niveles del ruido de impacto mejorando la impermeabilidad y reduciendo la fisuración por retracción. ${ }^{54}$

\subsection{6.- Morteros aligerados con residuos de poliuretano espumado}

El poliuretano es un polímero termoestable resultado de la polimerización de un monómero tipo poliisocionato y otro monómero con grupos polihidroxílicos. Los químicos alemanes Wurtz y Hentschel, obtuvieron en 1848 y 1884 los primeros isocianatos, hecho que condujo finalmente al desarrollo de los poliuretanos. Pero fueron Otto Bayer y sus colaboradores quienes hicieron posible el desarrollo comercial de los poliuretanos en $1937 .{ }^{55}$ Desde ese momento, se perfeccionan en formas que incluyen

\footnotetext{
${ }^{51}$ Mahdi F, Abbas H, Khan A.A. Strength characteristics of polymer mortar and concrete using different compositions of resins derived from post-consumer PET bottles. Constr Build Mater 2010, 24 (1), 25-36.

${ }^{52}$ Rebeiz K, Banko A, Craft A. Thermal properties of polymer mortar using recycled PET and fly ash. J Mater Civil Eng 1995, 7 (2), 129-133.

${ }^{53}$ Saoula S, Ait Mokhtar K, Haddadi S, Ghorbel E. Improvement of the performances of modified bituminous concrete with EVA and EVA-waste. Physics Procedia 2009, 2 (3), 1319-1326.

${ }^{54}$ Tutikian B, Nunes M, Leal L, Marquetto L. Impact sound insulation of lightweight concrete floor with EVA waste. Building Acoustics 2012, 19 (2), 75-88.

55 Szycher M. Szycher's Handbook of Polyurethanes. CRC Press, Boca Raton (FL). 1999.
} 
recubrimientos, elastómeros, adhesivos, compuestos de moldeo, espumas y fibras.

Dependiendo del proceso de fabricación y de los monómeros utilizados, el poliuretano espumado se presenta en forma flexible, semirrígida o rígida y en diferente rango de densidades, lo que le convierten en un material versátil, con elevada resistencia a la abrasión, poca conductividad térmica y baja densidad aparente. ${ }^{56}$

Se ha encontrado diversa bibliografía referente al uso del poliuretano fabricado in situ en composiciones basadas en conglomerados aligerados de cemento. Por ejemplo, en 2006, Verdolotti et al. ${ }^{57}$ investigaron sobre la posibilidad de producir un nuevo material aligerado mezclando poliuretano espumado in situ con diferentes proporciones de cemento Portland y agua.

Sin embargo, son muy escasas las referencias experimentales relativas a la incorporación de residuos de espuma rígida de poliuretano. Sólo el grupo de investigación de Pierre Mounanga trabaja desde 2008 en este campo de aplicación, habiendo presentado los resultados de la introducción de poliuretano, procedentes de la destrucción de paneles aislantes, en mezclas de cemento con el fin de producir un hormigón aligerado. ${ }^{58}$ Posteriormente, con objeto de mejorar las propiedades mecánicas de este tipo de composites, introdujeron en 2010 el uso de aditivos superplastificantes basados en policarboxilatos, logrando alcanzar los niveles exigidos para hormigones estructurales. ${ }^{59}$ Recientemente, han determinado la respuesta térmica transitoria de estos materiales. ${ }^{60}$

No se han encontrado más referencias bibliográficas sobre la utilización de residuos de espumas de poliuretano como adiciones ligeras para morteros $\mathrm{u}$ hormigones, aunque se considera que los productos de residuos de poliuretano-cemento podrían ser potencialmente competitivos con los

\footnotetext{
${ }^{56}$ Wu JW, Sung WF, Chu HS. Thermal conductivity of polyurethane foams. Int. J. Heat Mass Transf 1999, 42, 2211-2217.

57 Verdolotti L, Di Maio E, Lavorgna M, lannace S, Nicolais L. Polyurethane-cementbased foams: Characterization and potential uses. J Appl Polym Sci 2008, 107(1), 1-8.

${ }^{58}$ Mounanga P, Gbongbon W, Poullain P, Turcry P. Proportioning and characterization of lightweight concrete mixtures made with rigid polyurethane foam wastes. Cem Concr Compos 2008, 30, 806-814.

${ }_{59}$ Ben Fraj A, Kismi M, Mounanga P. Valorization of coarse rigid polyurethane foam waste in lightweight aggregate concrete. Constr Build Mater 2010, 24 (6), 1069-1077.

${ }^{60}$ Kismi M, Poullain P, Mounanga P. Transient Thermal Response of Lightweight Cementitious Composites Made with Polyurethane Foam Waste. International J Thermophysics 2012, 1-20.
} 
productos convencionales aceptados actualmente, debido a las propiedades que previsiblemente tendrán estos materiales compuestos.

Por este motivo, en 2009, el Grupo de Materiales de la Universidad de Burgos comenzó la investigación hacia la formulación de nuevos materiales aligerados de construcción, incorporando residuos de diferentes espumas rígidas de poliuretano procedentes de la industria del automóvil y de la producción de productos de refrigeración, como son los yesos aligerados ${ }^{61}$, los hormigones bituminosos, ${ }^{62}$ o los pavimentos asfálticos fundidos. ${ }^{63}$

Debido a los buenos resultados previos obtenidos se ha profundizado en la elaboración de morteros aligerados, investigación dentro de la que se enmarca esta Tesis Doctoral.

\section{4.- Morteros para albañilería}

\subsection{1.- Introducción.}

Los morteros son mezclas plásticas de un conglomerante o aglomerante, un árido y agua, que sirven para unir piezas de construcción entre sí o a una base y para realizar revestimientos verticales y horizontales.

La palabra mortero procede del término latino "mortarium", que significa argamasa, y que aparece descrito por Vitruvio en el siglo I a. J.C. ${ }^{64}$ Los escritos de Vitruvio definen el "mortarium" como combinación de cal y arena, con proporciones de una unidad de cal por tres de arena o dos de cal por cinco de arena en función de las características de la arena utilizada. ${ }^{65}$

\footnotetext{
${ }^{61}$ Gutiérrez-González S, Gadea J, Rodríguez A, Junco C, Calderón V. Lightweight plaster materials with enhanced thermal properties made with polyurethane foam wastes. Constr Build Mater 28 (1), 653-658.

62 Gutiérrez-González S, Gadea J, Calderón V, Junco C. Procedimiento de obtención de hormigón bituminoso en caliente con residuo de poliuretano espumado. Patente de invención (2011). Número de solicitud: P201100023.

63 Salas M.A. Hormigones bituminosos y pavimentos asfálticos con residuos de poliuretano. Trabajo de investigación (2011). Universidad de Burgos.

${ }^{64}$ Vitruvio Polion, M.: "Los Diez Libros de Arquitectura". Traducción de D. José Ortiz Sanz. Imprenta Real. Madrid, 1787.

${ }^{65}$ Vitruvio Polion, M.: "Los Diez Libros de Arquitectura". Traducción directa y notas de D. Agustín Blázquez. Universidad de Barcelona. Colección Obras Maestras. Editorial Iberia. Barcelona, 1992.
} 
Los aglomerados utilizados en las más antiguas construcciones estaban compuestos de barro y en su caso de árido de pequeño tamaño; estos aglomerados se pueden observar en monumentos megalíticos de Grecia. También los egipcios utilizaron el limo del río Nilo como aglomerante.

El yeso como conglomerante, procedente de la calcinación de piedras de algez impurificadas de cal, es común en la unión de los sillares de piedra arenisca de la pirámide de Keops; también los interiores de las cámaras se recubrían con yeso estucado. ${ }^{66}$

Sin embargo las primeras obras de piedra unidas por conglomerante hidráulico, obtenido al calcinar conchas marinas, aparecen al norte de Chile hace 5.000 años. $^{67}$

El empleo de un tipo de mortero compuesto de cal aérea, arena y agua, fue técnica común en la antigua Grecia para unir bloques de piedra y para el revestimiento y ornato de los elementos arquitectónicos. También los romanos, herederos de la técnica y tradiciones de los griegos, generalizaron el uso de los morteros y mejoraron sensiblemente la calidad de los mismos, mezclando materiales puzolánicos, provenientes de un lugar llamado Puzzoli, con cal y arena. Estos morteros eran estables en el agua, y sus propiedades, semejantes a los actuales conglomerados hidráulicos. ${ }^{68}$

Durante la Edad Media solo se utilizan morteros de cal, arena y materiales puzolánicos, agregando en ocasiones yeso y sustituyendo parcialmente la arena o la puzolana, por materiales reciclados tales como ladrillo picado. Las deficientes técnicas de cocción de cal y yeso, unidas a la falta de innovaciones en la fabricación de morteros, son el origen de la baja calidad de los morteros utilizados desde el final del Imperio Romano hasta el Renacimiento.

Con el Renacimiento se recupera la técnica de la fabricación y puesta en obra de los morteros, fruto de la vuelta a los modelos clásicos de las

\footnotetext{
66 Rodríguez Sáiz. A. Tesis Doctoral. "Fabricación de morteros de albañilería con escoria blanca de horno de cuchara y su utilización en construcción. Universidad de Burgos. España. 2008

67 Alejandre Sánchez, F.J. Tesis Doctoral. "Historia, caracterización y restauración de morteros". Instituto Universitario de Ciencias de la Construcción de la Universidad de Sevilla. Sevilla, 2002.

68 Gárate Rojas, I: "Artes de la Cal". Ministerio de Cultura. Dirección General de Bellas Artes y Archivos. Madrid, 1994.
} 
culturas griega y romana. La imitación del estilo clásico en juntas y revestimientos, requiere una homogeneidad en las materias primas empleadas en los morteros y una rigurosa ejecución de las fábricas y revocos, que tienen su apogeo con la llegada del Barroco, cuando el estuco adquiere la categoría de arte. El desarrollo del arte de estucar obliga a la investigación de nuevos productos y nuevas mezclas, empleándose por primera vez aditivos para mejorar su aplicación y las técnicas del policromado.

Hasta el siglo XVIII solo se utilizan los morteros de cal, yeso y materiales puzolánicos, si bien en la segunda mitad de ese siglo, se investigan mezclas calcinadas de arcilla y caliza que se emplean como conglomerantes hidráulicos. Concretamente en el año 1756, en la construcción del faro Eddyston, en Plymouth, se utilizaron cales procedentes de la calcinación de piedra caliza impurificada con arcillas; estos conglomerantes resistían bien el agua de mar, ya que su composición química es muy similar a la de las actuales cales hidráulicas.

En el año 1812, Vicat investiga las reacciones del material procedente de la cocción, a elevada temperatura, de mezclas de roca caliza y arcillosa, ${ }^{69}$ descubriendo que el buen comportamiento de estos conglomerantes frente al agua se debía a la presencia de la materia arcillosa, cuya descomposición a altas temperaturas daba lugar a la aparición de los compuestos de carácter hidráulico. También comprobó que, elevando la temperatura de cocción hasta un cierto límite, la capacidad y resistencia del conglomerante aumentaba. ${ }^{70}$

Finalmente, en 1824, un albañil de Wake-eld, llamado Joseph Aspdin, patenta un producto, basado en las investigaciones de Vicat, que afirmaba ser "tan duro como la piedra de Pórtland", dando origen a lo que hoy conocemos como cemento de clinker de Pórtland o simplemente Cemento Pórtland, base de la inmensa mayoría de los morteros que se utilizan en construcción.

\footnotetext{
${ }^{69}$ Vicat, L.J.: "Recherches expérimentales su les chaux de construcción les bétons et les mortiers ordinaires" Libraire de LL.AA.RR. madamme la Duchesse de Berry. Paris, 1818.

70 Vicat, L.J.: "Investigaciones sobre morteros: Las Cales de Construcción, los Hormigones y los Morteros Ordinarios". Traducción de Da Ana María Calavera. INTEMAC. Madrid, 1999.
} 
Los avances científicos y tecnológicos posteriores aplicados a la selección de las materias primas y al sistema de producción, han permitido desarrollar morteros con propiedades específicas para usos concretos, de modo que hoy en día se fabrican morteros cuyo pedido se realiza exclusivamente en función de las prestaciones del mortero. Esto ha dado lugar a la elaboración de normas que recogen la realidad de la industria de los morteros, distinguiendo claramente los morteros prefabricados o preparados en fábrica, de los morteros tradicionales confeccionados en obra hasta muy entrada la década de los 70 del siglo pasado.

\subsection{2.- Empleo de material reciclado en los morteros. Breve reseña histórica}

El empleo de material reciclado en la confección de morteros data casi de los propios orígenes del mortero. El mortero es un material compuesto de un conglomerante y un árido. Inicialmente la facilidad de extracción y la cercanía del árido al lugar de fabricación del mortero resultaba una condición determinante para la elección del mismo. La única exigencia del árido era su dureza.

Uno de esos elementos duros y resistentes que mejora el comportamiento de los morteros de cal son los materiales cerámicos finamente triturados, por lo que ya en el siglo $X$ a. de J.C. se utilizaba el ladrillo o teja molidos como sustitución de la arena o roca volcánica en los morteros. Los romanos también aplicaron esta técnica de reciclaje, empleando restos cerámicos y escorias procedentes del combustible de los hornos.

La "Opus Signimun", pavimento impermeable utilizado por los Romanos, se componía de diversas capas; la capa inferior estaba compuesta de morteros de cal y arena con cascotes o restos de ladrillos cerámicos de cierto tamaño; la capa intermedia tenía la misma composición pero con cascotes de menor tamaño. Las escorias procedentes de los residuos de hornos de forja u otros, añadidos realmente como sustitutivo del árido, se pueden observar en el mortero de juntas de las obras públicas romanas (puentes, acueductos, etc.).

Estas técnicas de reciclaje de residuos de materiales, se utilizaron con mayor o menor profusión hasta bien entrado el siglo XX, sin experimentarse avances dignos de reseñar, salvo la depuración de las técnicas de 
preparación de morteros en el Renacimiento y Barroco, con empleo de restos de mármoles seleccionados, finamente triturados.

Los primeros estudios para la utilización de residuos reciclados no tradicionales, empleados en la sustitución del árido de los morteros y hormigones, se inician después de la segunda guerra mundial, con el objeto de dar salida a la gran acumulación de escombros de las ciudades destruidas. A partir del año 1946, sobre todo en Inglaterra, Alemania y Rusia se trabaja en la incorporación de los escombros de los edificios, previamente tratados (reciclados), a los hormigones y en menor medida a los morteros de cemento, ${ }^{71-73}$ investigaciones que concluyen cuando se agotan o eliminan esos escombros.

En las últimas décadas del siglo $\mathrm{XX}$, la optimización de recursos y la toma de conciencia de la sociedad, impulsa realmente a investigar y a emplear los residuos industriales y escombros de la construcción como material alternativo a ciertas materias primas en la confección de morteros para albañilería. La elaboración del hormigón con agregados reciclados han mostrado que tales materiales resultan un sustitutivo satisfactorio y económico. $^{74}$

\subsection{3.- Concepto de mortero}

El diccionario de la Real Academia de la Lengua (RAE), define el mortero como Conglomerado o masa constituida por arena, conglomerante y agua, que puede contener además algún aditivo. ${ }^{75}$

El concepto de mortero, como mezcla de aglomerante-conglomerante, árido y agua, para unir o proteger las fábricas, aparece en los manuales de materiales de construcción históricos, y es el mismo que aún hoy se mantiene.

\footnotetext{
${ }^{71}$ Nixon, P.J. The use of materials from demolition in construction. Report of the Building Research Establishment. Garston, Watford, Inglaterra, 1976

72 Gluzge,P. I. The work of scientific research institutes. Gidrotekhnicheskoye Stroitelstvo (URSS) No. 4, Abril 1946, 27-28

73 Ploger, R. An Investigation of the Compressive Strength of Concrete in which Concrete Rubble was used as Aggregate, Ithaca, MS Thesis, Cornell University. 1947

${ }^{74}$ Frondistou-Yannas Stamatia. Waste Concrete as Aggregate for a New Concrete. Journal of Amerícan Concrete Institute. Detroit Vol 74 n 8 . Aug. 1977, 373-376

${ }^{75}$ Diccionario de la lengua española. Real Academia Española. 22a edición. Madrid: Espasa Calpe. 2001.
} 
El profesor Félix Orús Asso define los morteros como una mezcla plástica obtenida con un aglomerante, arena y agua, que sirve para unir piedras o ladrillos, que integran obras de fábrica y para revestirlos con enlucidos o revocos. ${ }^{76}$

Las normas UNE-EN 998-1 y 998-2 clasifican dos tipos de mortero en función de su uso. ${ }^{77,78}$

- Mortero para revoco/enlucido: Mezcla compuesta de uno o varios conglomerantes inorgánicos, de áridos, de agua y a veces de adiciones y/o de aditivos, para realizar revocos exteriores o enlucidos interiores. (998-1)

- Mortero para albañilería: Mezcla compuesta de uno o varios conglomerantes inorgánicos, de áridos, de agua y a veces de adiciones y/o de aditivos, para fábricas de albañilería (fachadas, muros, pilares, tabiques), rejuntado y trabazón de albañilería. (9982)

Unificando ambas definiciones podemos expresar el concepto de mortero como "Mezcla compuesta de uno o varios conglomerantes inorgánicos, de áridos, de agua y a veces de adiciones y/o de aditivos, para realizar revestimientos y sentar fábricas." Sin embargo los usos del mortero hoy día son más extensos, pues encontramos morteros para solados, morteros de reparación, impermeabilizantes, etc.

Todas las definiciones anteriores enumeran los componentes y usos del mortero pero resultan incompletas, al no explicar que el mortero se coloca en estado plástico y resulta apto una vez endurecido por efecto del fraguado del conglomerante.

Es necesario introducir el término conglomerar entendido como Unir fragmentos de una o varias sustancias con un conglomerante, con tal coherencia que resulte una masa compacta (RAE), ya que la función del

\footnotetext{
76 Orús Asso, F. "Materiales de construcción" séptima edición, reimpresión. Editorial Dossat, S.A. Madrid. 1984

77 Norma Española UNE-EN 998-1. Especificaciones de los morteros para albañilería. Parte 1: Morteros para revoco y enlucido. 2010

78 Norma Española UNE-EN 998-2. Especificaciones de los morteros para albañilería. Parte 2: Morteros para albañilería. 2004
} 
mortero no solo es unir materiales, sino principalmente conglomerar sus propios materiales constitutivos.

Los componentes obligados de un mortero son el conglomerante, el árido y el agua, siendo los aditivos y adiciones componentes esporádicos que se añaden al mortero para modificar, mejorar $u$ obtener propiedades especiales. Si comparamos la definición del profesor Orús Asso con la recogida en las normas UNE, vemos que la diferencia fundamental en los componentes esenciales del mortero, estriba en la sustitución de la palabra "arena" del profesor Orús Asso, por la palabra "árido" de la normativa.

\subsection{4.- Componentes del mortero}

\subsubsection{1.- Conglomerantes}

Definimos conglomerante como Material utilizado para unir partículas sólidas de tal manera que formen una masa coherente (UNE-EN 998-2), es decir, la parte activa de los morteros o material que es capaz de aglutinar el árido.

Los conglomerantes más empleados, tradicionalmente y en la actualidad, para la confección de los morteros son el cemento Portland, la cal hidratada en sus distintas variedades y el yeso.

Los morteros pueden contener uno o varios conglomerantes. Dentro de los morteros con más de un conglomerante, llamados morteros bastardos, se encuentran los morteros de cemento y cal y los morteros de cal y yeso.

El mortero de cemento Portland es el más utilizado en el asiento de fábricas y en los revestimientos expuestos a ambientes húmedos (exterior y cuartos húmedos en interior). Las soleras o capas de nivelación para tapar tubos y que sirven de base para la colocación del solado en el interior de los edificios, se ejecutan también con mortero de cemento, aunque en este caso se emplea mezcla de árido fino y árido algo más grueso, por lo que se puede hablar de mortero u hormigón.

\subsubsection{2.- Áridos}

La definición que recoge la Norma UNE-EN 998-2, Material granular que no contribuye a la reacción de endurecimiento del mortero, resulta muy 
adecuada para la comprensión del árido como material inerte dentro del mortero.

El árido de los morteros es un material inorgánico inerte, que sustituye parcialmente al conglomerante y cuyas características mecánicas mejoran la resistencia y minimizan el efecto de la retracción en los morteros de cemento y de cal. Actúa como el esqueleto del mortero, pues es cohesionado con el conglomerante y forma parte de un material compacto. El conglomerante tiene que ser capaz de rodear completamente al árido para cohesionarlo y con ello formar una matriz que impida el contacto de partículas de árido entre sí, ya que esto daría lugar a superficies de árido sin cohesionar, creando una discontinuidad en ciertos planos del mortero.

Por este motivo, la forma y tamaño de los áridos resultan muy importantes a la hora de facilitar la unión de los mismos a través del conglomerante. El objetivo es conseguir esa unión resistente con la mínima cantidad de pasta conglomerante, a fin establecer una relación óptima entre el precio del producto y sus prestaciones mecánicas.

La Norma UNE-EN 13139:2002 ${ }^{79}$, Áridos para morteros define el árido como Material granular utilizado en construcción. Esta definición de árido no refleja la función del árido como componente del mortero, pero especifica las condiciones mínimas de los áridos para morteros, con el objeto de implantar un modelo final de utilización basado en la experiencia con distintos tipos de áridos. El modelo establece unas exigencias para los áridos que denomina "requisitos" y que son:

- Requisitos geométricos: relativos al tamaño del árido, granulometría, forma de las partículas y contenido y calidad de los finos.

- Requisitos físicos: densidad de las partículas, absorción de agua, resistencia al hielo y al deshielo.

- Requisitos químicos: contenido en cloruros, componentes que contienen azufre, o que alteran la velocidad de fraguado y el endurecimiento del mortero, reactividad álcali sílice. Para los áridos artificiales establece también un contenido máximo de sustancias solubles en agua y una pérdida por calcinación limitada.

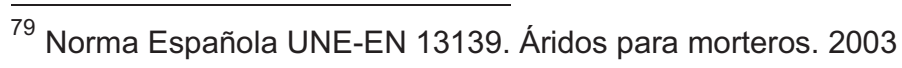


La norma describe el árido en función de los tamaños mínimo y máximo, por medio de la relación entre sus diámetros $d / D(d$ = máxima luz de malla que deja pasar menos del $10 \%$ de la mezcla, $\mathrm{D}=$ mínima luz de malla que deja pasar más del $90 \%$ de la mezcla), y define dos tipos de árido:

- Árido grueso: árido con $D$ igual o mayor de $4 \mathrm{~mm}$ y $d$ igual o mayor de $2 \mathrm{~mm}$, correspondientes a los tamaños 0/8, 2/4 y 2/8.

- Árido fino: árido con $D$ igual o menor de $4 \mathrm{~mm}$, correspondientes a los tamaños $0 / 1,0 / 2$ y $0 / 4$.

El tamaño del árido fino en la Instrucción de Hormigón Estructural, ${ }^{80}$ coincide con el de la Norma UNE-EN 13139, lo que confirma un campo común entre morteros con áridos gruesos y ciertos hormigones con tamaño máximo de árido limitado.

Los agregados sustitutivos del árido que se han utilizado en la confección de los morteros de esta Tesis, residuos reciclados de espuma rígida de poliuretano, son materiales de densidad aparente muy baja, muy inferior a $1.200 \mathrm{~kg} / \mathrm{m}^{3}$. Para estos áridos, denominados áridos ligeros, la Norma UNE-EN $13055-1^{81}$ no establece condiciones distintas a las exigidas en la norma UNE-EN 13139, excepción hecha de la densidad inferior a 1.200 $\mathrm{kg} / \mathrm{m}^{3}$.

En todos los casos la normativa se refiere a áridos de carácter mineral inorgánico, no dando opción a la utilización de materiales de origen orgánico, como las espumas de poliuretano.

Sin embargo el erratum de la versión oficial de la norma, la Norma UNE-EN 13055-1 $1^{82}$ comenta en el apartado 1 OBJETO Y CAMPO DE APLICACIÓN "NOTA 1, entre otros, los siguientes: "El mandato M/125 "Áridos" incluye áridos reciclados y algunos materiales de origen nuevo o no habitual así como áridos naturales y manufacturados conocidos y tradicionales". "Para materiales no habituales de origen secundario, sin embargo, el trabajo de normalización ha empezado recientemente y se necesita más tiempo para definir claramente el origen y características de estos materiales".

\footnotetext{
80 Instrucción de Hormigón Estructural (EHE-08). R.D. 1247/2008 de 18 de julio. BOE n 203 de 22/08. 2008

81 Norma Española UNE-EN 13055-1. Áridos ligeros. Parte 1: Áridos ligeros para hormigón, mortero e inyectado. 2002

82 Norma Española UNE-EN 13055-1/AC. Áridos ligeros. Parte 1: Áridos ligeros para hormigón, mortero e inyectado. 2004
} 
No existe normativa de aplicación para los áridos "no inorgánicos", "no origen mineral", por lo que la idoneidad del agregado de PUR, dependerá de los ensayos de aptitud y durabilidad que se han propuesto.

\subsubsection{3.- Agua}

El agua de los morteros tiene una doble función. Por un lado es necesaria para hidratar el conglomerante cemento y el conglomerante yeso, y por otro lado sirve como lubricante para mojar las partículas de árido y facilitar su moldeo y compactación.

El agua tiene que ser inocua, no debiendo contener sustancias que puedan alterar el fraguado de los conglomerantes o las propiedades del resto de componentes. En general se aceptarán todas las aguas potables sancionadas por la práctica, sin necesidad de garantizar su calidad.

\subsubsection{4.- Adiciones}

El concepto de adición que recoge la Norma UNE-EN 998-2 es: Material inorgánico finamente dividido (que no es árido, ni conglomerante) que se puede añadir al mortero para mejorar o para obtener propiedades especiales.

No existe norma UNE que indique las especificaciones de las posibles adiciones que puedan formar parte de los morteros.

La Norma UNE 83481 EX, de Adiciones al hormigón, ${ }^{83}$ es la única que se refiere al empleo de adiciones en el mortero de cemento, y como recomendaciones de uso indica las relativas a dosificación de la adición y a las condiciones medioambientales.

Las adiciones que se pueden incorporar a los morteros son materiales puzolánicos, cenizas volantes, escorias granuladas, humo de sílice, filleres minerales, o incluso pigmentos. Muchos de estos elementos pueden modificar el endurecimiento y fraguado del cemento, y solamente son utilizables cuando se dosifica con CEM I. Los filleres minerales son adiciones que mejoran la trabajabilidad del mortero ya que son materiales

83 Norma Española Experimental UNE 83481 EX, Adiciones al hormigón. Escorias granuladas molidas de horno alto. Recomendaciones de uso para las escorias granuladas molidas utilizadas en los hormigones y morteros fabricados con cemento portland tipo I. 1996 
inertes que en todo caso se pueden considerar como parte del árido. Los pigmentos deben ser también inertes, durables e inalterables a la radiación solar y a los cambios térmicos.

Rara vez se utilizan adiciones en morteros fabricados en obra, pues la dosificación y mezcla de los componentes del mortero requiere unas garantías de homogeneidad difícilmente alcanzables en condiciones de obra.

\subsubsection{5.- Aditivos}

La norma UNE-EN 998-2 define el aditivo como Material añadido en pequeñas cantidades para obtener modificaciones especificadas de las propiedades.

Los aditivos pueden modificar las propiedades tanto del mortero en estado fresco como del mortero endurecido; el término "pequeñas cantidades" en la definición de la norma, no tiene un significado concreto. La norma UNEEN 934-3, ${ }^{84}$ hace mención a la "dosificación de referencia", como la cantidad en masa expresada en \%, del aditivo con respecto a la masa del cemento, y que debe ser fijada por el fabricante entre unos límites máximo y mínimo, es decir, en un intervalo. Solamente describe dos tipos de aditivo en función de las mejoras que puedan producir y son: inclusor de aire/plastificante y retardador de fraguado para mortero para albañilería fuertemente retardado.

El aditivo inclusor de aire en el mortero genera pequeñas burbujas de aire que facilitan el moldeo del mortero y favorecen el efecto de lubricante entre las partículas del mortero. A su vez las burbujas de aire interrumpen la red capilar y facilitan la deformación del mortero (sin rotura) cuando se producen aumentos importantes de volumen por efecto de la congelación del agua en sus poros abiertos. El aditivo inclusor de aire tiene por tanto, el doble efecto de ser un plastificante y un anticongelante.

El aditivo retardador de fraguado actúa en el mortero aislando las partículas del agua, retrasando la hidratación del cemento. La Norma UNE-EN 934-

\footnotetext{
${ }^{84}$ Norma Española UNE-EN 934-3. Aditivos para hormigones, morteros y pastas. Parte 3: Aditivos para morteros de albañilería. Definiciones, requisitos, conformidad, marcado y etiquetado. 2009
} 
$2^{85,86}$ de aditivos para morteros está destinada especialmente a los aditivos retardadores por incorporación de aire atrapado.

Existen otros tipos de aditivos no normalizados, como son aditivos plastificantes por modificación de la reología en estado fresco, aditivos hidrofugantes, retenedores de agua, ligantes orgánicos, etc. En cualquier caso el empleo de aditivos tiene que ser eficaz, para obtener el efecto deseado y no debe producir efectos perjudiciales.

\subsection{5.- Propiedades de los morteros}

La definición amplia del término "mortero", como compuesto homogéneo formado por la unión de conglomerante, árido y agua, que se moldea en estado plástico y que una vez endurecido resulta apto y durable para su uso en albañilería, nos permite ordenar el estudio del mortero, en base a sus propiedades en estado plástico y a sus prestaciones una vez endurecido.

\subsubsection{1.- Propiedades del mortero fresco}

Se denomina "estado fresco del mortero" la fase inmediatamente posterior a la mezcla homogénea de los componentes, que se caracteriza por presentar una consistencia que permite dar una forma adecuada al mortero. En esta fase los componentes son susceptibles de tener movimientos independientes, lo que puede ocasionar la pérdida de homogeneidad de la mezcla al producirse ciertas agrupaciones de una parte de sus componentes.

Para impedir la pérdida de homogeneidad en el interior del mortero, es necesario que la consistencia, es decir, la fuerza de atracción entre los distintos componentes, sea superior a las acciones externas que actúan sobre el mortero, incluida la fuerza de la gravedad. Por otro lado, la consistencia del mortero tiene que permitir, en estado fresco, un moldeo adecuado a los medios y técnicas habituales, facilitando la adaptación a la forma final e impidiendo la aparición de espacios vacíos que creen una estructura heterogénea y discontinua en el conglomerado.

\footnotetext{
${ }^{85}$ Norma Española UNE-EN 934-1. Aditivos para hormigones, morteros y pastas. Parte 1: Requisitos, comunes. 2008

${ }^{86}$ Norma Española UNE-EN 934-2. Aditivos para hormigones, morteros y pastas. Parte 2: Aditivos para hormigones. Definiciones, requisitos, conformidad, marcado y etiquetado. 2009
} 
Una vez moldeado el mortero, es decir colocado en un soporte, debe conservar su forma antes del endurecimiento y mantener una adherencia suficiente al soporte que impida su desprendimiento. Finalmente la propia composición del mortero y las condiciones medioambientales tienen que permitir el correcto endurecimiento del mortero, para alcanzar las prestaciones de servicio.

El conjunto de todas las propiedades anteriores se puede resumir en el concepto de trabajabilidad, entendido como "facilidad de puesta en obra", definición que coincide con la de la Norma Americana ASTM C 125: Propiedad que determina el esfuerzo requerido para manipular una cierta cantidad de material recién mezclado con la mínima pérdida de homogeneidad. ${ }^{87}$

Para poder evaluar las condiciones anteriores se utilizan parámetros que miden la trabajabilidad del mortero, tales como la consistencia, la densidad del mortero fresco, la retención de agua, la adherencia en fresco, etc. La Norma UNE-EN 1015-9, ${ }^{88,89}$ no define el concepto de trabajabilidad; solamente indica el procedimiento para determinar el tiempo durante el cual el mortero se puede colocar en obra, después del amasado, sin haber sufrido merma en los parámetros que miden su trabajabilidad.

\subsubsection{2.- Propiedades del mortero endurecido}

El mortero endurecido es un conglomerado sólido de estructura porosa, compuesto de una matriz que rodea y aglutina un árido, y cuyas propiedades fundamentales son, resistencia a compresión, dureza superficial, adherencia a los materiales pétreos, cierta impermeabilidad y buen comportamiento frente a los agentes atmosféricos.

Se puede considerar el mortero como un material compuesto, en el que la parte débil es la matriz cementicia y la parte más fuerte es el árido. El cemento, constituido en su mayor parte por silicatos cálcicos, se hidrata

\footnotetext{
${ }^{87}$ ASTM C 125 "Standard Terminology Relating to Concrete and Concrete Aggregates". American Society for Testing and Materials (ASTM), Philadelphia, PA. Annual Book of ASTM Standard. 2007

88 Norma Española UNE-EN 1015-9. Métodos de ensayo de los morteros para albañilería. Parte 9: Determinación del periodo de trabajabilidad y del tiempo abierto del mortero fresco. 2000

89 Norma Española UNE-EN 1015-9:2000/A1. Métodos de ensayo de los morteros para albañilería. Parte 9: Determinación del periodo de trabajabilidad y del tiempo abierto del mortero fresco. 2007
} 
debido a la mezcla coloidal de la fase líquida y sólida, formando un gel que cristaliza. La aparición de los cristales es la base de la resistencia del cemento endurecido y del efecto adhesivo con el árido.

Para que las finísimas partículas de cemento se hidraten completamente, se requiere una cantidad crítica de agua, a la que se añade el agua necesaria para mojar la superficie del árido. Una escasez de agua impedirá la correcta hidratación del cemento y el correcto moldeo del mortero; un exceso de agua favorecerá la hidratación del cemento y el moldeo del mortero, pero su posterior evaporación dejará espacios vacíos. La hidratación del cemento se produce una vez transcurrido un cierto tiempo, durante el cual es necesario evitar la evaporación o la migración del agua del mortero, para asegurar que en todo momento las partículas de cemento dispongan de la suficiente cantidad de agua para su hidratación.

Las reacciones de hidratación del cemento son procesos fuertemente exotérmicos, que favorecen una evaporación rápida del agua sobrante, lo que produce tensiones en la masa, todavía poco resistente del mortero, dando lugar a fisuras superficiales. Este fenómeno se conoce como retracción plástica.

Una vez fraguado el cemento y rigidizado el mortero, el agua que todavía no se ha evaporado va saliendo al exterior en forma de vapor. Si la evaporación es rápida el camino del vapor de agua hacia el exterior puede encontrar obstáculos que dificulten su difusión, creando tensiones en la superficie del mortero y apareciendo fisuras y desconchones. Es la llamada retracción hidráulica o de secado.

Finalmente, las variaciones importantes de temperatura por efecto del fraguado del cemento, crean dilataciones y contracciones en el mortero, con la posible aparición de fisuras.

Una vez fraguado y curado el mortero, su estructura se compone, por lo general, de áridos de diversos tamaños rodeado de cristales de silicatos y aluminatos cálcicos, con espacios vacíos y fisuraciones próximas a la superficie.

\subsubsection{1.- Características mecánicas}

Los morteros endurecidos se encuentran sometidos a diversas tensiones mecánicas, que son función de su ubicación en obra: compresión, cortante 
y flexión en morteros de juntas, flexión y tracción en morteros para revocos, etc. A estas solicitaciones propias de la función que desempeñan los morteros en obra, se añaden las que provienen de la propia deformación del soporte, que pueden llegar a provocar incluso su rotura.

Las normas UNE-EN 998-1 y 998-2, exigen unas resistencias mínimas a compresión para todo tipo de morteros de albañilería. Cuando el destino de los morteros sea la utilización en construcciones sometidas a requisitos estructurales, las resistencias mecánicas serán las exigidas en el CTE, Documento Básico SE-F Fábrica (DB SE-F) ${ }^{90}$

La resistencia a compresión del mortero de cemento dependerá de su estructura y de la capacidad resistente del cemento fraguado.

La adherencia del mortero al soporte se define como la capacidad para soportar las tensiones normales y tangenciales en la interfase morterosoporte. Los morteros se adhieren al soporte por medio de anclaje mecánico, de modo que la pasta cementosa junto con el árido fino son capaces de penetrar en los poros abiertos del soporte, cristalizando el cemento y rigidizándose en el interior de esos poros abiertos. En consecuencia la capacidad de adhesión del mortero al soporte depende de las características mecánicas del mortero y de la estructura física del soporte.

Naturalmente y en todos los casos, la puesta en obra y las condiciones de curado son determinantes en las cualidades finales de los morteros.

\subsubsection{2.- Características físicas}

Los morteros son materiales de construcción que forman parte de unidades de obra colocadas, tanto en el interior como en el exterior del edificio, por lo que tienen que ofrecer unas prestaciones que les hagan aptos para ese uso.

El mortero de cemento es un material presente en numerosas unidades de obra de un edificio, utilizado como material de revestimiento, de juntas, de base para el solado y para albañilería en general. El volumen de mortero de

\footnotetext{
${ }^{90}$ Código Técnico de la Edificación (CTE). Documento Básico de Seguridad estructural, Fábrica (DB-SE F). RD 314-2006 de 17 de marzo. BOE nº 74 de 28/03. 2006
} 
cemento en las edificaciones repercute en las cargas permanentes que soporta la estructura del edificio.

En este sentido la densidad aparente del mortero es el factor determinante en la contribución del mortero a las cargas permanentes que tiene que soportar la estructura. Los factores que influyen en la densidad aparente del mortero son la proporción y densidad de sus componentes y la porosidad total, esta última dependiente a su vez de la estructura del mortero.

Los morteros de fachada e interior de los edificios tienen que cumplir ciertas condiciones de impermeabilidad a los fluidos, y en algunos casos de permeabilidad al vapor. En todos los casos, la permeabilidad a fluidos, la capacidad de succión y la permeabilidad al vapor dependen de la red porosa del mortero, es decir, de la configuración estructural del mortero.

También puede colocarse en unidades de obra ocultas (revestidas) o en unidades de acabado de muros, pilares, tabiques y techos, por lo que deberá cumplir con las condiciones obligadas de seguridad frente al riesgo de incendio.

La definición de "Reacción al fuego" en la Norma UNE-EN 13501-191,92 es: Respuesta del producto contribuyendo con su propia descomposición a un fuego al que esta expuesto, bajo condiciones especificadas. La norma también define el "Comportamiento frente al fuego" como la Respuesta de un elemento cuando se expone a un fuego específico. El RD 312/2005 de clasificación de productos de construcción, en función de su comportamiento frente al fuego, ${ }^{93}$ clasifica los morteros como agentes conglomerantes inorgánicos, con la clase de reacción al fuego A1 y A $1_{\mathrm{FL}}$. La propia norma UNE-EN 998-1, confirma esa clasificación siempre que no contengan una fracción superior al $1 \%$ en masa o volumen de materiales orgánicos. La clase de reacción al fuego "A1 y $\mathrm{A} 1_{\mathrm{FL}}$ " significa que el

\footnotetext{
${ }^{91}$ Norma Española UNE-EN 13501-1: A1. Clasificación en función del comportamiento frente al fuego de los productos de construcción y elementos para la edificación. Parte 1: Clasificación a partir de datos obtenidos en ensayos de reacción al fuego. 2009

92 Norma Española UNE-EN 13501-2: A1. Clasificación en función del comportamiento frente al fuego de los productos de construcción y elementos para la edificación. Parte 1: Clasificación a partir de datos obtenidos en ensayos de resistencia al fuego excluidas las instalaciones de ventilación. 2009

93 RD 312/2005 de 18 de marzo sobre la clasificación de los productos de construcción y de los elementos constructivos en función de sus propiedades de reacción y de resistencia frente al fuego. BOE $n^{\circ} 79$ de 02/04. 2005
} 
mortero de cemento no contribuye al fuego, al no producir llama sostenida y no producir humos ni gases, tanto colocado en paredes como en suelo.

La resistencia al fuego es un concepto aplicable solamente a unidades de obra completas y lo podemos definir como la capacidad de soportar durante un período de tiempo determinado la exposición al fuego sin pérdida de la estabilidad estructural y/o sin transmisión del fuego y/o sin transferencia de calor significativa. Ahora bien, el mortero de cemento empleado como revestimiento puede contribuir a la mejora de la resistencia al fuego del elemento constructivo del que forma parte, si mantiene durante un tiempo su integridad y aislamiento térmico.

La optimización de los recursos energéticos, con un consumo racional de los mismos, obliga a construir edificios eficientes, en los que priman los materiales aislantes térmicos, que aumentan el confort y reducen los gastos derivados del funcionamiento de las instalaciones térmicas. Los materiales pétreos en general, son buenos conductores del calor, es decir, no tienen gran capacidad para el aislamiento térmico. Las exigencias de conductividad térmica para los morteros para albañilería de la normativa vigente es solo aplicable a los morteros destinados a construcciones sujetas a requisitos térmicos.

\subsubsection{3.- Durabilidad}

Entendemos por durabilidad de un mortero "el tiempo durante el cual un mortero mantiene las prestaciones que le hacen apto para la función que cumple en la obra". Este concepto de durabilidad que se mide por el término "tiempo", depende de la calidad del mortero y su puesta en obra, del uso del mortero y de su mantenimiento.

A su vez la calidad del mortero depende de sus características físicas y mecánicas, de la puesta en obra, ubicación adecuada y de la calidad en la ejecución. El mortero debe ser apto para el uso previsto en consonancia con sus prestaciones, estando sometido a acciones directas derivadas del propio uso y a acciones indirectas, como son las medioambientales.

Las acciones medioambientales (agua, hielo, cambios térmicos, rayos solares, contaminación ambiental, etc.), pueden llegar a degradar un mortero, rebajando sus prestaciones y llegando incluso a transformarlo en no apto para su uso. Por ello resulta muy interesante conocer el 
comportamiento de los morteros expuestos a estas acciones indirectas a través de ensayos que simulan los efectos de la exposición de los morteros al medio ambiente. Estos ensayos de "envejecimiento acelerado", evalúan la pérdida de prestaciones del mortero con el paso del tiempo. 
N

O

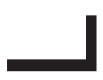

$\supset$

1

-

口

$\longrightarrow$

U

Experimental 



\section{Capítulo 2.- Experimental}

A continuación se describen los ensayos y procesos llevados a cabo para la caracterización de las materias primas y morteros así como los ensayos de durabilidad, especificando el procedimiento operatorio en cada ensayo.

\section{1.- Ensayos físicos}

\subsection{1.- Trituración de los residuos de espuma de poliuretano}

Descripción del tratamiento mecánico previo de las espumas (trituración)

- Para el triturado de las espumas se ha empleado una máquina de la Marca Retsch modelo SM 100, utilizando un tamiz de paso al recipiente contenedor de abertura $4 \mathrm{~mm}$.

- La máquina consta de un receptor de material situado en la zona superior, por el que se vierten trozos de espuma de un tamaño máximo limitado. Del receptor pasan a un compartimento donde se tritura la espuma, que una vez triturada, pasa a un último recipiente a través de una criba.

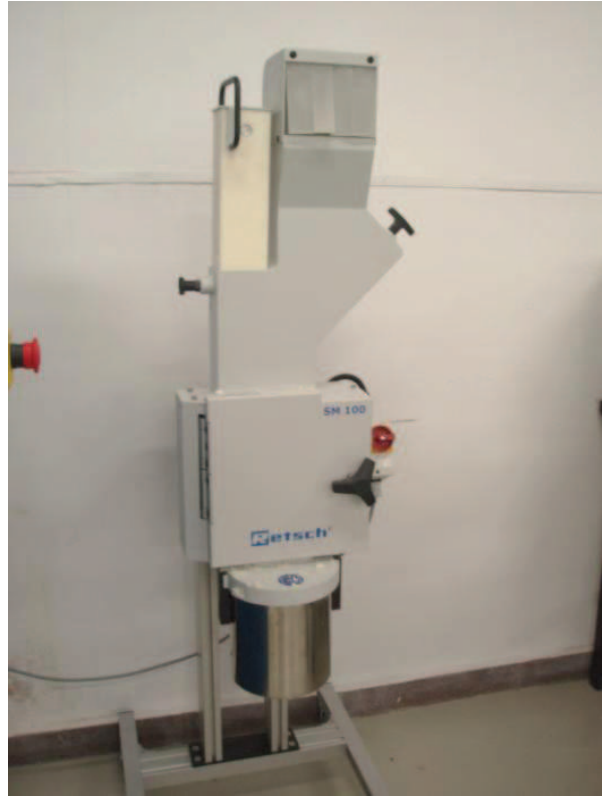

Máquina trituradora de espuma

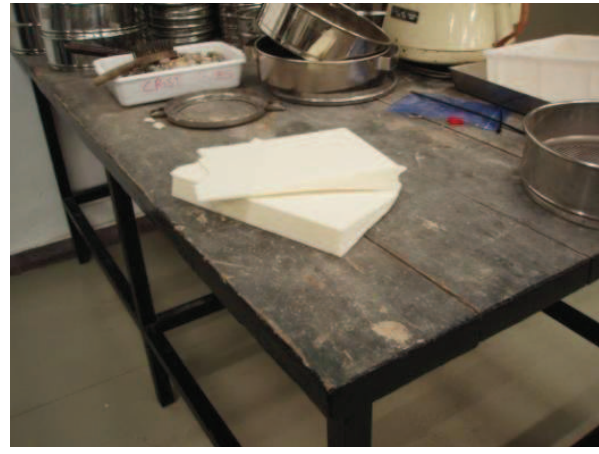

Residuo de espuma de poliuretano

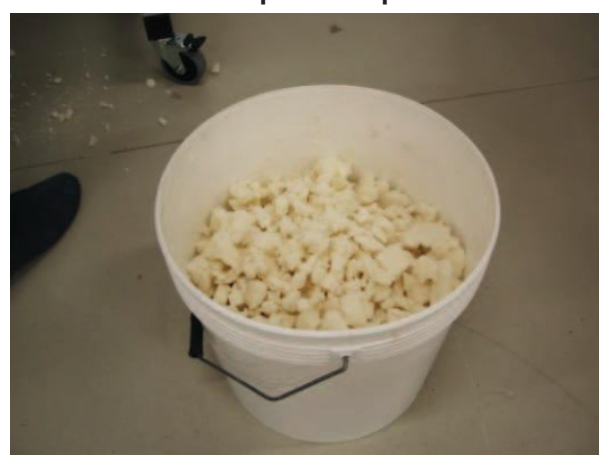

Troceado previo de la espuma 


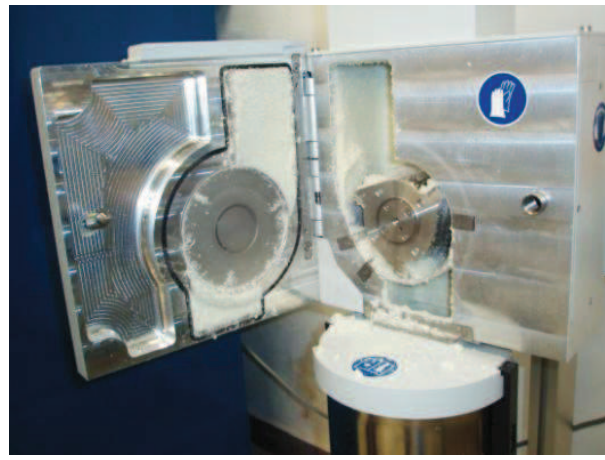

Compartimento triturador de la máquina

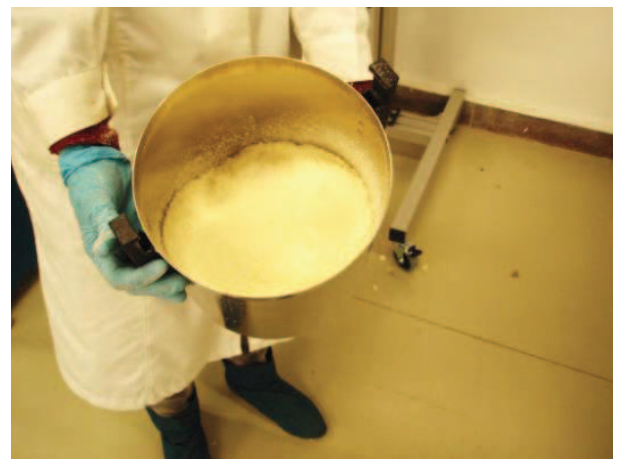

Recipiente de recogida de la espuma triturada

\subsection{2.- Densidad aparente.}

\section{Descripción del ensayo. Norma UNE-EN 1097-3.94}

- La densidad aparente se obtiene dividiendo el peso del árido seco que llena un recipiente de volumen conocido, por el volumen interior de ese recipiente.

- Se rellena el recipiente con el material a analizar sin producir ningún efecto de compactación.

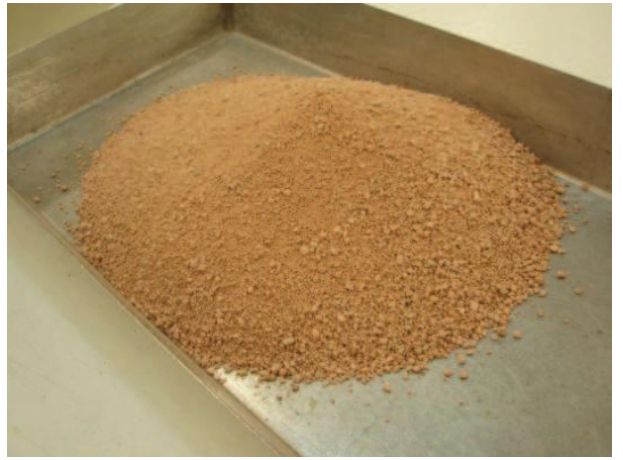

Aspecto de la arena

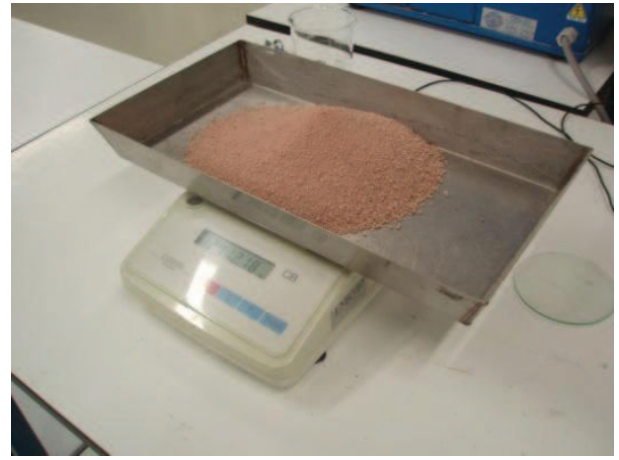

Pesada de la arena de volumen aparente conocido

94 Norma Española UNE-EN 1097-3. Ensayos para determinar las propiedades mecánicas y físicas de los áridos. Parte 3 . Determinación de la densidad aparente y de la porosidad. 1998 


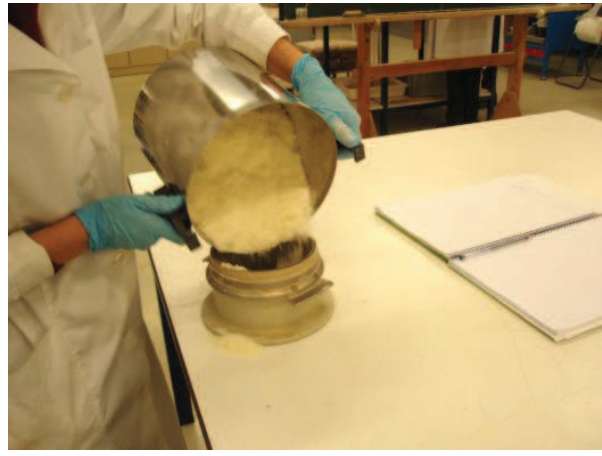

Relleno del molde con material

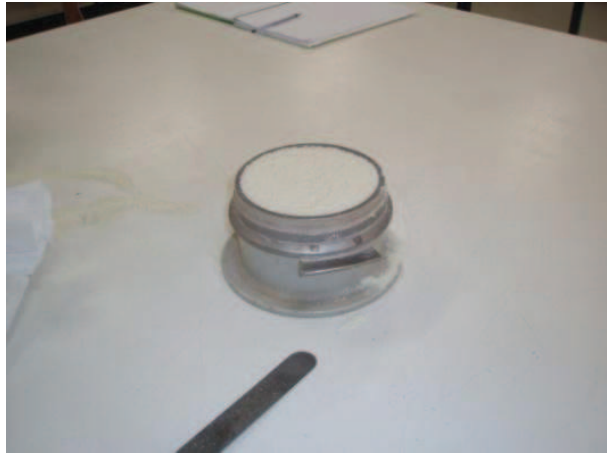

Enrasado del molde. Volumen determinado

- Se pesa el recipiente y se calcula la densidad aparente del árido por el valor medio de tres submuestras. Se calcula la densidad aparente de cada submuestra a partir de la siguiente ecuación:

$$
\rho_{b} \geq \frac{m_{2} \cdot m_{1}}{V}
$$

\subsection{3.- Densidad aparente de las partículas.}

Adaptación del ensayo para piedra natural

\section{Descripción del ensayo. Norma UNE-EN 1097-6.95,96}

- Se realiza por el método del picnómetro.

- La densidad de las partículas se obtiene como la relación entre la masa del árido secada en estufa, y el volumen de agua que desplaza cuando se introduce en un picnómetro. La porosidad se calcula a partir de la densidad aparente del árido y de la densidad aparente de las partículas.

- Se prepara la muestra de conformidad con las Normas UNE-EN 932-1 y se reduce según la Norma UNE-EN 932-2. Se lava para retirar las partículas adheridas y se retiran las que pasan del tamiz 0,063 $\mathrm{mm}$. Se introduce en el picnómetro, previamente calibrado y se realizan las pesadas que indica la Norma.

95 Norma Española UNE-EN 1097-6. Ensayos para determinar las propiedades mecánicas y físicas de los áridos. Parte 6. Determinación de la densidad de partículas y la absorción de agua. 2000

96 Norma Española UNE-EN 1097-6/A1 Ensayos para determinar las propiedades mecánicas y físicas de los áridos. Parte 6. Determinación de la densidad de partículas y la absorción de agua. 2006 


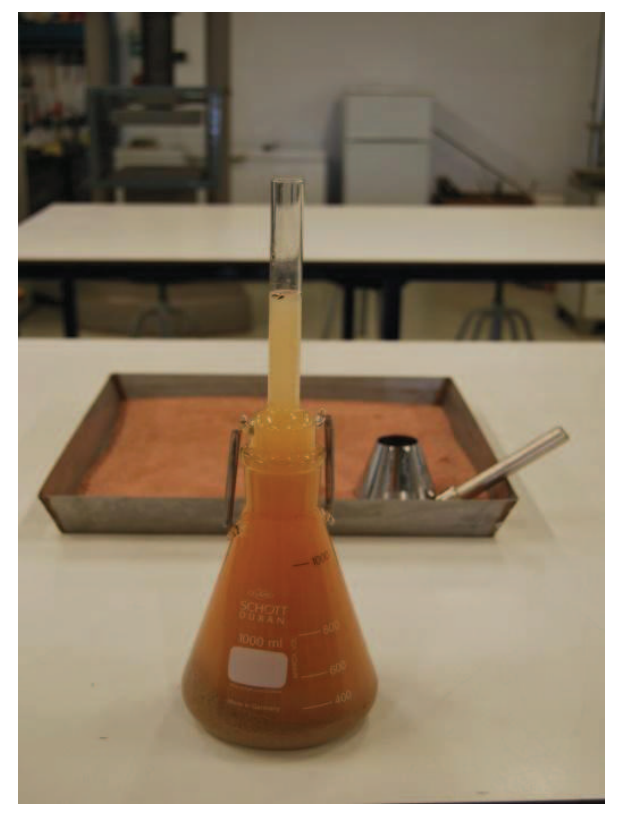

Picnómetro con arena

- La densidad de las partículas presecadas, $\rho_{P}$, se calcula empleando la siguiente expresión:

$$
\rho_{P}=\rho_{W} \frac{M_{2}-M_{1}}{V-\left(M_{3}-M_{2}\right)}
$$

donde $V$ es el volumen del picnómetro en mililitros, $M_{1}, M_{2}$ y $M_{3}$ son las pesadas del picnómetro vacío, picnómetro con muestra y picnómetro con muestra y agua respectivamente, expresadas en gramos y $\rho_{w}$ y $\rho_{p}$ son las densidades del agua y árido expresadas en megagramos.

\subsection{4.- Densidad aparente de la espuma conformada}

Al no existir norma para determinar la densidad de las partículas de la espuma, se ha diseñado un proceso que puede resultar suficientemente fiable y que se expone a continuación.

\section{Descripción del ensayo: Densidad aparente de la espuma conformada}

- La densidad se determina dividiendo la masa de las partículas de espuma, desecadas, por el volumen que ocupan.

- Se confeccionan 2 muestras con 10 probetas prismáticas cada una, de dimensiones de $200 \mathrm{~mm} \times 100 \mathrm{~mm}$ y con el espesor de la plancha de procedencia, que se han secado a peso constante y se calcula el volumen, efectuando dos mediciones con calibre de la longitud, anchura y grueso del prisma.

- El volumen de cada probeta se calcula como producto de las tres 
dimensiones obtenidas por media aritmética de las medidas. El volumen de cada muestra se obtiene por media aritmética de las 10 probetas, y el del prisma de espuma por media aritmética de las dos muestras.

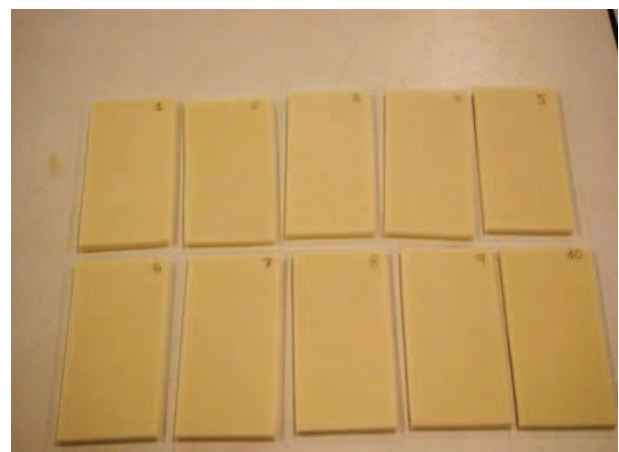

Muestra de 10 probetas prismáticas

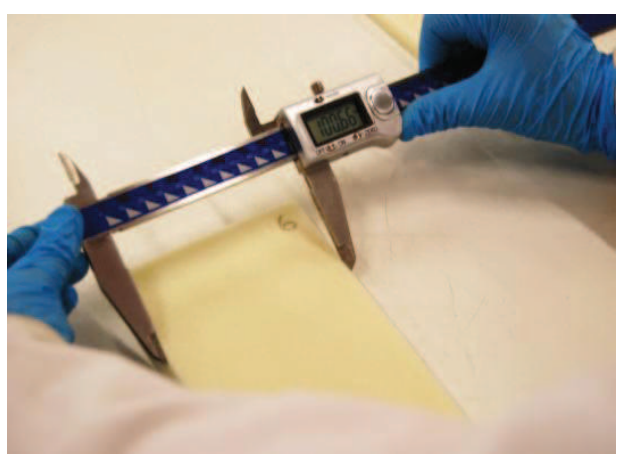

Medición de la anchura (2 medidas)

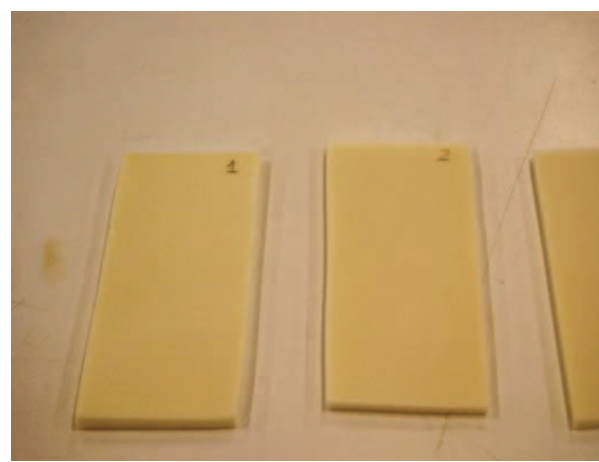

Base del prisma $200 \mathrm{~mm} \times 100 \mathrm{~mm}$

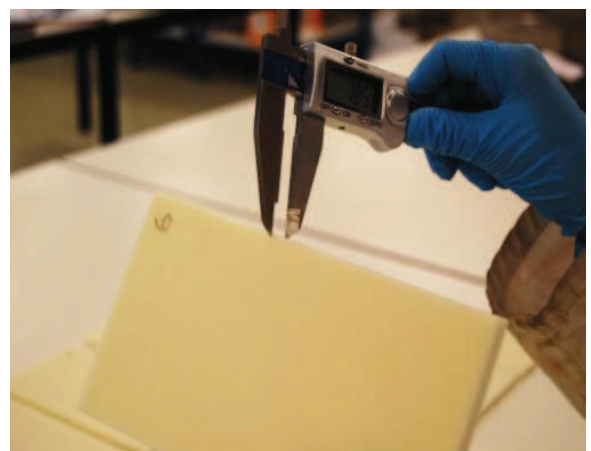

Medición del grueso (2 medidas)

- La densidad aparente de las partículas de espuma se obtiene por relación entre el peso desecado y el volumen del prisma.

\subsection{5.- Densidad real de la espuma triturada}

Adaptación del ensayo para piedra natural

\section{Descripción del ensayo. Norma UNE-EN 1936. ${ }^{97}$}

- La densidad real del poliuretano se obtiene al dividir el peso de una cantidad de poliuretano, triturado a tamaño menor a $0,063 \mathrm{~mm}$, por el volumen real del poliuretano.

- Se utiliza un picnómetro de volumen conocido y se realizan sucesivas pesadas del picnómetro vacío, picnómetro con isopropanol y picnómetro con isopropanol y muestra.

97 Norma Española UNE-EN 1936. Métodos de ensayo para piedra natural. Determinación de la densidad real y aparente y de la porosidad abierta y total. 2006 


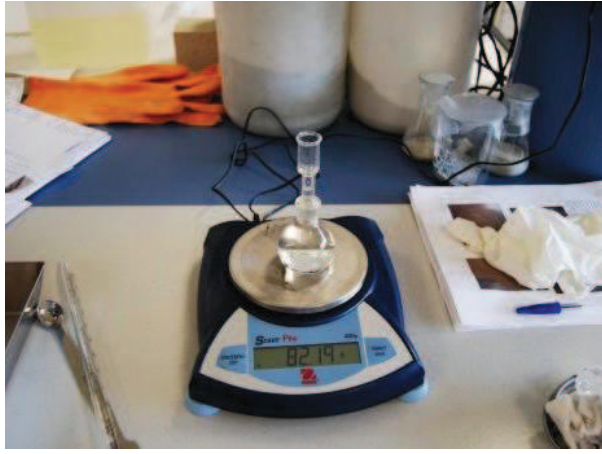

Pesada picnómetro con líquido

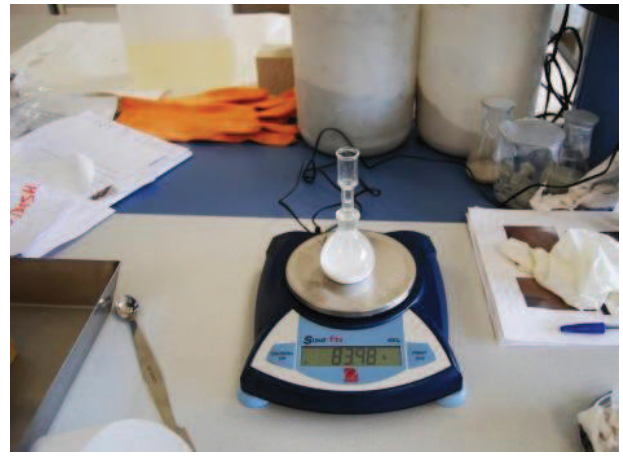

Pesada picnómetro con líquido y muestra

- Se calcula el volumen real de la muestra con la siguiente expresión

$$
\rho_{r}=\rho_{r h} \frac{m_{e}}{\left(m_{2}+m_{e}-m_{1}\right)}
$$

donde $\rho_{\mathrm{rh}}$ es la densidad del isopropanol, y $m_{2} m_{e}$ y $m_{1}$ son respectivamente el peso del picnómetro con lisopropanol, el peso desecado de la muestra y el peso del picnómetro con la muestra e isopropanol.

\subsection{6.- Medida de la consistencia del mortero fresco}

Descripción del ensayo. Norma UNE-EN 1015-3.98-100

- Preparación del mortero a partir de los componentes secos y agua.

- Se amasa el mortero con amasadora mecánica de 5 I de capacidad, según UNE-EN 196-1. Duración del amasado 60 segundos.

- Se rellena el molde y se compacta con la mesa de sacudidas. Posteriormente se retira el molde y el mortero queda extendido sobre el disco.

- Se mide el diámetro del mortero en dos direcciones perpendiculares entre sí con el calibre, según UNE-EN 1015-3:1999. Se calcula el valor medio de las dos medidas.

\footnotetext{
98 Norma Española UNE-EN 1015-3. Métodos de ensayo para morteros de albañilería. Parte 3: Determinación de la consistencia del mortero fresco (por la mesa de sacudidas). 2000

99 Norma Española UNE-EN 1015-3:2000/A1. Métodos de ensayo para morteros de albañilería. Parte 3: Determinación de la consistencia del mortero fresco (por la mesa de sacudidas). 2005

100 Norma Española UNE-EN 1015-3:2000/A2. Métodos de ensayo para morteros de albañilería. Parte 3: Determinación de la consistencia del mortero fresco (por la mesa de sacudidas). 2007
} 


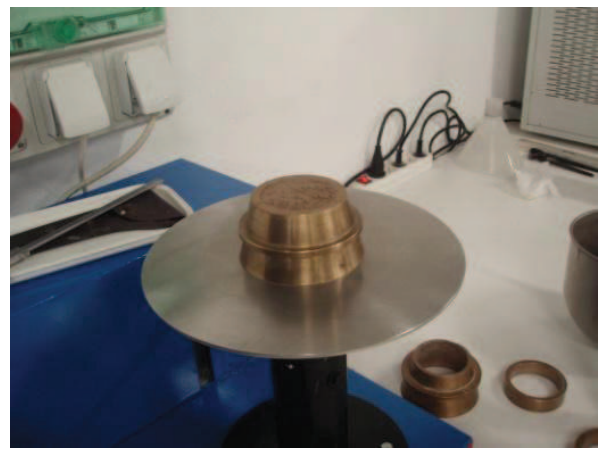

Mesa de sacudidas

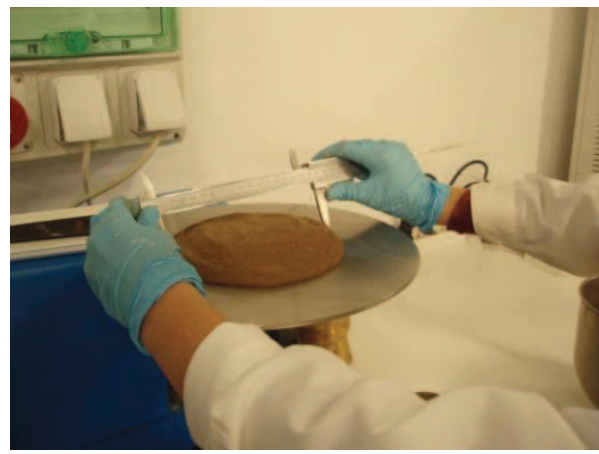

Medida del diámetro de la torta

\subsection{7.- Densidad aparente del mortero fresco}

Descripción del ensayo. Norma UNE-EN 1015-6. ${ }^{101,102}$

- Se determina la relación (W/C) respetando el valor fijado para el escurrimiento.

- La densidad aparente del mortero fresco se obtiene dividiendo su masa por el volumen que ocupa una vez introducido en un recipiente.

- Se amasa el mortero y se llena el recipiente de 1 I de capacidad. El llenado se realiza en dos fases; la primera llenando la mitad y la segunda llenando hasta rebosar.

- Para compactar la masa fresca se bascula el recipiente dejándolo caer.

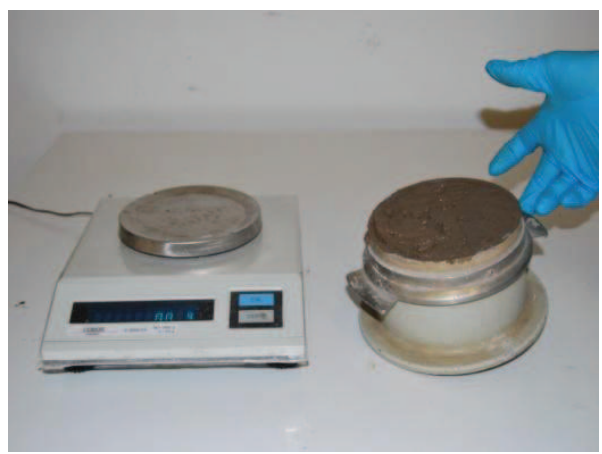

Compactado del mortero fresco

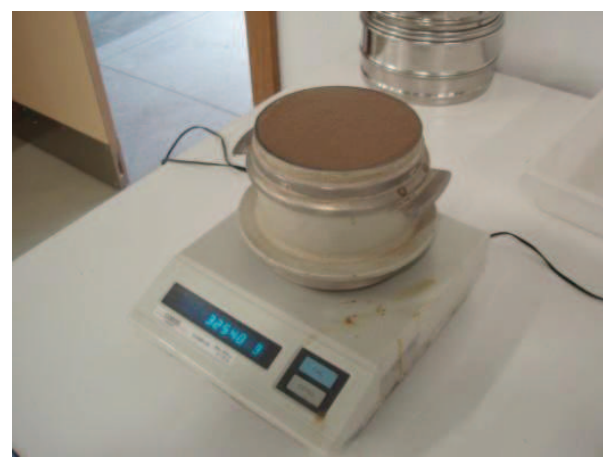

Peso con recipiente de 1 I de capacidad

- Se pesa el recipiente y se calcula la densidad del mortero fresco por el

101 Norma Española UNE-EN 1015-6. Métodos de ensayo de los morteros para albañilería. Parte 6: Determinación de la densidad aparente del mortero fresco.1999

102 Norma Española UNE-EN 1015-6:1999/A1. Métodos de ensayo de los morteros para albañilería. Parte 6: Determinación de la densidad aparente del mortero fresco. 2007 
valor medio de dos determinaciones, redondeando aproximadamente a 10 $\mathrm{kg} / \mathrm{m}^{3}$

\subsection{8.- Contenido de aire del mortero fresco}

\section{Descripción del ensayo. Norma UNE-EN 1015-7..$^{103}$}

- Se emplea el método de presión.

- Se coloca el mortero, previamente amasado, en un recipiente de medida conocida; se vierte agua en la superficie del mortero para asegurar que no queda aire en la superficie del mortero; se aplica una presión de aire especificada en una cámara del aparato de medida; se conecta esta cámara con la cámara que contiene el mortero; la disminución de presión en la cámara de aire refleja el contenido en aire de la muestra del mortero.

- El llenado del recipiente se realiza en cuatro capas aproximadamente iguales y el compactado se realiza con 10 golpes cortos de pisón, hasta obtener una superficie plana.

- Se utiliza una mesa de sacudidas para compactar la masa fresca.

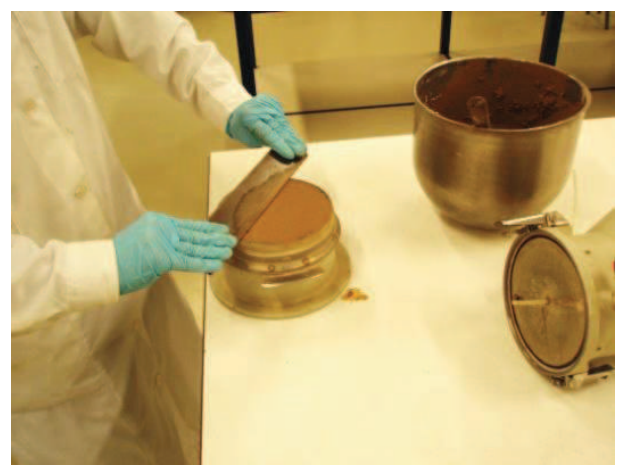

Enrasado del recipiente

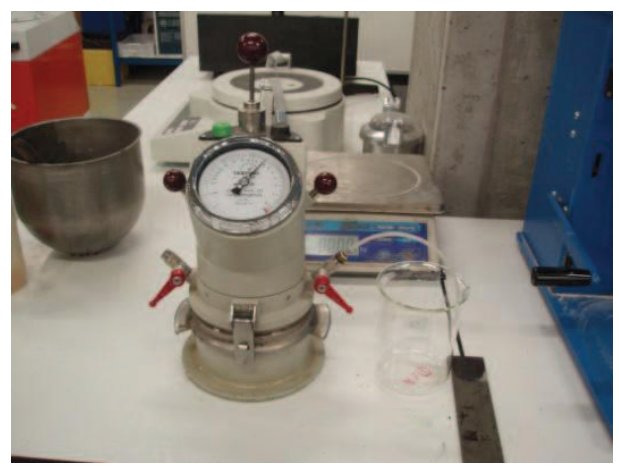

Lectura de la presión

- Se calcula el contenido en aire como el valor medio de los dos valores individuales de cada muestra de mortero ensayada.

103 Norma Española UNE-EN 1015-7. Métodos de ensayo de los morteros para albañilería. Parte 7: Determinación del contenido en aire en el mortero fresco. 1999 


\subsection{9.- Período de trabajabilidad del mortero fresco}

\section{Descripción del ensayo. Norma UNE-EN 1015-9:1999}

- El período de trabajabilidad se mide por el tiempo transcurrido, desde el comienzo del amasado de la mezcla, hasta que el mortero adquiere cierto grado de rigidez.

- Se vierte la muestra recién amasada en un recipiente que se enrasa; el recipiente se coloca en una balanza y se sitúa debajo de una sonda.

- Se baja lentamente la sonda de penetración hasta que la arandela roce la superficie.

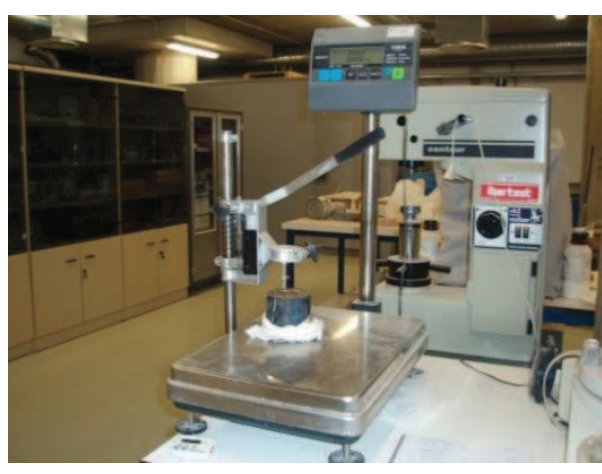

Balanza a "0", antes de la penetración

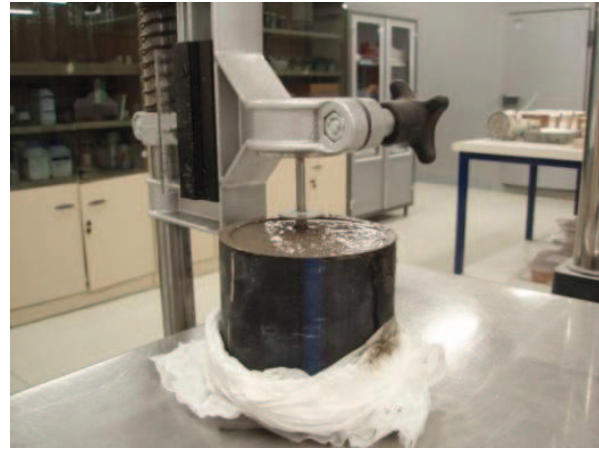

Penetración de la sonda

- El período de trabajabilidad (en minutos) se determina a partir del momento en que se añade el agua a los componentes secos, hasta que la resistencia a la penetración sea de $0,5 \mathrm{~N} / \mathrm{mm}^{2}$. 


\subsubsection{0.- Capacidad de retención de agua por succión del mortero fresco}

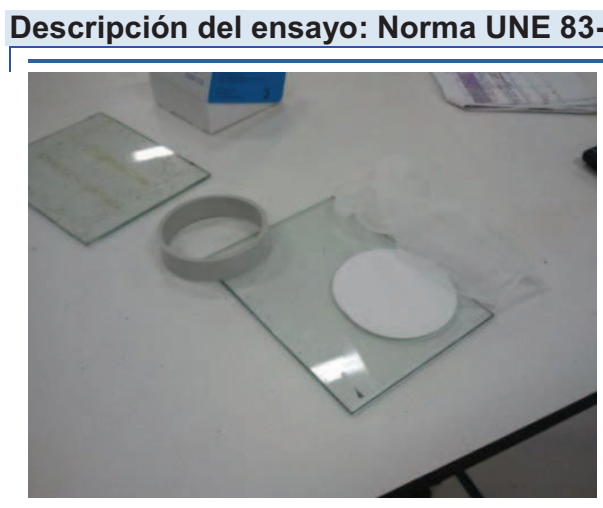

Cilindro, vidrio y papeles de filtro

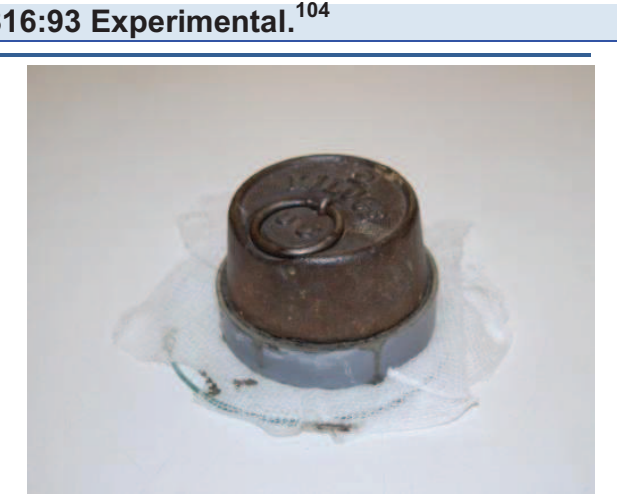

Aplicación de la carga de $\mathbf{2} \mathbf{~ k g}$

- Se calcula la capacidad de retención de agua como la relación entre el agua presente en el mortero fresco después de realizado el ensayo, y el agua del mortero antes del mismo, expresando el resultado en tanto por ciento respecto de la cantidad de agua inicial.

\subsubsection{1.- Densidad aparente del mortero endurecido}

\section{Descripción del ensayo. Norma UNE-EN 1015-10. ${ }^{105,106}$}

- Se emplean probetas de forma regular.

- La densidad aparente se calcula dividiendo la masa de la probeta, secada en estufa, por el volumen que ocupa cuando se sumerge en agua en estado saturado.

- Se han fabricado probetas prismáticas de dimensiones $160 \mathrm{~mm} \times 40 \mathrm{~mm}$ $x 40 \mathrm{~mm}$ que se han secado en estufa hasta peso constante. Posteriormente se han saturado a peso constante y se han sumergido en agua, para determinar su volumen aparente por pesada hidrostática.

\footnotetext{
104 Norma Española UNE 83816:1993 EX. Morteros. Métodos de ensayo. Morteros frescos. Determinación de la capacidad de retención de agua. 1993

105 Norma Española UNE-EN 1015-10. Métodos de ensayo de los morteros para albañilería. Parte 10: Determinación de la densidad aparente en seco del mortero endurecido. 2000

106 Norma Española UNE-EN 1015-10:2000/A1. Métodos de ensayo de los morteros para albañilería. Parte 10: Determinación de la densidad aparente en seco del mortero endurecido. 2007
} 


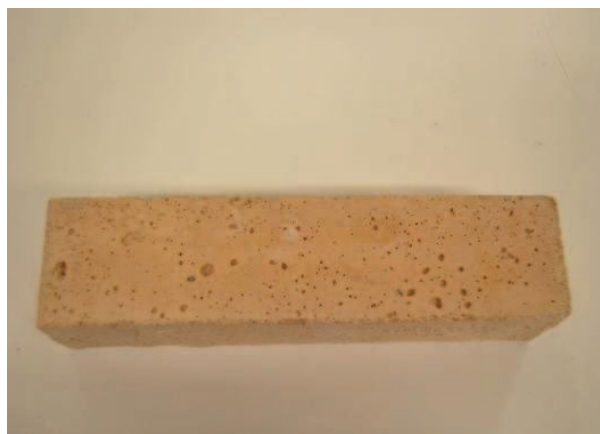

Probeta saturada

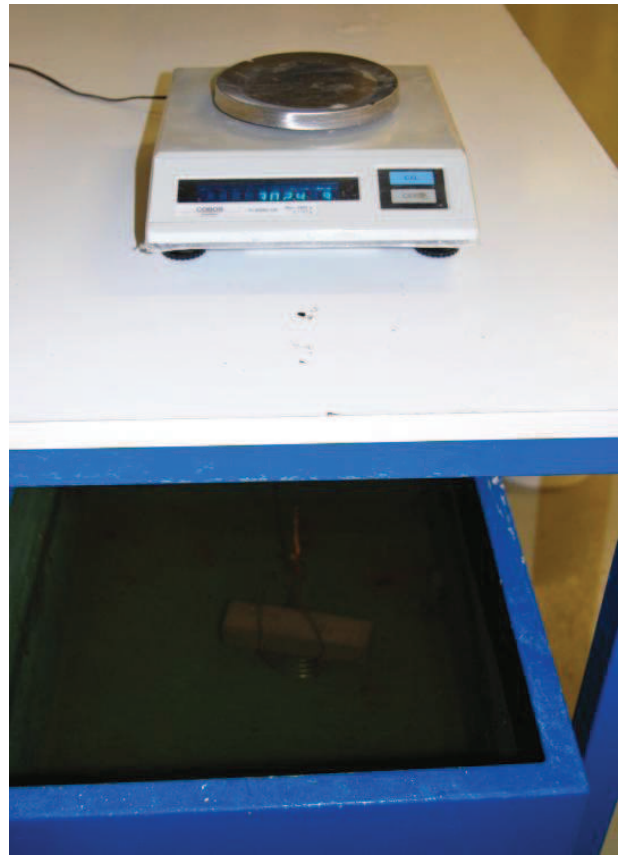

Balanza y recipiente para peso sumergido

- La densidad aparente en seco de cada probeta se calcula dividiendo la masa por el volumen. El valor final es el resultado de la media aritmética de los valores individuales.

\subsubsection{2.- Coeficiente de absorción del mortero endurecido}

Descripción del ensayo. Norma UNE-EN 1015-18:2002. ${ }^{107}$

- El objeto del ensayo es determinar el coeficiente de absorción de agua por capilaridad de los morteros endurecidos.

- El coeficiente de absorción de agua por capilaridad se mide por la cantidad de agua absorbida, en función de la superficie en contacto con el agua y del tiempo de exposición.

- Las probetas tienen forma prismática de dimensiones $(40 \times 40 \times 160)$ $\mathrm{mm}$.

- Se secan las probetas y se impregnan de parafina por las caras de mayor superficie; seguidamente se rompen por flexión y se introducen en un recipiente con la cara de rotura inmersa en agua $(5 \mathrm{~mm}$ a $10 \mathrm{~mm})$.

107 Norma Española UNE-EN 1015-18. Métodos de ensayo de los morteros para albañilería. Parte 18: Determinación del coeficiente de absorción de agua por capilaridad del mortero endurecido. 2003 
- Se pesan las probetas a los 10 minutos de inmersión y a los 90 minutos.

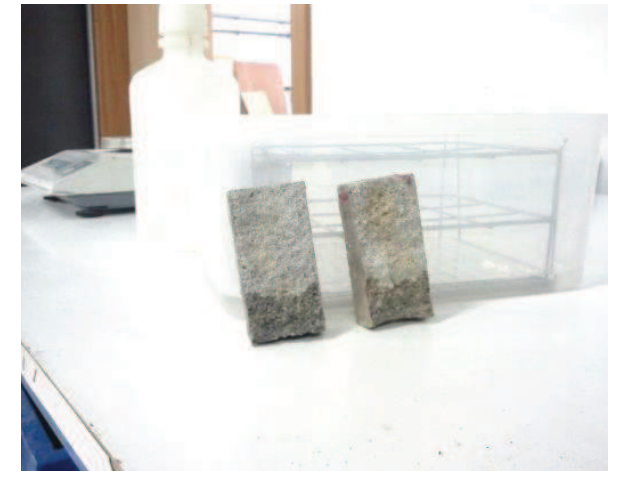

Altura penetración probetas sin aditivos

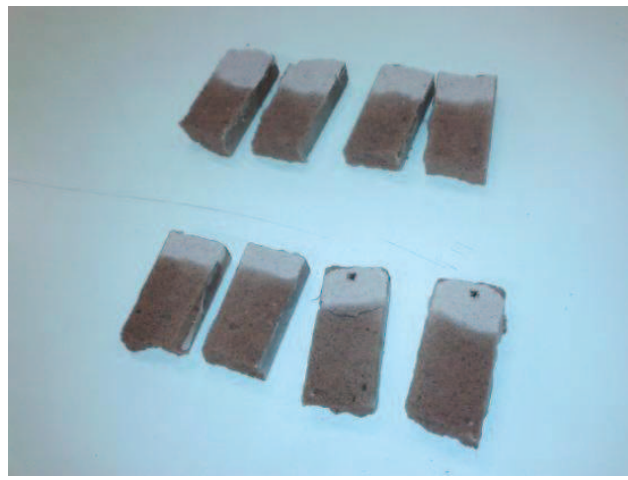

Altura penetración probetas con aditivos

- El coeficiente de absorción de agua por capilaridad es igual a la pendiente de la recta que une los puntos representativos de las medias tomadas a los 10 minutos y a los 90 minutos, mediante la siguiente expresión:

$$
C=0,1(M 2-M 1) \mathrm{kg} / \mathrm{m}^{2} \cdot \min ^{0,5}
$$

\subsubsection{3.- Permeabilidad al vapor de agua del mortero endurecido}

\section{Descripción del ensayo. UNE-EN 1015-19:1998 ${ }^{108-110}$}

- La permeabilidad al vapor de agua se calcula multiplicando la permeanza por el espesor de la probeta. La permeanza depende del flujo de vapor de agua que atraviesa la superficie y de la presión del vapor de agua

- Las probetas tienen forma cilíndrica, con superficie de la base de 0,0016 $\mathrm{m}^{2}$ y espesor de $10 \mathrm{~mm}$

- Se curan las probetas y se colocan en un recipiente circular, con disolución de sales en su interior que provocan una diferencia de presión entre las caras del mortero, siendo la humedad mucho mayor en el interior. Esto hace que el agua de la disolución salina atraviese el espesor de la probeta, lo que conduce a una evaporación progresiva de agua con el tiempo. Los recipientes se pesan a intervalos de $24 \mathrm{~h}$.

\footnotetext{
108 Norma Española UNE-EN 1015-19. Métodos de ensayo de los morteros para albañilería. Parte 19: Determinación de la permeabilidad al vapor de agua de los morteros endurecidos de revoco y enlucido. 1999

109 Norma Española UNE-EN 1015-19. ERRATUM. Métodos de ensayo de los morteros para albañilería. Parte 19: Determinación de la permeabilidad al vapor de agua de los morteros endurecidos de revoco y enlucido. 1999

110 Norma Española UNE-EN 1015-19:1999/A1. Métodos de ensayo de los morteros para albañilería. Parte 19: Determinación de la permeabilidad al vapor de agua de los morteros endurecidos de revoco y enlucido. 2005
} 


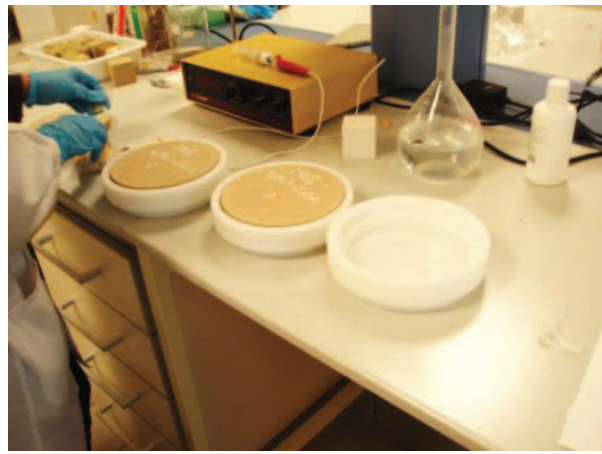

Colocación de la probeta

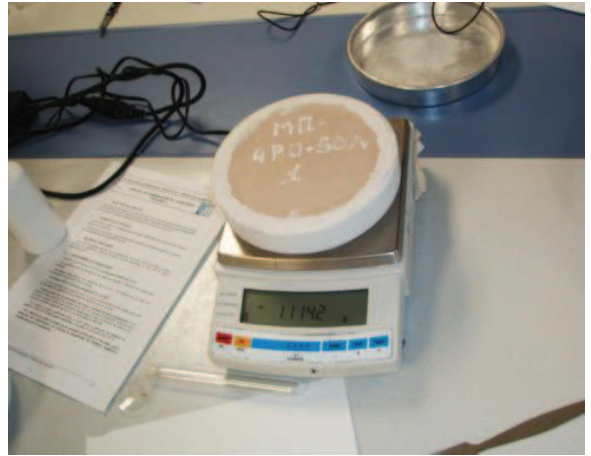

Sucesivas pesadas del molde y probeta

- La permeanza al vapor de agua se obtiene mediante la siguiente expresión:

$$
\Lambda=\frac{1}{A \Delta_{p} /(\Delta G / \Delta t)-R_{A}} \text { en } \mathrm{kg} / \mathrm{m}^{3} \cdot \mathrm{s} \cdot \mathrm{Pa}
$$

La permeabilidad al vapor de agua se halla multiplicando el valor medio de la permeanza (media de 5 probetas) y el espesor de la probeta.

\subsubsection{4.- Transmisión acústica a ruido aéreo}

\section{Descripción del ensayo. Petit Cabine. Grupo Antolín}

○ Equipo:

- Petite Cabine Grupo Antolín

- Analizador PULSE v 14 de Brüel \& Kjaer de 5 canales

- Software de análisis Pulse Labshop tipo CPB \& FFT

- Micrófono GRAS 40AF $n^{\circ}$ serie 11480

- Micrófono GRAS 26AF $n^{\circ}$ serie 11540

- Micrófono Brüel \& Kjaer tipo 4943-L001 nº serie 227670

。 Micrófono Brüel \& Kjaer tipo 4943-L001 nº serie 2277671

。 Micrófono Brüel \& Kjaer tipo 4189-A021 nº serie 2406837

- Calibrador de Micrófono Brüel \& Kjaer tipo $4231 n^{\circ}$ serie 2061601

- Amplificador de potencia Brüel \& Kjaer tipo ES 5001

- Generador de Ruido Blanco 

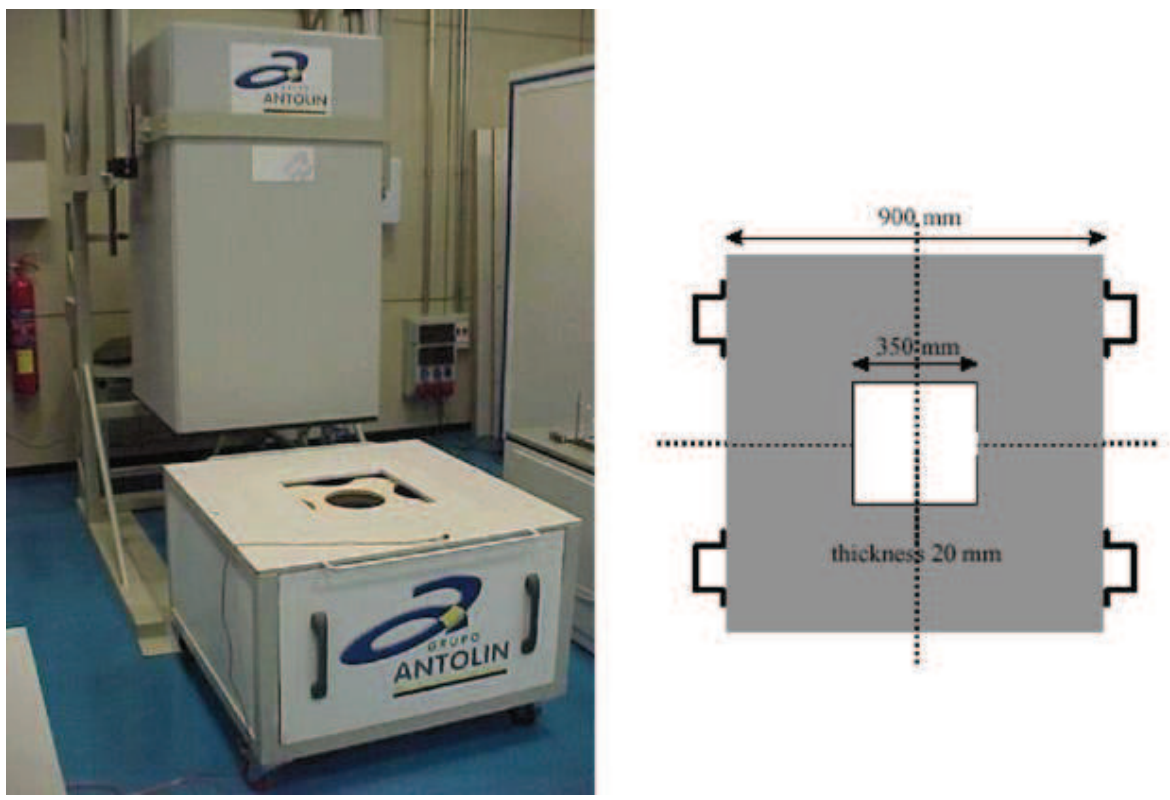

Petit Cabine

\section{2.- Ensayos químicos}

\subsection{1.- Granulometría por difracción de rayos láser}

\section{Descripción del ensayo.}

- Esta técnica se emplea para determinar la distribución del tamaño de grano de los residuos de poliuretano utilizados. El equipo es un analizador HELOS $12 \mathrm{~K}$ de la marca SYMPATEC. Las muestras se analizan suspendidas en alcohol isopropílico, con un tiempo de medida de 15 segundos

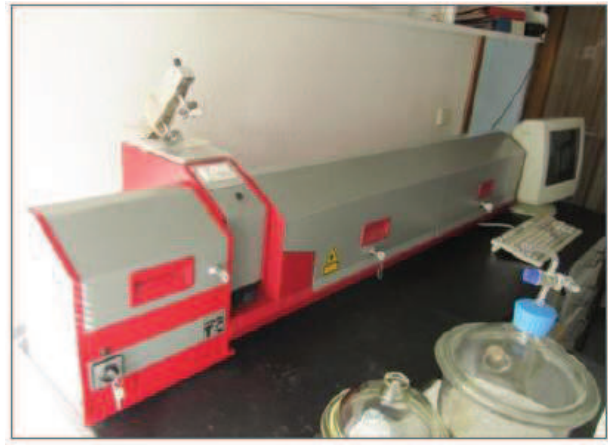

Analizador láser 


\subsection{2.- Difracción de rayos $x(D R X)$}

\section{Descripción del ensayo.}

- Se emplea para determinar cualitativamente la composición mineralógica del cemento empleado, utilizando para ello un difractómetro PHILIPS PW1830, que proporciona la cantidad de componentes mineralógicos del cemento en forma de óxidos

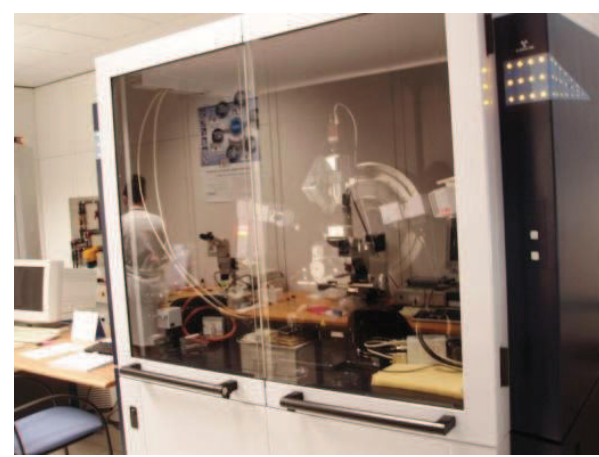

Aparato de difracción de rayos $\mathrm{X}$

\subsection{3.- Análisis elemental}

\section{Descripción del ensayo.}

- Se ha realizado el análisis elemental para la determinación cuantitativa de carbono, hidrógeno, nitrógeno, azufre y oxígeno, de los poliuretanos empleados como adición, con un analizador LECO CHNS-932. La técnica de análisis está automatizada, y se basa en la combustión de las muestras en condiciones óptimas $\left(T=950-1100^{\circ} \mathrm{C}\right.$, atmósfera de oxígeno puro) para convertir los elementos en gases simples $\left(\mathrm{CO}_{2}, \mathrm{NO}_{2}, \mathrm{H}_{2} \mathrm{O}\right.$ y $\mathrm{SO}_{2}$ ) consiguiendo una determinación cuantitativa

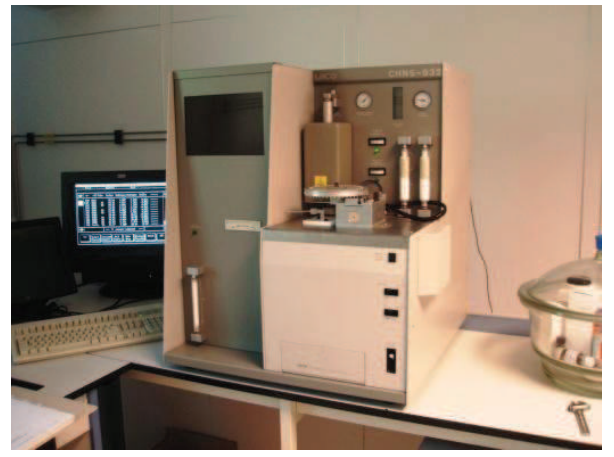

Analizador CHNS-932 


\subsection{4.- Microscopía electrónica de barrido (SEM)}

\section{Descripción del ensayo.}

- Esta técnica se utiliza para examinar la estructura microscópica de las mezclas de morteros. El equipo de medida empleado es un FSEM HITACHI S-4800, siendo la tensión de aceleración de $20 \mathrm{KV}$ y la intensidad de corriente $20 \mu \mathrm{A}$. La distancia de trabajo fue variable y el detector EDX Bruker XFlash-5030 lleva ventana de silicio. El recubrimiento de las muestras se realiza con oro y a vacío en atmósfera de helio

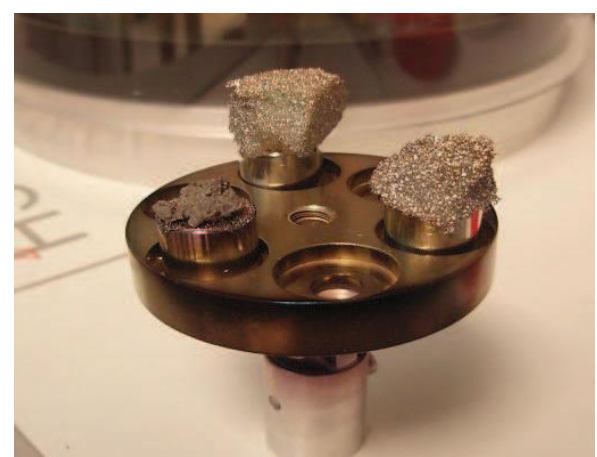

Preparación de las muestras

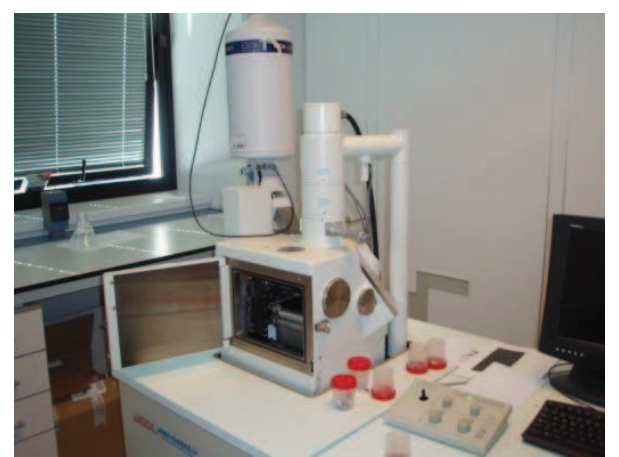

Microscopio electrónico de barrido

\subsection{5.- Termogravimetría (TGA)}

\section{Descripción del ensayo.}

- Se ha realizado este ensayo con un doble objetivo, por un lado, estimar la cantidad de poliuretano presente en cada muestra y, por otro lado, analizar el proceso de deshidratación y deterioro de los materiales con la temperatura.

- El equipo utilizado ha sido un analizador Mettler-Toledo TGA/SBTA851, donde se introducen $15 \mathrm{mg}$ de muestra en atmósfera de nitrógeno en una rampa desde temperatura ambiente hasta los $800^{\circ} \mathrm{C}$ a $10^{\circ} \mathrm{C} / \mathrm{min}$.

\subsection{6.- Tomografía axial computerizada (TAC)}

\section{Descripción del ensayo.}

- La tomografía axial computarizada (TAC) se ha utilizado para determinar cuantitativamente la macroporosidad de las muestras, es decir, los poros de tamaño mayor a $170 \mu \mathrm{m}$. El equipo consta de un sistema de rayos $X$ con un tubo Yxlon de $225 \mathrm{Kv} / 30 \mathrm{~mA}$ con cabina metálica de acero-plomo- 
acero, de forma que operando con una radiación máxima de $225 \mathrm{Kv} / 30 \mathrm{~mA}$ dentro de la cabina, la dosis máxima de radiación a una distancia de 100 $\mathrm{mm}$ de su superficie externa no excede de $2,5 \mu \mathrm{S} / \mathrm{h}$.

- Esta técnica se ha empleado en los morteros, en presencia y ausencia de residuo de poliuretano.
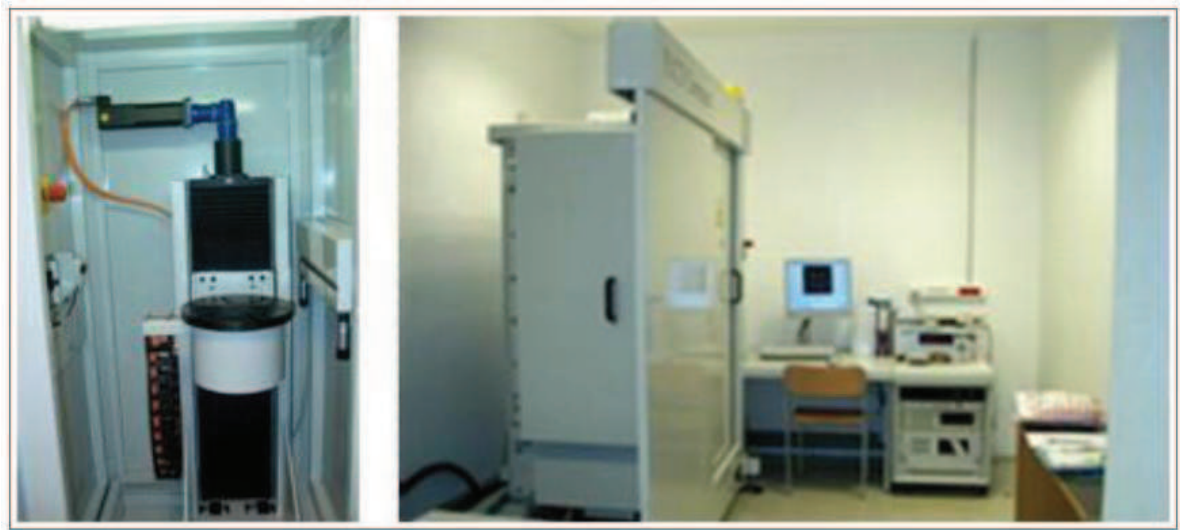

Equipo (TAC)

\section{3.- Ensayos mecánicos}

\subsection{1.- Resistencia a flexión}

Descripción del ensayo. Norma UNE-EN 1015-11. ${ }^{111,112}$

- La resistencia a flexión se determina aplicando una carga en tres puntos del prisma hasta su rotura.

- La probeta tiene forma prismática y dimensiones de $160 \mathrm{~mm} \times 40 \mathrm{~mm} \times$ $40 \mathrm{~mm}$, que se han curado y conservado en una cámara húmeda, a temperatura de $20^{\circ} \mathrm{C} \pm 2^{\circ} \mathrm{C}$ y humedad relativa del $95 \% \pm 5 \%$, hasta los 7 o 28 días.

- Las probetas se colocan en una máquina que aplica la carga a velocidad uniforme y que está provista de dos rodillos de apoyo de acero, separados entre ejes una longitud de $100,0 \mathrm{~mm} \pm 0,5 \mathrm{~mm}$ y de un tercer

111 Norma Española UNE-EN 1015-11. Métodos de ensayo de los morteros para albañilería. Parte 11: Determinación de la resistencia a flexión y a compresión del mortero endurecido. 2000

112 Norma Española UNE-EN 1015-11:2000/A1. Métodos de ensayo de los morteros para albañilería. Parte 11: Determinación de la resistencia a flexión y a compresión del mortero endurecido. 2007 
rodillo instalado centralmente entre los rodillos de apoyo, que es el que transmite la carga.

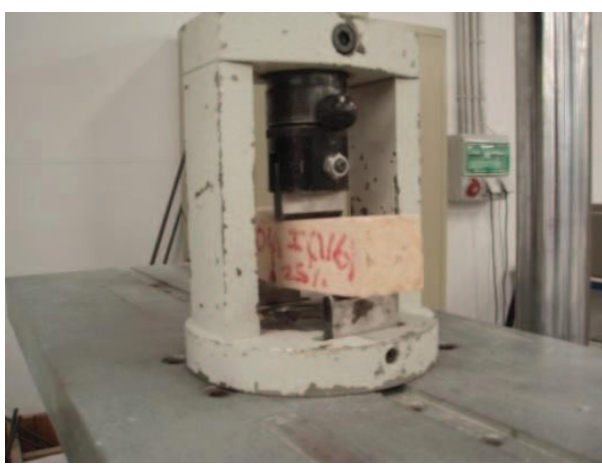

Dispositivo rotura y colocación de probeta

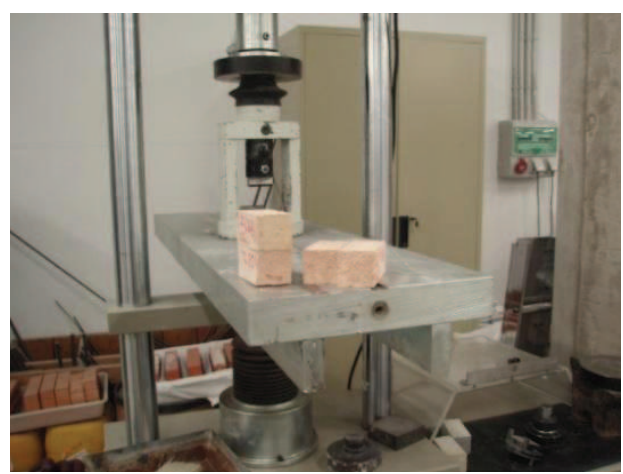

Rotura de la probeta a flexión

- La resistencia a flexión, $f$, de cada probeta se calcula por medio de la expresión:

$$
f=1,5 \frac{F l}{b d^{2}}
$$

en los que $b$ y $d$ se pueden considerar como las dimensiones del molde. El valor final es el resultado de la media aritmética de los valores individuales.

\subsection{2.- Resistencia a compresión}

\section{Descripción del ensayo. Norma UNE-EN 1015-11.}

- La resistencia a compresión se determina aplicando una carga sobre dos superficies opuestas del prisma hasta su rotura.

- Las probetas proceden de cada uno de los dos trozos de la probeta ensayada a flexión.

- La probeta se coloca entre dos platos de $40 \mathrm{~mm}$ de longitud $\times 40,0 \mathrm{~mm} \pm$ $0,1 \mathrm{~mm}$ de ancho y $10 \mathrm{~mm}$ de espesor. La máquina aplica la carga a velocidad uniforme hasta la rotura de la probeta 


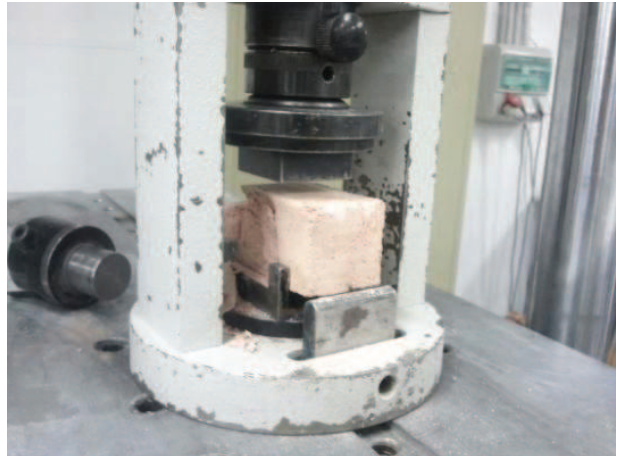

Dispositivo del ensayo

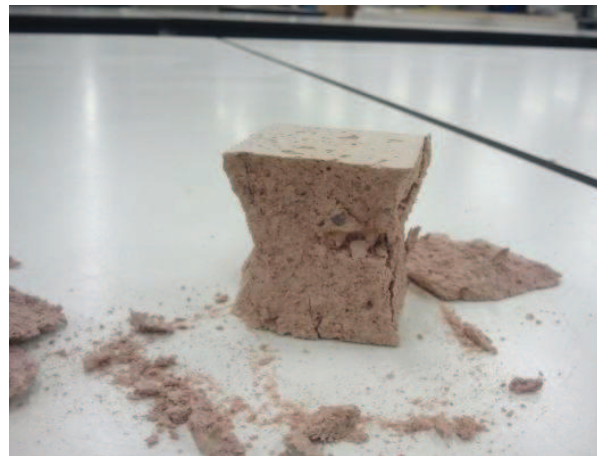

Estado de la probeta después del ensayo

- La resistencia a compresión se calcula dividiendo la carga máxima soportada por su sección transversal, que es de $40 \mathrm{~mm}$ x $40 \mathrm{~mm}$.

- El valor final es el resultado de la media aritmética de los valores individuales.

\subsection{3.- Resistencia a la adhesión}

Descripción del ensayo. Norma UNE-EN 1015-12:2000 ${ }^{113}$

- El objeto del ensayo es conocer la resistencia de unión entre un mortero para revoco-enlucido y un soporte

- La resistencia de unión se determina midiendo la tracción máxima al arrancamiento que soporta el mortero aplicado sobre el soporte.

- Las probetas tienen forma cilíndrica con diámetro de la base de $50 \mathrm{~mm}$ y altura del cilindro de $10 \mathrm{~mm}$.

- El mortero fresco se aplica sobre el soporte; después del fraguado inicial se coloca un anillo troncocónico, que presionando y girando sobre el mortero aísla el cilindro de mortero del resto de la masa. Una vez el mortero endurecido se pega la pastilla de tracción a la superficie circular vista del cilindro de mortero.

- Se coloca el mecanismo en la pastilla de tracción y se actúa hasta producirse el despegue.

113 Norma Española UNE-EN 1015-12. Métodos de ensayo de los morteros para albañilería. Parte 12: Determinación de la resistencia a la adhesión de los morteros de revoco y endurecidos aplicados sobre soportes. 2000 


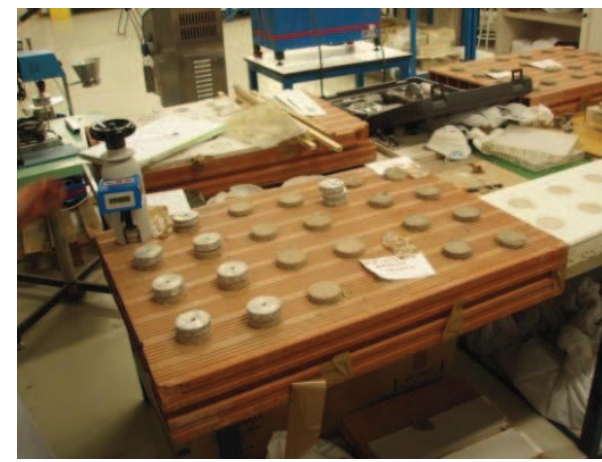

Probetas sobre ladrillo

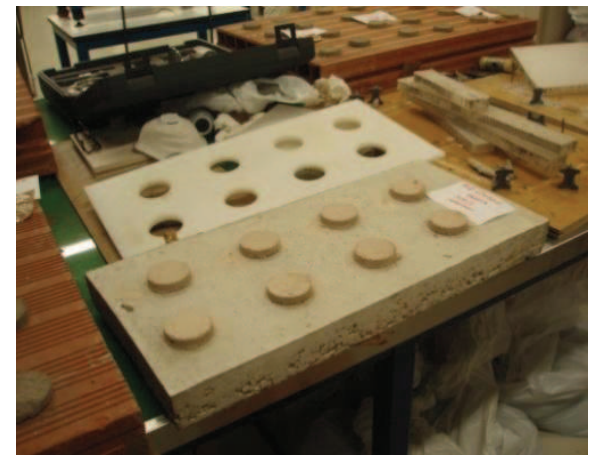

Probetas sobre hormigón

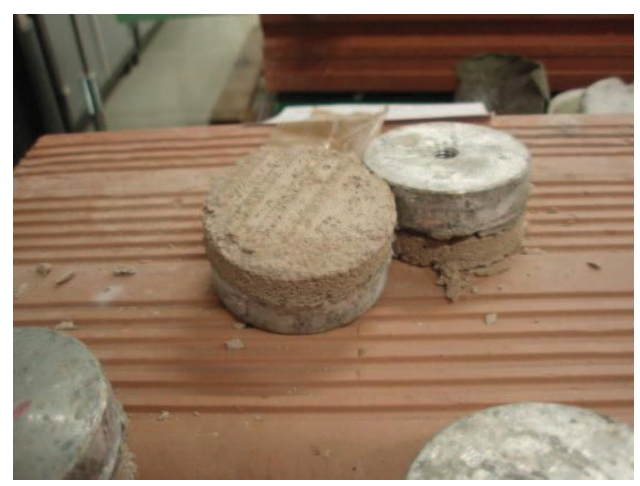

Probetas con la pastilla de tracción colocada

- Se calcula la resistencia a la adhesión, en $\mathrm{N} / \mathrm{mm}^{2}$ con la siguiente ecuación

$$
f_{u}=\frac{F_{u}}{A}
$$

en el que $F_{u}$ es la carga de rotura a Tracción y $A$ el área de la superficie de ensayo. 


\subsection{4.- Resistencia a la abrasión}

\section{Descripción del ensayo. Norma UNE-EN 14157:2004. ${ }^{114}$}

- El objeto del ensayo es determinar la resistencia a la abrasión de los morteros para soleras bajo pavimentos, por el método del disco de abrasión ancho.

- La resistencia a la abrasión de los morteros se mide por la anchura de la huella producida por el disco giratorio.

- Las probetas tienen forma de baldosa cuadrada de $100 \mathrm{~mm}$ de lado y se secan a peso constante. La cara vista se amolará si su superficie presenta irregularidades.

- Se coloca en el portaprobetas con la cara vista frente al disco giratorio.

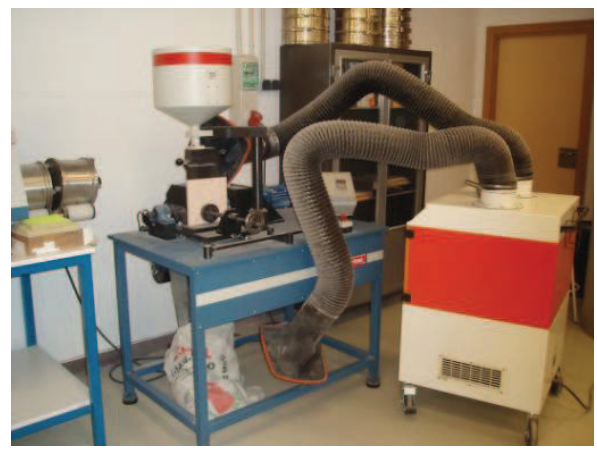

Máquina de abrasión

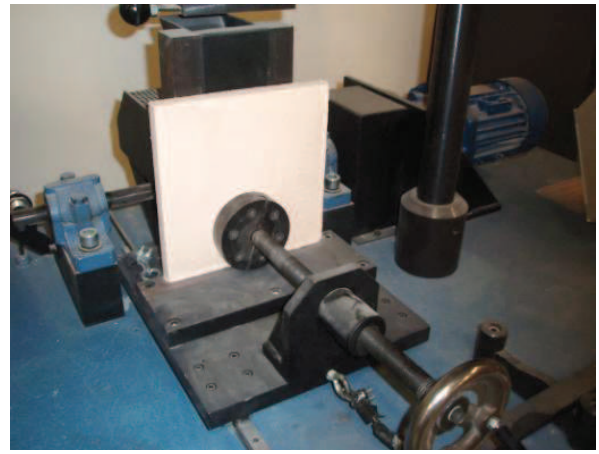

Baldosa colocada frente al disco giratorio

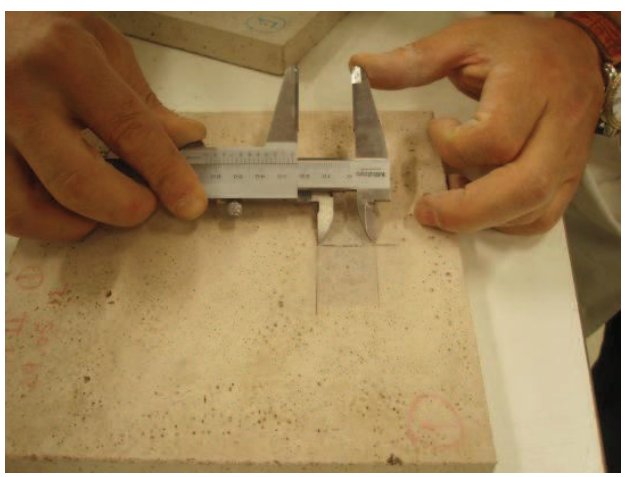

Medición de la huella

- La resistencia a la abrasión se calcula por la medida de la distancia, en el punto medio, de las líneas previamente trazadas, que limitan la huella.

${ }^{114}$ Norma Española UNE-EN 14157. Métodos de ensayo para la piedra natural. Determinación de la resistencia a la abrasión. 2004 


\subsection{5.- Medición de la capacidad de deformación}

\section{Descripción del ensayo de deformabilidad}

- Se determina la capacidad de deformación de los morteros en condiciones de confinamiento.

- La capacidad de deformación se ha medido por aplicación de ciclos de carga y descarga, evaluando la deformación máxima y la deformación remanente.

- Las probetas tienen forma cúbica con dimensiones de $100 \times 100 \times 100$ $\mathrm{mm}$. En las probetas se ha empotrado una pletina metálica que ha servido de referencia para realizar la medición con un reloj comparador digital. La pletina se ha colocado a $25 \mathrm{~mm}$ de la cara superior de la probeta.

- Las probetas se han sometido a 10 ciclos de carga y descarga con aplicación de fuerzas de compresión que en ningún caso han sobrepasado el $75 \%$ de la tensión de rotura. Cada ciclo dura 25 segundos con una carga aplicada ligeramente creciente en cada ciclo, hasta los cuatro últimos ciclos en que la carga máxima ha sido similar. Posteriormente se ha descargado la máquina durante 5 minutos.

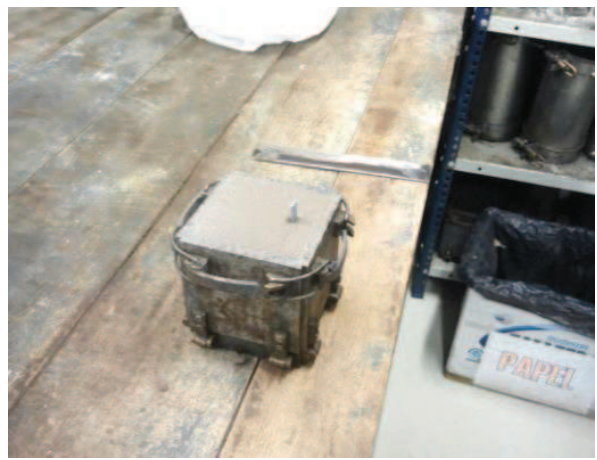

Confección de la probeta

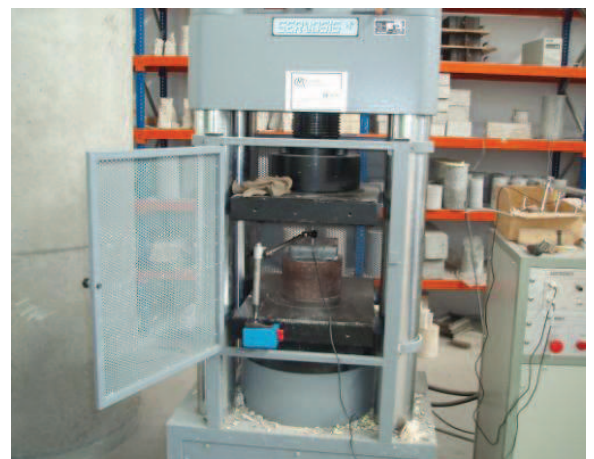

Máquina para ciclos de compresión 


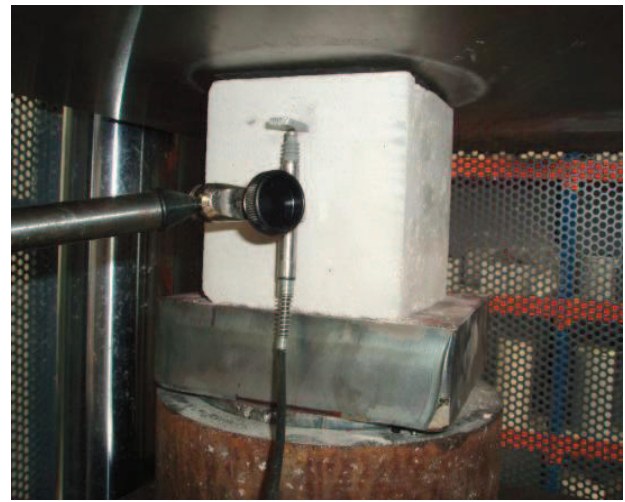

Colocación del comparador

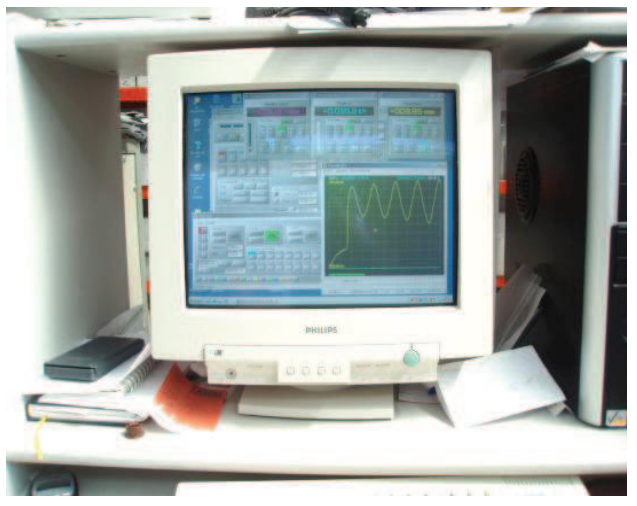

Recogida de datos en pantalla

- Se ha calculado la deformación máxima (deformabilidad) como la relación en \% entre la medida máxima y el porcentaje de la tensión aplicada con respecto a la de rotura

\section{4.- Ensayos de durabilidad}

\subsection{1.- Heladicidad}

Descripción del ensayo: Norma UNE-EN 12371:2010. ${ }^{115}$

- El comportamiento del mortero frente a la helada se determina por el deterioro sufrido en las probetas y por la pérdida de resistencias a flexión y compresión, una vez finalizados.

- Las probetas de forma prismática y dimensiones de $40 \times 40 \times 160 \mathrm{~mm}$, se someten a 56 ciclos de hielo/deshielo, que consisten en período de congelación al aire (6 horas), de las probetas saturadas, entre $-8^{\circ} \mathrm{C} \mathrm{y} \mathrm{-}$ $12^{\circ} \mathrm{C}$, seguido de período de descongelación de 6 horas, sumergidas en agua, a temperatura entre $5^{\circ} \mathrm{C}$ y $20^{\circ} \mathrm{C}$.

- Las probetas se colocan en una cámara de heladicidad en el ciclo de hielo y en un recipiente con agua en el ciclo de inmersión, sin estar en contacto entre ellas ni en contacto con las paredes

115 Norma Española UNE-EN 12371. Métodos de ensayo para piedra natural. Determinación de la resistencia a la heladicidad. 2010 


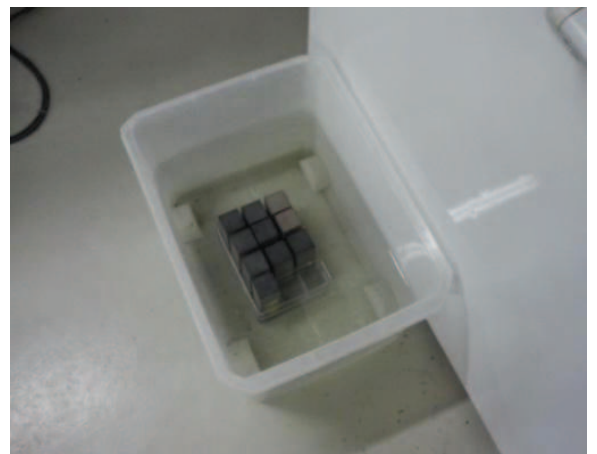

Recipiente para saturación de las probetas

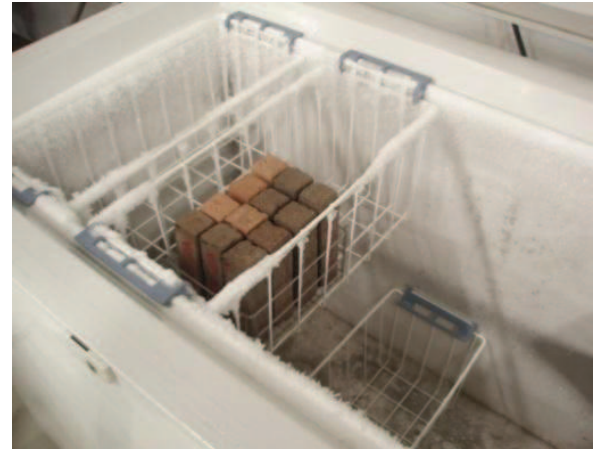

Congelación de probetas

- El comportamiento frente a la helada se determina por dos métodos:

1.- Inspección visual de los daños de las probetas sometidas al ensayo, valorando en una escala del 0 al 4 el grado de deterioro.

2.- Cálculo de la pérdida de resistencias, a flexión y compresión, de las probetas sometidas a ensayo, en comparación con las probetas no ensayadas.

\subsection{2.- Niebla salina}

\section{Descripción del ensayo. Norma UNE-EN 14147:2003. ${ }^{116}$}

- La resistencia al envejecimiento por niebla salina se evalúa por inspección visual y por pérdida de masa, una vez finalizado el ensayo.

- Las probetas tienen forma prismática de medidas $(40 \times 40 \times 160) \mathrm{mm}$.

- Se secan las probetas y se introducen en una cámara en la que se nebuliza una solución de cloruro sódico de gran pureza, manteniéndolas en la cámara durante 4 horas; se secan en la propia cámara durante 8 horas. Esto constituye un ciclo

- El ciclo se repite 60 veces.

116 Norma Española UNE-EN 14147. Métodos de ensayo para la piedra natural. Determinación de la resistencia al envejecimiento por niebla salina. 2003 


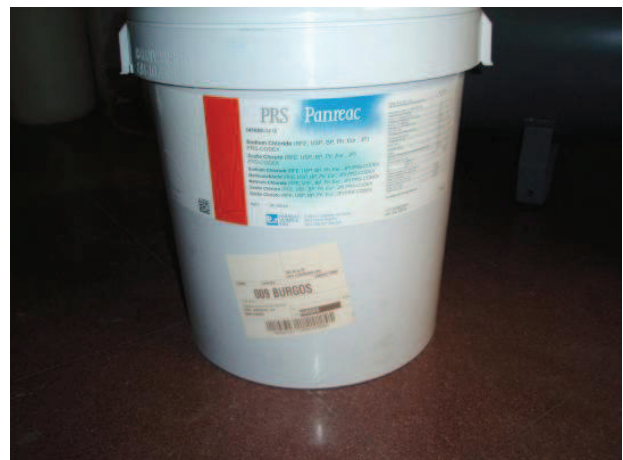

Cloruro sódico

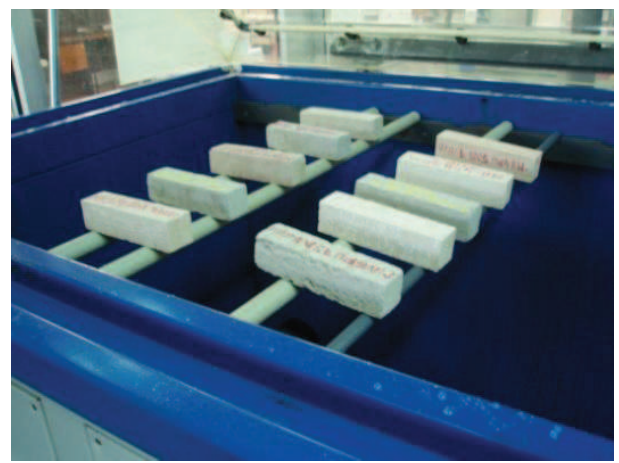

Probetas secas en la cámara

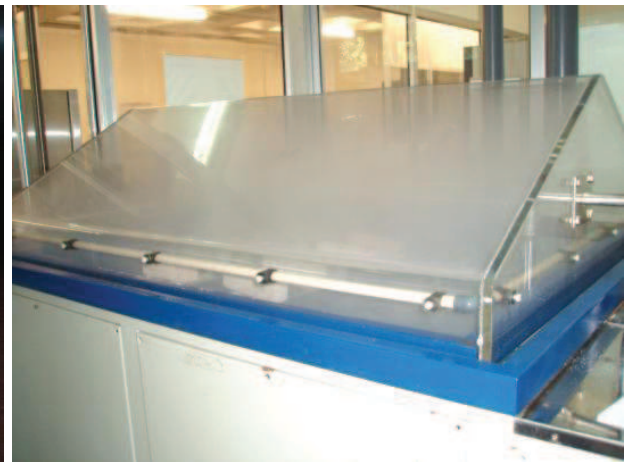

Cámara con nebulización de niebla salina

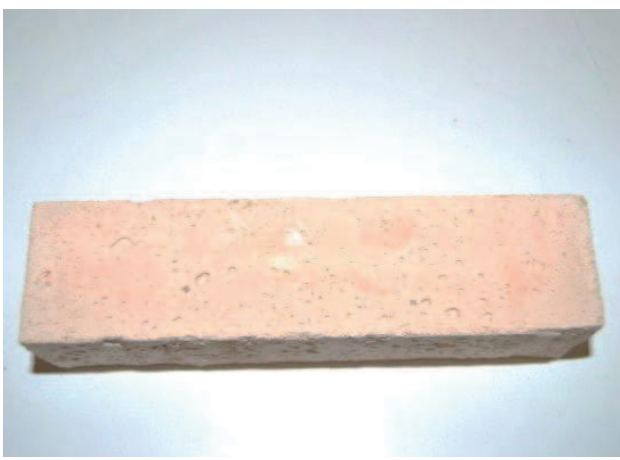

Depósito de sales en la superficie

- La resistencia al envejecimiento por niebla salina se calcula por la pérdida de masa en porcentaje de la probeta, después de realizado el ensayo, mediante la siguiente expresión:

$$
(\Delta M \%)=\frac{M_{0}-M_{n}}{M_{0}} \times 100
$$

- También se realiza inspección visual de las probetas, anotando la existencia de grietas u otros signos relevantes de degradación. 


\subsection{3.- Ensayo Kesternich}

\section{Descripción del ensayo. Norma UNE-EN ISO 6988. ${ }^{117}$ Ensayo Kesternich DIN} $50018^{118}$

- La resistencia al dióxido de azufre con condensación general se estima por inspección visual, por pérdida de masa y por caída en las resistencias mecánicas, una vez finalizado el ensayo.

- Las probetas tienen forma prismática de dimensiones (40 x 40 x 160) $\mathrm{mm}$.

- Se introducen las probetas en una cámara de $300 \mathrm{dm}^{3}$ de capacidad, en la que se produce una humedad condensada con dióxido de azufre, manteniendo estas condiciones durante 8 horas; seguidamente se sacan las muestras en la atmósfera ambiente durante 16 horas, completando así un ciclo.

- El ciclo se repite 10 veces.

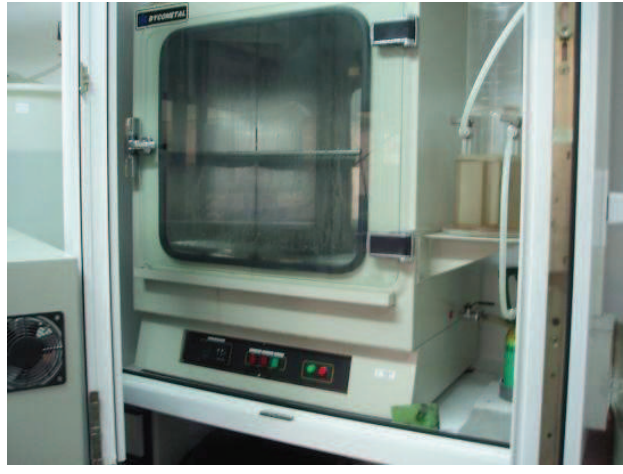

Cámara con humedad condensada

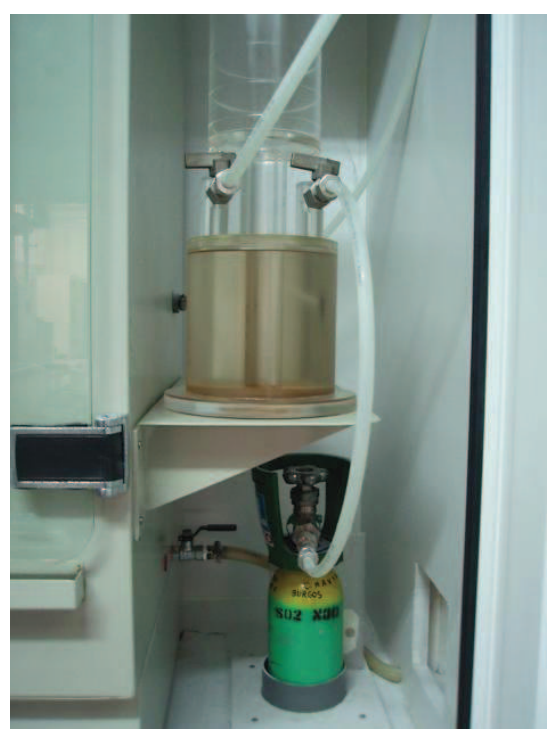

Depósito de $\mathrm{SO}_{2}$

- La resistencia al dióxido de azufre con humedad condensada se evalúa por tres procedimientos:

117 Norma Española UNE-EN ISO 6988. Recubrimientos metálicos y otros recubrimientos no orgánicos. Ensayo al dióxido de azufre con condensación general de humedad. 1985

118 Norma Alemana DIN 50018. Ensayos de corrosión en atmósferas húmedas saturadas con adición de bióxido de azufre 
1.- La pérdida de masa en porcentaje de la probeta, después de realizado el ensayo, mediante la siguiente expresión:

$$
(\Delta M \%)=\frac{M_{0}-M_{10}}{M_{0}} \times 100
$$

2.- Inspección visual de las probetas, anotando la existencia de signos relevantes de degradación.

3.- La pérdida de resistencias mecánicas a flexión y compresión.

\subsection{4.- Agua salina}

\section{Descripción del ensayo: Norma Americana ASTM-D-4792/99. ${ }^{119}$}

- La estabilidad del mortero se puede medir por pérdida de peso y/o dimensiones y por pérdida de resistencias mecánicas.

- Las probetas tienen forma prismática de dimensiones $(40 \times 40 \times 160)$ $\mathrm{mm}$.

- Se desecan las probetas en horno y seguidamente se sumergen en agua salina a temperatura de $70^{\circ} \mathrm{C}$, durante 28 días.

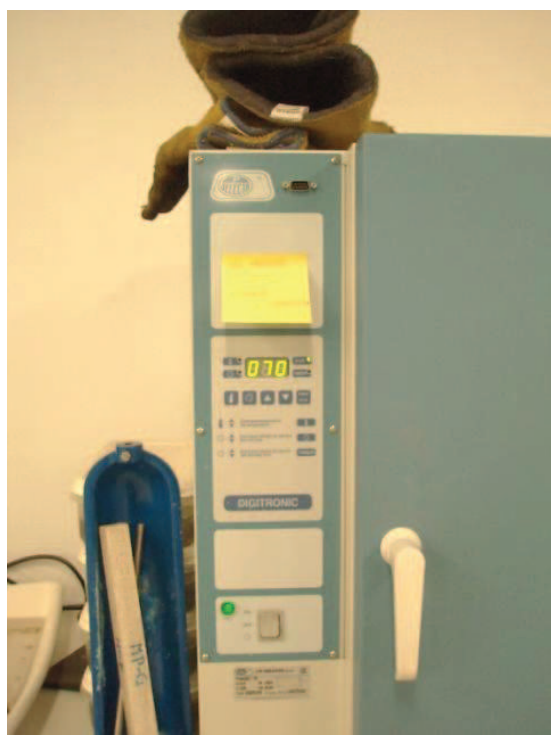

Probetas a $70^{\circ} \mathrm{C}$ durante 28 días en agua salina

- La resistencia al envejecimiento acelerado por agua salina se ha evaluado por dos procedimientos:

1.- Por la variación de masa en porcentaje de la probeta, después de

119 ASTM D 4792 "Standard test method for pontential expansion of Aggregates from hydration reactions". American Society for Testing and Materials (ASTM), Philadelphia, PA. Annual Book of ASTM Standard. 1999 
realizado el ensayo, mediante la siguiente expresión:

$$
\Delta m \%=\frac{m_{f}-m_{0}}{m_{0}} x 100
$$

2.- Por la pérdida de resistencias mecánicas a flexión y compresión.

\subsection{5.- Cristalización de sales}

\section{Descripción del ensayo. Norma UNE-EN 12370:1999. ${ }^{120}$}

- La resistencia a la cristalización de sales de los morteros se estudia por la variación de la masa en porcentaje, una vez finalizado el ensayo.

- Las probetas tienen forma prismática de dimensiones (40 x $40 \times 160)$ $\mathrm{mm}$.

- Se secan las probetas y se introducen en una solución de sulfato sódico decahidratado al $14 \%$; se mantienen durante 2 horas en la solución; se secan al horno durante 16 horas; se dejan enfriar y se vuelven a introducir en la solución salina.

- El ciclo anterior se repite 15 veces.

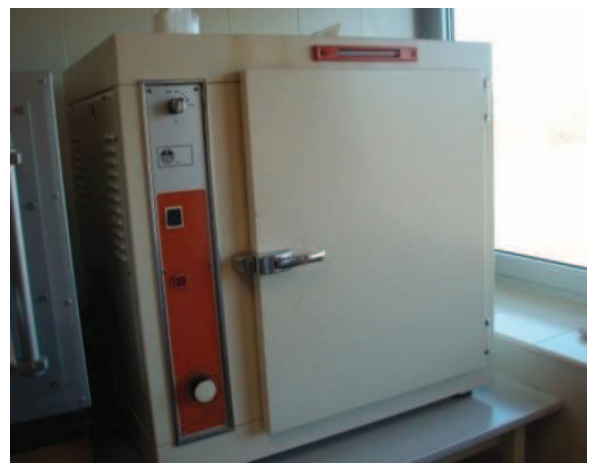

Horno de secado de las probetas

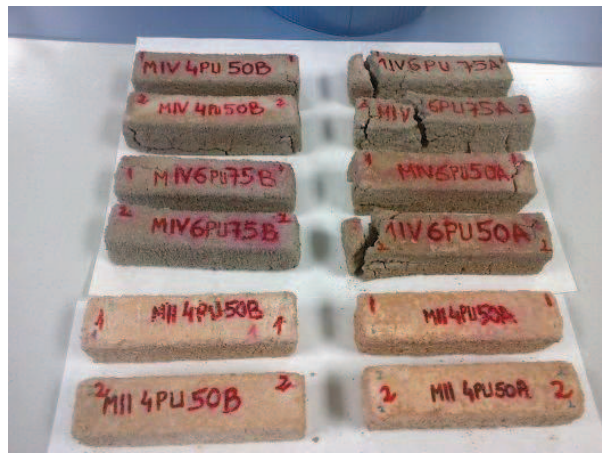

Examen general de las probetas

- La resistencia a la cristalización de sales solubles se calcula por la pérdida de masa de la probeta, después de realizado el ensayo, mediante la siguiente expresión:

$$
\Delta M=\frac{M_{f}-M_{d 1}}{M_{d}} \times 100
$$

Si durante el ensayo se ha producido una degradación excesiva, se suspenderá el ensayo y se anotará el número de ciclos efectuados

120 Norma Española UNE-EN 12370. Métodos de ensayo para la piedra natural. Determinación de la resistencia a la cristalización de sales. 1999 


\subsection{6.- Choque térmico}

\section{Descripción del ensayo: Norma UNE-EN 14066:2003. ${ }^{121}$}

- El objeto del ensayo es evaluar las modificaciones que sufre un mortero por efecto de repentinos cambios de temperatura.

- La resistencia al choque térmico se mide por inspección visual, por pérdida de masa y por caída en las resistencias mecánicas (módulo de elasticidad dinámico), una vez finalizado el ensayo.

- Las probetas tienen forma prismática de dimensiones $(40 \times 40 \times 160)$ $\mathrm{mm}$.

- Se secan las probetas en horno a $105^{\circ} \mathrm{C}$ durante 18 horas y seguidamente se sumergen en agua a temperatura de $20^{\circ} \mathrm{C}$, durante 6 horas.

- El ciclo de humedad-sequedad se repite 20 veces.

- La resistencia al envejecimiento por choque térmico se evalúa por tres procedimientos:

1.- Por la variación de masa en porcentaje de la probeta, después de realizado el ensayo, mediante la siguiente expresión:

$$
\Delta m \%=\frac{m_{f}-m_{0}}{m_{0}} \times 100
$$

2.- Por inspección visual de las probetas, anotando las modificaciones observadas.

3.- Por la pérdida de resistencias mecánicas a flexión y compresión.

121 Norma Española UNE-EN 14066. Métodos de ensayo para piedra natural. Determinación de la resistencia al envejecimiento por choque térmico. 2003 


\subsection{7.- Envejecimiento acelerado (materiales poliméricos celulares)}

\section{Descripción del ensayo: Norma UNE-EN ISO 2440:1997.122}

- El objeto del ensayo es el conocimiento de los efectos de reacciones naturales, como oxidación y/o hidrólisis, en el agregado de espuma de poliuretano del mortero de cemento, que pueden llegar a alterarlo.

- Los efectos de las reacciones de oxidación y/o hidrólisis se evalúan por la pérdida de resistencias mecánicas a flexión y compresión.

- Las probetas tienen forma prismática de dimensiones $(40 \times 40 \times 160) \mathrm{mm}$

- Se curan las probetas.

- Se introducen en la estufa a temperatura de $140^{\circ} \mathrm{C}$ durante 240 horas, para el ensayo de calor seco.

- Se colocan en un baño de agua a $105^{\circ} \mathrm{C}$ durante 3 horas, para el ensayo de envejecimiento por humedad.

- Se ensayan a flexión y compresión las probetas después de ambos ensayos.

- El porcentaje de cambio en las resistencias viene dado por la siguiente expresión:

$$
\frac{X a-X o}{X o} \times 100
$$

122 Norma Española UNE-EN ISO 2440. Materiales poliméricos celulares flexibles y rígidos. Ensayos de envejecimiento acelerado. 1997 
$m$

O

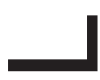

$\longrightarrow$

1

$1+$

0

$\longrightarrow$

৩

Caracterización de las materias primas 



\section{Capítulo 3.- Caracterización de las materias primas}

Las materias primas empleadas en la confección de los distintos tipos de morteros provienen de industrias ubicadas en la provincia de Burgos o en sus proximidades, con excepción de los aditivos, procedentes de industrias multinacionales. Se ha utilizado una única arena, tres tipos de cemento y diferentes residuos de espuma de poliuretano.

\section{1.- Cementos}

$\mathrm{Ni}$ las Normas UNE-EN 998-1 y 998-2 ni el Código Técnico de la Edificación (CTE) recomiendan ningún tipo de cemento para morteros de albañilería, haciendo solamente mención a que las características de las materias primas deben permitir que el producto terminado esté conforme con los requisitos de la norma.

Los cementos recomendados para la elaboración de los morteros en las Normas Tecnológicas de la Edificación (NTE RPE), ${ }^{123}$ son los designados como P-250 y P-350, cementos Portland cuyas resistencias a compresión a los 28 días alcanzan 25,0 MPa y 35,0 MPa respectivamente.

La norma UNE 803002000 IN Cementos. Recomendaciones para el uso de los cementos, en su apartado 9.1.15 Cementos para morteros y hormigones en edificación ( $\mathrm{OE}$ ), dice que, para morteros de relleno y juntas, revocos, enlucidos, solados, etc., exteriores o interiores, los cementos utilizables serán entre otros los cementos comunes, que a juicio del director o responsable de la obra presenten características y comportamientos más adecuados desde diversos puntos de vista, tales como estabilidad, impermeabilidad, consistencia, trabajabilidad, facilidad de puesta en obra, rendimiento, etc. ${ }^{124}$

El Código Técnico de la Edificación (CTE) no recomienda ningún cemento en especial, por lo que, al igual que en la fijación de relaciones, se utilizarán

\footnotetext{
123 Norma tecnológica de la edificación NTE-RPE/1974, «Revestimientos de paramentos enfoscados». Orden del Ministerio de la Vivienda. BOE nº 269 de 09/11. 1974

124 Norma Española UNE 80300 IN Cementos. Recomendaciones para el uso de los cementos. 2000
} 
los cementos habituales en la práctica, teniendo en cuenta la influencia que el tipo de cemento tenga en las prestaciones finales del mortero.

Recopilando todos estos parámetros y teniendo en cuenta las características de nuestros morteros, se han utilizado tres tipos de cemento común (clinker de Pórtland) de comercialización habitual que tienen el correspondiente marcado "CE", certificación Aenor voluntaria de calidad marca "N", que son:

1. CEM I 42,5 R UNE-EN 197-1:2000. Cemento Portland del tipo I, con una Clase de Resistencia Normal de 42,5 MPa y una Clase de Resistencia Inicial Elevada.

2. CEM II/B-L 32,5 R UNE-EN 197-1:2000. Cemento Portland con Adiciones del tipo II, Adición Caliza, con Alta Sustitución de Clinker, con una Clase de Resistencia Normal de 32,5 MPa y una Clase de Resistencia Inicial Elevada.

3. CEM IV/B (V) 32,5 N UNE-EN 197-1:2000. Cemento con Adiciones del tipo IV, Adición Ceniza Volante Silícica, con Alta Sustitución de Clinker, con una Clase de Resistencia Normal de 32,5 MPa y una Clase de Resistencia Inicial Ordinaria.

Se han elegido estos tres tipos de cemento, con categorías resistentes alta y media y clases resistentes $42,5 R, 32,5 R$ y $32,5 \mathrm{~N}$, por ser representativos de los que habitualmente se utilizan en la confección de los morteros diseñados (CEM I y CEM II/B-L) y de los morteros prescritos (CEM II/B-L y CEM IV/B), ya que con ello se cubre un amplio espectro, tanto de la composición química (cantidad y tipo de adición) como de las resistencias mecánicas.

Los cementos empleados proceden de la fábrica Hontoria, del grupo Portland Valderrivas, situada en la localidad de Venta de Baños, a $90 \mathrm{~km}$ de Burgos capital. El certificado de características técnicas expedido por la fábrica, para cada uno de los cementos se resume en las Tablas 3.1 y 3.2. 
Tabla 3.1. Características de los cementos. Certificado de la fábrica Hontoria

\begin{tabular}{|c|c|c|c|c|}
\hline & & $\begin{array}{l}\text { CEM I } \\
42,5 \text { R }\end{array}$ & $\begin{array}{c}\text { CEM II/B- } \\
\text { L } \\
32,5 \mathrm{R}\end{array}$ & $\begin{array}{c}\text { CEM IV/B } \\
\text { (V) } \\
32,5 \mathrm{~N}\end{array}$ \\
\hline \multicolumn{5}{|l|}{ Características químicas } \\
\hline Pérdida al fuego & $\%$ & 3,0 & - & - \\
\hline Residuo insoluble & $\%$ & 0,4 & - & - \\
\hline Sulfatos $\left(\mathrm{SO}_{3}\right)$ & $\%$ & 3,0 & 2,8 & 2,5 \\
\hline Cloruros & $\%$ & 0,01 & 0,01 & 0,01 \\
\hline Puzolanicidad & & - & - & 8 días \\
\hline \multicolumn{5}{|c|}{ Características físicas y mecánicas } \\
\hline Tiempo de inicio de fraguado & $\min$ & 160 & 175 & 230 \\
\hline Tiempo de final de fraguado & $\min$ & 210 & 225 & 285 \\
\hline Expansión Le Chatelier & mm & 0,0 & 0,0 & 0,0 \\
\hline Superficie específica (Blaine) & $\mathrm{cm}^{2} / \mathrm{g}$ & 3.500 & 4.000 & 4.400 \\
\hline $\begin{array}{l}\text { Resistencia compresión } \\
\text { inicial }\end{array}$ & $\mathrm{MPa}$ & $31^{\mathrm{a}}$ & $20^{a}$ & $25^{\mathrm{b}}$ \\
\hline $\begin{array}{l}\text { Resistencia compresión } 28 \\
\text { días }\end{array}$ & $\mathrm{MPa}$ & 57 & 43 & 40 \\
\hline
\end{tabular}

${ }^{a}$ Resistencia a compresión a los 2 días. ${ }^{\mathrm{b}}$ Resistencia a compresión a los 7 días

Tabla 3.2. Componentes de los cementos*. Certificado de la fábrica Hontoria

\begin{tabular}{|c|c|c|c|c|}
\hline & & $\begin{array}{l}\text { CEM I } \\
42,5 \text { R }\end{array}$ & $\begin{array}{c}\text { CEM II/B-L } \\
32,5 \mathrm{R}\end{array}$ & $\begin{array}{c}\text { CEM IV/B (V) } \\
32,5 \mathrm{~N}\end{array}$ \\
\hline Clinker (K) & $\%$ & 96 & 75 & 56 \\
\hline Caliza (L) & $\%$ & 4 & 25 & 3 \\
\hline $\begin{array}{l}\text { Ceniza volante } \\
\text { silícica (V) }\end{array}$ & $\%$ & - & - & 41 \\
\hline $\begin{array}{l}\text { Regulador de } \\
\text { fraguado }\end{array}$ & $\%$ & 5 & 4 & 4 \\
\hline
\end{tabular}

Las recomendaciones para cada tipo de cemento, según la ficha técnica del producto se reproducen en la Tabla 3.3.

Tabla 3.3. Recomendaciones de uso. Certificado de la fábrica Hontoria

\begin{tabular}{ll}
\hline CEM I 42,5R & Hormigón en masa, armado y pretensado de alta resistencia. \\
& Hormigón para desencofrado, descimbrado y desenmoldado rápido. \\
& Hormigón pretensado tanto para piezas prefabricadas estructurales \\
& como no estructurales. \\
\hline CEM II/B-L & Todo tipo de albañilería. \\
$32,5 R$ & Hormigón en masa y armado para obras incluso de gran volumen. \\
& Estabilización de suelos, cimentaciones, suelo-cemento, grava- \\
& cemento y obras subterráneas. \\
& Hormigones no estructurales y de limpieza \\
\hline CEM IV/B(V) & Hormigón armado y en masa, en obras de grandes volúmenes. \\
& Morteros plásticos de recubrimiento, agarre y juntas. \\
& Estabilización de suelos, bases de carreteras y cimentaciones en \\
& masa. \\
& Hormigón seco compactado con rodillo.
\end{tabular}


Además de la caracterización proporcionada por la empresa, se han realizado ensayos físicos de densidad. Los resultados se muestran en la Tabla 3.4.

Tabla 3.4. Densidad real de los cementos

\begin{tabular}{lccc}
\hline & CEM I 42,5 R & CEM II/B-L 32,5 R & CEM IV/B-(V) 32,5 N \\
\hline Densidad Real kg/l & 3,15 & 3,11 & 2,80 \\
\hline
\end{tabular}

El análisis químico de los cementos se ha completado con la determinación de fases por difracción y fluorescencia de rayos $X$. La fluorescencia es un tipo particular de luminiscencia que caracteriza las sustancias que son capaces de absorber energía en forma de radiaciones electromagnéticas, y luego emitir parte de esa energía en forma de radiación electromagnética de longitud de onda diferente.

Con la espectroscopía de fluorescencia electromagnética, obtenemos la composición química de los materiales de forma cuantitativa y en forma de óxidos de la Tabla 3.5.

Tabla 3.5. Análisis químico de los cementos. Difracción de Rayos $\mathrm{X}$.

Fluorescencia de Rayos $\mathrm{X}$

\begin{tabular}{lccc}
\multicolumn{1}{c}{ Elementos \% } & CEM I & CEM II/B-L \\
$\mathbf{3 2 , 5} \mathbf{~ R}$ & $\begin{array}{c}\text { CEM IV/B (V) } \\
\mathbf{3 2 , 5} \mathbf{~ N}\end{array}$ \\
\hline $\mathrm{SiO}_{2}$ & 21,30 & 15,8 & 32,9 \\
$\mathrm{Fe}_{2} \mathrm{O}_{3}$ & 4,00 & 1,5 & 3,6 \\
$\mathrm{Al}_{2} \mathrm{O}_{3}$ & 6,10 & 5,0 & 13,7 \\
$\mathrm{CaO}$ & 60,40 & 56,8 & 37,4 \\
$\mathrm{MgO}$ & 1,50 & 3,2 & 2,6 \\
$\mathrm{~K}_{2} \mathrm{O}$ & 1,30 & 0,8 & 1,7 \\
$\mathrm{Na}_{2} \mathrm{O}$ & 0,40 & 0,0 & 0,0 \\
$\mathrm{P}_{2} \mathrm{O}_{5}$ & -- & 0,17 & 0,32 \\
$\mathrm{MnO}$ & -- & 0,03 & 0,04 \\
$\mathrm{TiO}_{2}$ & -- & 0,13 & 0,4 \\
Otros & 4,30 & -- & -- \\
Pérdida al fuego & 2,00 & 13,3 & 6,8 \\
\hline
\end{tabular}

\section{2.- Arena}

La arena empleada en la confección de los morteros ha llegado al laboratorio desde la cantera, no habiendo sufrido ningún tipo de tratamiento posterior a su recepción en el laboratorio, excepción hecha de su secado en estufa. 
La caracterización de la arena se ha realizado acorde a la Norma UNE-EN 13139 Áridos para morteros, que define los distintos tipos de áridos que se pueden emplear en los morteros y especifica las exigencias para estos materiales, que se concretan en apartados siguientes. Esta norma clasifica este tipo de áridos dentro del "árido natural", "granular".

\subsection{1.- Requisitos geométricos}

\subsubsection{1.- Forma de las partículas}

La determinación de la forma de las partículas de los áridos se realiza con los ensayos de la Norma UNE-EN 933-3 Ensayos para determinar las propiedades geométricas de los áridos. Parte 4: Determinación de la forma de las partículas. Índice de lajas y la Norma UNE-EN 933-4 Ensayos para determinar las propiedades geométricas de los áridos. Parte 4: Determinación de la forma de las partículas. Coeficiente de forma.

En ambas normas se establece que la determinación de la forma de las partículas se realiza solo con tamaños mayores de $4 \mathrm{~mm}$. En consecuencia, las normas no son de aplicación para la arena utilizada, ya que en áridos de tamaño pequeño, es decir, arenas y finos, la forma de las partículas no es relevante para el comportamiento. Tampoco es relevante el contenido en conchas.

No obstante, a igualdad de peso de las partículas, la superficie específica de las mismas determina la cantidad de pasta cementosa necesaria para su correcta puesta en obra, lo que incide en la cantidad de agua y en la relación agua/cemento.

Por ello se han elegido arenas cuyas partículas tiendan a formas redondeadas y poco angulosas, propias de los áridos naturales granulares.

\subsubsection{2.- Granulometría y finos}

Para la elección de la arena empleada en la confección de todas las muestras ensayadas se han tenido en cuenta los requisitos geométricos, ya que los ensayos previos de esa arena garantizan el cumplimiento de los requisitos físicos y químicos. 
El primer parámetro que se establece en la arena es su tamaño. Para los morteros de revestimiento y juntas, las distintas normativas indican tamaños que son función del uso y espesor del mortero, fijando un tamaño máximo en todos los casos de $4 \mathrm{~mm}$ de acuerdo con la norma UNE-EN $933-2,{ }^{125}$ inferior a $1 / 3$ del espesor de un revestimiento o mortero de juntas de $1,5 \mathrm{~cm}$. El tamaño mínimo considerado es de $0 \mathrm{~mm}$, de acuerdo con la norma UNE-EN 13139, que fija los límites superiores e inferiores y el porcentaje máximo de finos (Tablas 3.6 y 3.7 ).

Tabla 3.6. Límites superior e inferior para el árido 0/4. UNE-EN 13139:2002

\begin{tabular}{|c|c|c|c|c|}
\hline \multirow[t]{2}{*}{$\begin{array}{l}\text { Tamaño del } \\
\text { árido mm }\end{array}$} & \multicolumn{3}{|c|}{$\begin{array}{c}\text { Límites superiores en masa } \\
\%\end{array}$} & \multirow[t]{2}{*}{$\begin{array}{l}\text { Límite } \\
\text { inferior }\end{array}$} \\
\hline & $2 D$ & $1,4 D$ & $D$ & \\
\hline $0 / 4$ & 100 & 95 a 100 & 85 a 99 & No se fija \\
\hline
\end{tabular}

Tabla 3.7. Límite del contenido en finos para el árido 0/4. UNE-EN 13139:2002 Tamaño del árido $\mathrm{mm}$

Porcentaje máximo en pasa por el tamiz $0,063 \mathrm{~mm}$

\begin{tabular}{|c|c|c|}
\hline & Categoría $2^{*}$ & Categoría $3^{*}$ \\
\hline $0 / 4$ & 5 & 8 \\
\hline
\end{tabular}

Seguidamente, se ha establecido la granulometría de la arena de acuerdo con los criterios de la Norma Básica NBE-FL $90^{126}$ "muros resistentes de fábrica de ladrillo", que coincide con los criterios de la Norma Tecnológica NTE-RPE "enfoscados".

Hay que reseñar que los tamices empleados en el tamizado de la arena son distintos a los de la Norma Básica NBE-FL 90, por lo que ha sido necesario modificar los límites para adaptarlos a la serie normalizada de tamices de la UNE-EN 933-2.

Se han utilizado tamices de tela metálica trenzada de acuerdo con la Norma ISO 3310-1, con una luz de malla en mm de: 4,00 - 2,00 - 1,00$0,50-0,25-0,125-0,063$, todos dentro de la serie de tamices de la norma

\footnotetext{
125 Norma Española UNE-EN 933-2. Ensayos para determinar las propiedades geométricas de los áridos. Parte 1: Determinación de la granulometría de las partículas. Tamices de ensayo, tamaño nominal de las aberturas. 1995

${ }^{126}$ Norma Básica de la Edificación NBE-FL 90 "muros resistentes de fábrica de ladrillo". RD 1.723/1990 de 20 de diciembre, BOE No 198 de 04/01. 1991
} 
UNE 7050-2. El tamizado de la arena se ha realizado según la norma UNEEN 933-1..$^{127}$

Por criterios de proximidad geográfica se ha elegido una arena silícica de la localidad de Espinosa de Juarros, a poca distancia de la capital burgalesa. Los resultados obtenidos de las curvas granulométricas se muestran en la Tabla 3.8

Se han determinado tres granulometrías de la arena, una coincidiendo con la confección de los morteros de referencia (granulometría 1), otra en la fase de realización de las mezclas con PUR (granulometría 2) y la tercera en la etapa de ensayos de los morteros con aditivos (granulometría 3). A partir de los resultados obtenidos se ha calculado el valor medio para cada tamiz y el módulo granulométrico, que ha resultado ser de 3,78 .

Tabla 3.8. Series numéricas del pasa en $\%$ de la arena

\begin{tabular}{lcccccccc}
\hline Tamiz mm & $\mathbf{4}$ & $\mathbf{2}$ & $\mathbf{1}$ & $\mathbf{0 , 5 0}$ & $\mathbf{0 , 2 5}$ & $\mathbf{0 , 1 2 5}$ & $\mathbf{0 , 0 6 3}$ & fondo \\
\hline Granulometría 1 & 98,56 & 92,63 & 76,08 & 43,16 & 15,34 & 4,74 & 1,37 & 0,00 \\
Granulometría 2 & 99,16 & 93,14 & 76,12 & 42,36 & 14,66 & 4,25 & 0,89 & 0,00 \\
Granulometría 3 & 98,48 & 91,85 & 70,14 & 32,75 & 8,21 & 1,78 & 0,45 & 0,00 \\
\hline Valor medio & 98,73 & 92,54 & 74,11 & 39,42 & 12,74 & 3,59 & 0,90 & 0,00 \\
\hline
\end{tabular}

No existe ninguna partícula de tamaño superior a $8 \mathrm{~mm}$ (2D), y las partículas de tamaño mayor a 5,6 mm (1,4D) en ningún caso alcanzan valores mayores al $5 \%$. El porcentaje del pasa por el tamiz 0,063 $\mathrm{mm}$ es de $0,90 \%$, cumpliendo con el límite de contenido en finos de la norma EN 13139, que para morteros para revocos y enlucidos y morteros para albañilería, fija un contenido máximo en finos del $5 \%$ y $8 \%$ respectivamente.

A la vista de los resultados de la Figura 3.1, se ha comprobado que la línea granulométrica de la arena se encuentra dentro de los límites de la Norma Básica NBE-FL 90, y el tamaño de la arena, expresada en término de diámetros, es de d/D: 0/4

127 Norma Española UNE-EN 933-1. Ensayos para determinar las propiedades geométricas de los áridos. Parte 1: Determinación de la granulometría de las partículas. Método del tamizado. 1997 


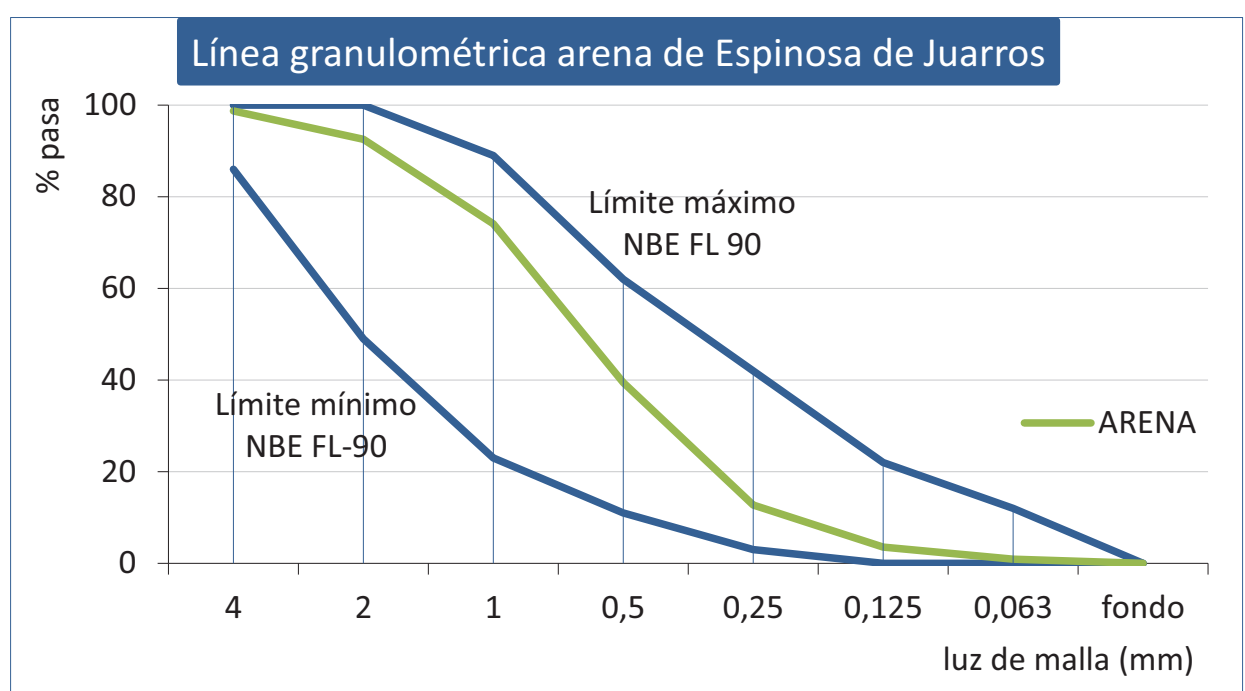

Figura 3.1 Línea granulométrica media de la arena de Espinosa de Juarros, en comparación con los límites de la NBE-FL 90, adaptados a la serie de tamices de la EN-933-2.

\subsection{2.- Requisitos físicos}

\subsubsection{1.- Densidad aparente del árido. Densidad aparente de las partículas. Porosidad como árido}

Se ha obtenido la densidad aparente de la arena como árido y la densidad de las partículas de arena, según la norma UNE-EN 1097-3. La densidad real como árido, coincidente con la densidad de las partículas se ha ensayado de acuerdo con la norma UNE-EN 1097-6.

En la Tabla 3.9 se resumen las características físicas de la arena.

Tabla 3.9. Tabla resumen de las características generales de la arena.

\begin{tabular}{lcc}
\hline \multicolumn{3}{c}{ Características de la arena } \\
\hline Ensayo & Norma & Resultado \\
\hline Contenido en finos & UNE-EN 933-1 & $0,90 \%$ \\
Tamaño de la arena & UNE-EN 13139 & $0 / 4$ \\
Calidad de finos & UNE-EN 13139 & Contrastado \\
Forma de las partículas & UNE-EN 13139 & No relevante \\
Densidad aparente & UNE-EN 1097-3 & $1,38 \mathrm{~kg} / \mathrm{l}$ \\
Densidad de las partículas & UNE-EN 1097-6 & $2,60 \mathrm{~kg} / \mathrm{l}$ \\
Porosidad & UNE-EN 1097-3 & $46,9 \%$ \\
\hline
\end{tabular}




\subsection{3.- Requisitos químicos}

La aplicación particular final o el origen de los áridos y el filler son los que determinan la realización o no de ensayos de las propiedades químicas, según indica la Norma UNE-EN 13139.

En principio, ni los áridos ni el filler contienen materiales nocivos que puedan afectar a la durabilidad o acabado superficial de los morteros; el análisis químico de la arena utilizada viene dado por el fabricante y se muestra en la Tabla 3.10.

Tabla 3.10. Tabla resumen de las características químicas de la arena.

\begin{tabular}{lcc}
\multicolumn{3}{c}{ Características químicas de la arena } \\
\hline Ensayo & Norma & Resultado \\
\hline Cloruros & UNE-EN 1744-1 & 0,00 \\
Sulfatos solubles en ácido & UNE-EN 1744-1 & 0,00 \\
Azufre total & UNE-EN 1744-1 & 0,00 \\
\hline
\end{tabular}

\section{3.- Agua}

El agua utilizada en este trabajo procede de la red municipal del Ayuntamiento de Burgos, de naturaleza inocua y sancionada por la práctica, cuyas características, una vez realizado el análisis químico, se muestran en la Tabla 3.11.

Tabla 3.11. Características generales del agua

\begin{tabular}{lc|lc}
\hline \multicolumn{4}{c}{ Análisis del agua potable de la ciudad de Burgos } \\
\hline Parámetro & Valor $(\mathbf{m g} / \mathbf{l})$ & Parámetro & Valor $(\mathbf{m g} / \mathbf{l})$ \\
\hline $\mathrm{pH}$ & 8,86 & Cloro libre & 0,39 \\
Turbidez & 0,17 & Cloro total & 0,45 \\
Conductividad & 47,70 & Calcio & 4,68 \\
Amonio & 0,01 & Carbonatos & 14,02 \\
Hierro & 0,06 & Cloruros & 1,77 \\
Manganeso & 0,00 & Sulfatos & 6,50 \\
Aluminio & 0,06 & & \\
${ }^{*}$ Análisis facilitado por el Servicio de Aguas & Municipal del Excmo. Ayuntamiento de Burgos, \\
2010 &
\end{tabular}

${ }^{128}$ Norma Española UNE-EN 1744 Ensayos para determinar las propiedades químicas de los áridos. 2009 


\section{4.- Residuos de espuma rígida de poliuretano}

El poliuretano en forma de residuo, empleado en la sustitución parcial o total de la arena, procede del reciclaje de restos de dos tipos de espuma rígida de poliuretano. Una de las espumas es de color blanco y la hemos denominado PUR "A"; la segunda espuma, de color gris se ha denominado PUR "B".

Ambas son de naturaleza orgánica, y por tanto no se pueden incluir en la clasificación de los áridos tradicionales de la normativa vigente, aunque se ha utilizado como guía las especificaciones de la UNE-EN 13139:2002/AC:2004, Áridos para morteros, en el Apartado 1, "NOTA 1", que indica que "para materiales no habituales de origen secundario, cuando se pongan en el mercado como áridos, deben cumplir totalmente con esta norma y con la reglamentación nacional sobre sustancias peligrosas, dependiendo del uso previsto."

La espuma remplaza al árido del mortero. Las características típicas que se estudian en los áridos determinan el comportamiento y prestaciones finales del mortero; ahora bien, la diferencia en la composición química de las espumas y en sus propiedades formales y estructurales (porosidad, resistencia, elasticidad, etc.), obligan a realizar un estudio más profundo y completo de ciertas propiedades. Por este motivo hemos analizado en la caracterización los siguientes parámetros:

Características geométricas

- Tamaño del árido (recomendación)

- Granulometría

- Finos

Características físicas

- Densidad de las partículas

- Absorción de agua

Características químicas

- Análisis elemental (CHNS)

- Difracción por rayos X (RX)

- Microscopía electrónica de barrido (SEM) 


\subsection{1.- Características geométricas}

Una vez depositadas en el laboratorio las espumas poliméricas se han triturado, mezclándolas posteriormente con el resto de componentes del mortero, por lo que se les ha aplicado solamente un tratamiento mecánico.

Las características geométricas de los agregados están condicionadas por el sistema de trituración y por la propia naturaleza física de los residuos que han llegado al laboratorio. En la Figura 3.2 se muestra el estado de las dos espumas después de la trituración.

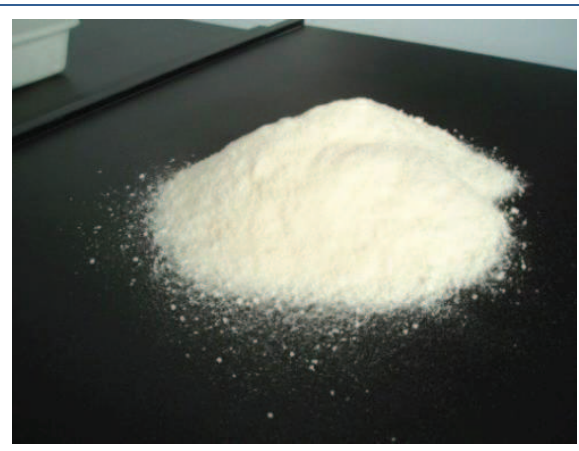

Figura 3.2. Espuma triturada tipo "A".

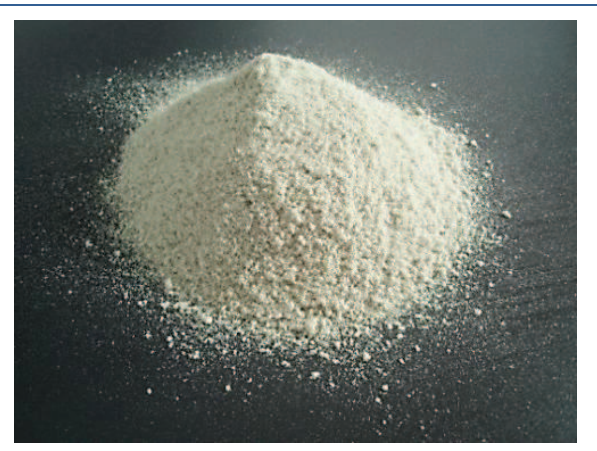

Espuma triturada tipo "B".

\subsubsection{1.- Forma de las partículas}

La molturación del árido comporta la fractura del mismo en partículas angulosas y con alta superficie específica, es decir partículas con formas muy alejadas del modelo de árido natural granular.

\subsubsection{2.- Granulometría y finos}

Los requisitos geométricos que se han impuesto a las espumas, en cuanto a tamaño máximo del árido, granulometría y finos han sido los mismos que a la arena empleada.

Las diferencias más importantes entre las líneas granulométricas de las espumas y de la arena empleada, se han producido por el empleo de la máquina trituradora; este tipo de máquinas tritura la espuma con tamaño máximo en función de la criba que se incorpora. Sin embargo, la cantidad de finos es significativamente menor que la aportada por la arena, ya que la espuma se tritura en un tiempo siempre fijo, y en el momento en que se alcanza el tamaño menor a la abertura de la criba, las partículas de 
espuma, por efecto de la presión que produce la cuchilla giratoria, se desplazan al recipiente-almacén de la máquina trituradora.

Los porcentajes en pasa en la serie normalizada de tamices de la norma UNE-EN 933-2 en cada una de las espumas vienen reflejadas en la tabla 3.12 .

Tabla 3.12. Serie numérica del pasa en $\%$ de las espumas

\begin{tabular}{cccccccccc}
\hline & Tamices & 4 & 2 & 1 & 0,50 & 0,25 & 0,125 & 0,063 & fondo \\
\hline \multirow{2}{*}{ Pasa \% } & PUR “A” & $\mathbf{1 0 0}$ & $\mathbf{9 8 , 3 9}$ & $\mathbf{7 9 , 1 8}$ & $\mathbf{2 2 , 2 1}$ & $\mathbf{3 , 2 2}$ & $\mathbf{0 , 2 9}$ & $\mathbf{0 , 0 0}$ & $\mathbf{0 , 0 0}$ \\
\cline { 2 - 9 } & PUR “B” & $\mathbf{1 0 0}$ & $\mathbf{9 8 , 8 0}$ & $\mathbf{8 0 , 8 8}$ & $\mathbf{3 3 , 8 6}$ & $\mathbf{5 , 1 8}$ & $\mathbf{0 , 0 0}$ & $\mathbf{0 , 0 0}$ & $\mathbf{0 , 0 0}$ \\
\cline { 2 - 9 }
\end{tabular}

Granulometría: Módulo granulométrico de la espuma "A": 4,00. Granulometría: Módulo granulométrico de la espuma "B": 3,81.

En ambos casos, el módulo granulométrico de las espumas es ligeramente superior al de la arena. El poliuretano "A" tiene mayor módulo granulométrico que el "B", lo que significa un mayor tamaño medio de sus partículas. La Figura 3.3 representa las líneas granulométricas de los dos tipos de espuma y de la arena, encontrándose en todos los casos, dentro de los límites que señala la Norma Básica NBE-FL 90.

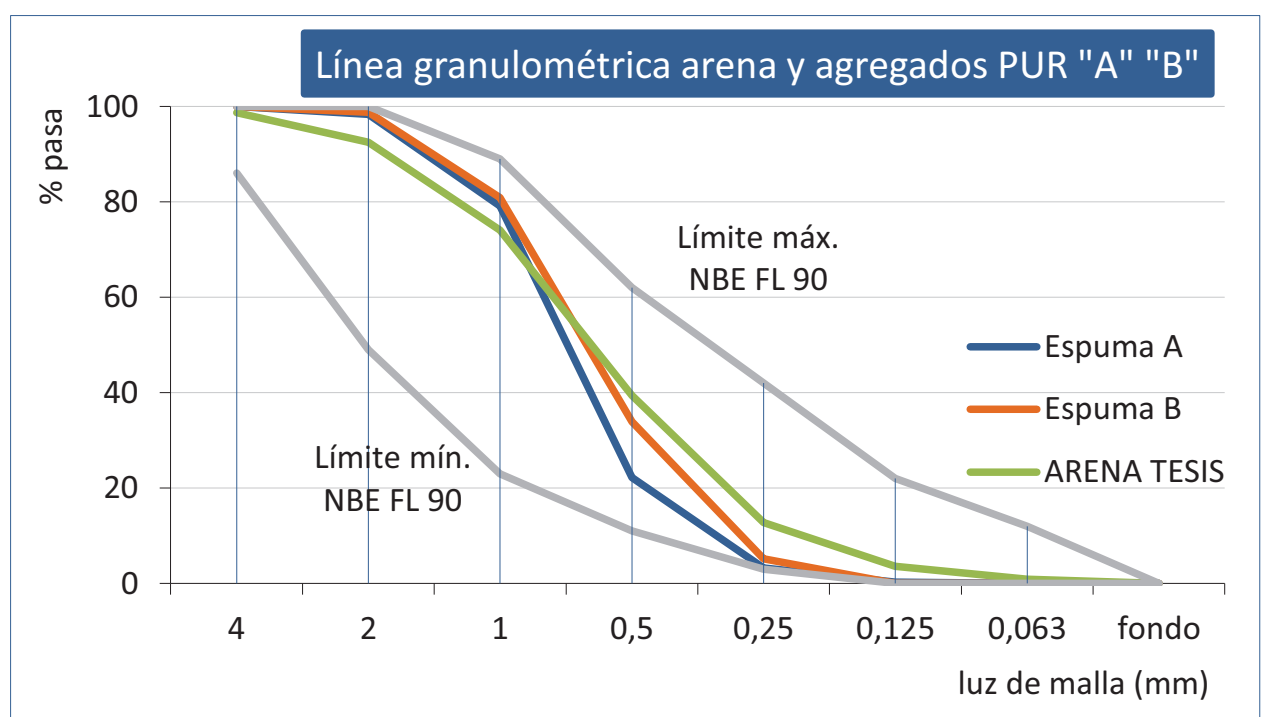

Figura 3.3. Línea granulométrica de la arena y de los agregados PUR "A" y "B"

El tamaño de las espumas como árido es $0 / 2$, pues se cumple con las limitaciones en cuanto a tamaño máximo, ya que no hay ninguna partícula de tamaño mayor a $4 \mathrm{~mm}$, siendo el pasa del diámetro $1,4 \mathrm{D}$, superior al 
$95 \%$. Pese a estar clasificados como áridos de tamaño distinto a la arena, pues el pasa del $4 \mathrm{~mm}$ es del $100 \%$, frente al $98,7 \%$ de la arena, se puede considerar que se trata de granulometrías similares.

La diferencia principal en cuanto a la granulometría de los polímeros y la de la arena de los morteros radica en la abundancia de tamaños intermedios en las espumas. En concreto, más del $75 \%$ en peso de ambos poliuretanos tiene tamaño comprendido entre $0,25 \mathrm{~mm}$ y $1 \mathrm{~mm}$, frente al $50 \%$ en la arena de referencia.

Finalmente, y pese a haber empleado los mismos métodos y maquinaria para el triturado de las espumas, la espuma "A" presenta menos cantidad de partículas de tamaño comprendido entre $0,25 \mathrm{~mm}$ y $0,50 \mathrm{~mm}$, lo que se traduce en el módulo granulométrico mayor de la espuma "A", y en consecuencia, en una posible menor demanda de agua para el amasado de los morteros.

\subsection{2.- Características físicas}

\subsubsection{1.- Densidad de la espuma conformada (antes del triturado)}

La densidad de las partículas, que coincide con la densidad real como árido, es la equivalente a la densidad aparente del material de procedencia de un árido natural triturado. Para hallar dicha densidad real como árido, se ha calculado la densidad aparente de los paneles de las espumas de procedencia es decir, de un trozo de espuma antes de su trituración.

\subsubsection{2.- Densidad aparente y real de la espuma triturada}

Para el cálculo de las densidades aparente y real de las espumas de poliuretano trituradas, se han llevado a cabo los procedimientos operatorios de los apartados 2.1.5 y 2.1.2.

En la Tabla 3.13 se resumen los resultados obtenidos.

Tabla 3.13. Densidades de las espumas "A" $y$ " $B$ "

\begin{tabular}{lccc}
\hline & $\begin{array}{c}\text { Densidad de las } \\
\text { partículas (espuma } \\
\text { panel) kg/l }\end{array}$ & $\begin{array}{c}\text { Densidad aparente } \\
\text { de la espuma kg/l } \\
\text { triturada }\end{array}$ & $\begin{array}{c}\text { Densidad real del } \\
\text { poliuretano } \\
\text { kg/l }\end{array}$ \\
\hline PUR “A" & 0,0433 & 0,0448 & 1,0674 \\
PUR "B" & 0,0262 & 0,0590 & 1,2087 \\
\hline
\end{tabular}


Para el poliuretano "A" la densidad aparente resulta similar a la densidad de la espuma triturada, lo que indica que el tamaño medio de los poros del material en forma de panel, es equivalente al tamaño medio de los huecos entre las partículas de espuma una vez triturada. Sin embargo, para la espuma "B" la densidad del material sin triturar es muy inferior a la densidad aparente del triturado, lo que significa que el tamaño medio de los poros del panel "B" es mucho mayor que el tamaño medio de los huecos entre las partículas de la espuma.

La densidad real del poliuretano, algo superior a la del agua, nos sirve para conocer la porosidad de la espuma conformada, que es de $95,94 \%$ para la espuma "A" y $97,83 \%$ para la espuma "B".

Una vez triturada la espuma, la forma y tamaño de los huecos y la porosidad en general de las partículas varía de forma muy significativa, por lo que el dato de la porosidad de la espuma conformada no puede ser utilizado para calcular la porosidad media de las partículas, al ser muchas de ellas de tamaño muy inferior a los poros de la espuma conformada.

\subsubsection{3.- Absorción de agua}

La absorción de agua de la espuma de poliuretano triturado para su empleo como árido resulta fundamental para conocer la porosidad accesible de las partículas que se llenarán parcialmente de pasta cementosa, por lo que el rendimiento de los morteros disminuirá sensiblemente en función de la cantidad de espuma presente.

Para el cálculo de la absorción de agua se ha empleado el procedimiento de la Norma UNE-EN 1015-18. Se han utilizado muestras de espuma conformada con los resultados de la Figura 3.4, en la que se observa que la absorción de la espuma "A" es mucho menor que la absorción de la espuma "B". A partir de los 35-37 minutos la absorción de agua se estabiliza en ambas espumas, produciéndose incluso un desorción posterior bastante más acusada en la espuma "B". 


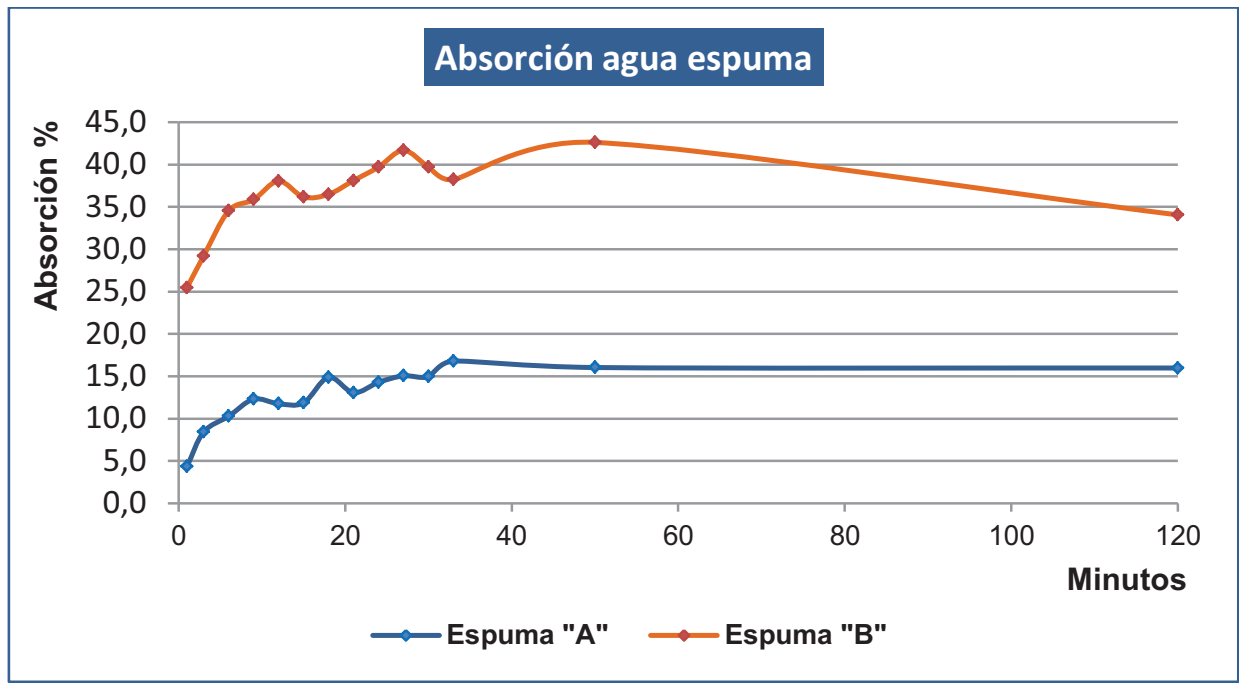

Figura 3.4. Gráfico de absorción de las espumas conformadas.

\subsection{3.- Características químicas}

El estudio de las características químicas de las espumas nos permitirá conocer su composición química y además la presencia de cloruros, compuestos de azufre $u$ otros compuestos que puedan alterar la velocidad de fraguado y el endurecimiento del mortero.

\subsubsection{1.- Composición química (CHNS)}

Los resultados de los ensayos se muestran en la tabla 3.14.

Tabla 3.14. Análisis elemental CHNS de las espumas " $A$ " $y$ " $B$ "

\begin{tabular}{lcccc}
\hline & Carbono $\%$ & Hidrógeno $\%$ & Nitrógeno $\%$ & Azufre $\%$ \\
\hline PUR "A" & 61,38 & 5,51 & 6,82 & 0,00 \\
PUR "B" & 68,49 & 5,76 & 24,50 & 0,02 \\
\hline
\end{tabular}

\subsubsection{2.- Microscopía electrónica de barrido (SEM). Microanálisis} por energía dispersa de barrido.

En la espuma "A" (Figura 3.5) se observa una estructura homogénea con celdillas esféricas y ciertas intercomunicaciones entre las celdas, probablemente por la rotura de las celdas en el corte del material. Sin embargo a los 350 aumentos se puede apreciar el fondo de la celdilla sin perforaciones. 
La combinación de la microscopía electrónica de barrido con el microanálisis por energía dispersa de barrido, en zonas concretas del material nos permite determinar la naturaleza de las partículas observadas.

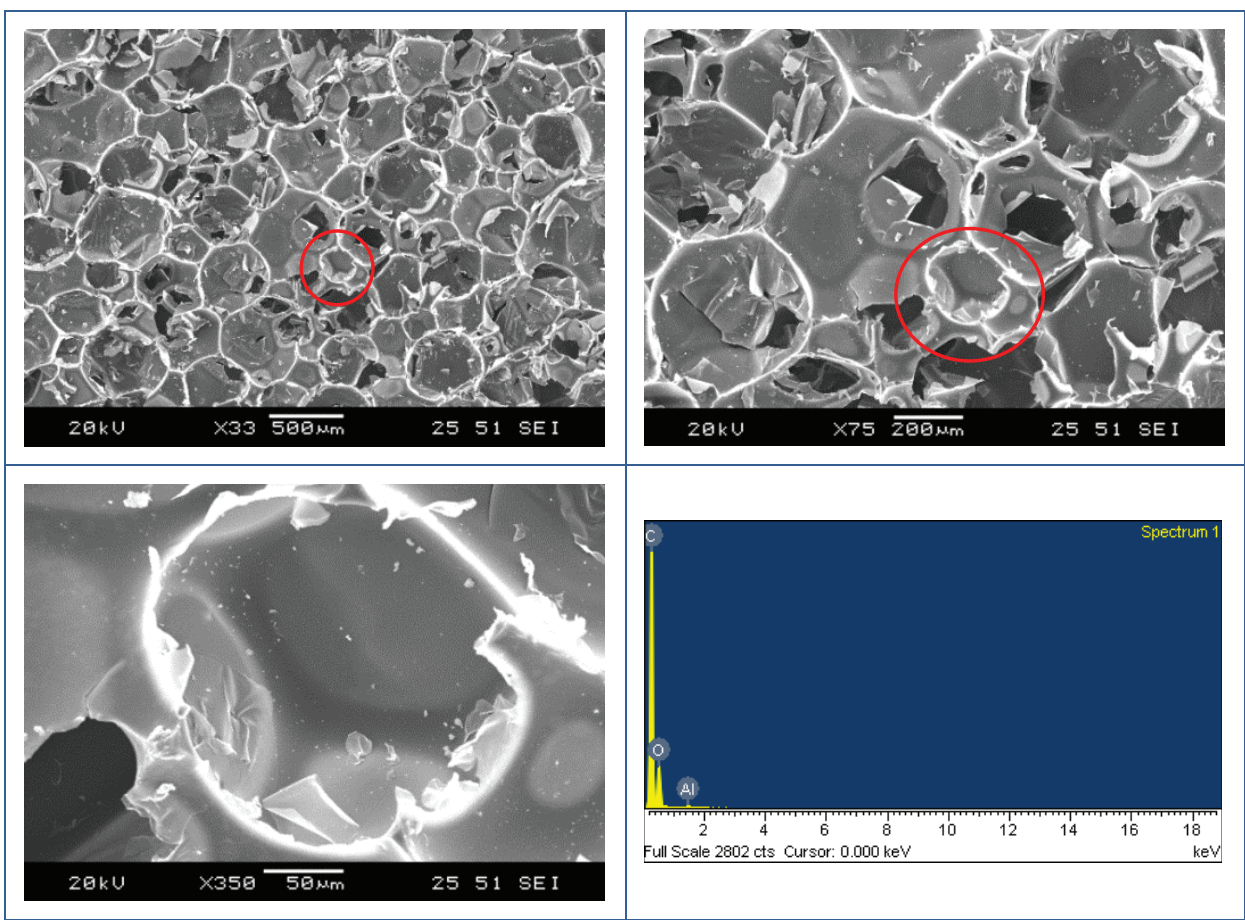

Figura 3.5. Microscopía electrónica de barrido PUR "A", sin triturar

Las celdillas de la espuma "B", parecen menos homogéneas en forma y tamaño, observándose fondos oscuros que parecen indicar agujeros que permiten la intercomunicación de huecos entre celdillas, según se muestra en la Figura 3.6.

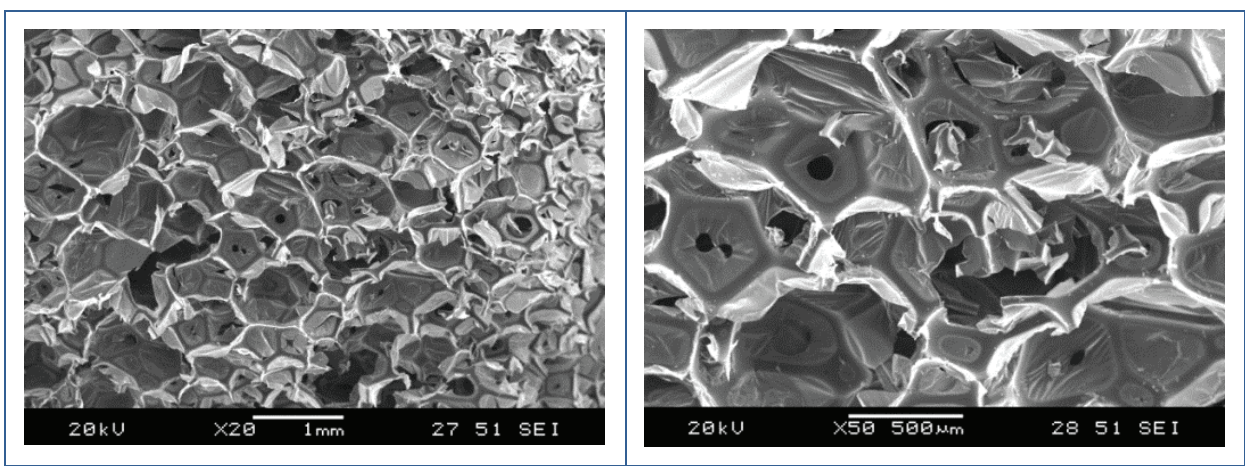

Figura 3.6. Microscopía electrónica de barrido PUR "B", sin triturar 
El tamaño medio de las celdas de la espuma "A" es aproximadamente de $0,4 \mathrm{~mm}$, mientras que para la espuma "B" es de $0,7 \mathrm{~mm}$, lo que indica un tamaño mayor de poros para la espuma "B", y por tanto una menor densidad aparente.

\section{5.- Aditivos}

\subsection{1.- Emulsión adhesiva}

Al ser un producto que se añade en pequeña cantidad al mortero para mejorar alguna de sus prestaciones, se puede considerar como un aditivo para mortero. Se trata de una emulsión adhesiva a base de látex, de la casa "Sika", denominada "Emulsión adhesiva para mortero o lechada de cemento".

Las características técnicas más destacables del aditivo, que se recogen en la Hoja de Datos del Producto son las de la Tabla 3.15.

Tabla 3.15. Características del aditivo Sikanol-M. Hoja de Datos del Producto

$$
\text { Sika Látex }
$$

Características químicas

Composición química

Densidad

Emulsión de estireno-butadieno

Contenido en sólidos

$1,02 \mathrm{~kg} / \mathrm{l}$

$36 \%$

Dosificación

$0,65 \mathrm{~kg} / \mathrm{m}^{2}$ y $\mathrm{cm}$ de espesor

\subsection{2.- Aditivo inclusor de aire/plastificante}

Se trata de un aditivo plastificante-aireante concentrado para mortero, de la casa Sika denominado Sikanol -M Polvo.

Las características técnicas más destacables del aditivo, que se recogen en la Hoja de Datos del Producto y se reflejan en la Tabla 3.16.

Tabla 3.16. Características del aditivo Sikanol-M. Hoja de Datos del Producto

\begin{tabular}{lc}
\hline Características químicas & Sikanol-M \\
\hline Composición química & Mezcla de lignosulfonatos, \\
contenido en cloruros & $\leq 0,1 \%$ \\
Contenido en alcalinos & $\leq 5 \%$ \\
\hline Dosificación & Entre $0,1 \%$ y $0,3 \%$ \\
\hline
\end{tabular}


$\forall$

O

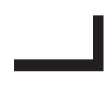

$\supset$

1

$1+$

0

$\longrightarrow$

0

Morteros de referencia y morteros aligerados con residuos de espuma de poliuretano 



\section{Capítulo 4.- Morteros de referencia y morteros aligerados con residuos de espuma de poliuretano}

La utilización de los morteros de cemento requiere un moldeado previo de los mismos para adecuarse a las formas finales que van a tener en obra. La fabricación se realiza con la mezcla previa de los componentes, homogénea y con el grado de consistencia adecuado, debiéndose mantener, durante un tiempo mínimo, en condiciones de ser moldeada. Estas condiciones de consistencia y tiempo disponible para su aplicación son las que definen la trabajabilidad del mortero.

Por tanto, para el correcto moldeo de los morteros, éstos deben tener una plasticidad que les permita adoptar las formas que impone el diseño, ya sea constructivo o meramente estético, sin deformaciones posteriores. De esta manera la primera condición que deben cumplir los morteros de cemento es la aptitud para la puesta en obra. Posteriormente a su colocación en obra, el mortero de cemento endurece y son las prestaciones en estado endurecido las que se deben exigir durante la vida útil de las construcciones.

En consecuencia, la caracterización de los morteros de cemento implica la caracterización de dos estados físicos muy diferentes, que son el "estado fresco" (mortero plástico) y el "estado endurecido" (mortero rígido).

Es evidente que las proporciones en la mezcla de los componentes determinarán las características del mortero, tanto en estado fresco como endurecido, por lo que estas propiedades se tendrán que estudiar de forma conjunta en ambos estados físicos.

La presente Tesis Doctoral trata de determinar las propiedades y prestaciones de los morteros con agregados de espuma rígida de poliuretano reciclado (PUR) para su uso en obra, que se evaluarán de acuerdo con las características señaladas en las Normas UNE-EN 998-1 y 998-2 correspondientes a los morteros para albañilería. Según estas normas los morteros para albañilería, definidos según el concepto, se clasifican en morteros diseñados y morteros prescritos. 
- Los morteros diseñados son aquellos cuya composición y sistema de fabricación ha sido elegido por el fabricante para obtener las propiedades especificadas (concepto de prestación).

- Los morteros prescritos son los que se fabrican en unas proporciones determinadas y cuyas propiedades dependen de las cantidades declaradas de los componentes (concepto de receta).

La diferencia fundamental entre un mortero diseñado y un mortero prescrito estriba en que, en el mortero diseñado la dosificación de los componentes se ha realizado en fábrica, y la puesta en obra del mortero se deberá realizar de acuerdo con las instrucciones del fabricante para obtener las prestaciones declaradas. Sin embargo, en el mortero prescrito la dosificación la debe realizar el director del proyecto, o en su caso el director de la obra, en base a resultados obtenidos por el conocimiento y experiencia, sin existir garantías precisas de las prestaciones del mortero, es decir, sin evaluación previa. Por ello, a la hora de indicar los requisitos para los morteros en estado fresco o en estado endurecido, las normas establecen ciertas diferencias entre los morteros diseñados y los morteros prescritos.

Los morteros fabricados con reciclados de espuma de poliuretano de este trabajo se deben incluir en el grupo de los morteros diseñados, ya que no hay experiencia contrastada de las prestaciones de los morteros con agregados de PUR puestos en obra, por lo que no se pueden establecer proporciones predeterminadas en base a resultados derivados de la experiencia, aunque, por otro lado, se han realizado diversos estudios de morteros de cemento con agregados ligeros, con resultados más que aceptables en cuanto a su comportamiento mecánico. ${ }^{129,130}$

La limitada experimentación en la fabricación de morteros con agregados de PUR, obliga a confeccionar además morteros que sirvan de referencia para la evaluación de sus prestaciones. Por tanto, previamente se deberán fijar las proporciones de las mezclas de referencia que serán las comúnmente admitidas para la fabricación de morteros prescritos. Con todo esto se podrá llevar a cabo un estudio comparativo de las propiedades de

129 Haque M.N, Al-Khaiat H, Kayali O. Strength and durability of lightweight concrete. Cem Concr Compos 2004, 26, 307-314.

${ }^{130}$ Czarnecki C. Polymer Concretes. Cement-Wapno-Beton 2010, 15(2), 63-85. 
los morteros aligerados con espuma de poliuretano y los de referencia fabricados con materiales tradicionales. ${ }^{131}$

El objetivo final se basa en la determinación de las características de los morteros con agregados (PUR) y su utilización como morteros para albañilería.

Los residuos que se emplean proceden de desperdicios originados en el propio proceso productivo y/o del rechazo del producto terminado, que se genera en industrias que utilizan conformados de espuma rígida de poliuretano en la fabricación de ciertos componentes de sus productos. Se presentan tanto en forma de planchas como en trozos de material sin forma determinada y de tamaño muy diverso.

La baja densidad de la espuma conformada incide de forma determinante en el elevado coste de su transporte, en relación con el peso transportado. Por ello para minimizar el coste del transporte, es obligado limitar geográficamente la procedencia de las espumas poliméricas, por lo que se han utilizado residuos de espumas de dos factorías ubicadas en Burgos. Una vez elegidos y caracterizados los agregados de poliuretano el siguiente paso es el diseño de las dosificaciones de los morteros con estos materiales. Por motivos de confidencialidad cada tipo de espuma y sus residuos, una vez reciclados, se han designado abreviadamente como (PUR)A y (PUR)B.

\section{1.- Diseño de los morteros}

\subsection{1.- Morteros de referencia}

Con cada uno de los tres cementos se han elaborado tres morteros de referencia, con relación de componentes en peso cemento/árido $(C / A)$ de $1 / 3,1 / 4$ y $1 / 6$, pues las exigencias mecánicas son distintas en los morteros para fábricas de albañilería que en los morteros de revoco y enlucido.

Los morteros de referencia tradicionales y usados habitualmente en obra, se incluyen en el grupo de morteros prescritos, pues las proporciones son

131 Gadea J, Rodríguez A, Campos P. L, Garabito J, Calderón V. Lightweight mortar made with recycled polyurethane foam. Cem Concr Compos 2010, 32 672-677. 
las que se han fijado en los proyectos o en la obra, y en todo caso, son proporciones basadas en la experiencia. No existe una regla general (receta) para fijar las proporciones de los componentes en los morteros prescritos, pues las únicas normas de obligado cumplimiento (CTE muros resistentes) se refieren a exigencias prestacionales. Por ello, y para confeccionar los morteros de referencia se recurre a las normas de buena construcción, y/o a las normas, que no siendo de obligado cumplimiento, son tradicionalmente de aplicación, siempre y cuando estos morteros cumplan con las prestaciones mínimas que exigen las correspondientes Normas UNE-EN.

\subsubsection{1.- Clasificación normalizada}

La Norma UNE-EN 998-2, clasifica los morteros en función de su resistencia a compresión a los 28 días (Tabla 4.1). La EN 998-1 amplía la clasificación en función de la absorción de agua por capilaridad y la conductividad térmica (Tabla 4.2). En ninguno de los casos apunta las proporciones de los componentes o cantidad mínima de alguno de ellos.

Tabla 4.1. Clasificación de las propiedades del mortero endurecido EN 998-1

\begin{tabular}{|c|c|c|}
\hline Propiedades & Categorías & Valores \\
\hline \multirow{4}{*}{$\begin{array}{l}\text { Intervalo de resistencia a compresión } \\
\qquad \text { a } 28 \text { días }\end{array}$} & CS I & $0,4 \mathrm{~N} / \mathrm{mm}^{2}$ a $2,5 \mathrm{~N} / \mathrm{mm}^{2}$ \\
\hline & CS II & $1,5 \mathrm{~N} / \mathrm{mm}^{2}$ a $5,0 \mathrm{~N} / \mathrm{mm}^{2}$ \\
\hline & CS III & $3,5 \mathrm{~N} / \mathrm{mm}^{2}$ a $7,5 \mathrm{~N} / \mathrm{mm}^{2}$ \\
\hline & CS IV & $\geq 6,0 \mathrm{~N} / \mathrm{mm}^{2}$ \\
\hline \multirow{3}{*}{ Absorción de agua por capilaridad } & W 0 & No especificada \\
\hline & W 1 & $\mathrm{c} \leq 0,40 \mathrm{~kg} / \mathrm{m}^{2} \cdot \mathrm{min}^{0,5}$ \\
\hline & W 2 & $\mathrm{c} \leq 0,20 \mathrm{~kg} / \mathrm{m}^{2} \cdot \mathrm{min}^{0,5}$ \\
\hline \multirow{2}{*}{ Conductividad Térmica } & $\mathrm{T} 1$ & $\leq 0,1 \mathrm{~W} / \mathrm{m} \cdot \mathrm{K}$ \\
\hline & T 2 & $\leq 0,2 \mathrm{~W} / \mathrm{m} \cdot \mathrm{K}$ \\
\hline
\end{tabular}

Tabla 4.2. Clases de mortero EN 998-2

\begin{tabular}{ccccccccc} 
Clase & M1 & M2 & M5 & M10 & M15 & M 20 & Md \\
\hline $\begin{array}{c}\text { Resistencia a compresión } \\
\text { N/mm }\end{array}$ & 1 & 2,5 & 5 & 10 & 15 & 20 & d \\
\hline d es una resistencia a compresión mayor de & 25 & $\mathrm{~N} / \mathrm{mm}^{2}$ & declarada por el fabricante & &
\end{tabular}

\subsubsection{2.- Dosificación y resistencia mecánica}

Para fijar las proporciones de los componentes, se ha recurrido a las recomendaciones tradicionales, que dependen de los usos de los morteros. 
- La bibliografía clásica recomienda unas proporciones entre el cemento Portland y la arena que es función del uso y exigencias del mortero.

Así Antonio Camuñas y Paredes ${ }^{132}$ indica las siguientes mezclas (Tabla 4.3), señalando que: las dosificaciones $1: 2$ y $1: 3$ se emplearán para enfoscados y enlucidos hidrófugos, la 1:4 y 1:5 para construcciones sobrecargadas y la 1:6 o 1:7 para trabajos corrientes.

Tabla 4.3. Dosificación de los morteros plásticos de Portland (Camuñas y Paredes)

\begin{tabular}{cccc}
\hline Relación C:S & $\begin{array}{c}\text { Cemento } \\
\text { kg }\end{array}$ & $\begin{array}{c}\text { Arena } \\
\text { litros }\end{array}$ & $\begin{array}{c}\text { Agua } \\
\text { litros }\end{array}$ \\
\hline $1: 1$ & 920 & 605 & 270 \\
$1: 2$ & 600 & 830 & 265 \\
$1: 3$ & 450 & 955 & 260 \\
$1: 4$ & 360 & 1.010 & 257 \\
$1: 5$ & 305 & 1.050 & 255 \\
$1: 6$ & 265 & 1.110 & 253 \\
$1: 7$ & 240 & 1.125 & 250 \\
$1: 8$ & 190 & 1.140 & 250 \\
$1: 9$ & 175 & 1.145 & 245 \\
$1: 10$ & 160 & 1.150 & 240 \\
\hline
\end{tabular}

El libro de Félix Orús Aso, prácticamente reproduce la misma dosificación (Tabla 4.4).

Tabla 4.4. Dosificación de los morteros plásticos de Portland (Orús Asso)

\begin{tabular}{cccc}
\hline $\begin{array}{c}\text { Relación } \\
\text { C:S }\end{array}$ & $\begin{array}{c}\text { Cemento } \\
\text { kg }\end{array}$ & $\begin{array}{c}\text { Arena } \\
\text { litros }\end{array}$ & $\begin{array}{c}\text { Agua } \\
\text { litros }\end{array}$ \\
\hline $1: 1$ & 920 & 680 & 270 \\
$1: 2$ & 600 & 880 & 265 \\
$1: 3$ & 440 & 975 & 260 \\
$1: 4$ & 350 & 1.030 & 260 \\
$1: 5$ & 290 & 1.070 & 255 \\
$1: 6$ & 250 & 1.100 & 255 \\
$1: 8$ & 190 & 1.140 & 250 \\
$1: 10$ & 160 & 1.150 & 250 \\
\hline
\end{tabular}

132 Camuñas y Paredes, A. "Materiales de construcción" Tomo I Novena Edición Latina Universitaria. 1980 
La aplicación de esos morteros es 1:2 para revocos, la 1:3 y 1:4 para trabajos corrientes y la 1:5 o más, cuando no se precise gran resistencia

- El Pliego de Condiciones Técnicas de la Dirección General de Arquitectura, del año $1960,{ }^{133}$ adoptado en la Dirección de Obras del Ministerio de la Vivienda, expresa, a título orientativo, las dosificaciones más usuales en función del empleo del mortero, y se resumen en la Tabla 4.5 .

Tabla 4.5. Dosificación. Pliego Condiciones Técnicas Dirección General de la Arquitectura

\begin{tabular}{|c|c|c|c|}
\hline $\begin{array}{c}\text { Relación } \\
\text { C/A }\end{array}$ & $\begin{array}{c}\text { Cemento } \\
\text { kg }\end{array}$ & $\begin{array}{c}\text { Arena } \\
\mathrm{m}^{3}\end{array}$ & $\underset{\mathrm{m}^{3}}{\text { Agua }}$ \\
\hline \multicolumn{4}{|l|}{ Albañilería } \\
\hline $1 / 3$ & 440 & 0,975 & 0,260 \\
\hline $1 / 4$ & 350 & 1,030 & 0,260 \\
\hline $1 / 6$ & 250 & 1,100 & 0,255 \\
\hline $1 / 7$ & 217 & 1,130 & 0,255 \\
\hline \multicolumn{4}{|l|}{ Mampostería } \\
\hline $1 / 4$ & 350 & 1,030 & 0,260 \\
\hline $1 / 6$ & 250 & 1,100 & 0,255 \\
\hline $1 / 7$ & 215 & 1,130 & 0,255 \\
\hline \multicolumn{4}{|c|}{ Revestimientos } \\
\hline $1 / 1$ & 920 & 0,680 & 0,270 \\
\hline $1 / 2$ & 600 & 0,880 & 0,265 \\
\hline $1 / 3$ & 440 & 0,975 & 0,260 \\
\hline $1 / 4$ & 350 & 1,030 & 0,260 \\
\hline $1 / 6$ & 250 & 1,100 & 0,255 \\
\hline $1 / 8$ & 190 & 1,140 & 0,250 \\
\hline \multicolumn{4}{|l|}{ Soleras } \\
\hline $1 / 6$ & 250 & 1,100 & 0,255 \\
\hline $1 / 8$ & 190 & 1,140 & 0,250 \\
\hline $1 / 10$ & 160 & 1,150 & 0,250 \\
\hline
\end{tabular}

- Las Normas Tecnológicas de la Edificación (NTE), Decreto $3565 / 1972^{134}$ son de aplicación común en las obras de edificación. En ellas se especifican los distintos tipos de morteros de cemento para cada unidad de obra. En todos los casos se refieren a los

133 Pliego de Condiciones Técnicas de la Dirección General de Arquitectura, adoptado en la Dirección de Obras del Ministerio de la Vivienda. Madrid. 1960

134 Normas Tecnológicas de la Edificación (NTE). Decreto 3565/1972, de 23 de diciembre. BOE no 13 de 15/01. 1973 y Orden de 27 de septiembre de 1974 por la que se desarrolla el Decreto 3565/1972, de 23 de diciembre, sobre Normas Tecnológicas de la Edificación. BOE nº 234 de 30/09. 1974 
morteros de cemento con indicación expresa de la relación de sus componentes. En la Tabla 4.6 se muestran las relaciones recomendada en las NTE ${ }^{135,136}$ para morteros de albañilería.

Tabla 4.6. Dosificación NTE

\begin{tabular}{|c|c|c|c|}
\hline $\begin{array}{c}\text { Relación } \\
\text { C/A }\end{array}$ & $\begin{array}{c}\text { Cemento } \\
\text { kg }\end{array}$ & $\begin{array}{c}\text { Arena } \\
\mathrm{m}^{3}\end{array}$ & $\begin{array}{c}\text { Agua } \\
\mathrm{m}^{3}\end{array}$ \\
\hline \multicolumn{4}{|l|}{ RPE Enfoscados } \\
\hline $1 / 3$ & 440 & 0,975 & 0,260 \\
\hline $1 / 4$ & 350 & 1,030 & 0,260 \\
\hline $1 / 6$ & 250 & 1,100 & 0,255 \\
\hline \multicolumn{4}{|l|}{ RPE Revocos } \\
\hline $1 / 1$ & 920 & 0,950 & 0,270 \\
\hline $1 / 2$ & 600 & 1,300 & 0,265 \\
\hline \multicolumn{4}{|l|}{ PTL Tabiques ladrillo } \\
\hline $1 / 6$ & -- & -- & -- \\
\hline \multicolumn{4}{|l|}{ FFL Fachadas ladrillo } \\
\hline $1 / 6$ & -- & -- & -- \\
\hline
\end{tabular}

- La Norma Básica NBE-FL 90 "muros resistentes de fábrica de ladrillo" RD 1.723 1990, de 4 de enero de 1991, (de obligado cumplimiento, hasta la entrada en vigor del CTE), recomendaba las siguientes relaciones de componentes de morteros tipo, en función de su resistencia a compresión (Tabla 4.7):

Tabla 4.7. NBE-FL 90. Extraído de la tabla 3.5. Dosificación de morteros tipo

\begin{tabular}{ccc}
\hline Mortero & $\begin{array}{c}\text { Resistencia a } \\
\text { compresión en } \mathbf{k g} / \mathbf{c m}^{\mathbf{2}}\end{array}$ & $\begin{array}{c}\text { Relación } \\
\text { C/A en volumen }\end{array}$ \\
\hline M-160 & 16 & $1 / 3$ \\
M-80 & 8 & $1 / 4$ \\
M-40 & 4 & $1 / 6$ \\
M-20 & 2 & $1 / 8$ \\
\hline
\end{tabular}

- La Norma UNE-EN 196-1 ${ }^{137}$ Métodos de ensayo de cementos, señala, en el punto 6.1 Composición del mortero, unas cantidades de $450 \mathrm{~g}$ de cemento, $1.350 \mathrm{~g}$ de arena y $225 \mathrm{~g}$ de agua en la

\footnotetext{
${ }^{135}$ Norma tecnológica de la Edificación NTE/FFL. «Fachadas de Fabrica de Ladrillo». Orden de 27 de febrero de 1979. Ministerio de Obras Públicas y Urbanismo. BOE nº 93 de 18/04. 1979

136 Norma tecnológica de la edificación NTE-PTL/1973, «Particiones tabiques de ladrillo». Orden del Ministerio de la Vivienda. BOE n 222 de 15/09. 1973

137 Norma Española UNE-EN 196-1. Métodos de ensayo de cementos. Parte 1: Determinación de las resistencias mecánicas. 2005
} 
confección de probetas para determinar la resistencia a compresión de los cementos, es decir, una relación en peso cemento/arena de $1 / 3$.

- El CTE apartado 4.6.2 Resistencia a compresión, recoge los casos más usuales de resistencia a compresión de las fábricas de ladrillo y bloque de hormigón, con indicación expresa de la resistencia mínima del mortero de juntas que se reproduce en la Tabla 4.8.

Tabla 4.8. CTE Tabla 4.4 Resistencia característica a la compresión de fábricas usuales $\mathrm{f}_{\mathrm{k}}\left(\mathrm{N} / \mathrm{mm}^{2}\right)$

\begin{tabular}{lcccccccc}
\hline Resistencia normalizada piezas, & \multicolumn{2}{c}{$\mathbf{1 0}$} & \multicolumn{2}{c}{$\mathbf{1 5}$} & \multicolumn{2}{c}{20} & 25 \\
$\mathrm{f}_{\mathrm{b}}\left(\mathrm{N} / \mathrm{mm}^{2}\right)$ & $\mathbf{5}$ & $\mathbf{7 , 5}$ & $\mathbf{7 , 5}$ & $\mathbf{1 0}$ & $\mathbf{1 0}$ & $\mathbf{1 5}$ & $\mathbf{1 5}$ \\
Resistencia mortero, $\mathrm{f}_{\mathrm{b}}\left(\mathrm{N} / \mathrm{mm}^{2}\right)$ & 5 & 5 & 7 & 7 & 9 & 10 & 11 \\
\hline Ladrillo macizo con junta delgada & 5 & 4 & 6 & 6 & 8 & 8 & 10 \\
Ladrillo macizo & 4 & 4 & 4 & 5 & 6 & 7 & 8 & 9 \\
Ladrillo perforado & 3 & 4 & 5 & 5 & 6 & 7 & 8 \\
Bloques aligerados & 2 & 3 & 4 & 4 & 5 & 6 & 6 \\
Bloques huecos & & & & & &
\end{tabular}

EI CTE exige al mortero de cemento para fábrica estructural, prestaciones exclusivamente resistentes, sin exigir proporciones para la composición del mortero ni cantidad mínima de cemento.

- Finalmente, la Asociación Nacional de Fabricantes de Mortero $(\text { AFAM })^{138}$ solamente reproduce las normas UNE-EN 998-1 y 998-2 en cuanto a designación de los morteros en función de su resistencia a compresión, absorción de agua por capilaridad y conductividad térmica.

Así pues, los morteros de albañilería tradicionales, para enfoscados y juntas, tienen unas proporciones en peso, entre el cemento y la arena, de $1 / 3,1 / 4$ y $1 / 6$, y para revocos $1 / 2$ y $1 / 3$.

La práctica habitual aconseja dosificar en volumen cuando la mezcla se vaya a realizar en obra, resultando más operativo cubicar con recipientes de volumen conocido, que pesar los materiales. En cualquier caso, la dosificación en plantas de preparación de morteros y lógicamente en laboratorio, se realiza siempre en peso. La transformación de volumen a peso se ha llevado a cabo con la densidad aparente de cada material.

${ }^{138}$ AFAM Asociación Nacional de Fabricantes de Mortero. Guía General. Madrid. 2003 
Como compendio de todas las dosificaciones estudiadas se indican las relaciones para morteros de enfoscados y usos corrientes (Tabla 4.9)

Tabla 4.9. Dosificación en peso y relaciones de componentes

\begin{tabular}{ccccc}
\hline $\begin{array}{c}\text { Relación } \\
\text { C/A en } \\
\text { volumen }\end{array}$ & $\begin{array}{c}\text { Cemento } \\
\mathbf{k g}\end{array}$ & $\begin{array}{c}\text { Arena } \\
\mathbf{m}^{\mathbf{3}}\end{array}$ & $\begin{array}{c}\text { Arena } \\
\mathbf{k g}\end{array}$ & $\begin{array}{c}\text { Relación } \\
\text { C/A en peso }\end{array}$ \\
\hline $1 / 3$ & 440 & 0,975 & 1.346 & $1 / 3,05$ \\
$1 / 4$ & 350 & 1,030 & 1.422 & $1 / 4,06$ \\
$1 / 6$ & 250 & 1,100 & 1.519 & $1 / 6,07$ \\
\hline
\end{tabular}

Del estudio de la tabla se deduce que las proporciones en volumen a que se refiere la normativa, transformadas en relaciones en peso, son aproximadamente 1/3,1/4 y 1/6. En consecuencia y en función de los distintos posibles usos, se han dosificado morteros de referencia con esas proporciones.

El último parámetro a determinar es la proporción entre el cemento y el agua, que va a determinar la trabajabilidad del mortero y que va a influir en las prestaciones finales del mismo. Esta relación se ha fijado para conseguir una consistencia adecuada para la correcta puesta en obra, (consistencia plástica), ensayada de acuerdo con la norma UNE-EN 10153. La relación agua/cemento (W/C) debe ser tal que el valor del escurrimiento esté dentro de los límites fijados en la Norma UNE-EN 1015$2,{ }^{139,140}$ que establece los valores límites del escurrimiento en función de la densidad aparente del mortero fresco, de acuerdo con la Tabla 4.10:

Tabla 4.10 Tabla 2. Valor del escurrimiento. Norma UNE-EN 1015-2:1998

\begin{tabular}{cc}
\hline $\begin{array}{c}\text { Densidad aparente del mortero fresco } \\
\left(\mathbf{k g} / \mathbf{m}^{\mathbf{3}}\right)\end{array}$ & $\begin{array}{c}\text { Valor del escurrimiento } \\
(\mathbf{m m})\end{array}$ \\
$>1200$ & $175 \pm 10$ \\
$>600 \mathrm{a} \leq 1200$ & $160 \pm 10$ \\
$>300 \mathrm{a} \leq 600$ & $140 \pm 10$ \\
$\leq 300$ & $120 \pm 10$ \\
\hline
\end{tabular}

La densidad de los morteros es función de los materiales utilizados y en el caso de los morteros de referencia, siempre será muy superior a 1.200

139 Norma Española UNE-EN 1015-2. Métodos de ensayo de los morteros para albañilería. Parte 2: Toma de muestra total de morteros y preparación de los morteros para ensayo. 1999

140 Norma Española UNE-EN 1015-2:1999/A1. Métodos de ensayo de los morteros para albañilería. Parte 2: Toma de muestra total de morteros y preparación de los morteros para ensayo. 2007 
$\mathrm{kg} / \mathrm{m}^{3}$, por lo que el valor del escurrimiento deberá estar comprendido entre $165 \mathrm{~mm}$ y $185 \mathrm{~mm}$, que se corresponde con una consistencia de utilización de mortero plástico.

\subsection{2.- Morteros con agregados de PUR}

Para el diseño de estos morteros sustituimos parcial o totalmente la arena, en los morteros de referencia, por agregado de PUR. Se han realizado mezclas con sustitución de la arena por (PUR) en porcentajes crecientes hasta la sustitución total del árido. Estas sustituciones se han realizado en volumen, dosificando con su equivalente en peso.

La granulometría del agregado de PUR se ha ajustado dentro de lo posible, a la granulometría de la arena, en lo relativo al tamaño máximo y a la línea granulométrica.

Se han confeccionado los morteros con agregados de residuos de espuma rígida de poliuretano, utilizando dos tipos de espuma y realizando las sustituciones de árido de cada mortero de referencia por agregado de PUR, en la siguiente proporción:

1. Mortero de referencia, sin sustitución de árido.

2. Sustitución de un $25 \%$ en volumen de árido por PUR.

3. Sustitución de un $50 \%$ en volumen de árido por PUR.

4. Sustitución de un $75 \%$ en volumen de árido por PUR.

5. Sustitución de un $100 \%$ en volumen de árido por PUR, es decir sustitución total del árido.

Ello supone 4 morteros por cada una de las dos espumas, para cada una de las tres dosificaciones $(1 / 3,1 / 4,1 / 5)$ y cada cemento (3 cementos), lo que hace un total de 72 dosificaciones distintas. A esto hay que sumarle 9 morteros de referencia ( 3 cementos con 3 dosificaciones cada uno), lo que hace un total de 81 mezclas distintas.

La nomenclatura utilizada para la designación de los morteros es la siguiente: 
- La letra "M" indicativa de la palabra Mortero, seguida de un espacio.

- Los números romanos "I", "II" o "IV", indicativos del tipo de cemento empleado y que son "CEM I 42,5 R", "CEM II/B-L 32,5 R", "CEM IV/B (V) 32,5 N", seguidos de un guión.

○ El número "3", "4" o "6", indicativo de la relación en peso, cemento/arena, utilizada en la confección de los morteros de referencia, que son "1/3", "1/4", "1/6".

- La letra "R" si se trata de un mortero de referencia.

- Las letras "PU" si se trata de un mortero con agregados de residuos de espuma rígida de poliuretano

- Los números "25", "50", "75" o “100", que señalan el porcentaje de sustitución de arena por espuma de poliuretano.

- Las letras "A" o "B", indicativas de la naturaleza y procedencia del agregado (PUR) empleado en la sustitución.

Así, por ejemplo, el tipo de mortero "M II-3R" designa un mortero de referencia confeccionado con cemento CEM II/A-L 32,5R, con relación en peso entre el cemento y la arena "1/3". El mortero "M II-3PU50A" designa un mortero confeccionado con cemento CEM II/A-L 32,5R, con relación en peso entre el cemento y la arena " $1 / 3$ ", con sustitución del $50 \%$ del árido (en volumen), por residuo de espuma rígida de poliuretano del tipo " $A$ ".

Al igual que en los morteros de referencia, la proporción entre el agua y el cemento (W/C) se ha calculado para conseguir una consistencia adecuada para su correcta puesta en obra, (consistencia plástica), de acuerdo con la norma UNE-EN 1015-3

La densidad de los morteros con agregados de PUR disminuye al aumentar el porcentaje de polímero, llegando incluso a ser menor de $1.200 \mathrm{~kg} / \mathrm{m}^{3}$ en morteros con sustitución total de la arena. Para este tipo de morteros el valor del escurrimiento deberá estar comprendido entre $150 \mathrm{~mm}$ y $170 \mathrm{~mm}$, frente al valor de $165 \mathrm{~mm}$ y $185 \mathrm{~mm}$ para el resto de morteros estudiados. 


\section{2.- Dosificación y fabricación de los conglomerados}

Los morteros de referencia se han fabricado con los tres tipos de cemento y con las tres relaciones en peso cemento/arena por cada tipo de cemento $(1 / 3,1 / 4$ y $1 / 6)$. Para los morteros con sustitución parcial o total de arena por agregado de PUR, se han pesado las cantidades de espuma en volumen equivalente de arena sustituida y se ha procedido a realizar la mezcla con la misma técnica y maquinaria empleada en la confección de los morteros de referencia.

Cumpliendo con los requisitos de consistencia de la norma se han confeccionado series de tres probetas cada una, de dimensiones $160 \mathrm{~mm} x$ $40 \mathrm{~mm} \times 40 \mathrm{~mm}$.

En las Tablas 4.11 a 4.16 se explicitan las cantidades de cada componente por metro cúbico de mortero, siendo un dato especialmente relevante el peso de cemento por $\mathrm{m}^{3}$ de mortero fresco, ya que es, con diferencia, el componente que mayor incidencia tiene en el precio del mortero.

Tabla 4.11. Dosificación morteros CEM I con PUR A

\begin{tabular}{|l|c|c|c|c|c|}
\hline \multicolumn{1}{|c|}{ Mortero } & \multicolumn{5}{c|}{ kg por $\mathrm{m}^{3}$ de mortero } \\
\hline M I-3R & 448,6 & $1.345,8$ & 0,0 & 328,5 & 0,73 \\
\hline M I-3PU25A & 504,9 & $1.136,1$ & 12,5 & 358,5 & 0,71 \\
\hline M I-3PU50A & 587,8 & 881,7 & 28,6 & 393,8 & 0,67 \\
\hline M I-3PU75A & 687,1 & 515,3 & 50,0 & 434,6 & 0,63 \\
\hline M I-3PU100A & 838,0 & 0,0 & 81,5 & 519,6 & 0,62 \\
\hline M I-4R & 352,2 & $1.408,6$ & 0,0 & 335,2 & 0,95 \\
\hline M I-4PU25A & 412,7 & $1.238,2$ & 13,4 & 346,7 & 0,84 \\
\hline M I-4PU50A & 488,3 & 976,6 & 31,7 & 381,4 & 0,78 \\
\hline M I-4PU75A & 535,0 & 535,0 & 52,1 & 409,9 & 0,77 \\
\hline M I-4PU100A & 616,3 & 0,0 & 80,0 & 554,7 & 0,90 \\
\hline M I-6R & 246,5 & $1.478,9$ & 0,0 & 319,6 & 1,30 \\
\hline M I-6PU25A & 296,6 & $1.334,6$ & 14,4 & 341,1 & 1,15 \\
\hline M I-6PU50A & 338,3 & $1.014,8$ & 32,9 & 405,9 & 1,20 \\
\hline M I-6PU75A & 354,2 & 531,3 & 51,7 & 495,8 & 1,40 \\
\hline M I-6PU100A & 412,5 & 0,0 & 80,3 & 596,2 & 1,45 \\
\hline
\end{tabular}


Tabla 4.12. Dosificación morteros CEM II con PUR A

\begin{tabular}{|l|c|c|c|c|c|}
\hline \multicolumn{1}{|c|}{ Mortero } & \multicolumn{5}{|c|}{ kg por $\mathrm{m}^{3}$ de mortero } \\
\hline M II-3R & 453,0 & $1.359,0$ & 0,0 & 310,0 & 0,68 \\
\hline M II-3PU25A & 515,0 & $1.158,7$ & 12,5 & 343,8 & 0,67 \\
\hline M II-3PU50A & 575,4 & 863,1 & 28,0 & 403,6 & 0,70 \\
\hline M II-3PU75A & 652,4 & 489,3 & 47,5 & 456,7 & 0,70 \\
\hline M II-3PU100A & 699,6 & 0,0 & 68,1 & 542,2 & 0,78 \\
\hline M II-4R & 356,3 & $1.425,4$ & 0,0 & 318,3 & 0,89 \\
\hline M II-4PU25A & 409,0 & $1.227,0$ & 13,3 & 343,7 & 0,84 \\
\hline M II-4PU50A & 467,4 & 934,7 & 30,3 & 392,6 & 0,84 \\
\hline M II-4PU75A & 546,4 & 546,4 & 53,2 & 484,0 & 0,89 \\
\hline M II-4PU100A & 470,6 & 0,0 & 65,9 & 583,5 & 1,24 \\
\hline M II-6R & 246,5 & $1.479,3$ & 0,0 & 312,2 & 1,27 \\
\hline M II-6PU25A & 297,8 & $1.340,1$ & 14,5 & 357,6 & 1,20 \\
\hline M II-6PU50A & 360,6 & $1.081,9$ & 35,1 & 317,4 & 0,88 \\
\hline M II-6PU75A & 363,8 & 545,8 & 53,1 & 479,3 & 1,32 \\
\hline M II-6PU100A & 358,2 & 0,0 & 69,7 & 499,1 & 1,39 \\
\hline
\end{tabular}

Tabla 4.13. Dosificación morteros CEM IV con PUR A

\begin{tabular}{|c|c|c|c|c|c|}
\hline \multirow[t]{2}{*}{ Mortero } & \multicolumn{4}{|c|}{ kg por $\mathrm{m}^{3}$ de mortero } & \multirow[t]{2}{*}{ W/C } \\
\hline & Cemento & Arena & PUR & Agua & \\
\hline M IV-3R & 442,3 & $1.327,0$ & 0,0 & 309,6 & 0,70 \\
\hline M IV-3PU25A & 504,3 & $1.134,7$ & 12,4 & 344,6 & 0,68 \\
\hline M IV-3PU50A & 574,2 & 861,2 & 27,8 & 382,8 & 0,67 \\
\hline M IV-3PU75A & 653,9 & 490,4 & 47,6 & 438,1 & 0,67 \\
\hline M IV-3PU100A & 709,6 & 0,0 & 69,0 & 475,4 & 0,67 \\
\hline M IV-4R & 360,8 & $1.443,3$ & 0,0 & 303,1 & 0,84 \\
\hline M IV-4PU25A & 412,1 & $1.236,2$ & 13,4 & 329,7 & 0,80 \\
\hline M IV-4PU50A & 482,3 & 964,6 & 31,3 & 371,0 & 0,77 \\
\hline M IV-4PU75A & 587,1 & 587,1 & 57,2 & 354,5 & 0,60 \\
\hline M IV-4PU100A & 619,0 & 0,0 & 80,3 & 545,3 & 0,88 \\
\hline M IV-6R & 248,6 & $1.491,4$ & 0,0 & 316,2 & 1,27 \\
\hline M IV-6PU25A & 299,2 & $1.346,6$ & 14,5 & 338,7 & 1,13 \\
\hline M IV-6PU50A & 328,7 & 986,2 & 32,0 & 401,7 & 1,22 \\
\hline M IV-6PU75A & 343,3 & 514,9 & 50,1 & 490,2 & 1,43 \\
\hline M IV-6PU100A & 405,6 & 0,0 & 78,9 & 528,3 & 1,30 \\
\hline
\end{tabular}


Tabla 4.14. Dosificación morteros CEM I con PUR B

\begin{tabular}{|l|c|c|c|c|c|}
\hline \multicolumn{1}{|c|}{ Mortero } & \multicolumn{5}{|c}{ kg por $\mathrm{m}^{3}$ de mortero } \\
\hline M I-3R & Cemento & Arena & PUR & Agua & \\
\hline M I-3PU25B & 548,6 & $1.345,8$ & 0,0 & 328,5 & 0,73 \\
\hline M I-3PU50B & 587,4 & $1.130,4$ & 16,1 & 377,1 & 0,75 \\
\hline M I-3PU75B & 711,5 & 531,2 & 37,6 & 405,8 & 0,69 \\
\hline M I-3PU100B & 847,7 & 0,0 & 108,7 & 542,7 & 0,64 \\
\hline M I-4R & 352,2 & $1.408,6$ & 0,0 & 335,2 & 0,95 \\
\hline M I-4PU25B & 406,7 & $1.220,2$ & 17,4 & 354,7 & 0,87 \\
\hline M I-4PU50B & 455,5 & 910,9 & 38,9 & 447,7 & 0,98 \\
\hline M I-4PU75B & 517,9 & 517,9 & 66,4 & 528,7 & 1,02 \\
\hline M I-4PU100B & 518,1 & 0,0 & 88,5 & 665,4 & 1,28 \\
\hline M I-6R & 246,5 & $1.478,9$ & 0,0 & 319,6 & 1,30 \\
\hline M I-6PU25B & 284,7 & $1.281,1$ & 18,2 & 343,0 & 1,20 \\
\hline M I-6PU50B & 305,2 & 915,6 & 39,1 & 496,0 & 1,63 \\
\hline M I-6PU75B & 320,2 & 480,3 & 61,6 & 587,0 & 1,83 \\
\hline M I-6PU100B & 324,2 & 0,0 & 84,9 & 726,8 & 2,24 \\
\hline
\end{tabular}

Tabla 4.15. Dosificación morteros CEM II con PUR B

\begin{tabular}{|c|c|c|c|c|c|}
\hline \multirow[t]{2}{*}{ Mortero } & \multicolumn{4}{|c|}{ kg por $\mathrm{m}^{3}$ de mortero } & \multirow[t]{2}{*}{ W/C } \\
\hline & Cemento & Arena & PUR & Agua & \\
\hline M II-3R & 453,0 & $1.359,0$ & 0,0 & 310,0 & 0,68 \\
\hline M II-3PU25B & 507,2 & $1.141,2$ & 16,2 & 359,1 & 0,71 \\
\hline M II-3PU50B & 566,1 & 849,0 & 36,2 & 428,3 & 0,76 \\
\hline M II-3PU75B & 622,3 & 466,8 & 59,8 & 519,5 & 0,83 \\
\hline M II-3PU100B & 669,8 & 0,0 & 85,9 & 614,8 & 0,92 \\
\hline M II-4R & 356,3 & $1.425,4$ & 0,0 & 318,3 & 0,89 \\
\hline M II-4PU25B & 410,6 & $1.231,8$ & 17,6 & 360,0 & 0,88 \\
\hline M II-4PU50B & 450,4 & 900,8 & 38,5 & 402,3 & 0,89 \\
\hline M II-4PU75B & 439,2 & 439,2 & 56,3 & 577,3 & 1,31 \\
\hline M II-4PU100B & 486,7 & 0,0 & 83,2 & 662,4 & 1,36 \\
\hline M II-6R & 246,5 & $1.479,3$ & 0,0 & 312,2 & 1,27 \\
\hline M II-6PU25B & 273,6 & $1.231,3$ & 17,5 & 400,0 & 1,46 \\
\hline M II-6PU50B & 322,5 & 967,6 & 41,3 & 454,4 & 1,41 \\
\hline M II-6PU75B & 365,2 & 547,8 & 70,2 & 553,8 & 1,52 \\
\hline M II-6PU100B & 382,9 & 0,0 & 100,3 & 695,2 & 1,82 \\
\hline
\end{tabular}


Tabla 4.16. Dosificación morteros CEM IV con PUR B

\begin{tabular}{|l|c|c|c|c|c|}
\hline \multicolumn{5}{|c|}{ Mortero } & \multicolumn{5}{|c|}{ kg por $\mathrm{m}^{3}$ de mortero } \\
\hline M IV-3R & Cemento & Arena & PUR & Agua & \\
\hline M IV-3PU25B & 502,5 & $1.130,7$ & 16,1 & 351,8 & 0,70 \\
\hline M IV-3PU50B & 547,7 & 821,6 & 35,1 & 445,8 & 0,81 \\
\hline M IV-3PU75B & 588,9 & 441,7 & 56,6 & 521,8 & 0,89 \\
\hline M IV-3PU100B & 722,9 & 0,0 & 92,7 & 712,5 & 0,99 \\
\hline M IV-4R & 360,8 & $1.443,3$ & 0,0 & 303,1 & 0,84 \\
\hline M IV-4PU25B & 387,1 & $1.161,3$ & 16,0 & 381,0 & 0,98 \\
\hline M IV-4PU50B & 473,3 & 946,6 & 40,5 & 394,4 & 0,83 \\
\hline M IV-4PU75B & 458,5 & 458,5 & 58,8 & 554,6 & 1,21 \\
\hline M IV-4PU100B & 434,0 & 0,0 & 74,2 & 678,1 & 1,56 \\
\hline M IV-6R & 248,6 & $1.491,4$ & 0,0 & 316,2 & 1,27 \\
\hline M IV-6PU25B & 283,6 & $1.275,8$ & 18,1 & 370,7 & 1,31 \\
\hline M IV-6PU50B & 300,1 & 900,4 & 38,5 & 493,0 & 1,64 \\
\hline M IV-6PU75B & 287,7 & 431,6 & 55,3 & 614,6 & 2,14 \\
\hline M IV-6PU100B & 326,0 & 0,0 & 85,4 & 704,4 & 2,16 \\
\hline
\end{tabular}

De los datos de las tablas se pueden extraer varias conclusiones:

- La cantidad de pasta cementosa (cemento más agua) por metro cúbico de mortero fresco aumenta en función del grado de sustitución de arena por espuma. Ello es debido a la forma y porosidad abierta de las partículas de PUR, pues la mayor superficie de las partículas, a igualdad de volumen, implica un requerimiento mayor de pasta cementosa para recubrir esas partículas. Por este motivo el rendimiento del mortero disminuye, y en consecuencia el volumen de los otros componentes por cada metro cúbico de mortero aumenta.

- El volumen de pasta cementosa está calculado como la suma de cemento y agua. En los casos en que el incremento de polímero implica un aumento de la relación agua/cemento, la cantidad de cemento aumenta ligeramente. Sin embargo, cuando no se produce ese incremento en la relación W/C, la necesidad del aumento de pasta cementosa implica un aumento superior de cemento.

En la Tabla 4.17 se puede observar este hecho. 
Tabla 4.17. Comparativa de contenido en pasta de cemento. Mortero con CEM II y relación $1 / 3$

\begin{tabular}{|c|c|c|c|c|c|c|c|}
\hline Mortero & $\begin{array}{c}\text { litro } \\
\mathbf{m}\end{array}$ & $\begin{array}{l}m^{3} \text { de } \\
\text { tero }\end{array}$ & W/C & Mortero & $\begin{array}{c}\text { litro } \\
\text { m }\end{array}$ & $\begin{array}{l}n^{3} \text { de } \\
\text { ero }\end{array}$ & W/C \\
\hline PUR A & Cem. & Pasta cem & & PUR B & Cem. & Pasta cem & \\
\hline M II-3R & 145,7 & 455,7 & 0,68 & M II-3R & 145,7 & 455,7 & 0,68 \\
\hline M II-3PU25A & 165,6 & 509,4 & 0,67 & M II-3PU25B & 163,1 & 522,2 & 0,71 \\
\hline M II-3PU50A & 185,0 & 588,6 & 0,70 & M II-3PU50B & 182,0 & 610,3 & 0,76 \\
\hline M II-3PU75A & 209,8 & 666,5 & 0,70 & M II-3PU75B & 200,1 & 719,6 & 0,83 \\
\hline M II-3PU100A & 225,0 & 767,2 & 0,77 & M II-3PU100B & 215,4 & 830,2 & 0,92 \\
\hline
\end{tabular}

También podemos constatar que en las dosificaciones con sustitución de arena del $50 \%$ y $75 \%$ de PUR "A", la relación W/C se mantiene en 0,70 , pero la necesidad de mayor cantidad de pasta cementosa por la mayor superficie específica de la espuma, obliga al aumento de la cantidad de cemento del orden del 13\%. En cambio en sus homólogas con arena "B" la relación $\mathrm{W} / \mathrm{C}$ pasa de 0,76 en la sustitución del $50 \%$ al 0,83 en la del $75 \%$; esto significa aumento de la cantidad de cemento del $10 \%$, frente al $13 \%$ en la mezcla con la espuma "A".

La demanda de pasta cementosa se incrementa con el aumento de sustitución de arena por PUR, incluso en los morteros con densidad inferior a $1.200 \mathrm{~kg} / \mathrm{m}^{3}$. Estos morteros precisan una menor cantidad de agua al fijar el escurrimiento en $160 \mathrm{~mm}$, inferior al escurrimiento de $175 \mathrm{~mm}$ del resto de morteros.

Otro aspecto destacable es que con el mismo tipo de mezcla y a igualdad de relación W/C, con idéntica sustitución de arena y misma consistencia, la demanda de pasta cementosa resulta similar con el empleo de los dos tipos de espuma, aunque es ligeramente superior en las mezclas realizadas con espuma "B".

Finalmente indicar que, en general, las mezclas realizadas con la espuma "B" necesitan una mayor relación W/C que sus homólogas con la espuma "A", lo que implica una menor cantidad de cemento por metro cúbico de mortero en las muestras con la espuma "B", que supondría a priori un menor coste en las materias primas. Esto es especialmente significativo con las dosificaciones de baja relación cemento/arena.

En las relaciones $1 / 4$ la proporción de agua con respecto al cemento es superior en el CEM I $(0,95)$ que en el CEM II $(0,89)$ y que en el CEM IV 
$(0,84)$. Probablemente eso es debido a la mayor finura de los cementos de categorías resistentes más altas, que demandan más agua para obtener la consistencia adecuada.

\section{3.- Resultados obtenidos}

\subsection{1.- Mortero fresco}

Los ensayos del mortero fresco que se realizan en esta fase previa son la densidad aparente y el contenido en aire, ya que ambos ensayos son indicativos del estado de amasado y compactación del mortero.

\subsubsection{1.- Densidad aparente}

El conocimiento de la densidad aparente del mortero fresco es un referente válido para calcular la cantidad de agua que se combina con el cemento y por añadidura, para conocer la cantidad de agua de amasado que se evaporará en el curado del mortero. El agua de amasado, que posteriormente se evaporará, deja espacios vacíos en el interior del mortero endurecido, disminuyendo su densidad aparente pero también disminuyendo su resistencia a compresión.

\subsubsection{2.- Contenido de aire ocluido}

La determinación del contenido de aire en el mortero fresco resulta relevante, ya que indica los espacios vacíos en el interior del mortero, que pueden deberse a un amasado deficiente y también a una inadecuada compactación del mortero.

\subsubsection{3.- Rendimiento}

Es preciso considerar el rendimiento del mortero, entendido como la relación entre el volumen del mortero fresco y la suma de volúmenes aparentes de los componentes. A menor rendimiento del mortero, mayor cantidad de cemento por metro cúbico, es decir mayor coste. 
En las Tablas 4.18 a 4.20 se especifican los resultados obtenidos de los ensayos de densidad aparente (Norma UNE-EN 1015-6) y del contenido de aire (Norma UNE-EN 1015-7), así como el rendimiento.

La barra inclinada empleada, entre espacios, separa la nomenclatura y resultados del mismo mortero con cada tipo de espuma "A" o "B"

Tabla 4.18. Densidad, contenido de aire y rendimiento de los morteros en estado fresco con CEM I

\begin{tabular}{|c|c|c|c|c|c|}
\hline Mortero & W/C & Densidad & $\begin{array}{l}\text { Contenido en } \\
\text { aire }\end{array}$ & \multicolumn{2}{|c|}{ Rendimiento } \\
\hline & & kg/l & $\%$ & & \\
\hline M I-3R & 0,73 & 2,123 & 4,7 & \multicolumn{2}{|c|}{0,692} \\
\hline M I-3PU25A / B & $0,71 / 0,75$ & $2,012 / 2,026$ & $5,6 / 5,1$ & 0,617 / & 0,614 \\
\hline M I-3PU50A / B & $0,67 / 0,69$ & $1,892 / 1,912$ & $12,8 / 7,6$ & $0,538 /$ & 0,535 \\
\hline M I-3PU75A / B & $0,63 / 0,64$ & $1,687 / 1,769$ & $14,0 / 9,0$ & 0,467 / & 0,449 \\
\hline M I-3PU100A / B & 0,62 / 0,64 & $1,439 / 1,499$ & $17,5 / 13,0$ & 0,384 / & 0,377 \\
\hline M I-4R & 0,95 & 2,096 & 4,7 & \multicolumn{2}{|c|}{0,681} \\
\hline M I-4PU25A / B & $0,84 / 0,87$ & $2,011 / 1,999$ & $6,8 / 5,6$ & $0,597 /$ & 0,601 \\
\hline M I-4PU50A / B & $0,78 / 0,98$ & $1,878 / 1,853$ & $7,4 / 5,6$ & 0,512 / & 0,523 \\
\hline M I-4PU75A / B & $0,77 / 1,02$ & $1,532 / 1,631$ & $11,4 / 7,4$ & 0,469 / & 0,456 \\
\hline M I-4PU100A / B & $0,90 / 1,28$ & $1,251 / 1,272$ & $19,0 / 11,2$ & 0,394 / & 0,429 \\
\hline M I-6R & 1,30 & 2,045 & 5,1 & \multicolumn{2}{|c|}{0,680} \\
\hline M I-6PU25A / B & $1,15 / 1,20$ & $1,987 / 1,927$ & $6,8 / 7,1$ & $0,580 /$ & 0,599 \\
\hline M I-6PU50A / B & $1,20 / 1,63$ & $1,792 / 1,756$ & $12,0 / 7,2$ & $0,504 /$ & 0,521 \\
\hline M I-6PU75A / B & $1,40 / 1,83$ & $1,433 / 1,449$ & $16,0 / 9,4$ & 0,466 / & 0,481 \\
\hline M I-6PU100A / B & $1,45 / 2,24$ & $1,089 / 1,136$ & $30,0 / 12,5$ & $0,397 /$ & 0,441 \\
\hline
\end{tabular}


Tabla 4.19. Densidad, contenido de aire y rendimiento de los morteros en estado fresco con CEM II

\begin{tabular}{|c|c|c|c|c|}
\hline Mortero & W/C & Densidad & $\begin{array}{l}\text { Contenido en } \\
\text { aire }\end{array}$ & Rendimiento \\
\hline & & kg/l & $\%$ & \\
\hline M II-3R & 0,68 & 2,122 & 4,8 & 0,694 \\
\hline M II-3PU25A / B & $0,67 / 0,71$ & $2,030 / 2,024$ & $5,4 / 5,0$ & $0,614 / 0,616$ \\
\hline M II-3PU50A / B & $0,70 / 0,76$ & $1,870 / 1,880$ & $7,2 / 5,4$ & $0,544 / 0,544$ \\
\hline M II-3PU75A / B & $0,70 / 0,83$ & $1,646 / 1,668$ & $11,2 / 7,0$ & $0,480 / 0,483$ \\
\hline M II-3PU100A / B & $0,78 / 0,92$ & $1,310 / 1,371$ & $18,0 / 11,5$ & $0,437 / 0,437$ \\
\hline M II-4R & 0,89 & 2,100 & 4,5 & 0,682 \\
\hline M II-4PU25A / B & $0,84 / 0,88$ & $1,993 / 2,020$ & $6,4 / 4,8$ & 0,602 / 0,594 \\
\hline M II-4PU50A / B & $0,84 / 0,89$ & $1,825 / 1,792$ & $10,0 / 5,4$ & $0,527 / 0,540$ \\
\hline M II-4PU75A / B & $0,89 / 1,31$ & $1,630 / 1,512$ & $12,0 / 8,0$ & $0,446 / 0,502$ \\
\hline M II-4PU100A / B & $1,24 / 1,36$ & $1,120 / 1,232$ & $20,0 / 12,0$ & $0,453 / 0,449$ \\
\hline M II-6R & 1,27 & 2,038 & 5,6 & 0,683 \\
\hline M II-6PU25A / B & $1,20 / 1,46$ & $2,010 / 1,922$ & $6,7 / 6,0$ & $0,572 / 0,596$ \\
\hline M II-6PU50A / B & $0,88 / 1,41$ & $1,795 / 1,786$ & $9,0 / 6,7$ & $0,500 / 0,510$ \\
\hline M II-6PU75A / B & $1,32 / 1,52$ & $1,425 / 1,537$ & $17,5 / 8,0$ & 0,459 / 0,443 \\
\hline M II-6PU100A / B & 1,39 / 1,82 & $0,927 / 1,178$ & $28,0 / 12,0$ & $0,461 / 0,397$ \\
\hline
\end{tabular}

Tabla 4.20. Densidad, contenido de aire y rendimiento de los morteros en estado fresco con CEM IV

\begin{tabular}{|c|c|c|c|c|c|}
\hline Mortero & W/C & Densidad & $\begin{array}{c}\text { Contenido en } \\
\text { aire }\end{array}$ & \multicolumn{2}{|c|}{ Rendimiento } \\
\hline & & kg/l & $\%$ & & \\
\hline M IV-3R & 0,70 & 2,079 & 5,0 & \multicolumn{2}{|c|}{0,700} \\
\hline M IV-3PU25A / B & $0,68 / 0,70$ & $1,996 / 2,001$ & $6,0 / 5,0$ & $0,616 /$ & 0,616 \\
\hline M IV-3PU50A / B & $0,67 / 0,81$ & $1,846 / 1,850$ & $7,4 / 6,2$ & 0,546 / & 0,546 \\
\hline M IV-3PU75A / B & $0,67 / 0,89$ & $1,630 / 1,609$ & $11,5 / 7,4$ & 0,479 / & 0,497 \\
\hline M IV-3PU100A / B & $0,67 / 0,99$ & $1,254 / 1,528$ & $16,5 / 12,0$ & $0,441 /$ & 0,393 \\
\hline M IV-4R & 0,84 & 2,107 & 4,5 & \multicolumn{2}{|c|}{0,677} \\
\hline M IV-4PU25A / B & $0,80 / 0,98$ & $1,991 / 1,946$ & $5,6 / 5,0$ & 0,598 / & 0,613 \\
\hline M IV-4PU50A / B & $0,77 / 0,83$ & $1,850 / 1,855$ & $8,0 / 5,6$ & $0,515 /$ & 0,455 \\
\hline M IV-4PU75A / B & $0,80 / 1,20$ & $1,586 / 1,530$ & $13,0 / 8,1$ & $0,441 /$ & 0,488 \\
\hline M IV-4PU100A / B & $0,88 / 1,60$ & $1,245 / 1,186$ & $17,5 / 13,0$ & $0,391 /$ & 0,478 \\
\hline M IV-6R & 1,05 & 2,095 & 3,8 & \multicolumn{2}{|c|}{0,673} \\
\hline M IV-6PU25A / B & $1,13 / 1,31$ & $1,999 / 1,948$ & $5,0 / 5,4$ & 0,573 / & 0,587 \\
\hline M IV-6PU50A / B & $1,22 / 1,64$ & $1,749 / 1,732$ & $9,6 / 5,5$ & $0,513 /$ & 0,525 \\
\hline M IV-6PU75A / B & $1,43 / 2,14$ & 1,399/1,389 & $16,0 / 7,4$ & $0,475 /$ & 0,508 \\
\hline M IV-6PU100A / B & $1,30 / 2,16$ & $1,013 / 1,116$ & $30,0 / 11,0$ & $0,411 /$ & 0,441 \\
\hline
\end{tabular}


Las densidades en fresco de los morteros con agregados de PUR disminuyen con la cantidad de polímero. Obviamente la baja densidad del PUR influye decisivamente en este parámetro. No se aprecian diferencias notables en las densidades del mortero fresco entre dosificaciones homólogas de las dos espumas. El aumento en espuma implica un aumento del aire ocluido del mortero fresco. Esto es debido a la propia porosidad del agregado y a la dificultad de la compactación del mortero, pues el bajo peso de las partículas de PUR no facilita la reordenación de los componentes del mortero por efecto de la gravedad.

Por ello, el aumento del porcentaje en contenido de aire es muy poco significativo en los morteros con sustitución baja de arena, pues en esos casos la propia densidad del mortero, relativamente elevada, mejora la compactación por gravedad.

La diferencia de aire ocluido entre los morteros homólogos de agregados "A" y "B", es bastante significativa. Con densidades en fresco similares se observa que en general, el aire ocluido de los morteros con agregado tipo "A" es mayor que con los agregados del tipo "B", llegando en algunos casos a porcentajes del doble de aire ocluido. Esto se comprueba comparando las cantidades en litros de pasta cementosa por $\mathrm{m}^{3}$ de mortero, que son mayores en los morteros con PUR "B" que en sus homólogos con PUR "A".

Como ejemplo ilustrativo se muestra la Figura 4.1, que relaciona la densidad en fresco y el aire ocluido en los morteros de CEM IV. Los morteros con agregado de PUR "A" tienen menos densidad y más aire ocluido que sus homólogos con agregado de PUR "B". También se observa que la relación entre densidad en fresco y aire ocluido es constante en mezclas con PUR "A", mientras que es más dispersa en los morteros con PUR "B". 


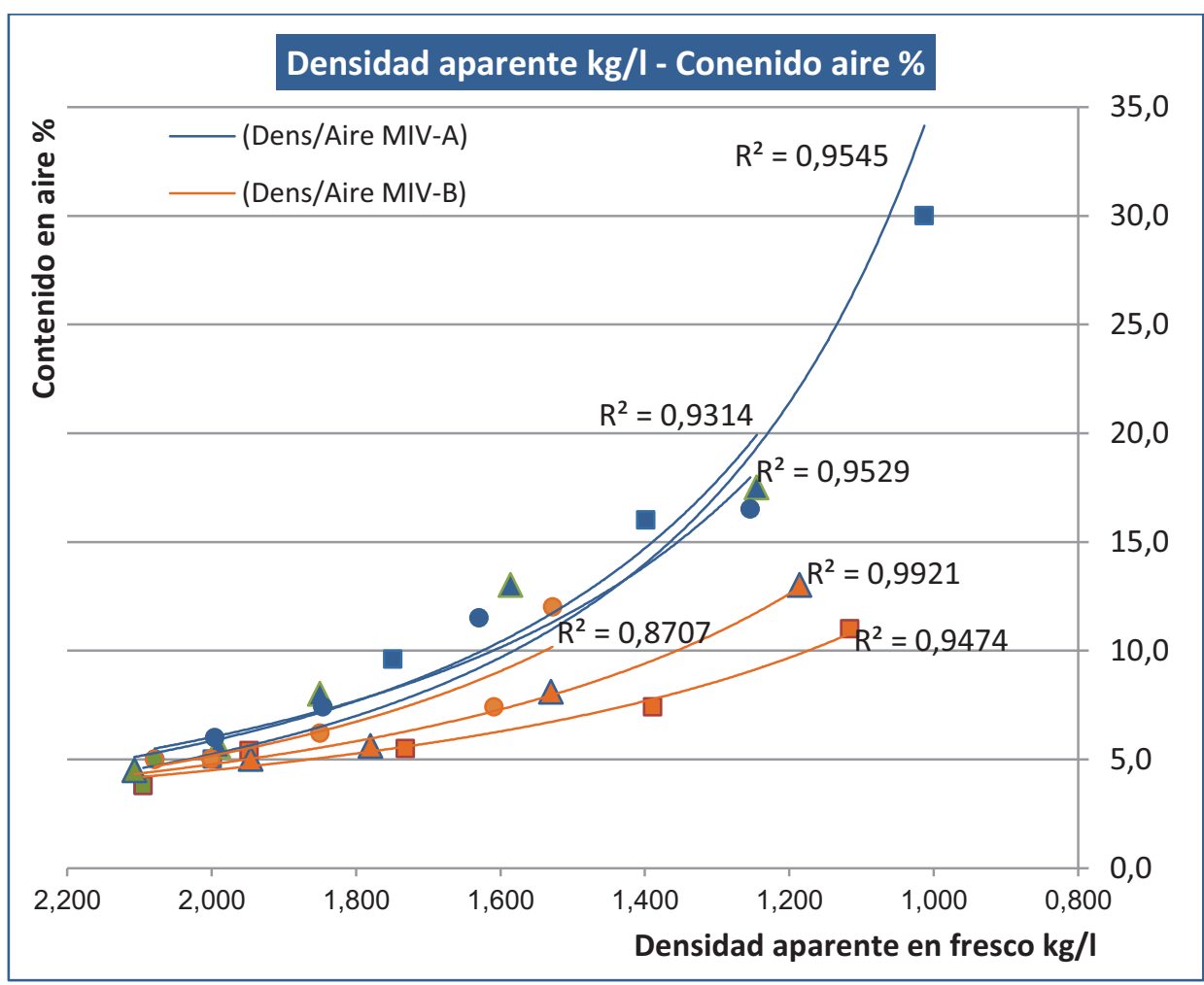

Figura 4.1. Relación densidad/contenido de aire de los morteros con CEM IV

\subsection{2.- Mortero endurecido}

Las normas europeas EN (998-1 y 998-2) de especificaciones de los morteros para albañilería evalúan las prestaciones de los morteros una vez puestos en obra y en servicio. De acuerdo con esto, los morteros se clasifican en función de su resistencia a compresión, absorción de agua por capilaridad y conductividad térmica.

La absorción de agua por capilaridad para un mortero de uso corriente "GP" no es una exigencia; para los morteros de juntas tampoco es un requerimiento, aunque su valor debe ser declarado por el fabricante. La conductividad térmica solo se evalúa para los morteros sometidos a requisitos térmicos. Por esta razón, la aptitud inicial de servicio de los morteros se determina solo a través de las resistencias mecánicas, que también son un índice de su durabilidad. Además se ha determinado la densidad aparente de todas las muestras. 


\subsubsection{1.- Densidad aparente}

La densidad aparente del mortero endurecido, Norma UNE-EN 1015-10, depende la densidad de sus componentes por separado y de su compactación. Por comparación con la densidad aparente del mortero seco se puede determinar la cantidad de agua evaporada, es decir, el agua destinada exclusivamente para el amasado, que no se combina con el cemento; también servirá para conocer la cantidad de agua que hidrata el cemento.

De las Tablas 4.21 a 4.26 se muestra una comparativa de las densidades de los morteros frescos y endurecidos con una estimación porcentual de la pérdida de densidad, que es un indicador del agua de amasado que se ha evaporado.

Tabla 4.21. Densidades de morteros frescos y endurecidos. Cem I. PUR "A"

\begin{tabular}{|c|c|c|c|c|c|}
\hline Mortero & W/C & $\begin{array}{l}\text { Densidad } \\
\text { fresco }\end{array}$ & $\begin{array}{l}\text { Densidad } \\
7 \text { días }\end{array}$ & $\begin{array}{l}\text { Densidad } \\
28 \text { días }\end{array}$ & $\begin{array}{c}\text { Variación } \\
28 \text { días/fresco }\end{array}$ \\
\hline & & kg/l & kg/l & $\mathrm{kg} / \mathrm{l}$ & $\%$ \\
\hline M I-3R & 0,73 & 2,123 & 2,100 & 2,035 & $-4,1$ \\
\hline M I-3PU25A & 0,71 & 2,012 & 1,783 & 1,678 & $-16,6$ \\
\hline M I-3PU50A & 0,67 & 1,892 & 1,658 & 1,550 & $-18,1$ \\
\hline M II-3PU75A & 0,63 & 1,687 & 1,489 & 1,311 & $-22,3$ \\
\hline M I-3PU100A & 0,62 & 1,439 & 1,310 & 1,250 & $-13,1$ \\
\hline M I-4R & 0,95 & 2,096 & 2,030 & 2,008 & $-4,2$ \\
\hline M I-4PU25A & 0,84 & 2,011 & 1,765 & 1,631 & $-18,9$ \\
\hline M I-4PU50A & 0,78 & 1,878 & 1,690 & 1,520 & $-19,1$ \\
\hline M I-4PU75A & 0,77 & 1,532 & 1,325 & 1,168 & $-23,8$ \\
\hline M I-4PU100A & 0,90 & 1,251 & 1,110 & 0,917 & $-26,7$ \\
\hline M I-6R & 1,30 & 2,045 & 1,998 & 1,996 & $-2,4$ \\
\hline M I-6PU25A & 1,15 & 1,987 & 1,880 & 1,545 & $-22,2$ \\
\hline M I-6PU50A & 1,20 & 1,792 & 1,677 & 1,465 & $-18,2$ \\
\hline M I-6PU75A & 1,40 & 1,433 & 1,240 & 1,005 & $-29,9$ \\
\hline M I-6PU100A & 1,45 & 1,089 & 0,854 & 0,734 & $-32,6$ \\
\hline
\end{tabular}


Tabla 4.22. Densidades de morteros frescos y endurecidos. Cem II. PUR "A"

\begin{tabular}{|l|c|c|c|c|c|}
\hline \multicolumn{1}{|c|}{ Mortero } & W/C & $\begin{array}{c}\text { Densidad } \\
\text { fresco }\end{array}$ & $\begin{array}{c}\text { Densidad } \\
7 \text { días }\end{array}$ & $\begin{array}{c}\text { Densidad } \\
28 \text { días }\end{array}$ & $\begin{array}{c}\text { Variación } \\
\text { dias/fresco }\end{array}$ \\
\hline M II-3R & 0,68 & 2,122 & 2,106 & 2,097 & kg/l \\
\hline M II-3PU25A & 0,67 & 2,030 & 1,825 & 1,667 & $-1,2$ \\
\hline M II-3PU50A & 0,70 & 1,870 & 1,691 & 1,521 & $-18,7$ \\
\hline M II-3PU75A & 0,70 & 1,646 & 1,550 & 1,326 & $-19,4$ \\
\hline M II-3PU100A & 0,78 & 1,310 & 0,925 & 0,675 & $-48,5$ \\
\hline M II-4R & 0,89 & 2,100 & 2,004 & 1,980 & $-5,7$ \\
\hline M II-4PU25A & 0,84 & 1,993 & 1,640 & 1,445 & $-27,5$ \\
\hline M II-4PU50A & 0,84 & 1,825 & 1,489 & 1,339 & $-26,6$ \\
\hline M II-4PU75A & 0,89 & 1,630 & 1,440 & 1,176 & $-27,9$ \\
\hline M II-4PU100A & 1,24 & 1,120 & 0,868 & 0,625 & $-44,2$ \\
\hline M II-6R & 1,27 & 2,038 & 1,999 & 1,900 & $-6,8$ \\
\hline M II-6PU25A & 1,20 & 2,010 & 1,691 & 1,389 & $-30,9$ \\
\hline M II-6PU50A & 0,88 & 1,795 & 1,678 & 1,234 & $-31,3$ \\
\hline M II-6PU75A & 1,32 & 1,425 & 1,301 & 1,086 & $-23,8$ \\
\hline M II-6PU100A & 1,39 & 0,927 & 0,865 & 0,590 & $-36,4$ \\
\hline
\end{tabular}

Tabla 4.23. Densidades de morteros frescos y endurecidos. Cem IV. PUR "A"

\begin{tabular}{|l|c|c|c|c|c|}
\hline \multicolumn{1}{|c|}{ Mortero } & W/C & $\begin{array}{c}\text { Densidad } \\
\text { fresco }\end{array}$ & $\begin{array}{c}\text { Densidad } \\
7 \text { dias }\end{array}$ & $\begin{array}{c}\text { Densidad } \\
28 \text { dias }\end{array}$ & $\begin{array}{c}\text { Variación } \\
28 \text { dias/fresco }\end{array}$ \\
\hline M IV-3R & 0,70 & 2,079 & 1,957 & 1,896 & $-8,8$ \\
\hline M IV-3PU25A & 0,68 & 1,996 & 1,896 & 1,645 & $-17,6$ \\
\hline M IV-3PU50A & 0,67 & 1,846 & 1,791 & 1,568 & $-15,1$ \\
\hline M IV-3PU75A & 0,67 & 1,630 & 1,487 & 1,397 & $-14,3$ \\
\hline M IV-3PU100A & 0,67 & 1,254 & 1,126 & 1,098 & $-12,4$ \\
\hline M IV-4R & 0,84 & 2,107 & 2,068 & 2,005 & $-4,8$ \\
\hline M IV-4PU25A & 0,80 & 1,991 & 1,763 & 1,601 & $-19,6$ \\
\hline M IV-4PU50A & 0,77 & 1,850 & 1,680 & 1,489 & $-19,5$ \\
\hline M IV-4PU75A & 0,60 & 1,586 & 1,290 & 1,098 & $-30,8$ \\
\hline M IV-4PU10A & 0,88 & 1,245 & 1,083 & 0,897 & $-28,0$ \\
\hline M IV-6R & 1,05 & 2,095 & 2,009 & 1,990 & $-5,0$ \\
\hline M IV-6PU25A & 1,13 & 1,999 & 1,712 & 1,548 & $-22,6$ \\
\hline M IV-6PU50A & 1,22 & 1,749 & 1,654 & 1,312 & $-25,0$ \\
\hline M IV-6PU75A & 1,43 & 1,399 & 1,267 & 0,987 & $-29,4$ \\
\hline M IV-6PU100A & 1,30 & 1,013 & 0,999 & 0,901 & $-11,1$ \\
\hline
\end{tabular}


Tabla 4.24. Densidades de morteros frescos y endurecidos. Cem I. PUR "B"

\begin{tabular}{|l|c|c|c|c|c|}
\hline \multicolumn{1}{|c|}{ Mortero } & W/C & $\begin{array}{c}\text { Densidad } \\
\text { fresco }\end{array}$ & $\begin{array}{c}\text { Densidad } \\
7 \text { dias }\end{array}$ & $\begin{array}{c}\text { Densidad } \\
28 \text { dias }\end{array}$ & $\begin{array}{c}\text { Variación } \\
\text { kg/lias/fresco }\end{array}$ \\
\hline M I-3R & 0,73 & 2,123 & 2,100 & 2,035 & $-4,1$ \\
\hline M I-3PU25B & 0,75 & 2,026 & 1,997 & 1,887 & $-6,9$ \\
\hline M I-3PU50B & 0,69 & 1,912 & 1,879 & 1,806 & $-5,5$ \\
\hline M I-3PU75B & 0,64 & 1,769 & 1,691 & 1,657 & $-6,3$ \\
\hline M I-3PU100B & 0,64 & 1,499 & 1,467 & 1,273 & $-15,1$ \\
\hline M I-4R & 0,95 & 2,096 & 2,030 & 2,008 & $-4,2$ \\
\hline M I-4PU25B & 0,87 & 1,999 & 1,940 & 1,867 & $-6,6$ \\
\hline M I-4PU50B & 0,98 & 1,853 & 1,878 & 1,678 & $-9,4$ \\
\hline M I-4PU75B & 1,02 & 1,631 & 1,564 & 1,445 & $-11,4$ \\
\hline M I-4PU100B & 1,28 & 1,272 & 0,888 & 0,769 & $-39,5$ \\
\hline M I-6R & 1,30 & 2,045 & 1,998 & 1,996 & $-2,4$ \\
\hline M I-6PU25B & 1,20 & 1,927 & 1,860 & 1,780 & $-7,6$ \\
\hline M I-6PU50B & 1,63 & 1,756 & 1,504 & 1,542 & $-12,2$ \\
\hline M I-6PU75B & 1,83 & 1,449 & 1,181 & 1,159 & $-20,0$ \\
\hline M I-6PU100B & 2,24 & 1,136 & 0,768 & 0,625 & $-45,0$ \\
\hline
\end{tabular}

Tabla 4.25. Densidades de morteros frescos y endurecidos. Cem II. PUR "B"

\begin{tabular}{|l|c|c|c|c|c|}
\hline \multicolumn{1}{|c|}{ Mortero } & W/C & $\begin{array}{c}\text { Densidad } \\
\text { fresco }\end{array}$ & $\begin{array}{c}\text { Densidad } \\
7 \text { dias }\end{array}$ & $\begin{array}{c}\text { Densidad } \\
28 \text { dias }\end{array}$ & $\begin{array}{c}\text { Variación } \\
\text { kg/l }\end{array}$ \\
\hline M II-3R & 0,68 & 2,122 & 2,106 & 2,097 & /fresco \\
\hline M II-3PU25B & 0,71 & 2,024 & 1,970 & 1,954 & $-1,2$ \\
\hline M II-3PU50B & 0,76 & 1,880 & 1,840 & 1,813 & $-3,6$ \\
\hline M II-3PU75B & 0,83 & 1,668 & 1,570 & 1,501 & $-10,0$ \\
\hline M II-3PU100B & 0,92 & 1,371 & 1,290 & 1,212 & $-11,6$ \\
\hline M II-4R & 0,89 & 2,100 & 2,004 & 1,980 & $-5,7$ \\
\hline M II-4PU25B & 0,88 & 2,020 & 1,977 & 1,888 & $-6,5$ \\
\hline M II-4PU50B & 0,89 & 1,792 & 1,730 & 1,629 & $-9,1$ \\
\hline M II-4PU75B & 1,31 & 1,512 & 1,476 & 1,287 & $-14,9$ \\
\hline M II-4PU100B & 1,36 & 1,232 & 1,190 & 1,054 & $-14,4$ \\
\hline M II-6R & 1,27 & 2,038 & 1,999 & 1,900 & $-6,8$ \\
\hline M II-6PU25B & 1,46 & 1,922 & 1,862 & 1,881 & $-2,1$ \\
\hline M II-6PU50B & 1,41 & 1,786 & 1,640 & 1,537 & $-13,9$ \\
\hline M II-6PU75B & 1,52 & 1,537 & 1,388 & 1,230 & $-20,0$ \\
\hline M II-6PU100B & 1,82 & 1,178 & 0,960 & 0,711 & $-39,6$ \\
\hline
\end{tabular}


Tabla 4.26. Densidades de morteros frescos y endurecidos. Cem IV. PUR "B"

\begin{tabular}{|l|c|c|c|c|c|}
\hline \multicolumn{1}{|c|}{ Mortero } & W/C & $\begin{array}{c}\text { Densidad } \\
\text { fresco }\end{array}$ & $\begin{array}{c}\text { Densidad } \\
7 \text { dias }\end{array}$ & $\begin{array}{c}\text { Densidad } \\
28 \text { dias }\end{array}$ & $\begin{array}{c}\text { Variación } \\
\text { kías/fresco }\end{array}$ \\
\hline M IV-3R & 0,70 & 2,079 & 1,957 & 1,896 & $-8,8$ \\
\hline M IV-3PU25B & 0,70 & 2,001 & 1,940 & 1,905 & $-4,8$ \\
\hline M IV-3PU50B & 0,81 & 1,850 & 1,765 & 1,500 & $-18,9$ \\
\hline M IV-3PU75B & 0,89 & 1,609 & 1,534 & 1,099 & $-31,7$ \\
\hline M IV-3PU100B & 0,99 & 1,528 & 1,190 & 0,810 & $-47,0$ \\
\hline M IV-4R & 0,84 & 2,107 & 2,068 & 2,005 & $-4,8$ \\
\hline M IV-4PU25B & 0,98 & 1,946 & 1,850 & 1,830 & $-6,0$ \\
\hline M IV-4PU50B & 0,83 & 1,855 & 1,680 & 1,610 & $-13,2$ \\
\hline M IV-4PU75B & 1,21 & 1,530 & 1,380 & 1,260 & $-17,6$ \\
\hline M IV-4PU100B & 1,56 & 1,186 & 1,130 & 0,803 & $-32,3$ \\
\hline M IV-6R & 1,05 & 2,095 & 2,009 & 1,990 & $-5,0$ \\
\hline M IV-6PU25B & 1,31 & 1,948 & 1,838 & 1,770 & $-9,1$ \\
\hline M IV-6PU50B & 1,64 & 1,732 & 1,679 & 1,420 & $-18,0$ \\
\hline M IV-6PU75B & 2,14 & 1,389 & 1,215 & 1,010 & $-27,3$ \\
\hline M IV-6PU100B & 2,16 & 1,116 & 1,099 & 0,780 & $-30,1$ \\
\hline
\end{tabular}

Las diferencias porcentuales entre la densidad en fresco y a los 28 días nos muestran que el agua evaporada deja en su lugar un vacío ocupado por aire. Una disminución grande de la densidad aparente del mortero endurecido indica una porosidad elevada y una cantidad de agua de amasado muy superior a la mínima necesaria para hidratar el cemento.

En general, la densidad en el estado endurecido es inversamente proporcional al contenido de espuma, ya que a mayor cantidad de agregado de PUR, mayor demanda de agua para conseguir la plasticidad adecuada. Este exceso de agua provoca, al evaporarse, más porosidad y en consecuencia un descenso más notable en la densidad aparente. También y salvo excepciones, se produce el mismo efecto cuando se incrementa la relación en peso entre el agua y el cemento, si bien este aumento en la relación W/C es consecuencia de la mayor cantidad de agua que requiere el polímero.

De todas las muestras ensayadas, hay 30 muestras cuya densidad se encuentra por debajo de $1,3 \mathrm{~kg} / \mathrm{l}$, por lo que esos morteros se pueden considerar como "Mortero para revoco/enlucido ligero (LW)", de acuerdo con la norma EN 998-1, y como "Mortero para albañilería ligero (L)", según 
norma EN 998-2. De los 30 morteros con agregados de PUR considerados como morteros ligeros, existen 20 morteros cuya densidad es inferior a 1,1 $\mathrm{kg} / \mathrm{l}$.

\subsubsection{2.- Resistencias mecánicas}

Se utilizan probetas prismáticas de 40,0 x 40,0 x 160,0 mm que se rompen inicialmente en dos trozos a flexotracción y que posteriormente se ensayan a compresión según la norma UNE-EN 1015-11.

Las normas de los morteros para albañilería exigen como requisito una resistencia mínima a compresión a los 28 días y, aunque la determinación de las resistencias a los 7 días no está normalizada, resulta un parámetro importante en todos los morteros que se emplean en enfoscados y en juntas, ya que el ritmo acelerado de algunas obras de construcción puede exigir unas resistencias mínimas a flexión y compresión a edades tempranas.

\subsubsection{1.- Resistencia a flexión}

La resistencia a flexión es un parámetro que no se tiene en cuenta a la hora de clasificar los morteros. Es necesario advertir que la resistencia a flexión del mortero endurecido es un indicativo muy importante de su durabilidad, pues a los esfuerzos de flexión a que están sometidos tanto los morteros de juntas como los de revestimiento, por ser parte inseparable de los soportes en que están colocados, hay que añadir los esfuerzos de flexión derivados de agentes externos, especialmente climatológicos, como son los ciclos de humedad-sequedad, hielo-deshielo, calor-frío, etc.

\subsubsection{2.- Resistencia a compresión}

El valor de la resistencia a compresión exigida para los morteros de uso corriente, varía de $0,4 \mathrm{~N} / \mathrm{mm}^{2}$ a $7,5 \mathrm{~N} / \mathrm{mm}^{2}$, admitiéndose también valores superiores. En los morteros para albañilería (EN 998-2), es decir, los morteros para trabazón de fábricas, la resistencia mínima a compresión debe ser superior a $1 \mathrm{~N} / \mathrm{mm}^{2}$. El valor de $1 \mathrm{~N} / \mathrm{mm}^{2}$ es un valor muy bajo, fácil de alcanzar incluso en dosificaciones de relación 1/10 de cemento y arena, por lo que debemos considerar la resistencia a compresión del mortero endurecido, más como un indicativo de la durabilidad que como un 
parámetro de aptitud, exceptuando los morteros de juntas para fábricas resistentes.

En las Tablas 4.27 a 4.32 se relacionan las resistencias a flexión y compresión, a 7 y 28 días, y el contenido de cemento por metro cúbico de mortero.

Tabla 4.27. Resistencias flexión-compresión 7-28 días. Morteros CEM I. PUR "A"

\begin{tabular}{|l|c|c|c|c|c|}
\hline \multicolumn{1}{|c|}{ Mortero } & Cemento & \multicolumn{3}{|c|}{ Resistencia Flexión } & \multicolumn{2}{|c|}{ Resistencia Compresion } \\
\hline & $\mathrm{kg} / \mathrm{m}^{3}$ & \multicolumn{2}{|c|}{ Mpa } & \multicolumn{2}{|c|}{ Mpa } \\
\hline M I-3R & 448,6 & 5,00 & 5,28 & 15,90 & 23,69 \\
\hline M I-3PU25A & 504,9 & 3,37 & 3,62 & 14,90 & 18,01 \\
\hline M I-3PU50A & 587,8 & 2,84 & 4,88 & 12,90 & 20,56 \\
\hline M I-3PU75A & 687,1 & 2,80 & 3,39 & 12,80 & 16,00 \\
\hline M I-3PU100A & 838,0 & 1,82 & 2,10 & 7,19 & 10,23 \\
\hline M I-4R & 352,2 & 3,45 & 5,28 & 10,76 & 18,02 \\
\hline M I-4PU25A & 412,7 & 3,38 & 4,85 & 9,28 & 18,23 \\
\hline M I-4PU50A & 488,3 & 3,40 & 4,59 & 13,11 & 17,63 \\
\hline M I-4PU75A & 535,0 & 3,00 & 3,12 & 10,22 & 14,16 \\
\hline M I-4PU100A & 616,3 & 1,03 & 1,40 & 3,65 & 5,44 \\
\hline M I-6R & 246,5 & 3,24 & 2,88 & 9,84 & 11,19 \\
\hline M I-6PU25A & 296,6 & 2,51 & 3,07 & 7,55 & 10,64 \\
\hline M I-6PU50A & 338,3 & 2,40 & 2,41 & 5,21 & 7,89 \\
\hline M I-6PU75A & 354,2 & 2,29 & 1,62 & 3,85 & 4,21 \\
\hline M I-6PU100A & 412,5 & 0,61 & 0,74 & 1,52 & 1,78 \\
\hline
\end{tabular}


Tabla 4.28. Resistencias flexión-compresión 7-28 días. Morteros CEM II. PUR "A"

\begin{tabular}{|c|c|c|c|c|c|}
\hline \multirow[t]{3}{*}{ Mortero } & \multirow{3}{*}{$\begin{array}{l}\text { Cemento } \\
\mathrm{kg} / \mathrm{m}^{3}\end{array}$} & \multicolumn{2}{|c|}{ Res istencia Flexión } & \multicolumn{2}{|c|}{ Resistencia Compresión } \\
\hline & & \multicolumn{2}{|c|}{ Mpa } & \multicolumn{2}{|c|}{ Mpa } \\
\hline & & 7 días & 28 días & 7 días & 28 días \\
\hline M II-3R & 453,0 & 5,41 & 6,06 & 16,13 & 19,34 \\
\hline M II-3PU25A & 515,0 & 3,09 & 3,99 & 10,73 & 14,86 \\
\hline M II-3PU50A & 575,4 & 3,01 & 3,52 & 8,52 & 15,83 \\
\hline M II-3PU75A & 652,4 & 4,58 & 3,26 & 4,36 & 19,34 \\
\hline M II-3PU100A & 699,6 & 1,26 & 0,46 & 2,01 & 1,17 \\
\hline M II-4R & 356,3 & 2,25 & 3,38 & 7,61 & 11,67 \\
\hline M II-4PU25A & 409,0 & 1,42 & 2,05 & 4,45 & 6,32 \\
\hline M II-4PU50A & 467,4 & 1,80 & 1,92 & 6,54 & 7,01 \\
\hline M II-4PU75A & 546,4 & 1,76 & 1,90 & 4,55 & 6,15 \\
\hline M II-4PU100A & 470,6 & 0,58 & 0,65 & 1,32 & 1,56 \\
\hline M II-6R & 246,5 & 2,05 & 3,22 & 5,02 & 8,75 \\
\hline M II-6PU25A & 297,8 & 1,26 & 1,32 & 4,21 & 5,01 \\
\hline M II-6PU50A & 360,6 & 1,16 & 1,15 & 3,00 & 3,22 \\
\hline M II-6PU75A & 363,8 & 1,88 & 1,06 & 5,90 & 2,98 \\
\hline M II-6PU100A & 358,2 & 0,25 & 0,56 & 1,01 & 0,89 \\
\hline
\end{tabular}

Tabla 4.29. Resistencias flexión-compresión 7-28 días. Morteros CEM IV. PUR "A"

\begin{tabular}{|c|c|c|c|c|c|}
\hline \multirow[t]{3}{*}{ Mortero } & \multirow{3}{*}{$\begin{array}{c}\text { Cemento } \\
\mathrm{kg} / \mathrm{m}^{3}\end{array}$} & \multicolumn{2}{|c|}{ Resistencia Flexión } & \multicolumn{2}{|c|}{ Resistencia Compresión } \\
\hline & & \multicolumn{2}{|c|}{ Mpa } & \multicolumn{2}{|c|}{ Mpa } \\
\hline & & 7 días & 28 días & 7 días & 28 días \\
\hline M IV-3R & 442,3 & 3,85 & 4,05 & 12,21 & 12,40 \\
\hline M IV-3PU25A & 504,3 & 3,65 & 3,92 & 10,96 & 11,08 \\
\hline M IV-3PU50A & 574,2 & 3,01 & 3,87 & 9,89 & 10,76 \\
\hline M IV-3PU75A & 653,9 & 2,36 & 3,05 & 6,36 & 9,65 \\
\hline M IV-3PU100A & 709,6 & 1,05 & 1,12 & 3,58 & 3,98 \\
\hline M IV-4R & 360,8 & 2,65 & 3,79 & 8,33 & 9,36 \\
\hline M IV-4PU25A & 412,1 & 1,79 & 2,60 & 6,20 & 8,44 \\
\hline M IV-4PU50A & 482,3 & 1,31 & 2,01 & 4,40 & 5,80 \\
\hline M IV-4PU75A & 587,1 & 0,34 & 2,32 & 4,96 & 7,91 \\
\hline M IV-4PU100A & 619,0 & 0,25 & 1,31 & 2,60 & 6,98 \\
\hline M IV-6R & 248,6 & 1,03 & 1,30 & 3,81 & 6,01 \\
\hline M IV-6PU25A & 299,2 & 1,69 & 1,99 & 4,89 & 5,32 \\
\hline M IV-6PU50A & 328,7 & 1,11 & 1,39 & 4,02 & 5,01 \\
\hline M IV-6PU75A & 343,3 & 1,01 & 1,15 & 3,87 & 4,03 \\
\hline M IV-6PU100A & 405,6 & 0,67 & 0,80 & 1,96 & 2,06 \\
\hline
\end{tabular}


Tabla 4.30. Resistencias flexión-compresión 7-28 días. Morteros CEM I. PUR "B"

\begin{tabular}{l|l|l|l} 
Mortero & Cemento & RESISTENCIA FLEXIÓN RESISTENCIA COMPRESIÓN
\end{tabular}

\begin{tabular}{|l|c|c|c|c|c|}
\hline & $\mathrm{kg} / \mathrm{m}^{3}$ & \multicolumn{2}{|c|}{ M pa } & \multicolumn{2}{|c|}{ Mpa } \\
\hline M I-3R & 448,6 & 5,00 & 5,28 & 15,90 & 23,69 \\
\hline M I-3PU25B & 502,4 & 4,93 & 7,79 & 19,39 & 24,04 \\
\hline M I-3PU50B & 587,4 & 3,23 & 5,51 & 18,83 & 22,50 \\
\hline M I-3PU75B & 711,5 & 3,29 & 5,38 & 15,20 & 20,23 \\
\hline M I-3PU100B & 847,7 & 2,52 & 3,52 & 8,27 & 12,29 \\
\hline M I-4R & 352,2 & 3,45 & 5,28 & 10,76 & 18,02 \\
\hline M I-4PU25B & 406,7 & 2,76 & 5,31 & 3,46 & 19,65 \\
\hline M I-4PU50B & 455,5 & 2,06 & 5,02 & 2,32 & 17,98 \\
\hline M I-4PU75B & 517,9 & 0,98 & 4,15 & 2,28 & 15,65 \\
\hline M I-4PU100B & 518,1 & 0,71 & 0,48 & 2,23 & 1,04 \\
\hline M I-6R & 246,5 & 3,24 & 2,88 & 9,84 & 11,19 \\
\hline M I-6PU25B & 284,7 & 2,11 & 2,55 & 4,87 & 10,11 \\
\hline M I-6PU50B & 305,2 & 0,99 & 1,49 & 3,29 & 3,37 \\
\hline M I-6PU75B & 320,2 & 0,59 & 0,97 & 1,59 & 2,18 \\
\hline M I-6PU100B & 324,2 & 0,32 & 0,96 & 0,67 & 0,82 \\
\hline
\end{tabular}

Tabla 4.31. Resistencias flexión-compresión 7-28 días. Morteros CEM II. PUR “B”

\begin{tabular}{|l|c|c|c|c|c|}
\hline \multicolumn{1}{|c|}{ Mortero } & Cemento & \multicolumn{2}{|c|}{ Resistencia Flexión } & \multicolumn{2}{c|}{ Resistencia Compresión } \\
\hline & $\mathrm{kg} / \mathrm{m}^{3}$ & \multicolumn{2}{|c|}{ M pa } & \multicolumn{2}{c|}{ M pa } \\
\hline M II-3R & 453,0 & 5,41 & 6,06 & 16,13 & 19,34 \\
\hline M II-3PU25B & 507,2 & 3,35 & 4,79 & 13,29 & 21,05 \\
\hline M II-3PU50B & 566,1 & 2,77 & 3,21 & 10,76 & 13,34 \\
\hline M II-3PU75B & 622,3 & 1,73 & 2,21 & 5,87 & 7,02 \\
\hline M II-3PU100B & 669,8 & 1,15 & 1,45 & 3,35 & 4,12 \\
\hline M II-4R & 356,3 & 2,25 & 3,38 & 7,61 & 11,67 \\
\hline M II-4PU25B & 410,6 & 2,66 & 3,91 & 9,73 & 15,47 \\
\hline M II-4PU50B & 450,4 & 1,75 & 2,23 & 4,94 & 6,39 \\
\hline M II-4PU75B & 439,2 & 0,75 & 1,21 & 1,92 & 3,34 \\
\hline M II-4PU100B & 486,7 & 0,65 & 1,05 & 0,91 & 2,12 \\
\hline M II-6R & 246,5 & 2,05 & 3,22 & 5,02 & 8,75 \\
\hline M II-6PU25B & 273,6 & 1,13 & 2,72 & 3,10 & 10,02 \\
\hline M II-6PU50B & 322,5 & 1,04 & 1,28 & 2,75 & 4,04 \\
\hline M II-6PU75B & 365,2 & 0,72 & 0,95 & 1,72 & 2,86 \\
\hline M II-6PU100B & 382,9 & 0,37 & 0,52 & 0,62 & 1,10 \\
\hline
\end{tabular}


Tabla 4.32. Resistencias flexión-compresión 7-28 días. Morteros CEM II. PUR "B"

\begin{tabular}{|c|c|c|c|c|c|}
\hline \multirow[t]{3}{*}{ Mortero } & \multirow{3}{*}{$\begin{array}{c}\text { Cemento } \\
\mathrm{kg} / \mathrm{m}^{3}\end{array}$} & \multicolumn{2}{|c|}{ Resistencia Flexión } & \multicolumn{2}{|c|}{ Resistencia Compresión } \\
\hline & & \multicolumn{2}{|c|}{ Mpa } & \multicolumn{2}{|c|}{ Mpa } \\
\hline & & 7 días & 28 días & 7 días & 28 días \\
\hline M IV-3R & 442,3 & 3,85 & 4,05 & 12,21 & 12,40 \\
\hline M IV-3PU25B & 502,5 & 3,68 & 4,30 & 10,29 & 18,16 \\
\hline M IV-3PU50B & 547,7 & 2,98 & 2,74 & 7,45 & 8,29 \\
\hline M IV-3PU75B & 588,9 & 1,47 & 1,35 & 4,73 & 4,17 \\
\hline M IV-3PU100B & 722,9 & 0,66 & 1,10 & 1,84 & 1,30 \\
\hline M IV-4R & 360,8 & 2,65 & 3,79 & 8,33 & 9,36 \\
\hline M IV-4PU25B & 387,1 & 1,97 & 2,76 & 5,31 & 11,00 \\
\hline M IV-4PU50B & 473,3 & 1,36 & 2,25 & 3,60 & 7,30 \\
\hline M IV-4PU75B & 458,5 & 0,75 & 1,74 & 1,84 & 4,05 \\
\hline M IV-4PU100B & 434,0 & 0,33 & 0,48 & 0,52 & 1,22 \\
\hline M IV-6R & 248,6 & 1,03 & 1,30 & 3,81 & 6,01 \\
\hline M IV-6PU25B & 283,6 & 1,65 & 1,98 & 4,31 & 5,94 \\
\hline M IV-6PU50B & 300,1 & 1,28 & 1,32 & 3,08 & 3,08 \\
\hline M IV-6PU75B & 287,7 & 0,69 & 0,72 & 2,88 & 3,01 \\
\hline M IV-6PU100B & 326,0 & 0,45 & 0,46 & 1,02 & 1,06 \\
\hline
\end{tabular}

Por otro lado, si representamos los valores de resistencia a compresión a 28 días (Figuras 4.2 a 4.7), se aprecia con claridad cómo disminuyen los valores a medida que se incorporan cantidades mayores de PUR.

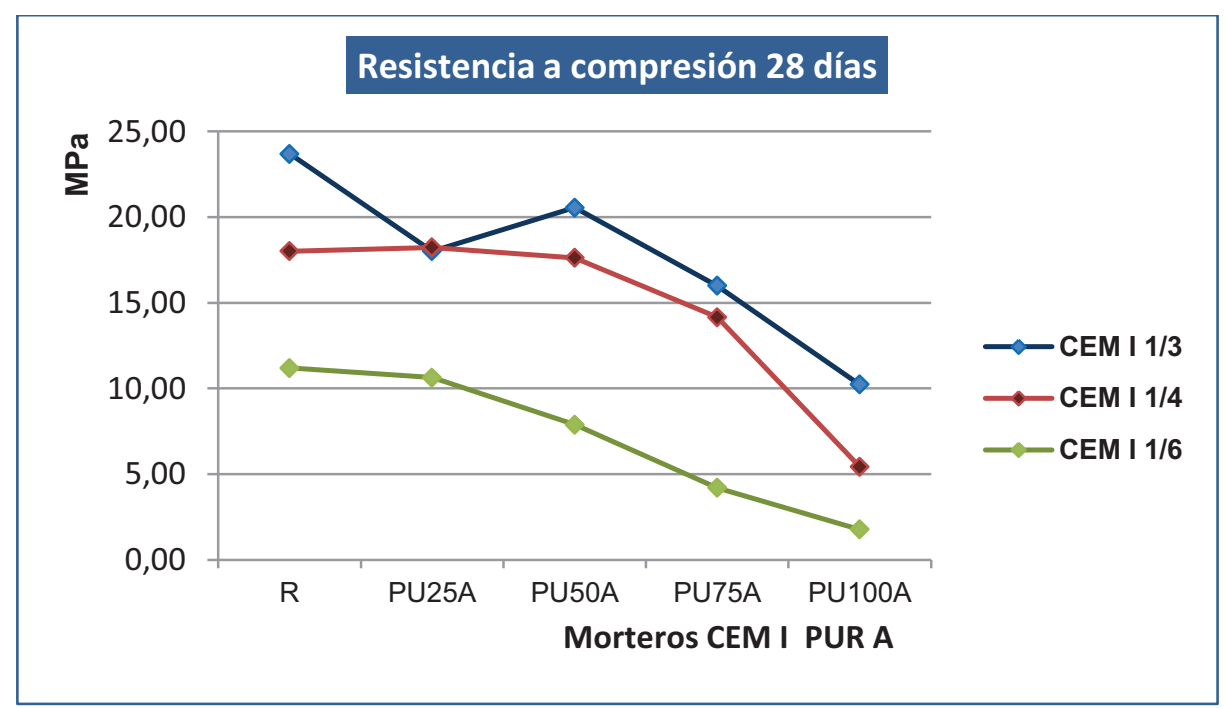

Figura 4.2. Resistencia a compresión a los 28 días. Morteros CEM I. PUR "A" 


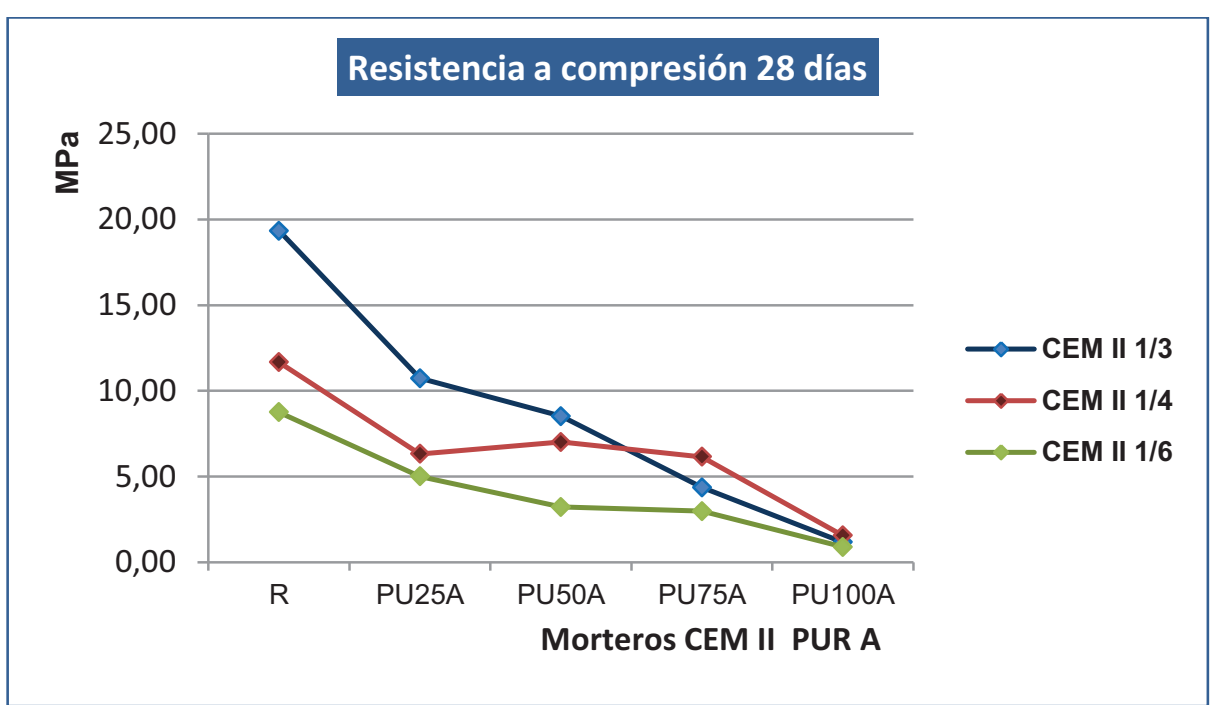

Figura 4.3. Resistencia a compresión a los 28 días. Morteros CEM II. PUR "A"

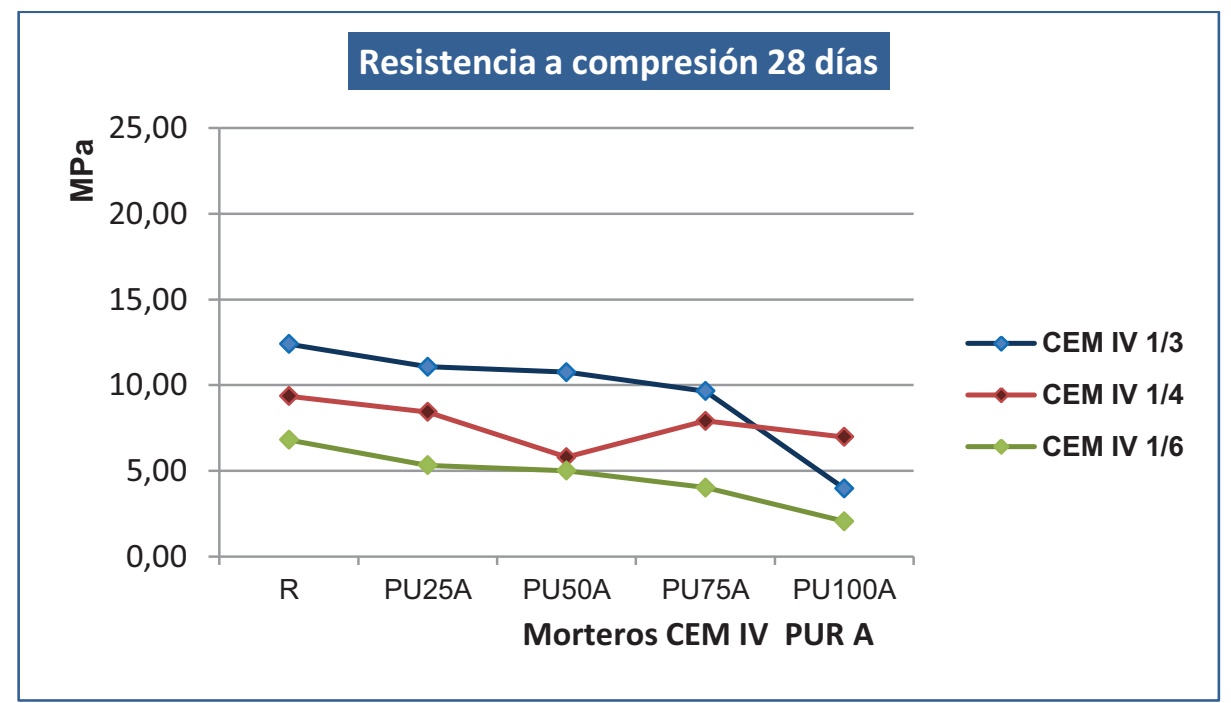

Figura 4.4. Resistencia a compresión a los 28 días. Morteros CEM IV. PUR "A" 


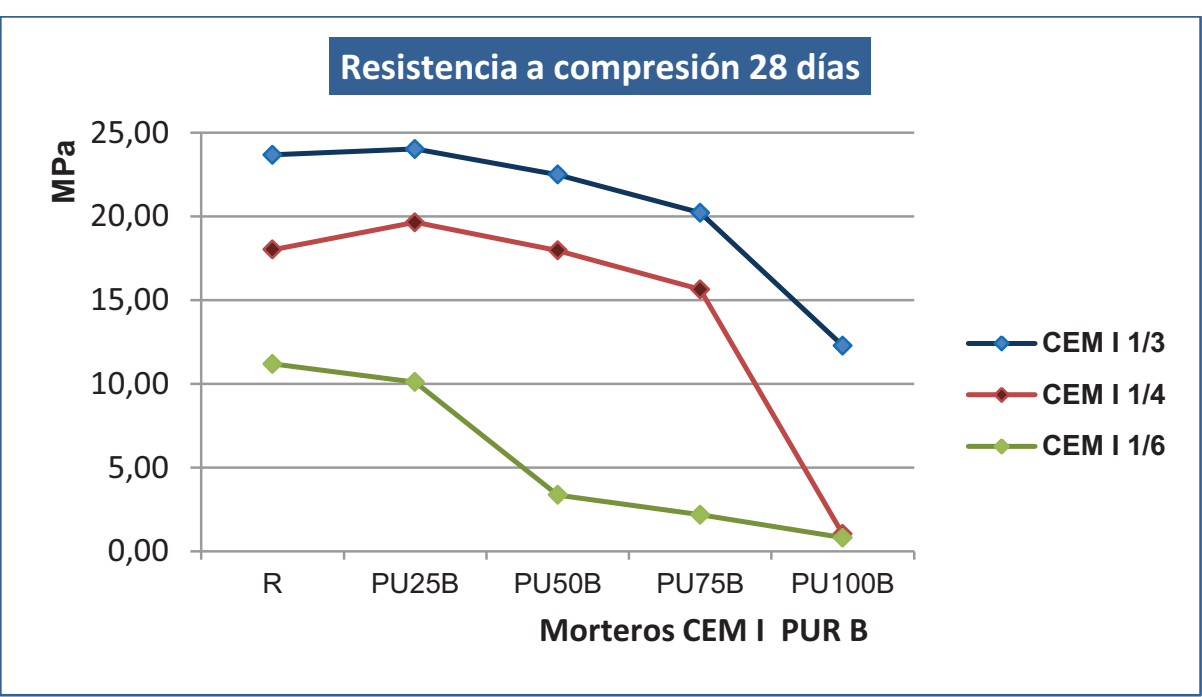

Figura 4.5. Resistencia a compresión a los 28 días. Morteros CEM I. PUR "B”

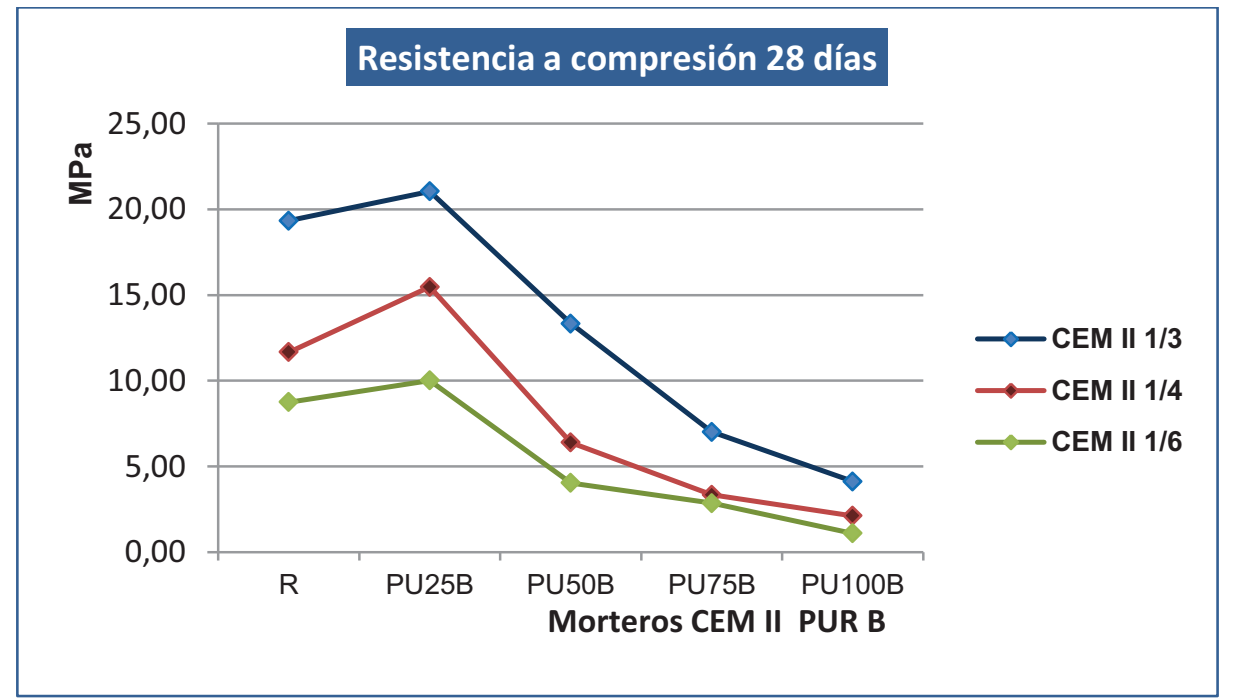

Figura 4.6. Resistencia a compresión a los 28 días. Morteros CEM II. PUR "B" 


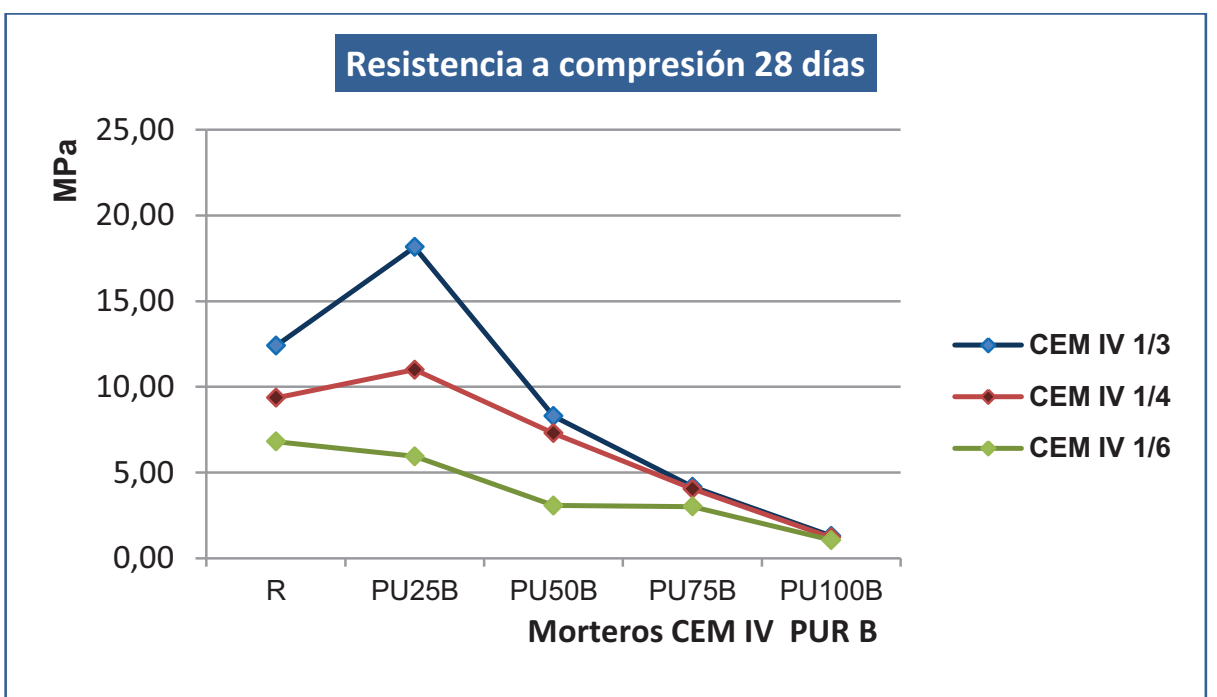

Figura 4.7. Resistencia a compresión a los 28 días. Morteros CEM IV. PUR "B"

En las mezclas con agregado de PUR "A", las resistencias a compresión a los 28 días disminuyen a medida que aumenta el grado de sustitución de arena por espuma. En los morteros con remplazo de arena por el $25 \%$ de agregado de PUR "B", no se aprecia una pérdida de resistencia a compresión, incluso en ocasiones se produce un incremento de la resistencia, posiblemente por el mayor contenido de cemento por metro cubico de mortero, que suple la pérdida de resistencia de la escasa sustitución de espuma.

La disminución de resistencia es más acusada para el CEM II que para los CEM I y CEM IV. El motivo puede ser que el incremento de la cantidad de conglomerante que acompaña al aumento de espuma, es menor para el CEM II lo que indicaría que el CEM II produce morteros más trabajables y necesita menos cantidad de conglomerante. La pérdida más importante de resistencias mecánicas se produce en todos los casos y como era de esperar, en las mezclas con sustitución del $75 \%$ y del $100 \%$.

En un mortero con poca cantidad de arena y gran cantidad de agregado de PUR, la estructura resistente del mortero, que también es más rica en cemento, presenta una mayor discontinuidad por la abundancia de espuma (material poco resistente) y la ausencia de arena (esqueleto del mortero), lo que crea planos muy poco resistentes y, en consecuencia, se produce una importante merma en las resistencias mecánicas. 
Las resistencias de los morteros con agregados de PUR "B" siguen parecida tendencia a sus homólogos con agregado de PUR "A", si bien, se aprecia un aumento de la resistencia en las mezclas con sustitución del $25 \%$ sobre las mezclas de referencia. Posteriormente se produce una disminución de resistencia más acusada que con la espuma " $A$ ", hasta llegar a valores similares.

En la Figura 4.8 se representan las resistencias a compresión a los 28 días de los morteros de referencia. Sobre el gráfico se ha colocado una línea límite de $7,5 \mathrm{MPa}$, ya que es un valor válido para todo tipo de morteros y está en concordancia tanto con las normas UNE, como con el marcado $\mathrm{CE}^{141}$ y el CTE.

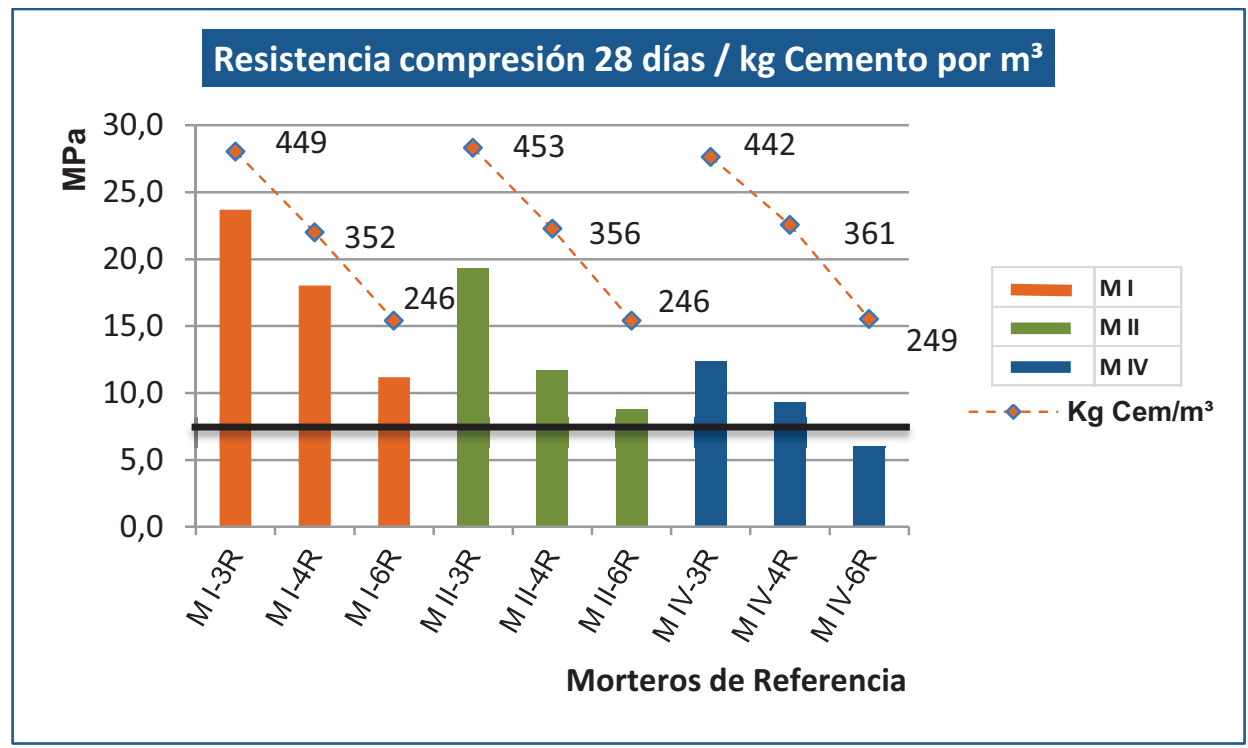

Figura 4.8. Resistencia a compresión a 28 días y $\mathrm{kg}$ de cemento por $\mathrm{m}^{3} \mathrm{de}$ mortero

Se puede observar que todos los morteros de referencia, excepto el M IV$6 \mathrm{R}$, superan la resistencia mínima a compresión exigida para la clase $\mathrm{M}$ 7,5 , suficiente para morteros de albañilería y morteros de juntas de particiones, muros de cerramiento no estructurales y ciertos muros estructurales. La resistencia mínima a compresión a los 28 días es en todos los casos superior a $6 \mathrm{MPa}$, por lo que en principio todos los morteros de

\footnotetext{
${ }^{141}$ Instrucción sobre criterios para la puesta en práctica del marcado CE de los morteros para albañilería. Ministerio de industria, Turismo y Comercio. Dirección General de Desarrollo Industrial. Revisión 1. 28/03. 2006
} 
referencia cumplen con las máximas exigencias para los morteros de revoco y enlucido. En el gráfico también se observa una tendencia muy definida de disminución de las resistencias, en función de la disminución del contenido de cemento y de su clase resistente.

Las resistencias y contenido de cemento de estos morteros sirven de referencia para le estudio comparativo con los morteros con agregados de PUR.

Se ha establecido la relación entre la resistencia a flexión a los 28 días y la resistencia a compresión a la misma edad. El resultado es una línea de tendencia con desviaciones puntuales poco significativas.

En las Figuras 4.9, a 4.11 se muestra esta relación entre la resistencia a compresión y flexión de los morteros.

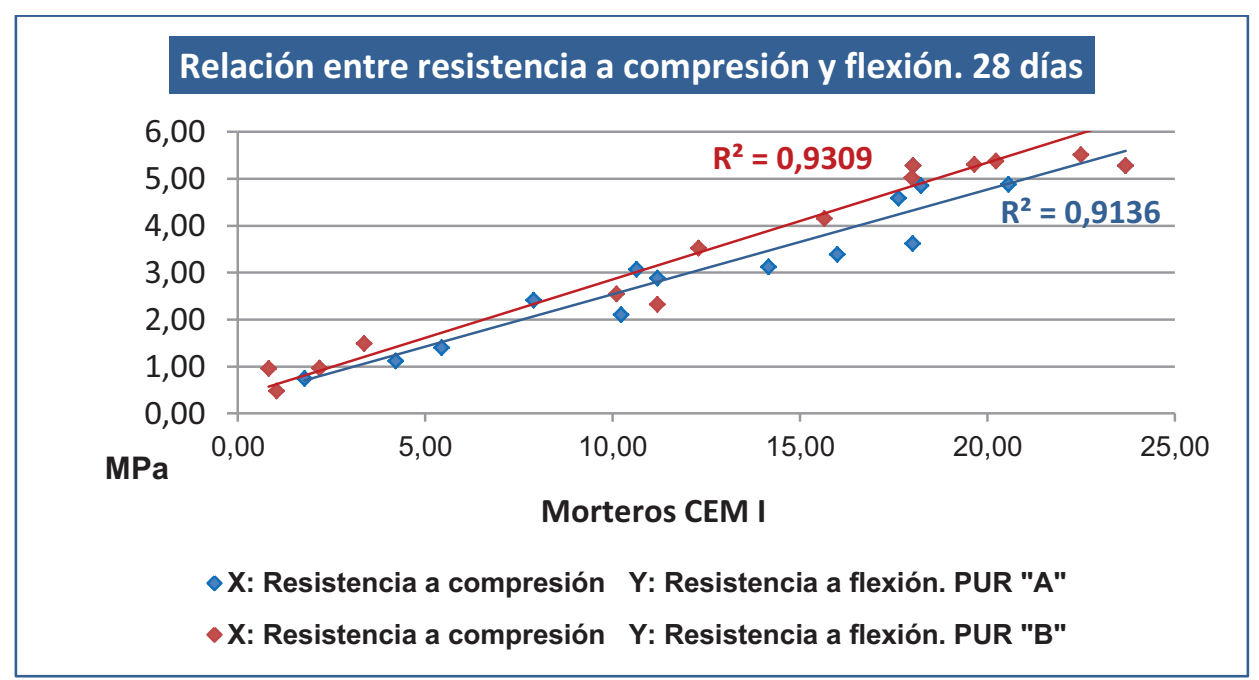

Figura 4.9. Relación entre resistencias a compresión y flexión morteros CEM I 


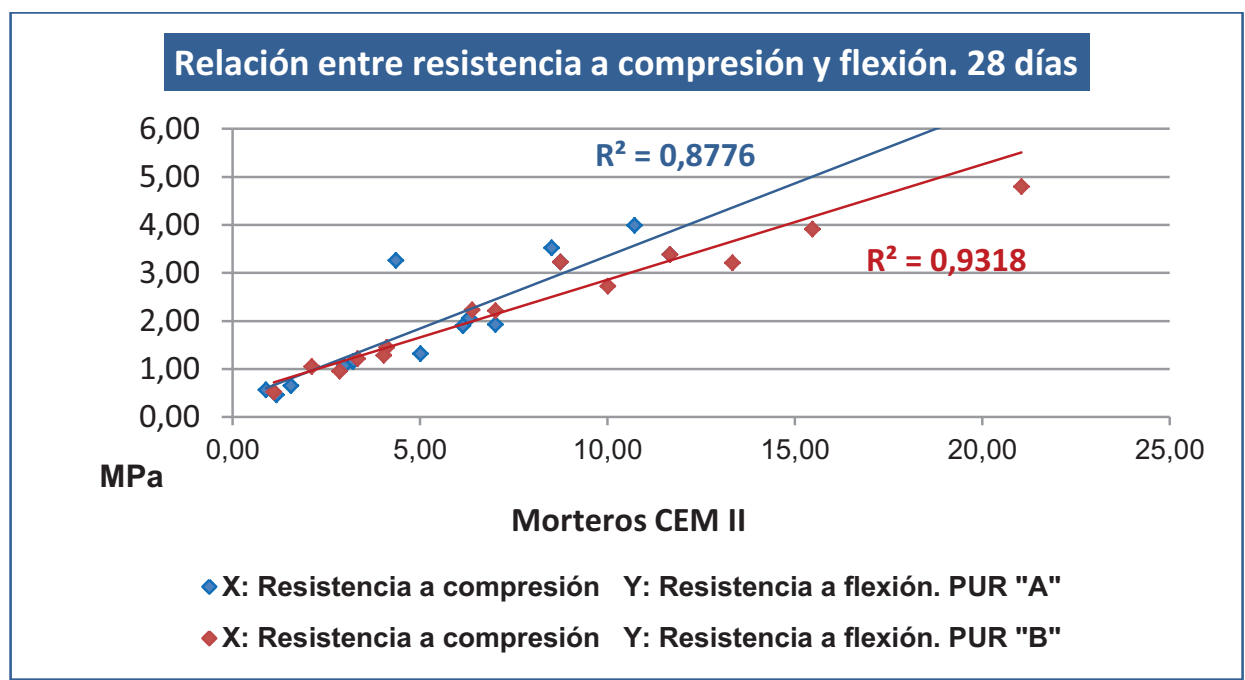

Figura 4.10. Relación entre resistencias a compresión y flexión morteros CEM II

\section{Relación entre resistencia a compresión y flexión. 28 días}

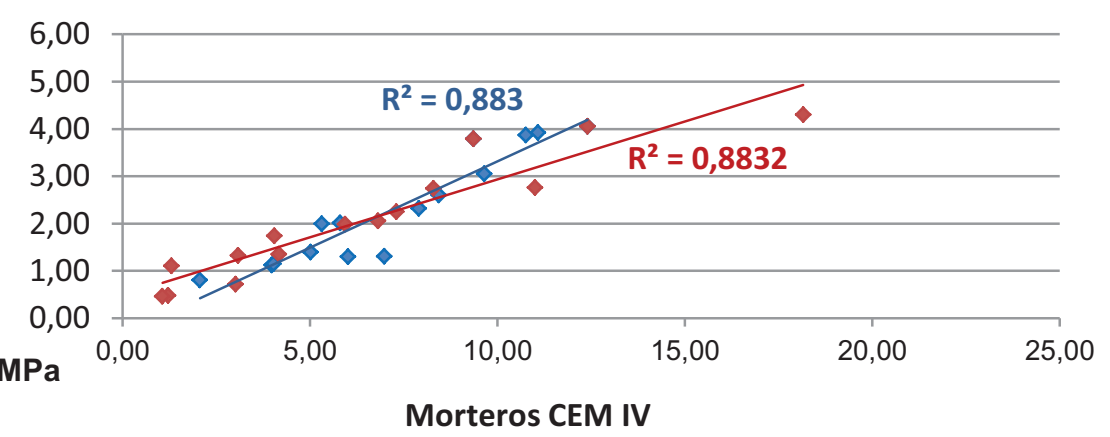

•X: Resistencia a compresión Y: Resistencia a flexión. PUR "A"

- X: Resistencia a compresión Y: Resistencia a flexión. PUR "B"

Figura 4.11. Relación entre resistencias a compresión y flexión morteros CEM IV

Con el objetivo de profundizar en el comportamiento de este tipo de materiales, se han estudiado los gráficos de tensión-deformación obtenidos de las roturas a compresión. En la Figura 4.12 se observa el gráfico de tensión-deformación de 4 probetas con distinta sustitución de arena por PUR. Se puede comprobar que la deformación de los morteros a igualdad de tensión es mayor en función del contenido de agregado PUR. 


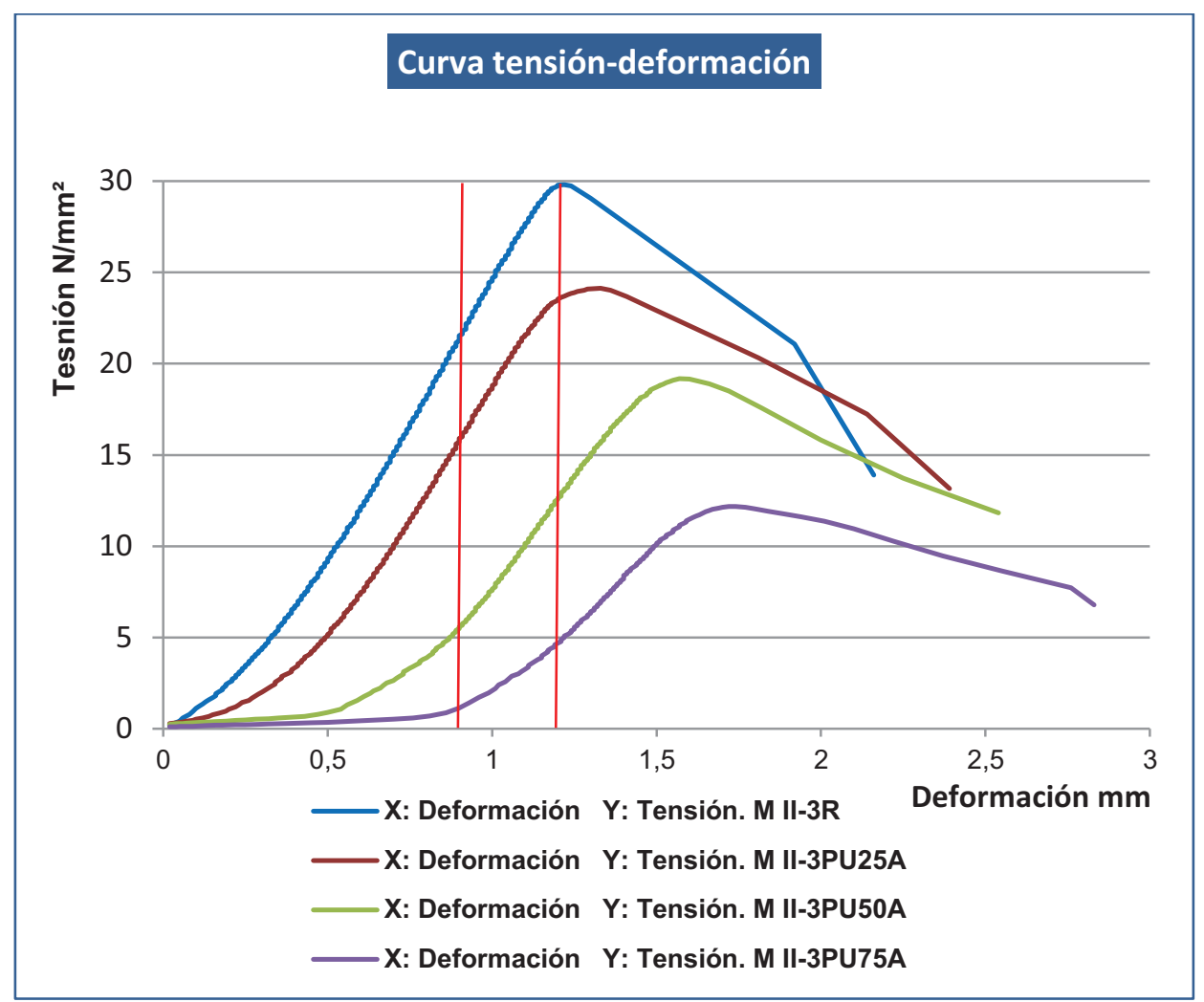

Figura 4.12. Gráfica tensión-deformación morteros CEM II relación 1/3

Las dos líneas rojas verticales nos muestran las tensiones a que estaría sometido el mortero en caso de deformación obligada, tal y como ocurre con los muros y tabiques confinados entre forjados. Las fábricas confinadas entre forjados acompañan la deformación "admisible" de los mismos (flechas). Así en el primer caso (línea roja de la izquierda), una deformación obligada de $0,9 \mathrm{~mm}$ crearía una tensión en la muestra de mortero con $75 \%$ de PUR de $1,14 \mathrm{~N} / \mathrm{mm}^{2}$, que supone menos del $10 \%$ de la tensión de rotura; esa misma deformación crea una tensión de $20,95 \mathrm{~N} / \mathrm{mm}^{2}$ en el mortero de referencia homólogo, que representa más del $70 \%$ de la tensión de rotura del mortero.

Del mismo modo, una deformación obligada de 1,22 $\mathrm{mm}$ (línea roja de la derecha) crearía una tensión en la muestra de mortero con $75 \%$ de PUR de $4,99 \mathrm{~N} / \mathrm{mm}^{2}$; esa misma deformación produciría la rotura en el mortero de referencia homólogo. 
En la Figura 4.13 se ha ampliado la escala de la tensión para apreciar con mayor claridad las tensiones producidas con bajas deformaciones.

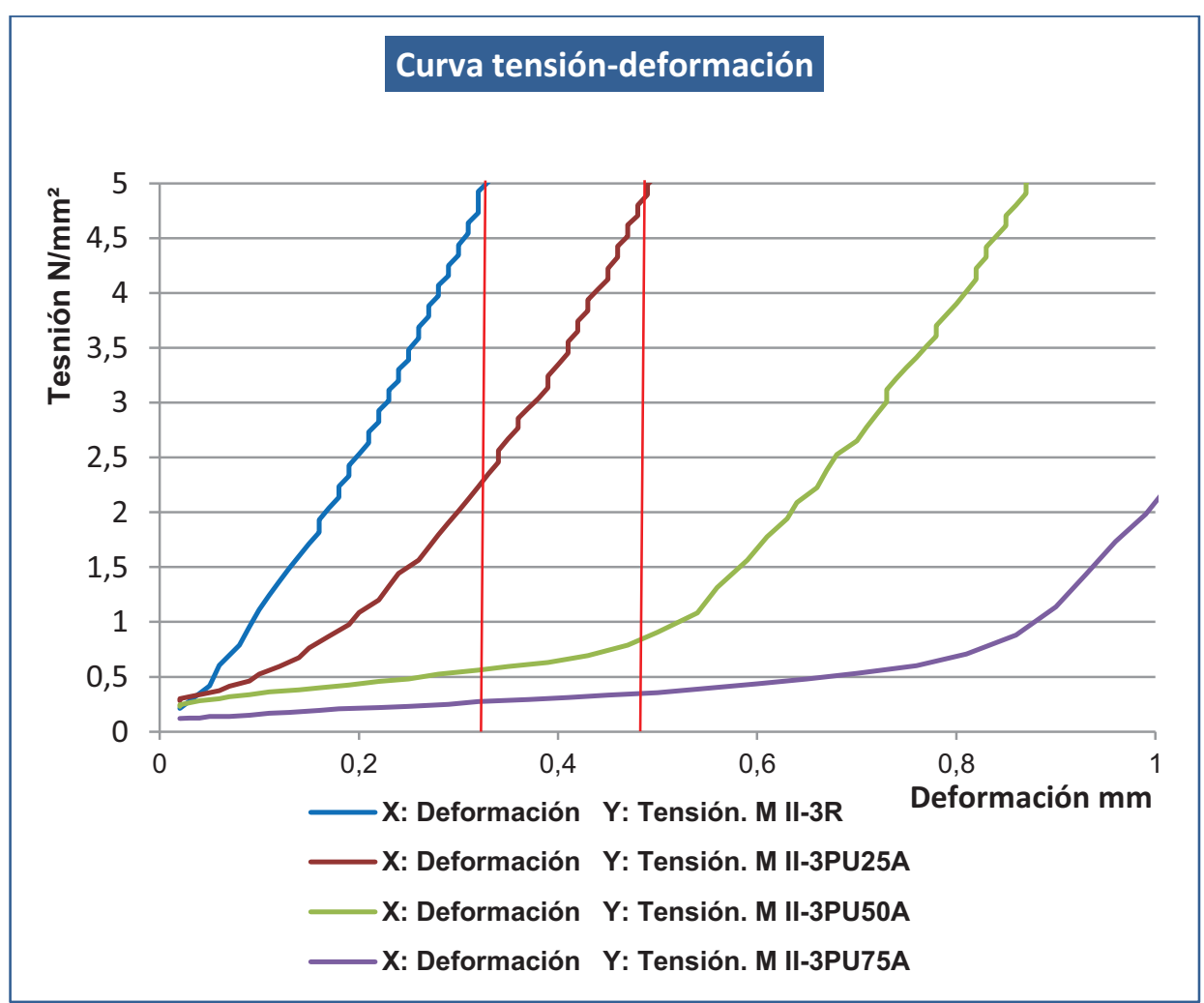

Figura 4.13. Gráfica tensión-deformación morteros CEM II relación 1/3, ampliada

Esto demuestra que los morteros que incluyen espuma polimérica son menos rígidos que los morteros tradicionales, es decir, más deformables, lo que podría tener importantes aplicaciones en las fábricas de albañilería, especialmente en las particiones confinadas entre forjados, como son los cerramientos de fachada y la tabiquería interior, que se pueden adaptar mucho mejor a los movimientos estructurales, sin asumir una tensión excesiva por motivo de la deformación de los forjados.

En la Figura 4.14 se aprecia la importante deformación, en la rotura a compresión, de un mortero con sustitución total de arena por PUR y un mortero de referencia. 


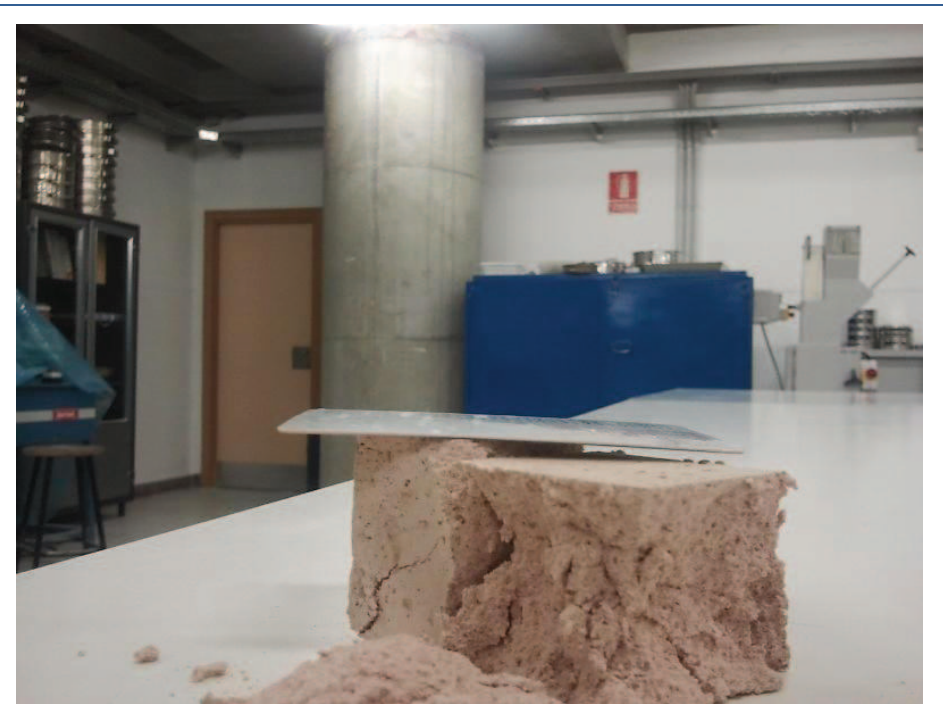

Figura 4.14. Comparativa deformación M II-6R y M II-6PU100A.

\subsubsection{3.- Características químicas}

\subsubsection{1.- Microscopía electrónica de barrido (SEM)}

Se ha realizado la caracterización microestructural de los morteros por SEM. En las Figuras 4.15 y 4.16 se distinguen las formas de las partículas de espuma y la porosidad en el mortero endurecido.

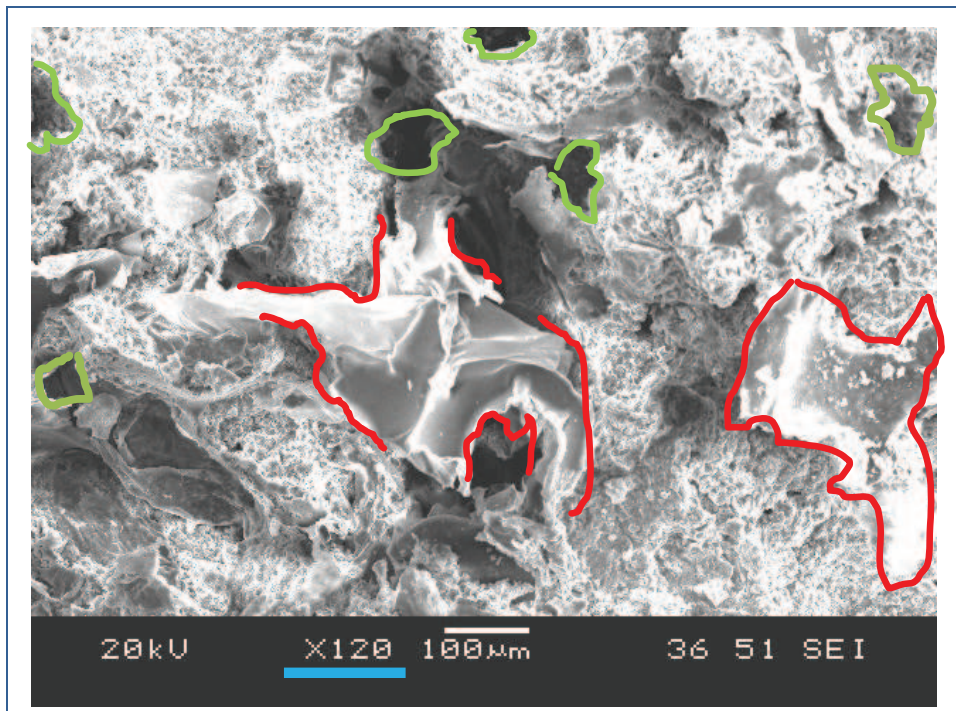

Figura 4.15. Partículas de espuma en mortero. Porosidad. M II-4PU50A 


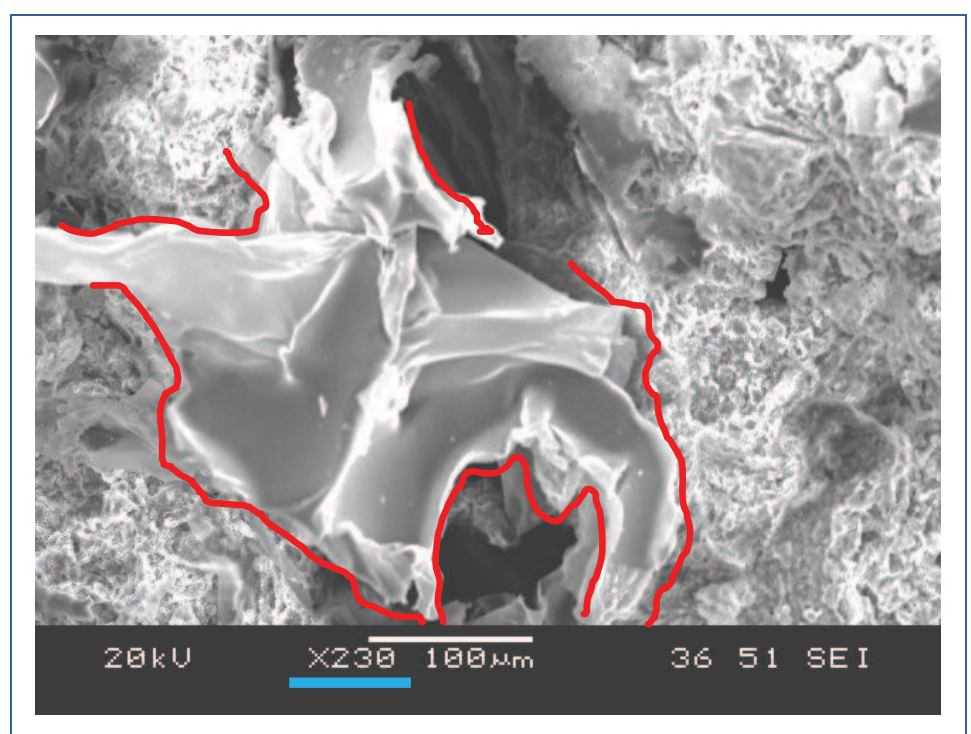

Figura 4.16. Partícula de espuma. M II-4PU50A.

Además la microscopía permite apreciar la adherencia de la pasta cemento-arena a la espuma de poliuretano (Figura 4.17).

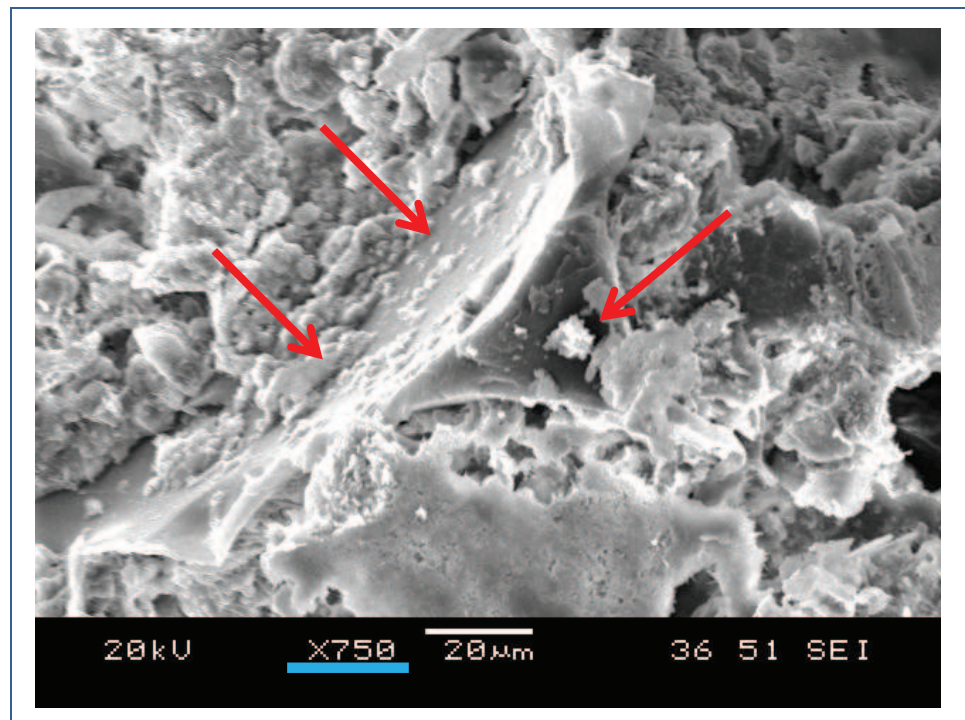

Figura 4.17. Partículas de mortero adheridas a la espuma. M II-4PU50A.

\subsubsection{2.- Termogravimetría (TGA)}

Se ha llevado a cabo la caracterización de una de las series de morteros, cuya dosificación de referencia es la M I-3R, mediante termogravimetría 
(TGA) para analizar el proceso de deshidratación de los componentes del mortero, especialmente para determinar la degradación que sufre el poliuretano con la temperatura, lo que proporciona una idea del comportamiento frente al fuego de estos materiales (Figura 4.18).

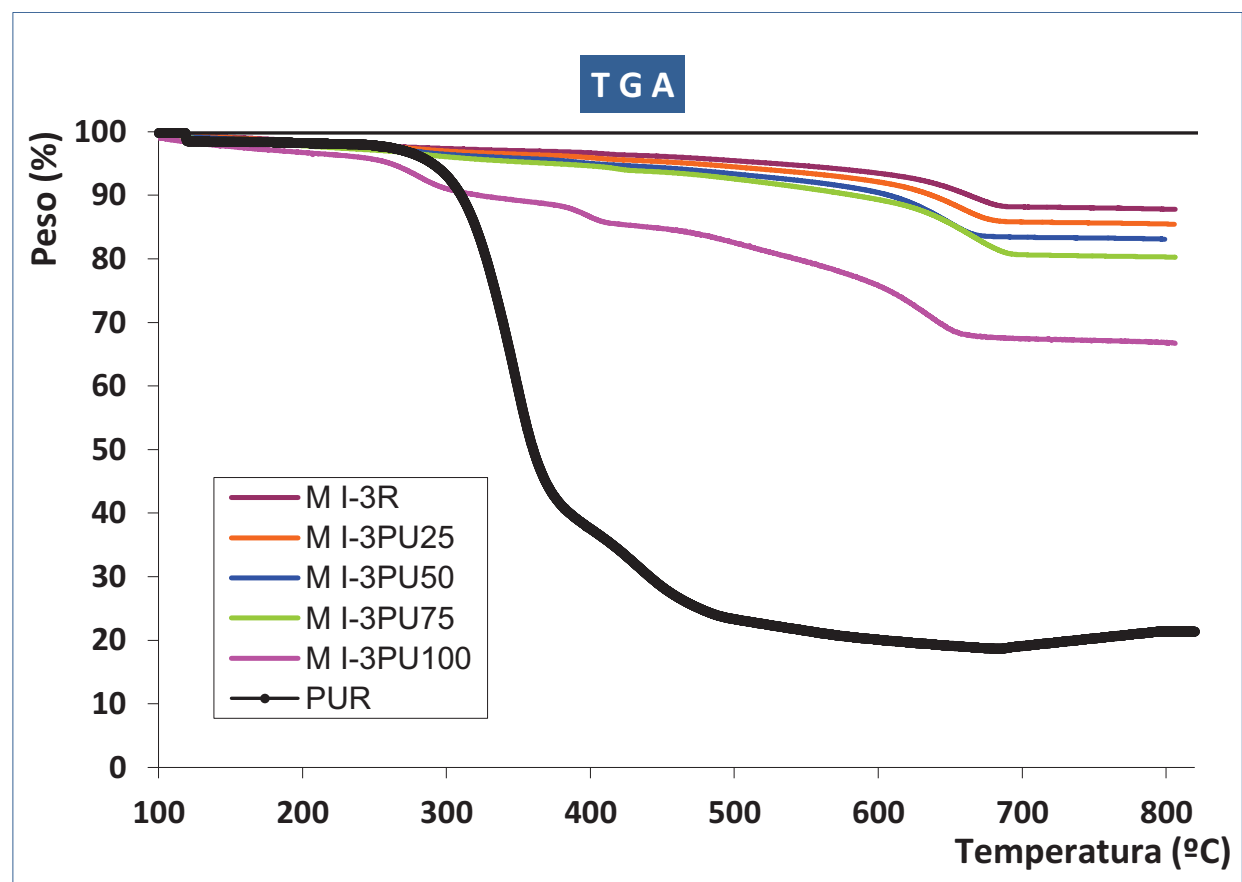

Figura 4.18. TgA. Degradación por temperatura de la serie de morteros con CEM I dosificación 1/3.

En la gráfica se observa que se produce una pérdida importante de masa del poliuretano puro entre $200-500^{\circ} \mathrm{C}$, y es debida probablemente a la descomposición de parte de la cadena polimérica.

\subsubsection{3.- Tomografía axial computerizada (TAC)}

Para dar una idea aproximada de la distribución de los macroporos y de cada uno de los componentes que forman los morteros, así como para determinar cuantitativamente los mismos, se ha medido la macroporosidad de las mezclas con poliuretano mediante tomografía axial computerizada (TAC) según lo descrito en el Capítulo 2.

EI TAC es una técnica basada en el análisis computacional de una secuencia de imágenes obtenidas por rayos $\mathrm{X}$, de donde se obtiene una 
imagen tridimensional de la estructura interna de matrices pétreas a escala real, identificando los poros con tamaño de diámetro superior a $170 \mu \mathrm{m}$ (macroporos). ${ }^{142}$

El tratamiento de datos se ha llevado a cabo con el software Mimics 10.0. El programa identifica las densidades de los diferentes materiales por colores. De esta manera, en la Figura 4.19 se observa la distribución de materiales en una sección de las probetas, en las que el color cian se corresponde con los poros, el amarillo con el cemento, el magenta con el poliuretano y el anaranjado con la arena. Se ve claramente la distribución homogénea de los materiales componentes en todas las mezclas y el aumento creciente de la cantidad de cemento y de la porosidad en las dosificaciones con mayor sustitución de espuma.

En las Figuras 4.20 y 4.21, con la misma secuencia de colores, se han visualizado las probetas prismáticas. Se aprecia una distribución homogénea de los macroporos en la matriz del conglomerante.

Se puede comprobar también que a medida que aumenta el contenido de poliuretano en la composición del mortero, el porcentaje de poros es también mayor, lo que significa que el polímero introduce cantidades de aire cada vez mayores en el material.

142 Manso J.M, Rodriguez A, Aragón A, Javier J. Gonzalez J. J. The durability of masonry mortars made with ladle furnace slag. Constr Build Mater 2011, 25, 3508-3519. 


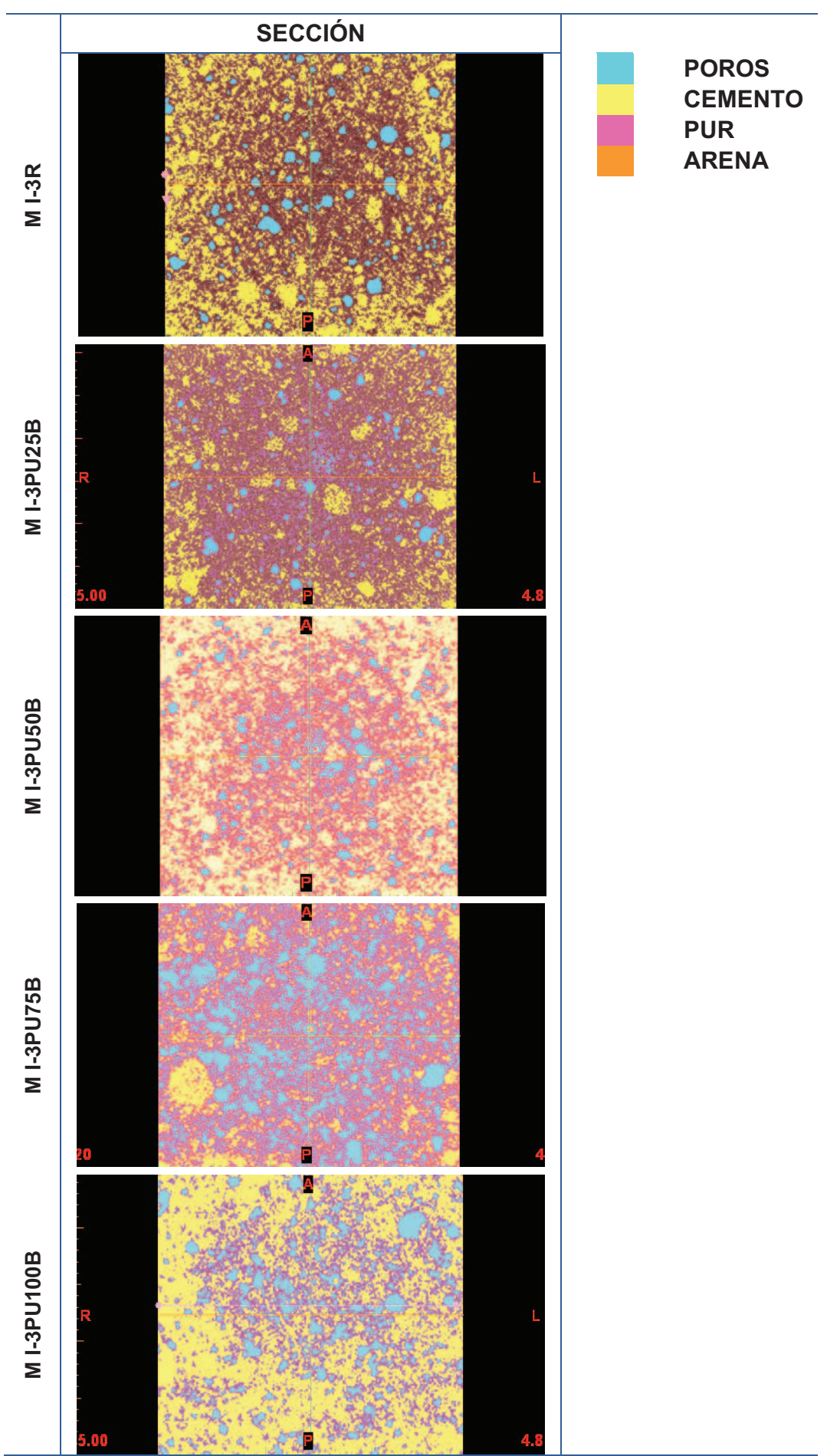

Figura 4.19. Fotografías TAC. Sección 

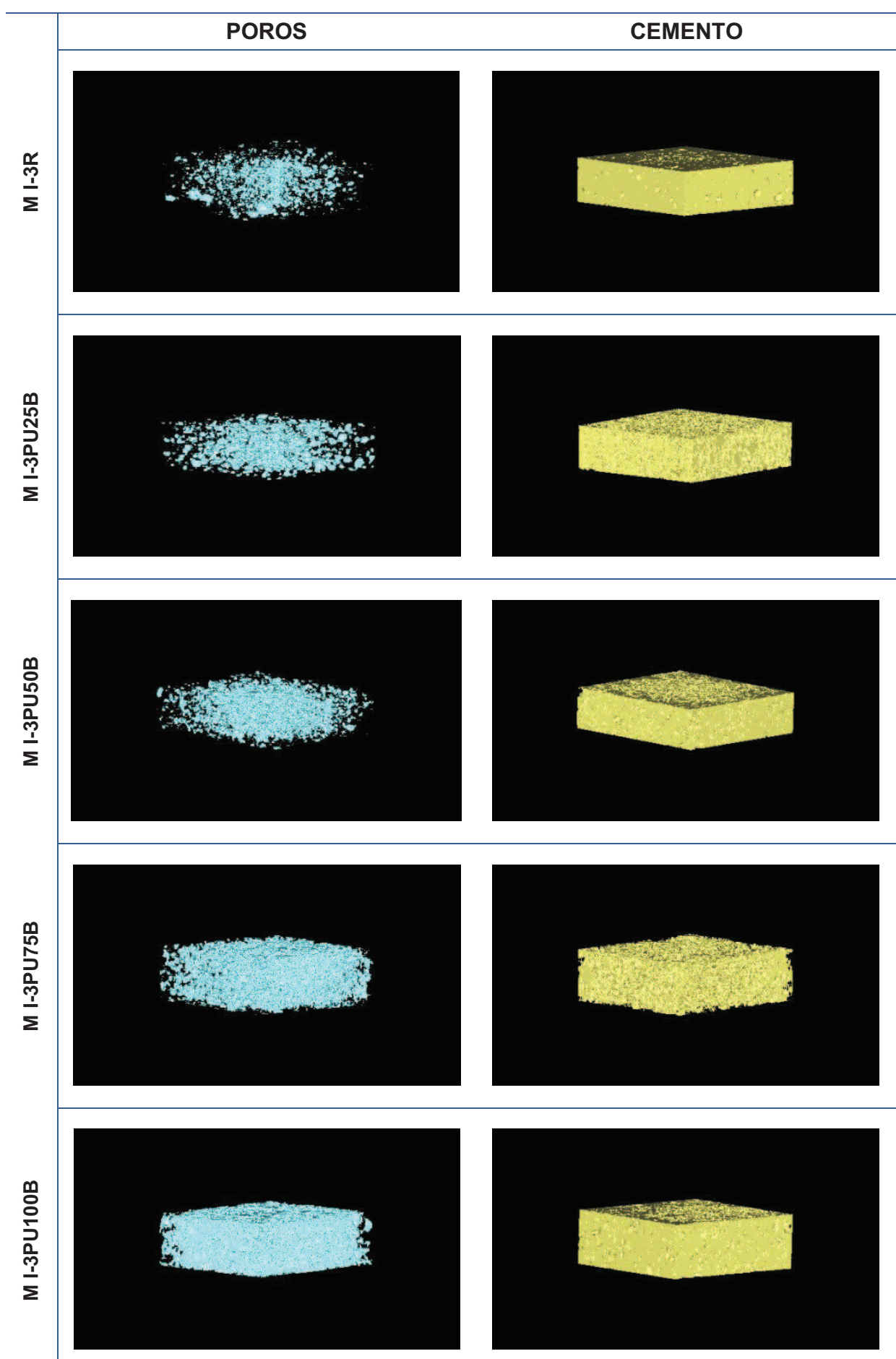

Figura 4.20. Fotografías TAC. Poros y cemento 


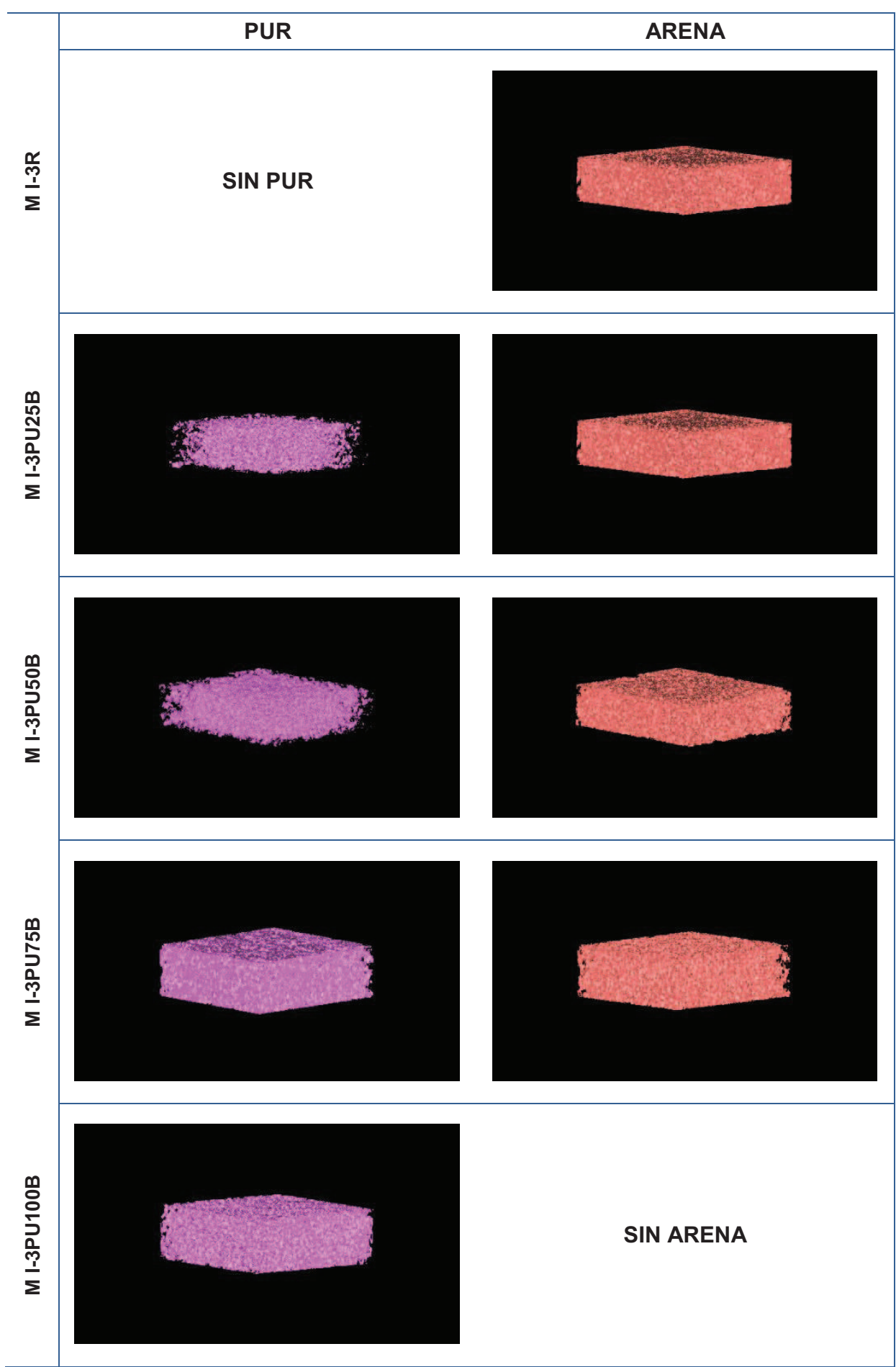

Figura 4.21. Fotografías TAC. PUR y arena 
Aunque la realización de un estudio en profundidad de la porosidad del material debería incluir el estudio de la microporosidad, por ejemplo mediante la técnica de porosimetría de intrusión de mercurio (MIP), la obtención de resultados viables no ha sido posible. La dificultad encontrada a la hora de abordar este ensayo se basa en que las altas presiones de mercurio en contacto con las partículas de poliuretano alteran la geometría inicial del polímero, poco rígida y deformable, dando lugar a resultados poco fiables que no pueden ser tenidos en cuenta, ya que son imprecisos y poco reproducibles. 
เ

O

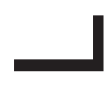

$\supset$

1

1

0

$\longrightarrow$

$\circlearrowleft$

Fabricación y caracterización de morteros con aditivos 

Capítulo 5.- Fabricación y caracterización de morteros con aditivos

\section{1.- Criterios de selección}

Los aditivos pueden modificar y en su caso mejorar ciertas propiedades en estado fresco, como son:

- La trabajabilidad

- La cantidad de agua de amasado

- La resistencia al hielo

- El aire ocluido

- La densidad aparente

- El tiempo de fraguado

También pueden quedar modificadas otras propiedades en estado endurecido, como:

- El color

- Las resistencias mecánicas

- La porosidad

- La durabilidad

- La impermeabilidad

- La densidad aparente

Para estudiar el efecto de los aditivos sobre los morteros con agregados de PUR se han escogido los que ofrecen las características más adecuadas para su utilización en obra, estableciendo los criterios de una mínima resistencia y un contenido en cemento limitado, siempre y cuando la sustitución de arena por agregado (PUR) sea significativamente importante. Por tanto se han discriminado las muestras de mortero que se consideran viables, en función de los criterios que pasamos a definir:

- Primer criterio: cantidad de agregado de PUR por metro cúbico de mortero. Este Trabajo pretende facilitar el empleo de reciclado de residuo de espuma de poliuretano en los morteros utilizados en construcción. Con un porcentaje mayor de agregado de PUR en el mortero, se conseguirá una mayor utilización de los residuos. 
- Segundo criterio: resistencia mecánica a compresión, ya que es una exigencia de las normas UNE-EN 998-1 y 998-2.

- Tercer criterio: cantidad de cemento por metro cúbico de mortero. Se ha primado la menor cantidad de cemento por metro cúbico de mezcla, que es el factor más influyente en el precio final del mortero.

- Cuarto criterio: tipo de cemento y resistencia, pues el tipo de cemento tiene influencia en la resistencia final del mortero y el precio del cemento es a su vez función de sus resistencias.

Criterio de discriminación $n^{\circ}$ 1: cantidad de espuma reciclada

Se ha establecido un límite mínimo del $50 \%$ de sustitución de arena por agregado de PUR, de modo que los morteros con sustitución del $25 \%$ de arena no se han ensayado.

Criterio de discriminación $n^{\circ} 2$ : resistencia mecánica a compresión.

La resistencia a compresión es una exigencia para los morteros empleados en muros resistentes. Sin embargo, no se requiere una resistencia mínima a compresión para muros no resistentes. La norma básica de edificación NBE-FL-90, en la Tabla 5.1. "resistencia de cálculo de las fábricas de ladrillo macizo" exigía una resistencia mínima del mortero de $2 \mathrm{MPa}$.

En los muros portantes, la resistencia mínima a compresión es función de la resistencia requerida a la fábrica, y en todo caso, siempre mayor de 5 MPa (CTE).

El uso de mortero para revestimientos requiere una resistencia a compresión mínima de 1,5 MPa para todo tipo de revestimientos interiores y 3,5 MPa para revestimientos exteriores, por lo que también es posible fijar la condición de resistencia mínima a compresión de 3,5 MPa para los morteros de revestimiento.

Así pues se ha señalado en primer lugar la condición de resistencia mínima a compresión de $5 \mathrm{MPa}$ para la investigación de los morteros elegidos, pues es una condición válida tanto para juntas como para revestimiento. 
Criterio de discriminación $\mathrm{n}^{\circ}$ 3: cantidad de cemento por $\mathrm{m}^{3}$ de mortero.

La cantidad de cemento es el factor más influyente en el precio final del mortero. Debemos limitar el contenido de cemento con el objeto de no encarecer su precio. Los morteros de referencia con dosificaciones 1/3, 1/4 y $1 / 6$, emplean cantidades de cemento que están por encima de los $200 \mathrm{~kg}$ y por debajo de los $500 \mathrm{~kg}$ por $\mathrm{m}^{3}$ de mezcla, por ello establecemos un límite máximo de contenido de cemento de $500 \mathrm{~kg}$ sin fijar, lógicamente, el límite mínimo.

Criterio de discriminación $n^{\circ} 4$ : tipo de cemento.

El conglomerante recomendado en la confección de morteros para usos corrientes debe ser un cemento con adiciones, con una clase de resistencia a compresión media o baja, pues ese tipo de cementos dan mezclas más trabajables y con menor retracción plástica. Los cementos que se ajustan a estas recomendaciones son el CEM II/B-L 32,5 R y el CEM IV/B-(V) 32,5 N. En consecuencia, se ha excluido el CEM I, que sin embargo ha supuesto una buena referencia para la realización de los estudios comparativos con los otros cementos. Por último, los cementos empleados en la albañilería corriente que son fabricados por casi todas las cementeras y se comercializan con más profusión en los almacenes de materiales de construcción, son los de la clase resistente 32,5 con adiciones, especialmente los cementos del tipo IV o cementos del tipo II-L.

En las Figuras 5.1, 5.2 y 5.3 se representan los 54 tipos de mortero con agregado de PUR, señalando los cuatro criterios empleados en la primera selección. 


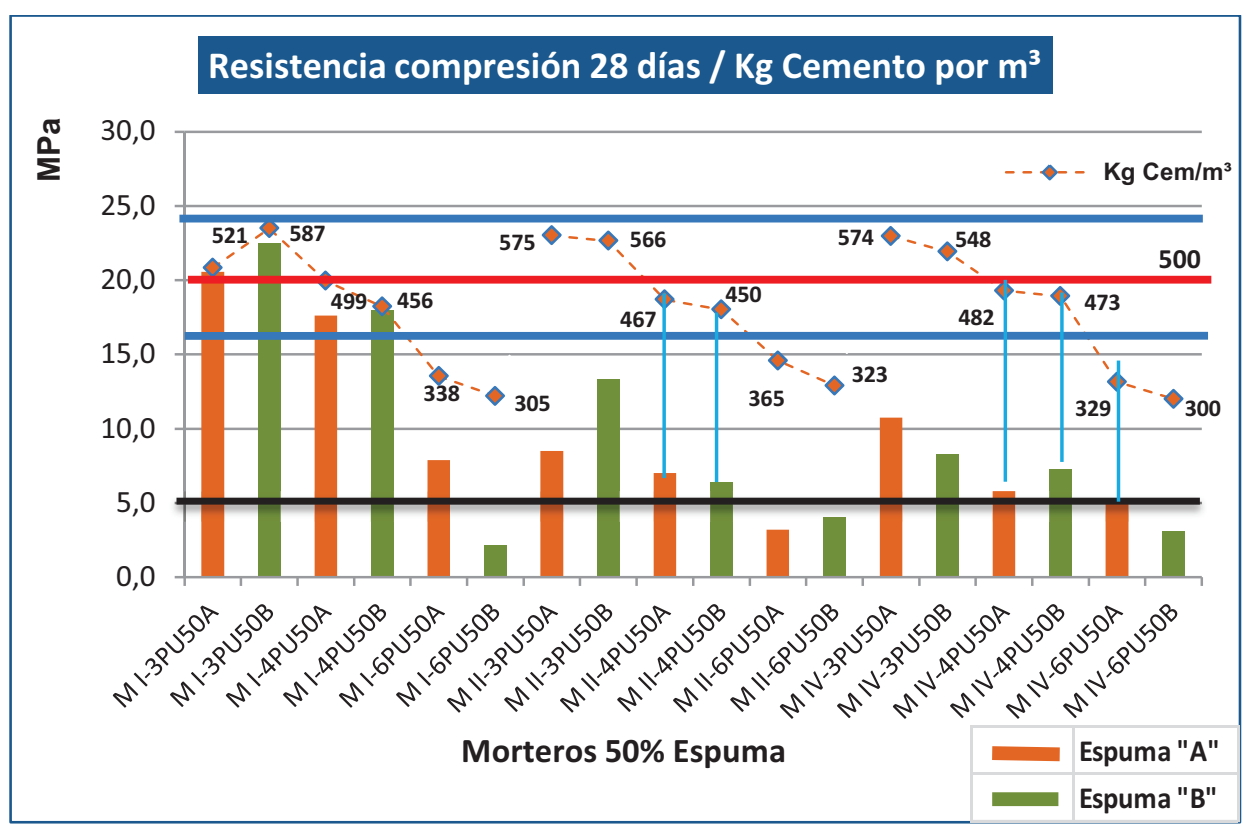

Figura 5.1. Resistencia a compresión y contenido de cemento de los morteros con agregado del $50 \%$ de PUR

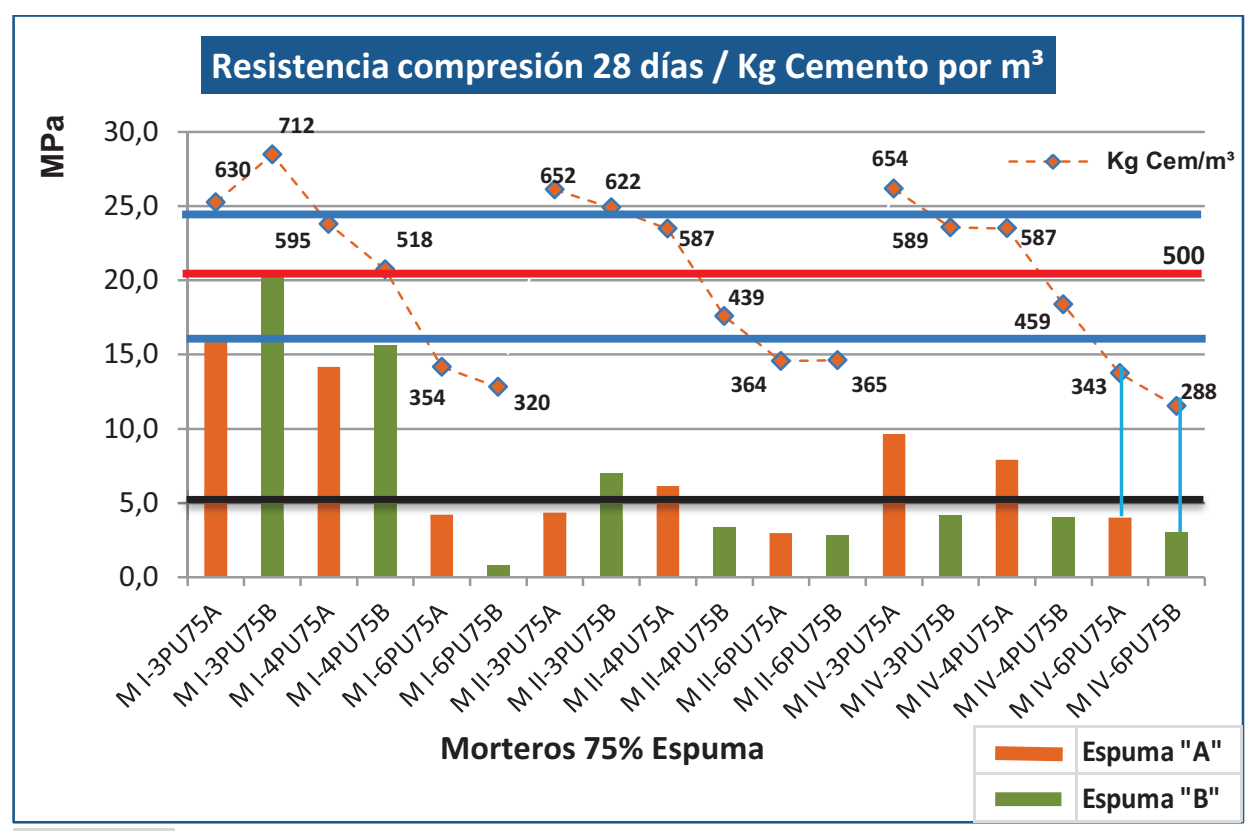

Figura 5.2. Resistencia a compresión y contenido de cemento de los morteros con agregado del $75 \%$ de PUR 


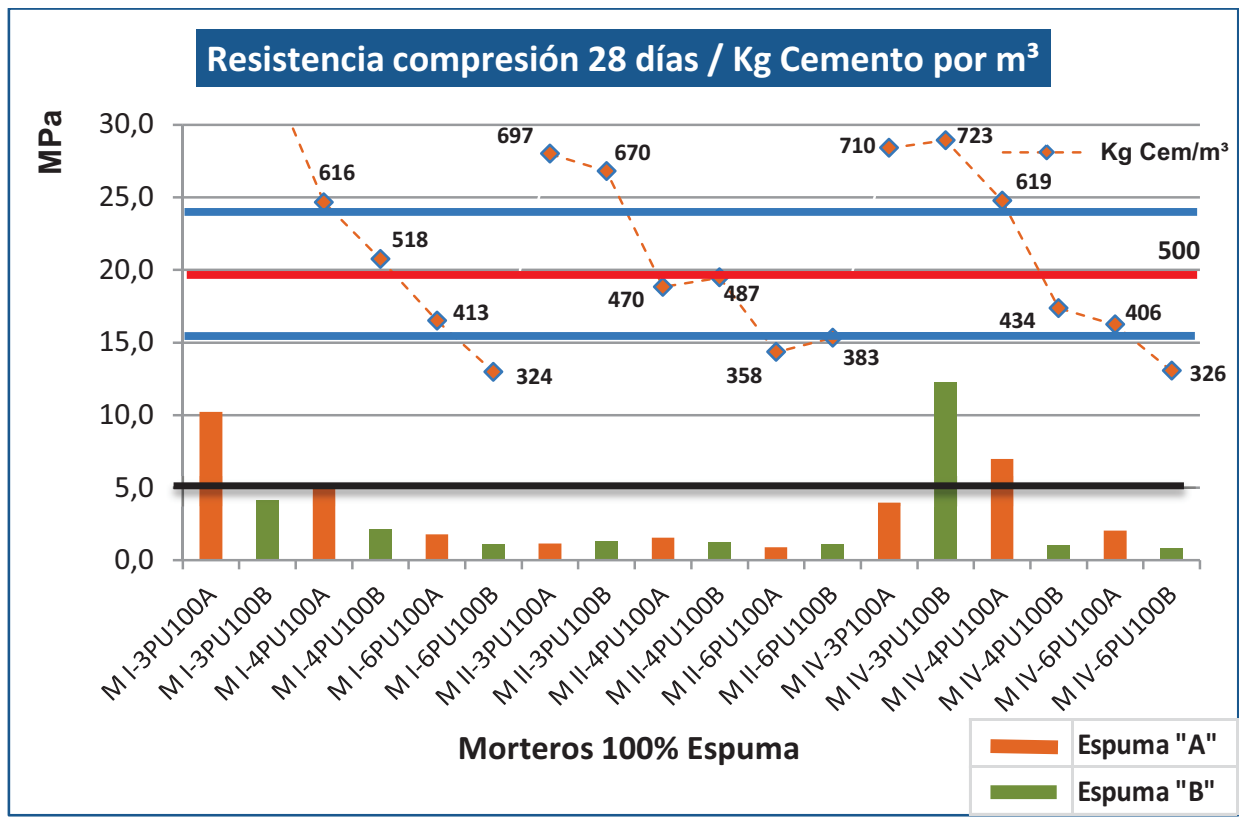

Figura 5.3. Resistencia a compresión y contenido de cemento de los morteros con agregado del $100 \%$ de PUR

Los morteros que cumplen con los requisitos de resistencia mínima a compresión de $5,0 \mathrm{~N} / \mathrm{mm}^{2}$ y contenido máximo de cemento inferior a 500 $\mathrm{kg} / \mathrm{m}^{3}$ son:

- $\quad$ M II-4PU50A

- $\quad$ M II-4PU50B

- $\quad$ M IV-4PU50B

- $\quad$ M IV-4PU50A

- $\quad$ M IV-6PU50A

En esta selección de morteros la mezcla M IV-4PU50A tiene un contenido en cemento próximo a $500 \mathrm{~kg}$, por lo que se considera suficiente escoger su homólogo con PUR B, de mayor resistencia y menor contenido de cemento.

No existe ninguna dosificación con sustitución de arena superior al $50 \%$ en volumen, ya que no se alcanza la resistencia mínima a compresión de 5,0 $\mathrm{MPa}$ o el contenido de cemento supera los $500 \mathrm{~kg}$.

Existe sin embargo un mortero, el M IV-6PU75A, con un alto contenido en espuma, un bajo contenido en cemento y una resistencia a compresión de 
$4 \mathrm{MPa}$, próxima a los $5 \mathrm{MPa}$ y suficiente para su empleo como mortero de juntas y de enfoscados, por lo que se ha considerado muy interesante investigar los resultados de esta mezcla, junto con su homólogo el M IV6PU75B.

En la Figura 5.4 se resumen las características de los morteros elegidos, junto con sus homólogos de referencia.

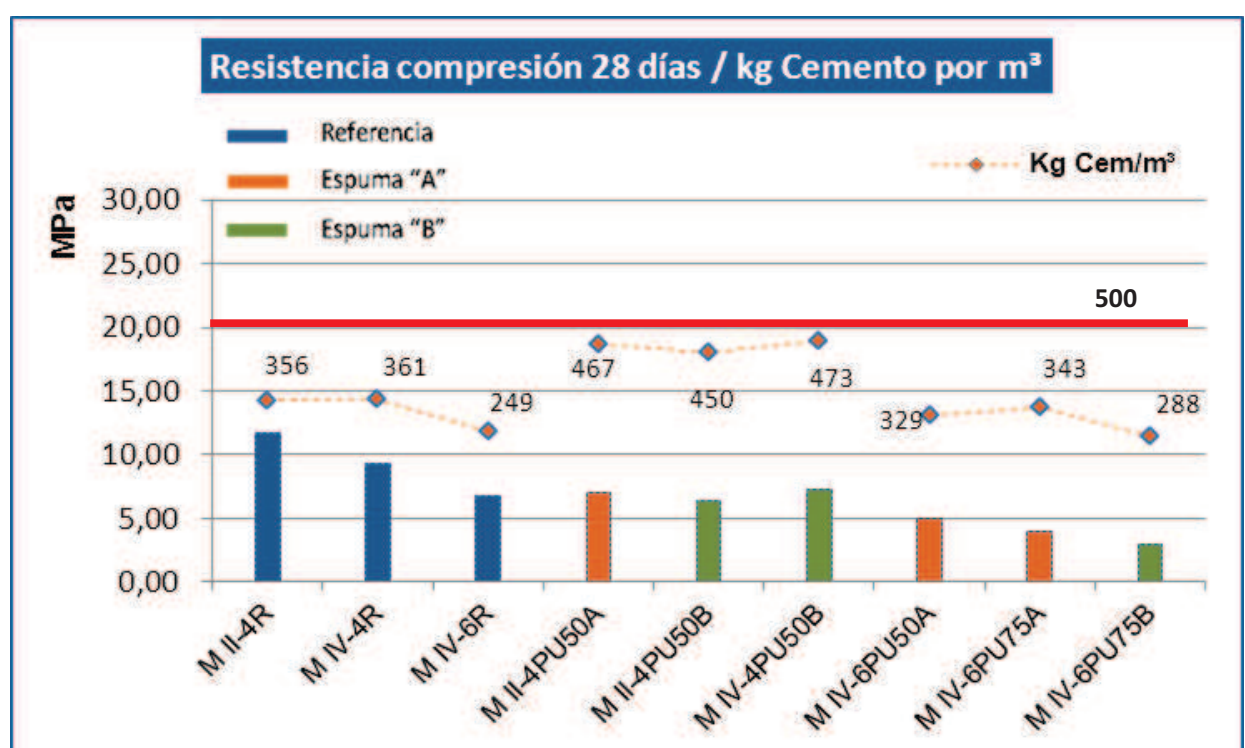

Figura 5.4. Resistencia a compresión y contenido de cemento de los morteros elegidos

Por último, resulta conveniente indicar que las mezclas M IV-6PU75A y M IV-6PU75B, tienen densidades de 0,987 kg/l y 1,010 kg/l respectivamente, por lo que en ambos casos se trata de morteros ligeros.

Los morteros con agregados de PUR elegidos presentan como inconvenientes más destacados unas resistencias mecánicas relativamente bajas, una elevada cantidad de cemento por $\mathrm{m}^{3}$ de mortero y una alta relación $W / C$, que dificulta la trabajabilidad por la menor capacidad de retención de agua (Tabla 5.1). 
Tabla 5.1. Dosificación morteros elegidos y resistencia a compresión

\begin{tabular}{|l|c|c|c|c|c|c|}
\hline \multirow{2}{*}{ Mortero } & \multicolumn{4}{|c|}{ kg por $\mathrm{m}^{3}$ de mortero } & W/C & $\begin{array}{c}\text { Resistencia a } \\
\text { compresión } \\
\text { 28 d. }\end{array}$ \\
\hline & Cemento & Arena & PUR & Agua & & Mpa \\
\hline M II-4R & 356,3 & $1.425,4$ & 0,0 & 318,3 & 0,89 & 11,67 \\
\hline M IV-4R & 360,8 & $1.443,3$ & 0,0 & 303,1 & 0,84 & 9,36 \\
\hline M IV-6R & 248,6 & $1.491,4$ & 0,0 & 316,2 & 1,27 & 6,01 \\
\hline M II-4PU50A & 467,4 & 934,7 & 30,3 & 392,6 & 0,84 & 7,01 \\
\hline M II-4PU50B & 450,4 & 900,8 & 38,5 & 402,3 & 0,89 & 6,39 \\
\hline M IV-4PU50B & 473,3 & 946,6 & 40,5 & 394,4 & 0,83 & 7,30 \\
\hline M IV-6PU50A & 328,7 & 986,2 & 32,0 & 401,7 & 1,22 & 5,01 \\
\hline M IV-6PU75A & 343,3 & 514,9 & 50,1 & 490,2 & 1,43 & 4,03 \\
\hline M IV-6PU75B & 287,7 & 431,6 & 55,3 & 614,6 & 2,14 & 3,01 \\
\hline
\end{tabular}

Con la incorporación de aditivos se pretende conseguir la mejora de propiedades. Por ello uno de los aditivos elegido es un inclusor de aire/plastificante, que se contempla en la norma UNE-EN 934-3.

La menor adherencia de la pasta cementosa a la espuma de poliuretano, que se observa en el microscopio electrónico, obliga a experimentar con un segundo aditivo, que aunque no esté normalizado, de acuerdo con la norma UNE-EN 934-3, puede mejorar sensiblemente la adherencia interna, con el posible aumento de la resistencia a flexión. Este aditivo es una emulsión adhesiva a base de látex.

En los ensayos previos realizados con morteros con agregados de PUR, se han detectado modificaciones significativas en los tiempos de fraguado con respecto a los morteros de referencia, por lo que sería conveniente, en un futuro próximo, experimentar con un aditivo retardador de fraguado.

\section{2.- Diseño de los morteros modificados con aditivos}

Los aditivos se han dosificado dentro de los intervalos de dosificación recomendados por los fabricantes, empleando las siguientes proporciones:

- Aditivo "L". Emulsión adhesiva Sika-Látex: Dosificación de 2,0\% en masa de la masa del cemento. 
- Aditivo "P". Inclusor de aire/plastificante Sikanol-M Polvo: Dosificación de $0,2 \%$ en masa de la masa del cemento.

La dosificación de los morteros diseñados con la incorporación de aditivos, se ha realizado partiendo de las mismas premisas empleadas para los morteros sin aditivos, es decir, ajustando las proporciones de cemento, árido y PUR y añadiendo la cantidad de agua precisa para conseguir la consistencia plástica.

Los 6 morteros con agregado de PUR, dosificados con los 2 aditivos escogidos, dan lugar a la confección de 12 nuevas muestras diferentes, que servirán para el estudio más profundo de las propiedades especificadas en las normas EN de aplicación.

Los morteros confeccionados con aditivos se designan de acuerdo con la siguiente nomenclatura:

- La letra "M" indicativa de la palabra Mortero, seguida de un espacio.

- Los números romanos "I", "II" o "IV", indicativos del tipo de cemento empleado y que son "CEM I 42,5 R", "CEM II/B-L 32,5 R", "CEM IV/B (V) 32,5 N", seguidos de un guion.

○ El número "3", "4" o "6", indicativo de la relación previa en peso, cemento/arena, utilizada en la confección de los morteros de referencia, que son "1/3", "1/4", "1/6".

- La letra "R" si se trata de un mortero de referencia.

- Las letras "PU" si se trata de un mortero con agregados de residuos de espuma rígida de poliuretano

○ Los números "25", "50", "75" o "100", indicativos del porcentaje de sustitución de arena por espuma de poliuretano.

- Las letras "A" o "B", indicativas de la naturaleza y procedencia del agregado (PUR) empleado en la sustitución.

- Finalmente las letras "L" o "P", precedidas de una barra inclinada, que indican el tipo de aditivo. "L" para la emulsión de látex y "P" para el inclusor de aire-plastificante.

Así, por ejemplo, el tipo de mortero "M II-4PU50A/L" se refiere a un mortero confeccionado con cemento CEM II/A-L 32,5R, con relación previa en peso, entre el cemento y la arena " $1 / 4$ ", con sustitución del $50 \%$ del árido (en volumen), por residuo de espuma rígida de poliuretano del tipo "A", y modificado con el aditivo "L", emulsión adhesiva de látex en la proporción del $2,0 \%$ sobre la masa del cemento. 


\section{3.- Dosificación y fabricación de los conglomerados modificados con aditivos}

La fabricación de los morteros modificados con aditivos se ha realizado con la misma técnica y herramientas empleadas en la confección de los morteros de referencia, incorporando los aditivos antes del amasado y siempre de acuerdo con las instrucciones del fabricante.

En la Tabla 5.2 se explicitan las cantidades de cada componente por metro cúbico de mortero, habiéndose empleado el siguiente orden: morteros de referencia ( $3 \mathrm{ud}$.); morteros de referencia con aditivo "L" ( $3 \mathrm{ud}$.); morteros de referencia con aditivo "P", (3 ud.); morteros con agregados de PUR (6 ud.); morteros con agregado y aditivo "L" (6 ud.); morteros con agregado y aditivo "P" (6 ud.). 
Tabla 5.2. Dosificación morteros con aditivos

\begin{tabular}{|c|c|c|c|c|c|c|}
\hline \multirow{2}{*}{ Mortero } & \multicolumn{5}{|c|}{ kg por $\mathrm{m}^{3}$ de mortero } & \multirow[t]{2}{*}{ W/C } \\
\hline & Cemento & Arena & PUR & Agua & Aditivo & \\
\hline M II-4R & 356,3 & $1.425,4$ & 0,0 & 318,3 & 0,0 & 0,89 \\
\hline M IV-4R & 360,8 & $1.443,3$ & 0,0 & 303,1 & 0,0 & 0,84 \\
\hline M IV-6R & 248,6 & $1.491,4$ & 0,0 & 316,2 & 0,0 & 1,27 \\
\hline M II-4R/L & 327,0 & $1.307,9$ & 0,0 & 245,2 & 6,5 & 0,75 \\
\hline M IV-4R/L & 342,0 & $1.368,1$ & 0,0 & 291,0 & 6,8 & 0,85 \\
\hline M IV-6R/L & 259,2 & $1.555,2$ & 0,0 & 216,2 & 5,2 & 0,83 \\
\hline$M$ II-4R/P & 342,8 & $1.371,3$ & 0,0 & 302,0 & 0,7 & 0,88 \\
\hline$M$ IV-4R/P & 361,2 & $1.444,7$ & 0,0 & 298,0 & 0,7 & 0,83 \\
\hline M IV-6R/P & 289,7 & $1.738,3$ & 0,0 & 266,5 & 0,6 & 0,92 \\
\hline M II-4PU50A & 467,4 & 934,7 & 30,3 & 392,6 & 0,0 & 0,84 \\
\hline M II-4PU50B & 450,4 & 900,8 & 38,5 & 402,3 & 0,0 & 0,89 \\
\hline M IV-4PU50B & 473,3 & 946,6 & 40,5 & 394,4 & 0,0 & 0,83 \\
\hline M IV-6PU50A & 328,7 & 986,2 & 32,0 & 401,7 & 0,0 & 1,22 \\
\hline M IV-6PU75A & 343,3 & 514,9 & 50,1 & 490,2 & 0,0 & 1,43 \\
\hline M IV-6PU75B & 287,7 & 431,6 & 55,3 & 614,6 & 0,0 & 2,14 \\
\hline M II-4PU50A/L & 381,2 & 762,3 & 24,7 & 244,3 & 7,6 & 0,64 \\
\hline M II-4PU50B/L & 325,1 & 650,3 & 27,8 & 236,2 & 6,5 & 0,73 \\
\hline M IV-4PU50B/L & 410,7 & 821,5 & 35,1 & 317,8 & 8,2 & 0,77 \\
\hline M IV-6PU50A/L & 310,0 & 929,9 & 30,2 & 318,7 & 6,2 & 1,03 \\
\hline M IV-6PU75A/L & 320,6 & 480,8 & 46,9 & 393,6 & 6,4 & 1,23 \\
\hline M IV-6PU75B/L & 297,8 & 446,7 & 57,3 & 397,2 & 6,0 & 1,33 \\
\hline M II-4PU50A/P & 425,7 & 851,4 & 27,6 & 315,0 & 0,9 & 0,74 \\
\hline M II-4PU50B/P & 369,2 & 738,4 & 31,6 & 360,3 & 0,7 & 0,98 \\
\hline M IV-4PU50B/P & 415,0 & 830,0 & 35,5 & 429,6 & 0,8 & 1,04 \\
\hline M IV-6PU50A/P & 354,8 & 1064,5 & 34,6 & 391,3 & 0,7 & 1,10 \\
\hline M IV-6PU75A/P & 393,2 & 589,8 & 57,4 & 471,8 & 0,8 & 1,20 \\
\hline M IV-6PU75B/P & 324,8 & 487,2 & 62,5 & 553,4 & 0,6 & 1,70 \\
\hline
\end{tabular}

La conclusión que se extrae del empleo de aditivos es la importante disminución en la relación agua/cemento. La excepción es el mortero M II 4PU50B/P, con relación agua/cemento de 0,98, algo superior a su homólogo sin aditivo. En la Tabla 5.3 se aprecia esa disminución de la cantidad de agua que en algunos casos llega a suponer casi un $38 \%$ como ocurre para el mortero M IV-6PU75B/L con aditivo de emulsión de látex. 
Tabla 5.3. Relación W/C en morteros con aditivos

\begin{tabular}{|l|c|c|c|}
\hline \multicolumn{1}{|c|}{ Mortero } & \multicolumn{3}{c|}{ Relación agua / cemento } \\
\hline M II-4R & 0,89 & 0,75 & 0,88 \\
\hline M IV-4R & 0,84 & 0,85 & 0,83 \\
\hline M IV-6R & 1,27 & 0,83 & 0,92 \\
\hline M II-4PU50A & 0,84 & 0,64 & 0,74 \\
\hline M II-4PU50B & 0,89 & 0,73 & 0,98 \\
\hline M IV-4PU50B & 0,83 & 0,77 & 1,04 \\
\hline M IV-6PU50A & 1,22 & 1,03 & 1,10 \\
\hline M IV-6PU75A & 1,43 & 1,23 & 1,20 \\
\hline M IV-6PU75B & 2,14 & 1,33 & 1,70 \\
\hline
\end{tabular}

La cantidad de cemento por $\mathrm{m}^{3}$ en la comparativa entre morteros con o sin aditivos, Tabla 5.4, muestra modificaciones significativas en ciertos casos, produciéndose en algunas dosificaciones un aumento de la cantidad de cemento y en otras una disminución. La diferencia más importante radica en la rebaja en la cantidad de cemento en las dosificaciones con el CEM II.

Tabla 5.4. Cantidad de cemento y pasta cementosa morteros con aditivos

\begin{tabular}{|c|c|c|c|c|c|c|}
\hline \multirow[t]{2}{*}{ Mortero } & \multicolumn{3}{|c|}{$\mathrm{kg}$ cemento $/ \mathrm{m}^{3}$ de mortero } & \multicolumn{3}{|c|}{$\begin{array}{c}\text { litros pasta cementosa } / \mathrm{m}^{3} \\
\text { mortero }\end{array}$} \\
\hline & Sin aditivo & Aditivo L & Aditivo $\mathbf{P}$ & Sin aditivo & Aditivo L & Aditivo $\mathbf{P}$ \\
\hline M II-4PU50A & 467,37 & 381,17 & 425,71 & 542,87 & 366,82 & 451,91 \\
\hline M II-4PU50B & 450,38 & 325,14 & 369,20 & 547,16 & 340,71 & 479,00 \\
\hline M IV-4PU50B & 473,30 & 410,7 & 415,0 & 677,28 & 464,54 & 577,81 \\
\hline M IV-6PU50A & 328,74 & 309,97 & 354,84 & 519,13 & 429,42 & 517,98 \\
\hline M IV-6PU75A & 343,27 & 320,55 & 393,19 & 612,79 & 508,12 & 612,25 \\
\hline M IV-6PU75B & 287,72 & 297,80 & 324,77 & 717,32 & 503,52 & 669,35 \\
\hline
\end{tabular}

En la Tabla 5.4 también se comprueba una importante disminución en el volumen de pasta cementosa de los morteros con aditivo de emulsión de látex con respecto a la pasta cementosa de sus homólogos sin aditivos, producto de la disminución en la cantidad de cemento y de la relación agua cemento. Sin embargo, el aditivo plastificante no rebaja sensiblemente la cantidad de pasta cementosa, salvo en los morteros de cemento CEM II. 


\section{4.- Resultados obtenidos}

Las características ensayadas en los morteros con agregados (PUR), modificados con aditivos, son las mismas que las ensayadas para el resto de morteros, con el objeto de poder realizar un estudio comparativo de las distintas dosificaciones. Los posteriores ensayos de durabilidad no se han completado en todos los casos con los morteros modificados con aditivos, pues el empleo de los aditivos ha tenido por objeto el estudio de las mejoras en las condiciones de amasado y en las resistencias mecánicas finales.

\subsection{1.- Mortero fresco}

\subsubsection{1.- Densidad aparente y aire ocluido}

La Tabla 5.5 nos muestra la densidad aparente, el aire ocluido y el rendimiento de los morteros modificados con aditivos 
Tabla 5.5. Densidad, contenido de aire y rendimiento de los morteros con aditivos

\begin{tabular}{|c|c|c|c|c|}
\hline Mortero & W/C & Densidad & Contenido en aire & Rendimiento \\
\hline & & kg/l & $\%$ & \\
\hline M II-4R & 0,89 & 2,100 & 4,5 & 0,597 \\
\hline M IV-4R & 0,84 & 2,107 & 4,5 & 0,597 \\
\hline M IV-6R & 1,27 & 2,056 & 3,8 & 0,616 \\
\hline M II-4R/L & 0,75 & 1,887 & 15,0 & 0,668 \\
\hline M IV-4R/L & 0,85 & 2,008 & 8,1 & 0,625 \\
\hline M IV-6R/L & 0,83 & 2,036 & 6,9 & 0,632 \\
\hline M II-4R/P & 0,88 & 2,017 & 8,6 & 0,622 \\
\hline M IV-4R/P & 0,83 & 2,105 & 5,2 & 0,598 \\
\hline M IV-6R/P & 0,92 & 2,295 & 15,0 & 0,559 \\
\hline M II-4PU50A & 0,84 & 1,825 & 10,0 & 0,461 \\
\hline M II-4PU50B & 0,89 & 1,792 & 5,4 & 0,472 \\
\hline M IV-4PU50B & 0,83 & 1,855 & 5,6 & 0,455 \\
\hline M IV-6PU50A & 1,22 & 1,749 & 9,6 & 0,470 \\
\hline M IV-6PU75A & 1,43 & 1,399 & 16,0 & 0,436 \\
\hline M IV-6PU75B & 2,14 & 1,389 & 7,4 & 0,470 \\
\hline M II-4PU50A/L & 0,64 & 1,420 & 29,0 & 0,588 \\
\hline M II-4PU50B/L & 0,73 & 1,601 & 23,3 & 0,676 \\
\hline M IV-4PU50B/L & 0,77 & 1,593 & 20,0 & 0,529 \\
\hline M IV-6PU50A/L & 1,03 & 1,595 & 20,0 & 0,512 \\
\hline M IV-6PU75A/L & 1,23 & 1,248 & 28,0 & 0,479 \\
\hline M IV-6PU75B/L & 1,33 & 1,205 & 28,0 & 0,508 \\
\hline M II-4PU50A/P & 0,74 & 1,621 & 21,0 & 0,517 \\
\hline M II-4PU50B/P & 0,98 & 1,500 & 22,0 & 0,566 \\
\hline M IV-4PU50B/P & 1,04 & 1,711 & 6,6 & 0,497 \\
\hline M IV-6PU50A/P & 1,10 & 1,846 & 7,4 & 0,443 \\
\hline M IV-6PU75A/P & 1,20 & 1,513 & 25,0 & 0,394 \\
\hline M IV-6PU75B/P & 1,70 & 1,428 & 9,2 & 0,442 \\
\hline
\end{tabular}

El empleo del aditivo "L" produce una significativa disminución de la densidad aparente en fresco; si tenemos en cuenta que también se ha producido una disminución de la cantidad de pasta cementosa, a igualdad de peso de árido, tendremos que concluir que el motivo de la bajada de densidad aparente en fresco es la presencia de un volumen mayor de aire ocluido, que se puede contrastar en la siguiente Tabla 5.6. 
Tabla 5.6. Comparativa de densidad en fresco y aire ocluido de los morteros con aditivos

\begin{tabular}{|l|c|c|c|c|c|c|}
\hline \multirow{2}{*}{ Mortero } & \multicolumn{3}{|c}{ Densidad en fresco kg/l } & \multicolumn{3}{c|}{ Aire ocluido \% } \\
\hline & Sin aditivo & Aditivo L & Aditivo P & Sin aditivo & Aditivo L & Aditivo P \\
\hline M II-4PU50A & 1,825 & 1,420 & 1,621 & 10,0 & 29,0 & 21,0 \\
\hline M II-4PU50B & 1,792 & 1,601 & 1,500 & 5,4 & 23,3 & 22,0 \\
\hline M IV-4PU50B & 1,855 & 1,593 & 1,711 & 5,6 & 20,0 & 6,6 \\
\hline M IV-6PU50A & 1,749 & 1,595 & 1,846 & 9,6 & 20,0 & 7,4 \\
\hline M IV-6PU75A & 1,399 & 1,248 & 1,513 & 16,0 & 28,0 & 25,0 \\
\hline M IV-6PU75B & 1,389 & 1,205 & 1,428 & 7,4 & 28,0 & 9,2 \\
\hline
\end{tabular}

La densidad en fresco en las dosificaciones con aditivo "P" no sufre cambios importantes. Hay tres dosificaciones en que la densidad aparente en fresco aumenta, y que se corresponden con morteros con CEM IV y tres dosificaciones en la que la densidad disminuye. La razón del incremento de la densidad aparente se puede deber al aumento de la cantidad de cemento por $\mathrm{m}^{3}$ de mortero, lo que conduce a un peso del mortero mayor, aun a pesar de la disminución de la relación agua/cemento, o del aumento del aire ocluido.

La disminución de la relación agua/cemento indica que casi todo el agua de amasado se emplea para hidratar el cemento, es decir, queda poco agua libre que podrá evaporarse en el secado del mortero por lo que la variación de la densidad en seco con respecto a la densidad en fresco será menor en los morteros con aditivos.

Finalmente hay que remarcar que el empleo del aditivo de emulsión de látex produce un mayor volumen de aire ocluido que el empleo del aditivo inclusor de aire/plastificante.

\subsubsection{2.- Período de trabajabilidad}

Si entendemos la trabajabilidad de un mortero, en sentido amplio, como la facilidad de su puesta en obra, vemos que la trabajabilidad depende inicialmente de dos factores:

- La plasticidad del mortero, que es la inversa de la resistencia al moldeo. 
- El tiempo durante el cual el mortero puede ser utilizado, es decir, no opone resistencia añadida a su moldeo.

Además, otros factores que influyen en la trabajabilidad son la adherencia al soporte, que puede obligar al aplicador a ejercer fuerzas importantes de presión sobre el soporte, o el descolgamiento del mortero por falta de cohesión de los componentes en fresco. Finalmente, existen factores externos, tales como la calidad del soporte o las condiciones ambientales, que pueden alterar la trabajabilidad de los morteros.

Se define el tiempo de utilización como el tiempo durante el cual un mortero posee la suficiente trabajabilidad para ser utilizado sin adición posterior de agua (AFAM. Morteros Guía General). Durante este período el mortero no debe alcanzar un nivel de endurecimiento, por efecto del principio de fraguado que impida su correcta puesta en obra.

El tiempo de utilización depende de la velocidad de fraguado y endurecimiento del cemento empleado, así como de la cantidad de agua presente en la mezcla, pues un aumento en la relación agua/cemento disminuye la velocidad de fraguado, con lo que se mejora la trabajabilidad.

La norma UNE-EN 1015-9, define la trabajabilidad como el tiempo que tarda un mortero en alcanzar un cierto grado de rigidez, o lo que es lo mismo, una cierta resistencia al moldeo ocasionada por el inicio de fraguado del cemento, que se suma a la resistencia inicial del mortero recién amasado.

En las mezclas a las que se han incorporado aditivos, no se han medido expresamente los tiempos de utilización, ya que los aditivos empleados no son retardadores de fraguado, aunque se han ensayado algunas muestras con aditivos para compararlas con sus homólogos sin ellos, para poder estimar su influencia en la velocidad de fraguado y endurecimiento de los morteros frescos.

En la Tabla 5.7 se muestra la trabajabilidad obtenida según el procedimiento del apartado 2.1.9. Destaca el elevado tiempo de trabajabilidad de los morteros con espuma, especialmente los que llevan una sustitución del $75 \%$ de arena por PUR. En estos casos, los tiempos llegan a superar las 24 horas, lo que parece señalar que el agregado de PUR actúa como retardador de fraguado. 
Tabla 5.7. Tiempo de trabajabilidad

\begin{tabular}{|l|c|c|c|}
\multicolumn{1}{|c|}{ Mortero } & \multicolumn{3}{c|}{ Tiem po de trabajabilidad en } \\
m inutos \\
\hline & Sin aditivo & Aditivo L & Aditivo P \\
\hline M II-4R & 231,00 & -- & -- \\
\hline M IV-4R & 172,00 & -- & -- \\
\hline M IV-6R & 225,00 & -- & -- \\
\hline M II-4PU50A & 459,00 & 251,00 & -- \\
\hline M II-4PU50B & W/C 0,84 & W/C 0,64 & \\
\hline M IV-4PU50B & 269,00 & -- & 431,00 \\
\hline M IV-6PU50A & 400,00 & -- & W/C 0,83 \\
\hline M IV-6PU75A & $\mathbf{4 1 , 5 0 0 , 0 0}$ & -- & -- \\
\hline M IV-6PU75B & 1457,00 & -- & -- \\
\hline
\end{tabular}

El efecto retardador de fraguado de la espuma incide en las resistencias mecánicas a corto y medio plazo, por lo que es posible que en períodos posteriores a los 28 días mejoren sensiblemente sobre las obtenidas hasta entonces.

La disminución o aumento del tiempo de trabajabilidad de las muestras ensayadas con aditivos son consecuencia de la menor o mayor relación agua/cemento con respecto a sus homólogas sin aditivos.

En la Figura 5.4 se muestra la gráfica que se ha empleado para representar el tiempo de trabajabilidad. Se han comparado los datos de un mortero de referencia con un mortero con agregado del $50 \%$ de espuma y otro con el $75 \%$. 


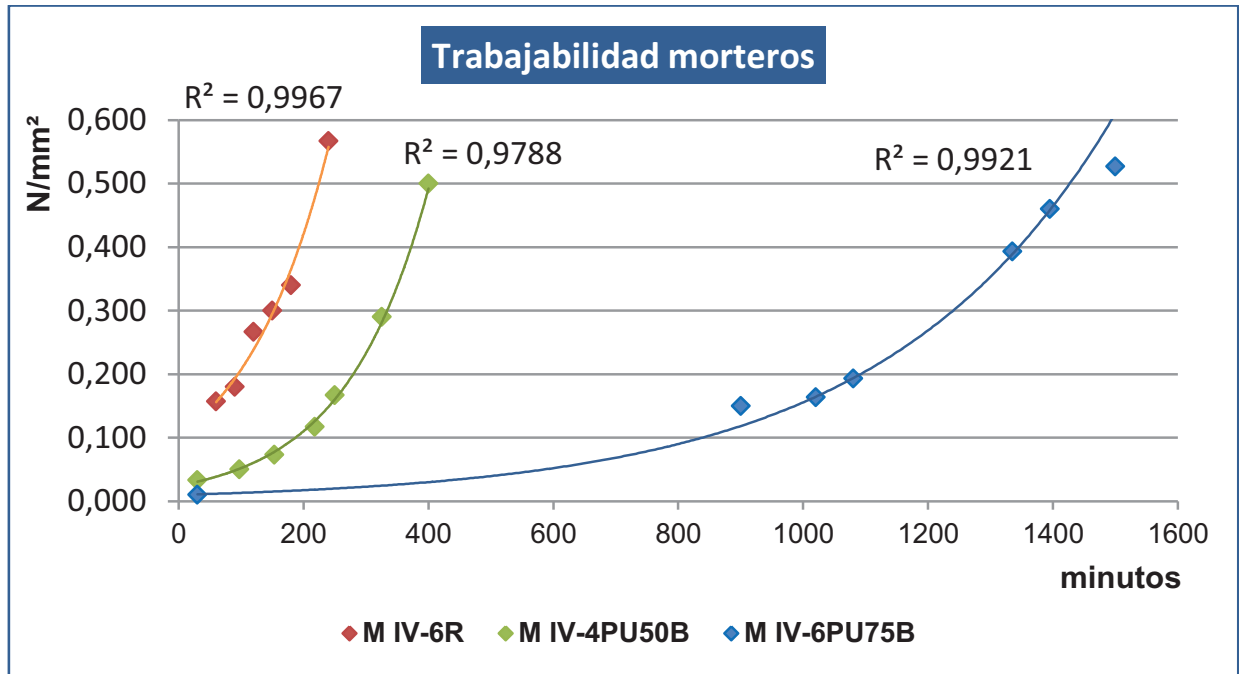

Figura 5.4. Comparativa del tiempo de trabajabilidad. Morteros referencia $50 \%$ y $75 \%$ PUR

De los resultados obtenidos se deduce que el tiempo de trabajabilidad es función del contenido de agregado, siendo en los morteros con porcentajes del $75 \%$ de 24 horas o superior. Ese importante aumento en el tiempo de trabajabilidad puede deberse a las propias características de las espumas, que tienen, como la mayoría de los polímeros, una capacidad de absorción muy elevada y durante el amasado actúan absorbiendo agua como un efecto "esponja". Posteriormente, a medida que el mortero va perdiendo agua por evaporación, el efecto "esponja" de las espumas actúa en sentido contrario, es decir, cediendo agua al mortero. Por ese motivo es muy probable que el cemento no pueda hidratarse totalmente en las primeras horas y necesite incluso varios días en completar la hidratación.

En consecuencia, parece probable que las resistencias características del cemento y por añadidura del mortero no se alcancen a los 28 días, sino bastante tiempo después.

No obstante, los morteros de bajas resistencias finales, como son los morteros con sustitución del $75 \%$ de arena por PUR y con moderada cantidad de cemento, tienen unas resistencias iniciales también muy bajas, lo que puede influir en que los resultados del ensayo de trabajabilidad indiquen períodos excesivamente largos, debido a la falta de rigidez de la mezcla por falta de resistencia. 


\subsubsection{3.- Capacidad de retención de agua}

Se puede definir la capacidad de retención de agua de un mortero como la propiedad que tiende a conservar el agua precisa para mojar e hidratar la superficie de las partículas del conglomerante, y para mojar las partículas de árido y burbujas de aire ocluido. La cantidad de agua que el mortero es incapaz de retener es un agua que se perderá antes del inicio del fraguado, bien por cesión al soporte, lo cual depende de la capacidad de succión del soporte, o bien simplemente por pérdida debida a exudación.

Los factores que determinan esta propiedad están relacionados con la granulometría y con la superficie específica de las partículas del árido y conglomerante, así como con la viscosidad de la pasta.

Durante la elaboración de los ensayos de consistencia del mortero fresco se ha apreciado una insuficiente capacidad de retención de agua en las mezclas de alta sustitución de arena por agregado (PUR), lo que en algunos casos ha llevado a reducir la proporción de agua, a pesar de no conseguir el valor del escurrimiento indicado en la normativa.

La asociación nacional de fabricantes de mortero AFAM, en su publicación Morteros Guía General, indica que la capacidad de retención de agua de los morteros se debe evaluar de acuerdo con la norma UNE-EN $1347^{143}$ de morteros cola, sin embargo existe la norma experimental UNE 83-816:93, cuya metodología se basa en la cantidad de agua absorbida por unos discos de papel absorbente colocados sobre el mortero fresco, que es la técnica que se ha empleado.

Se considera una buena capacidad de retención de agua cuando un mortero está por encima del $80 \%$, que suele ser un valor medio empleado por los fabricantes de mortero. En nuestro caso los morteros de referencia tienen una capacidad de retención de agua superior al $80 \%$. Las mezclas con agregados de PUR tienen una capacidad que también ronda el $80 \%$, si bien algunas de ellas se encuentran ligeramente por debajo. Con todo, se puede considerar la capacidad de retención de agua como adecuada, sobre todo teniendo en cuenta que las relaciones agua/cemento son superiores, lo que implica más cantidad de agua sobrante y en consecuencia mayor posibilidad de cesión de agua al soporte (Tabla 5.8).

\footnotetext{
143 Norma Española UNE-EN 1347. Adhesivos para baldosas cerámicas. Determinación de la capacidad humectante. 2007
} 
Tabla 5.8. Tiempo de trabajabilidad

\begin{tabular}{|l|c|c|}
\hline \multicolumn{1}{|c|}{$\begin{array}{c}\text { Mortero } \\
\text { Cagua }\end{array}$} & w/c \\
\hline M II-4R & 91,2 & \\
\hline M IV-4R & 89,1 & 0,89 \\
\hline M IV-6R & 84,7 & 0,84 \\
\hline M II-4PU50A & 81,8 & 1,27 \\
\hline M II-4PU50B & 73,2 & 0,84 \\
\hline M IV-4PU50B & 84,9 & 0,89 \\
\hline M IV-6PU50A & 77,9 & 0,83 \\
\hline M IV-6PU75A & 76,0 & 1,22 \\
\hline M IV-6PU75B & 79,9 & 1,43 \\
\hline
\end{tabular}

\subsection{2.- Mortero endurecido}

Los ensayos sobre el mortero endurecido incluyen los realizados de densidad aparente y de resistencia a flexión y compresión. Además, dentro de las características físicas, se ha analizado la absorción de agua, la permeabilidad al vapor y el aislamiento acústico.

El conocimiento de las características mecánicas se ha completado con el estudio de la resistencia a la adhesión y resistencia a la abrasión. También se ha analizado en alguna muestra específica la deformabilidad del mortero sometido a ciclos de carga-descarga, con el objeto de conocer su elasticidad.

\subsubsection{1.- Características físicas}

\subsubsection{1.- Densidad aparente del mortero endurecido}

En la Tabla 5.9 se muestra la evolución de la densidad aparente del mortero fresco y del mortero endurecido 
Tabla 5.9. Densidad del mortero endurecido con aditivos

\begin{tabular}{|c|c|c|c|c|c|c|c|c|c|}
\hline \multirow{3}{*}{ ortero } & \multicolumn{9}{|c|}{ Densidad aparente $\mathrm{kg} / \mathrm{l}$} \\
\hline & \multicolumn{3}{|c|}{ Sin aditivos } & \multicolumn{3}{|c|}{ Aditivo L } & \multicolumn{3}{|c|}{ Aditivo P } \\
\hline & Fresco & 7 días & 28 días & Fresco & 7 días & 28 días & Fresco & 7 días & 28 días \\
\hline M II-4R & 2,100 & 2,004 & 1,980 & 1,887 & 1,852 & 1,815 & 2,017 & 1,946 & 1,887 \\
\hline M IV-4R & 2,107 & 2,068 & 2,005 & 2,008 & 1,967 & 1,935 & 2,105 & 2,044 & 1,988 \\
\hline M IV-6R & 2,095 & 2,009 & 1,990 & 2,036 & 1,990 & 1,940 & 2,295 & 2,153 & 2,020 \\
\hline M II-4PU50A & 1,825 & 1,400 & 1,339 & $1,4<v$ & 1,385 & 1,280 & 1,621 & 1,575 & 1,558 \\
\hline M II-4PU50B & 1,792 & 1,730 & 1,629 & 1,601 & 1,575 & 1,327 & 1,500 & 1,378 & 1,348 \\
\hline M IV-4PU50B & 1,855 & 1,680 & 1,610 & 1,593 & 1,530 & 1,460 & 1,711 & 1,690 & 1,629 \\
\hline M IV-6PU50A & 1,749 & 1,654 & 1,312 & 1,595 & 1,550 & 1,412 & 1,846 & 1,808 & 1,697 \\
\hline M IV-6PU75A & 1,399 & 1,267 & 0,987 & 1,248 & 1,232 & 1,110 & 1,513 & 1,466 & 1,288 \\
\hline M IV-6PU75B & 1,389 & 1,215 & 1,010 & 1,205 & 1,180 & 1,040 & 1,428 & 1,403 & 1,198 \\
\hline
\end{tabular}

Como se observa, la variación de la densidad aparente del mortero fresco al endurecido es menor en los morteros con aditivos, y especialmente en los morteros con aditivo "L". La razón es que los morteros modificados con aditivos emplean menos cantidad de agua, por lo que la evaporación del agua sobrante es menor y en consecuencia la disminución de la densidad aparente a los 28 días sufre menos variación.

De la Tabla 5.10 comparativa de las densidades a los 28 días se puede extraer que las densidades aparentes finales a 28 días, aumentaron con el empleo de aditivos en los morteros con relación 1:6, es decir, en aquéllos que incluyen una menor cantidad de cemento.

Tabla 5.10. Densidad de los morteros a los 28 días

\begin{tabular}{|l|c|c|c|}
\hline \multicolumn{1}{|c|}{ Mortero } & \multicolumn{3}{c|}{ Sensidad aparente a los 28 dias } \\
\hline M II-4R & 1,980 & 1,815 & 1,887 \\
\hline M IV-4R & 2,005 & 1,935 & 1,988 \\
\hline M IV-6R & 1,990 & 1,940 & 2,020 \\
\hline M II-4PU50A & 1,339 & 1,280 & 1,558 \\
\hline M II-4PU50B & 1,629 & 1,327 & 1,348 \\
\hline M IV-4PU50B & 1,610 & 1,460 & 1,629 \\
\hline M IV-6PU50A & 1,312 & 1,412 & 1,697 \\
\hline M IV-6PU75A & 0,987 & 1,110 & 1,288 \\
\hline M IV-6PU75B & 1,010 & 1,040 & 1,198 \\
\hline
\end{tabular}




\subsubsection{2.- Absorción de agua}

La actividad humana, las condiciones climatológicas o el terreno, son las fuentes que originan la presencia de agua en los paramentos; el agua que aparece en los revestimientos puede proceder de fuentes directas, como el agua de lluvia que presiona sobre el paramento, o el agua presente en el terreno; también puede proceder de fuentes indirectas, como son las condiciones ambientales de humedad y temperatura en el interior de los edificios.

En todos los casos, cuando existe agua en forma líquida en un material ésta puede migrar a través del mismo, bien por fenómenos de permeabilidad (presión sobre una de las caras), bien por fenómenos de capilaridad, pudiendo manifestarse en cualquier parte del paramento afectado. El agua presente en el interior de los paramentos migra hacia la superficie, provocando por un lado el deterioro del acabado, por otro la aparición de hongos, y finalmente crea unas condiciones de humedad que pueden hacer la estancia insalubre.

Para conocer el comportamiento de los morteros frente a la presencia de agua, se estudia la capacidad de absorción de agua con la norma UNE-EN 1015-18 y posteriormente la permeabilidad al vapor de agua, ya que la presencia de agua en forma líquida en los paramentos puede autoeliminarse si sus materiales constitutivos son capaces de facilitar la difusión del agua (efecto esponja) en forma de vapor al ambiente, es decir, si son capaces de secarse en ciertas condiciones, lo que impediría la formación de manchas de humedad y la aparición de hongos en el interior.

La capacidad de un mortero para atraer y retener agua en su interior depende de la cantidad y configuración de sus poros abiertos (tamaño, interconexión), por lo que el estudio de la absorción y permeabilidad además serán un indicativo de la red de poros abiertos.

Aunque la normativa no indica la necesidad de medir la altura de penetración del agua, se ha tomado ésta para poder evaluar la capacidad de penetración de agua por capilaridad de los morteros, especialmente en los más absorbentes.

En la Tabla 5.11 se indican los coeficientes de permeabilidad junto con la altura de penetración del agua, calculados según lo descrito en el apartado 2.1.12. 
Tabla 5.11. Absorción de agua por capilaridad. Morteros sin aditivos

\begin{tabular}{|l|c|c|c|}
\hline \multicolumn{1}{|c|}{ Mortero } & Absorcion de agua por capilaridad & Aire ocluido \\
\hline M II-4R & C & Altura m m & $\%$ \\
\hline M IV-4R & 0,26 & 19,48 & 4,5 \\
\hline M IV-6R & 0,14 & 12,89 & 4,5 \\
\hline M II-4PU50A & 0,24 & 17,48 & 3,8 \\
\hline M II-4PU50B & 0,36 & 18,35 & 10,0 \\
\hline M IV-4PU50B & 0,46 & 22,30 & 5,4 \\
\hline M IV-6PU50A & 0,34 & 26,33 & 5,6 \\
\hline M IV-6PU75A & 0,70 & 43,49 & 9,6 \\
\hline M IV-6PU75B & 1,02 & 35,00 & 16,0 \\
\hline
\end{tabular}

Los coeficientes de absorción son más elevados en los morteros con sustitución de agregado PUR, debido probablemente a una red capilar mucho más desarrollada, que facilita una mayor absorción de agua. Sin embargo, si se toma como referencia la altura máxima de penetración, una vez descontados los $8 \mathrm{~mm}$ de lámina de agua en que han quedado sumergidas las probetas, se observa que la altura de penetración en ningún caso supera los $40 \mathrm{~mm}$. Por lo que podemos concluir que para un mortero de juntas, colocado sobre ladrillo tabicón o de medio pie, la penetración de agua por capilaridad no llegará a la superficie no expuesta de la fábrica.

Se han realizado además ensayos sobre dos muestras de mortero con aditivo "L" de látex, obteniendo los resultados de la Tabla 5.12, que incluyen sus correspondientes homólogos sin aditivos. El látex no produce aumento en el coeficiente de absorción, aunque se comprueba un importante incremento en la altura de penetración de agua, por la configuración de la red capilar. El mortero con látex tiene una importante cantidad de aire ocluido y la absorción de agua a los 10 minutos es comparativamente mucho mayor que la de sus homólogos, por lo que la altura final que alcanza el agua en el interior del mortero es también más elevada. La razón de la absorción inicial tan alta se puede deber a la gran porosidad superficial del mortero que satura rápidamente el mismo. Una vez saturado el mortero inmerso en agua, la absorción posterior es similar a la de sus homólogos sin aditivos. 
Tabla 5.12. Absorción de agua por capilaridad. Comparativa morteros sin y con aditivos

\begin{tabular}{|l|c|c|c|}
\hline \multicolumn{1}{|c}{ Mortero } & \multicolumn{2}{c|}{ Absorcion de agua por capilaridad } & Aire ocluido \\
\hline & C & Altura $\mathbf{~ m ~}$ & $\%$ \\
\hline M II-4PU50A & 0,36 & 18,35 & 10,0 \\
\hline M II-4PU50A/L & 0,38 & 58,19 & 29,0 \\
\hline M II-4PU50B & 0,46 & 22,30 & 5,4 \\
\hline M II-4PU50B/L & 0,40 & 52,63 & 23,3 \\
\hline
\end{tabular}

De la Tabla 5.12 se puede extraer la conclusión de que a pesar de que los coeficientes de absorción son similares en los morteros con agregados y sus homólogos con aditivos de látex, la altura que alcanza el agua en el interior de las muestras es muy superior en los morteros con aditivos. La razón estriba en la configuración de los poros: el gran porcentaje de aire ocluido en los morteros con látex ha creado una porosidad importante en forma de pequeñas burbujas que parecen estar interconectadas, y que se saturan en los primeros 10 minutos, dando lugar a un ascenso rápido del agua en el interior del mortero por capilaridad; pasados los primeros 10 minutos la absorción de agua por capilaridad tiene un ascenso similar en ambos morteros.

Las Figuras 5.5 y 5.6 muestran las pendientes de la líneas de 0 min. a 10 min. y de $10 \mathrm{~min}$. a $90 \mathrm{~min}$. para un mismo mortero sin aditivo y con aditivo. Se constata la elevada absorción inicial del mortero con látex (primeros 10 min); en cambio la absorción en el período comprendido entre 10 y 90 minutos es similar en ambos morteros. 


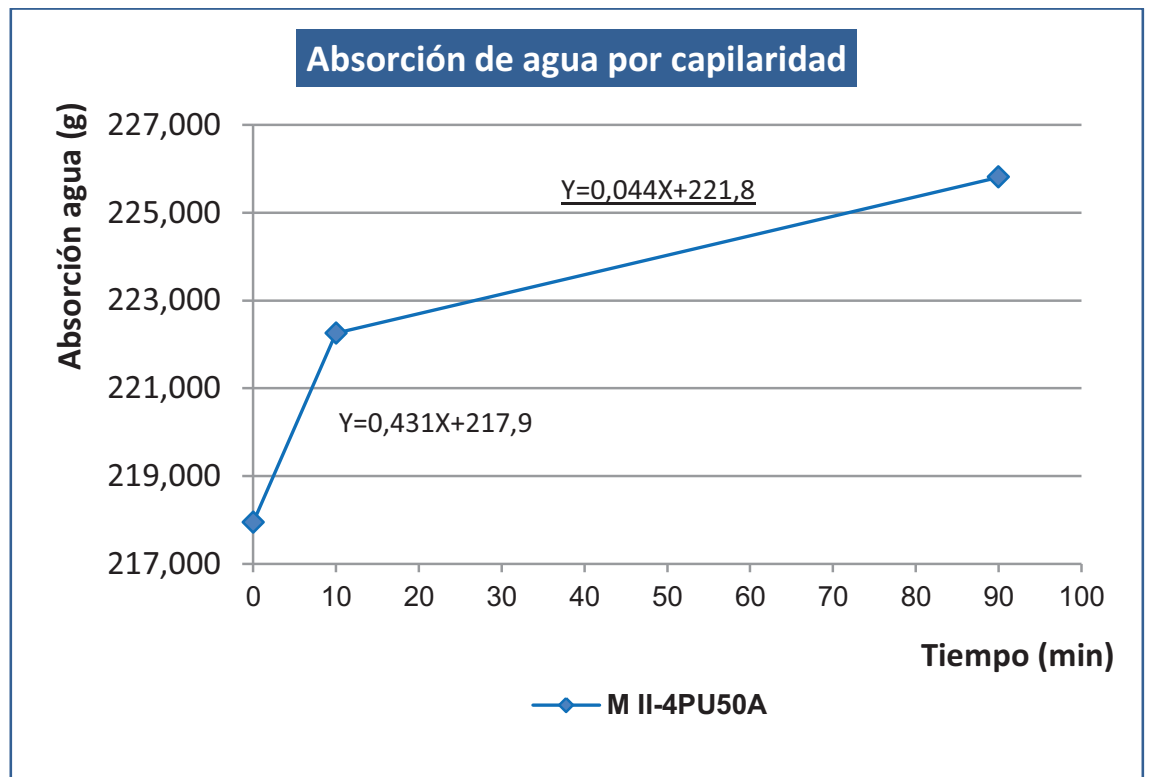

Figura 5.5. Pendiente línea absorción de agua. 0-10 min. 10-90 min. M II4PU50A

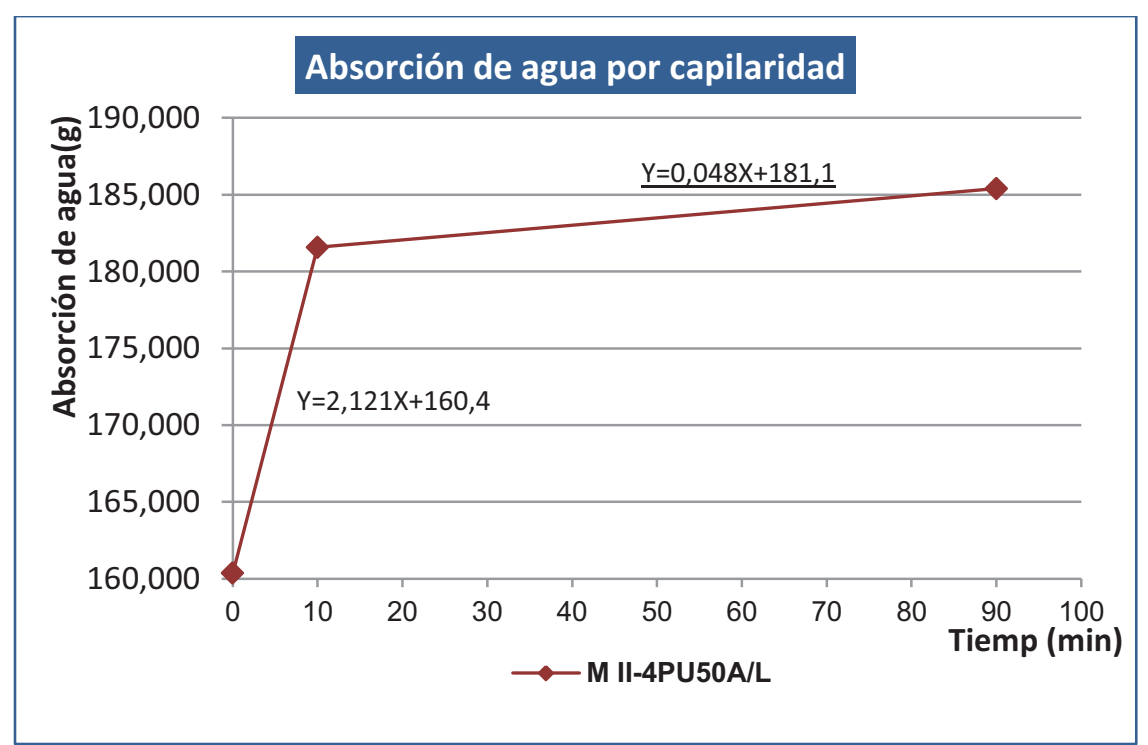

Figura 5.6. Pendiente línea absorción de agua. 0-10 $\mathrm{min}$. 10-90 $\mathrm{min}$. M II4PU50A/L

\subsubsection{3.- Permeabilidad al vapor}

Los morteros de cemento utilizados en paramentos expuestos a condensaciones por razones de la elevada humedad ambiente y bajas 
temperaturas exteriores, se localizan especialmente en cerramientos de fachadas, formando parte de la hoja exterior del cerramiento. Los fenómenos de condensación del vapor de agua en el interior de los cerramientos dependen de factores tales como la humedad relativa del aire interior y la configuración propia del cerramiento.

Si el aire del interior de un cerramiento de fachada, con unas condiciones de humedad relativa elevada se enfría, es probable que se produzcan condensaciones en el interior. El agua en forma líquida puede migrar hasta la cara exterior o interior del cerramiento, produciéndose manchas de humedad. Al mismo tiempo, el agua que permanece en el interior del paramento puede perjudicar al propio material constitutivo del cerramiento, ya sea por disolución, o por efecto de la helada si la zona condensada se encuentra próxima al exterior.

Si el material del cerramiento tiene una estructura interna que favorezca el paso del vapor de agua a su través, es probable que el agua líquida de su interior se evapore en determinadas circunstancias, reduciéndose el peligro de deterioro en el paramento.

La capacidad de difusión de vapor de agua a través de un mortero para revoco y enlucido, se evalúa con el ensayo de permeabilidad al vapor de agua de la norma UNE-EN 1015-19, según el procedimiento operatorio del capítulo 2.

Una vez obtenidos los valores medios y representadas las gráficas (Figuras 5.7 a 5.13), con dispersiones mínimas respecto de la recta de tendencia, se puede calcular tanto la permeanza como la permeabilidad al vapor. 


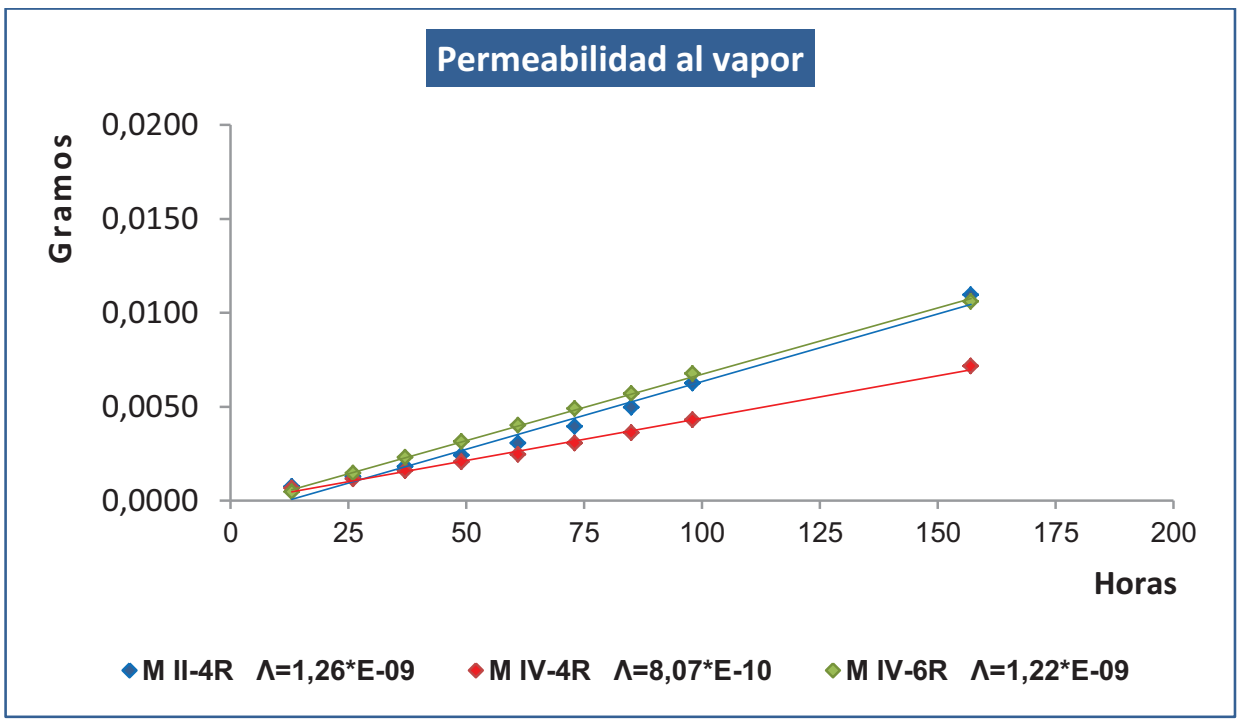

Figura 5.7. Permeabilidad al vapor morteros de referencia

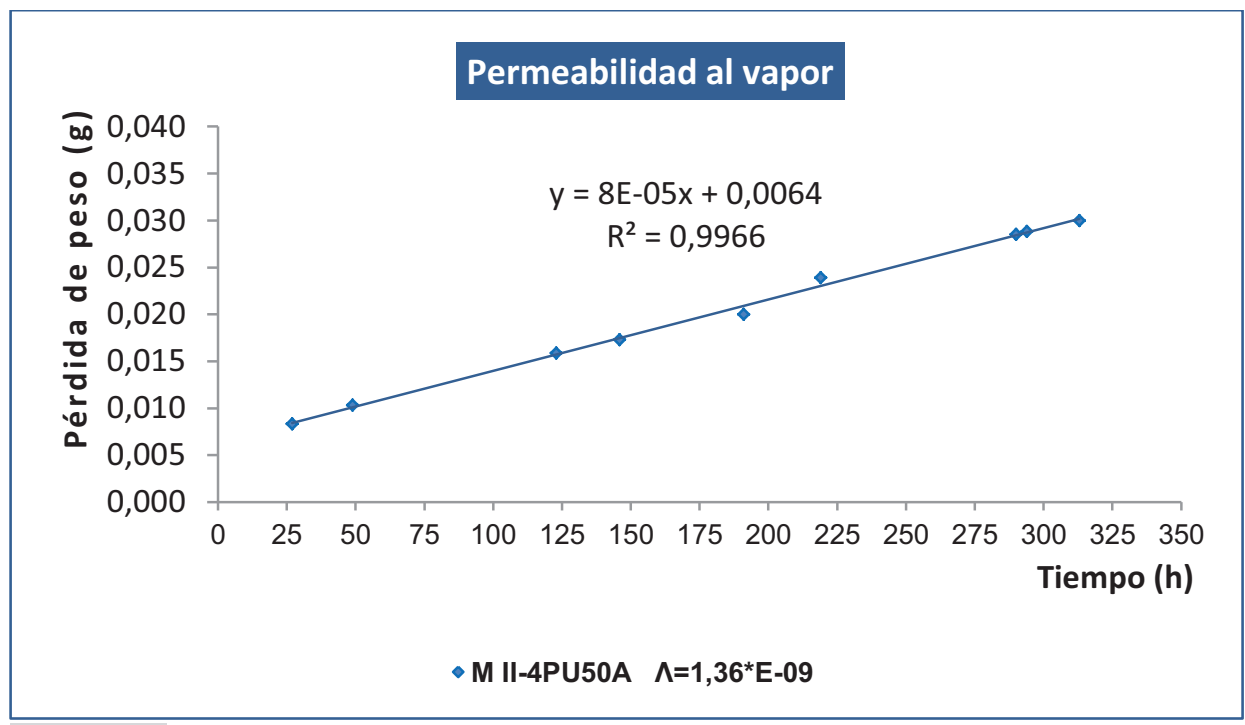

Figura 5.8. Permeabilidad al vapor M II-4PU50A 
Fabricación y caracterización de morteros con aditivos

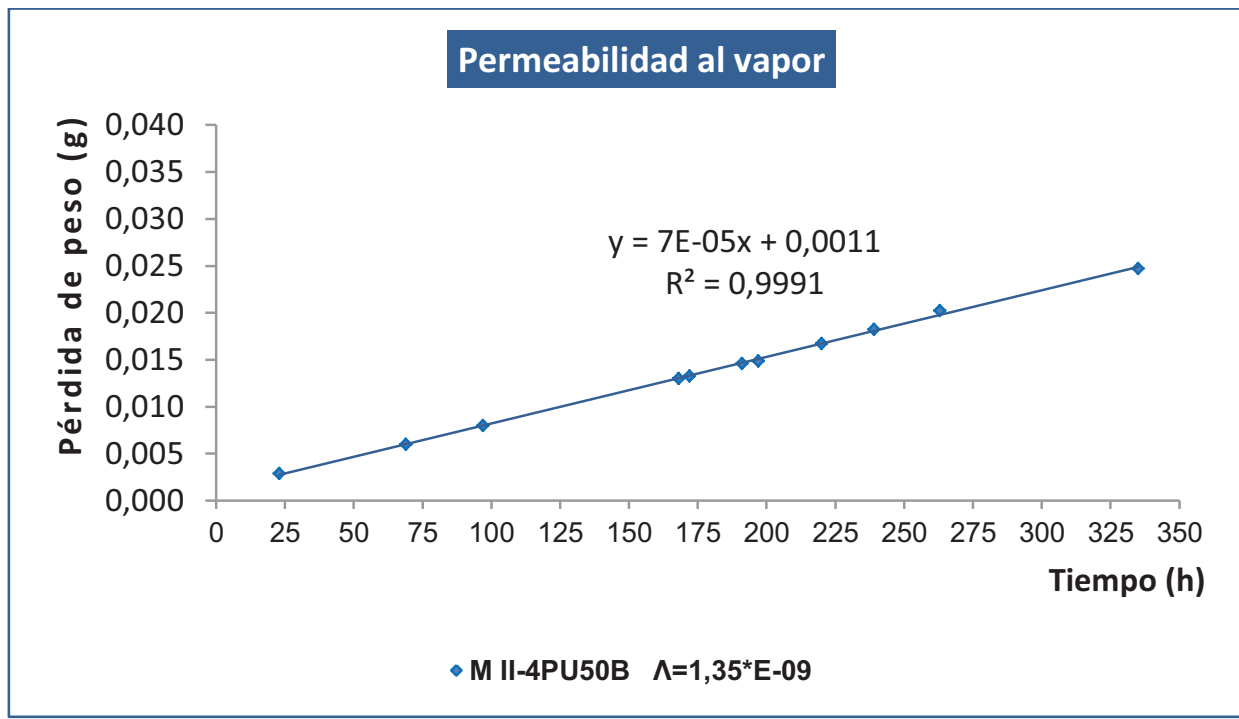

Figura 5.9. Permeabilidad al vapor M II-4PU50B

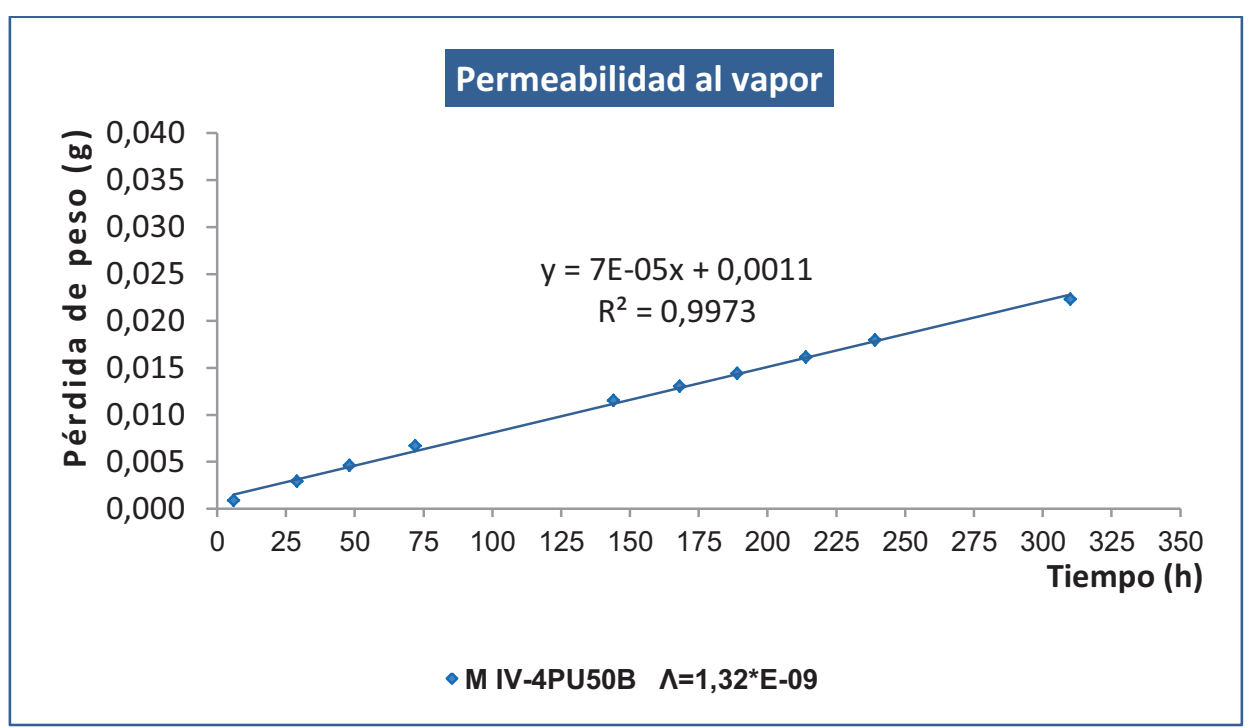

Figura 5.10. Permeabilidad al vapor M IV-4PU50B 
Fabricación y caracterización de morteros con aditivos

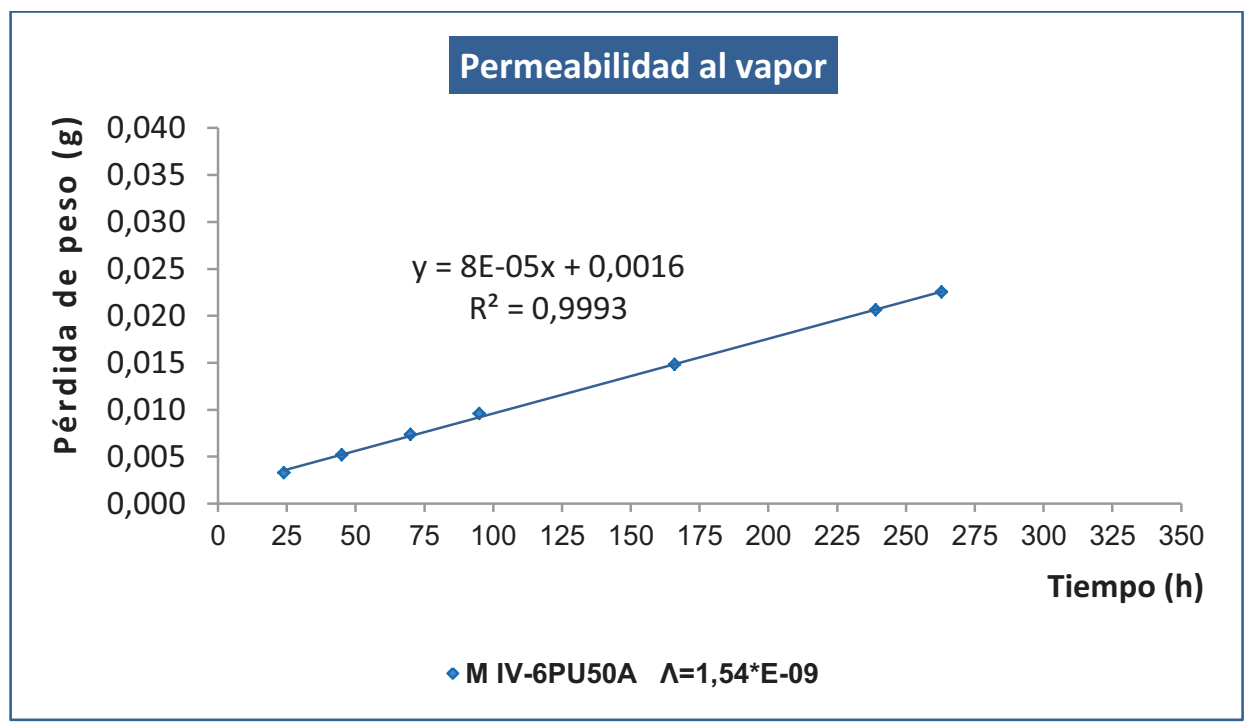

Figura 5.11. Permeabilidad al vapor M IV-6PU50A

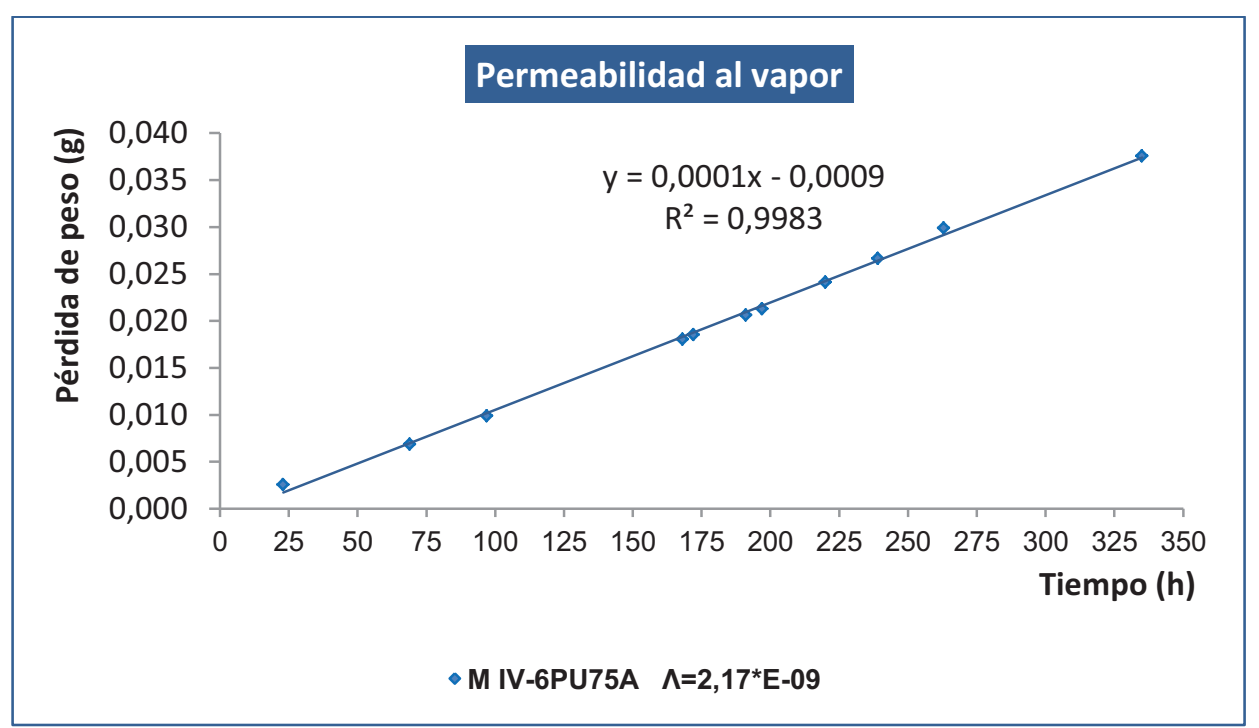

Figura 5.12. Permeabilidad al vapor M IV-6PU75A 


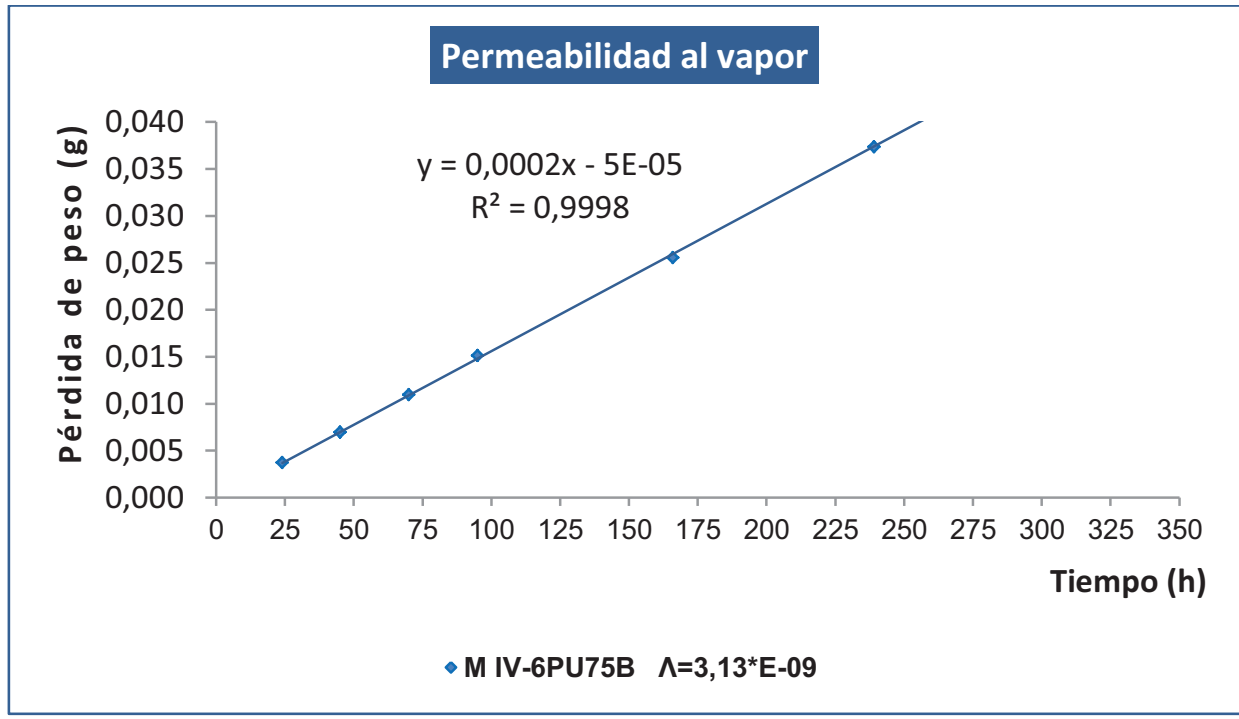

Figura 5.12. Permeabilidad al vapor M IV-6PU75B

La Tabla 5.13 muestra las permeanzas y permeabilidades al vapor de los morteros con y sin agregados de espuma, comprobándose que los morteros con alto porcentaje de agregados de PUR tienen una permeabilidad al vapor muy superior a los morteros de referencia. Esto los hace adecuados como morteros de revestimiento exterior y también como morteros de rehabilitación. En el caso de los morteros de rehabilitación, al no poder actuar en muchas ocasiones en el interior del paramento, pueden resultar muy adecuados para favorecer la evaporación de las posibles condensaciones intersticiales.

Tabla 5.13. Permeabilidad al vapor de agua

\begin{tabular}{|l|c|c|}
\hline \multicolumn{2}{|c|}{ Mortero } & \multicolumn{2}{c|}{ Permeabilidad al vapor de agua } \\
\hline M II-4R & 1,26379 & 1,26379 \\
\hline M IV-4R & 0,80660 & 0,80660 \\
\hline M IV-6R & 1,21957 & 1,21957 \\
\hline M II-4PU50A & 1,36361 & 1,36361 \\
\hline M II-4PU50B & 1,34616 & 1,34616 \\
\hline M IV-4PU50B & 1,31871 & 1,31871 \\
\hline M IV-6PU50A & 1,53717 & 1,53717 \\
\hline M IV-6PU75A & 2,16979 & 2,16979 \\
\hline M IV-6PU75B & 3,13435 & 3,13435 \\
\hline
\end{tabular}


Adicionalmente, se ha estimado la permeabilidad al vapor de las dos mezclas de CEM II con aditivo de látex, obteniéndose permeabilidades superiores al doble de sus homólogos sin látex, y siendo éstas incluso superiores a la permeabilidad de los morteros con sustitución del $75 \%$ de arena (Figuras 5.14 y 5.15), (Tabla 5.14).

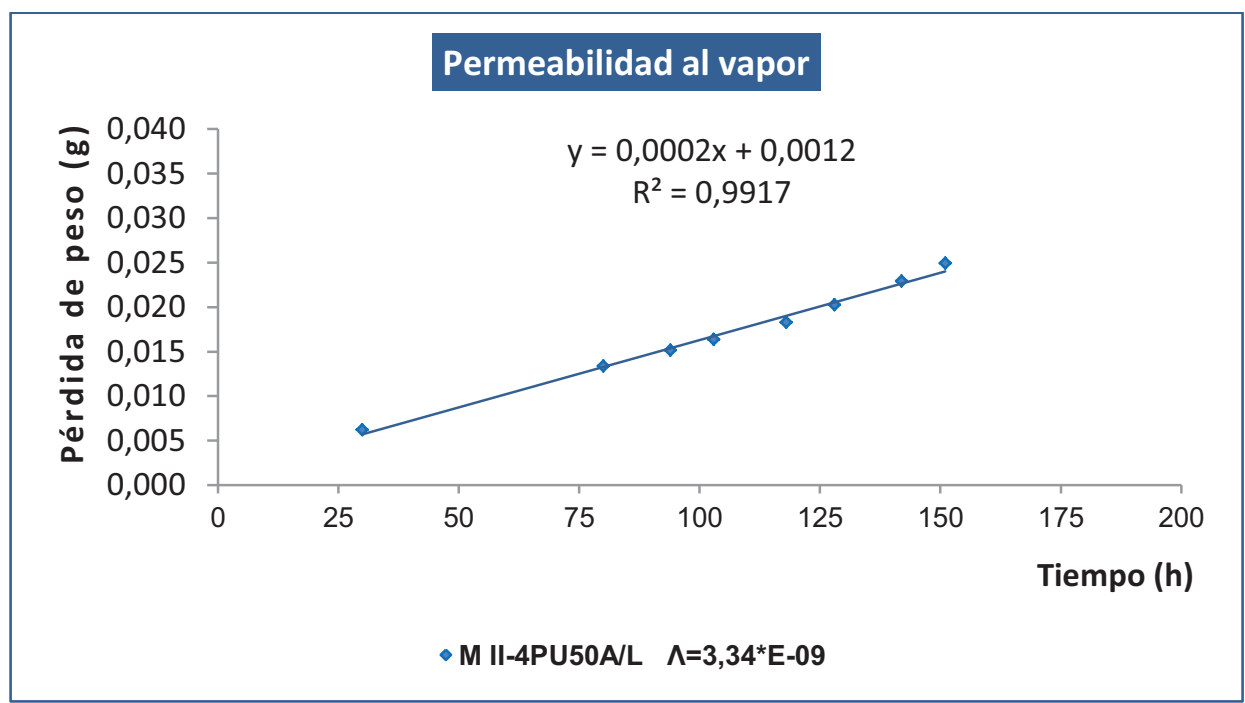

Figura 5.14. Permeabilidad al vapor M II-4PU50A/L

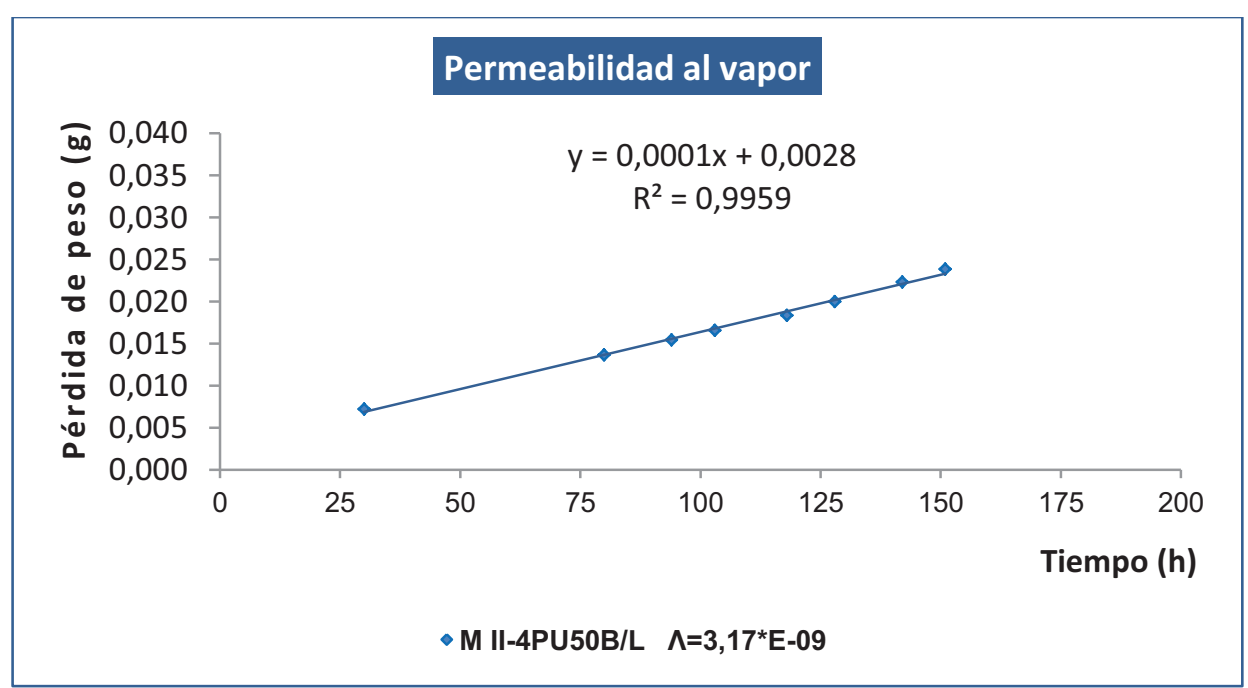

Figura 5.15. Permeabilidad al vapor M II-4PU50B/L 
Tabla 5.14. Permeabilidad al vapor. Comparativa morteros sin y con aditivos

\begin{tabular}{|l|c|c|}
\multicolumn{2}{|c}{ Mortero } & \multicolumn{2}{c|}{ Permeabilidad al vapor de agua } \\
\hline & Permeanza*10-09 & Permeabilidad*10-11 \\
\hline M II-4PU50A & 1,36361 & 1,36361 \\
\hline M II-4PU50A/L & 3,33870 & 3,33870 \\
\hline M II-4PU50B & 1,34616 & 1,34616 \\
\hline M II-4PU50B/L & 3,17192 & 3,17192 \\
\hline
\end{tabular}

\subsubsection{4.- Transmisión acústica a ruido aéreo}

Se ha realizado un ensayo comparativo de transmisión acústica a ruido aéreo de probetas con agregado de PUR, acorde a lo especificado en el capítulo 2.

Los valores numéricos de aislamiento medio se han calculado para diferentes bandas de frecuencia:

- $\quad$ Entre $500 \mathrm{~Hz}$ y $10 \mathrm{KHz}$

- Entre $500 \mathrm{~Hz}$ y $4 \mathrm{KHz}$

En los resultados del ensayo (Figura 5.16), se comprueba el cumplimiento del principio de disminución del aislamiento acústico en función de la disminución de la densidad aparente.

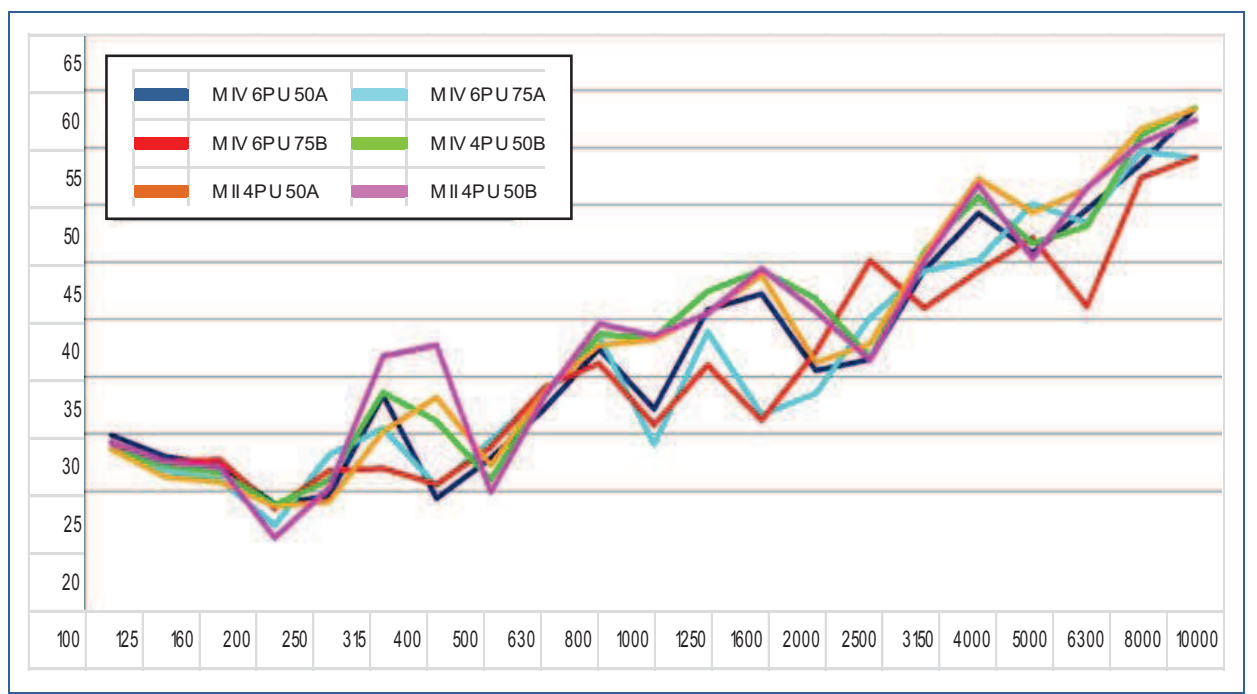

Figura 5.16. Aislamiento acústico en Petit Cabine 
La placa M IV-4PU50B presenta el mayor aislamiento acústico ya que su densidad también es la más elevada.

Se ha calculado el valor de la relación aislamiento/peso (Figura 5.17), donde se observa que, aunque hay una disminución de aislamiento en las placas más ligeras, la relación aislamiento/densidad es mejor en esas placas.

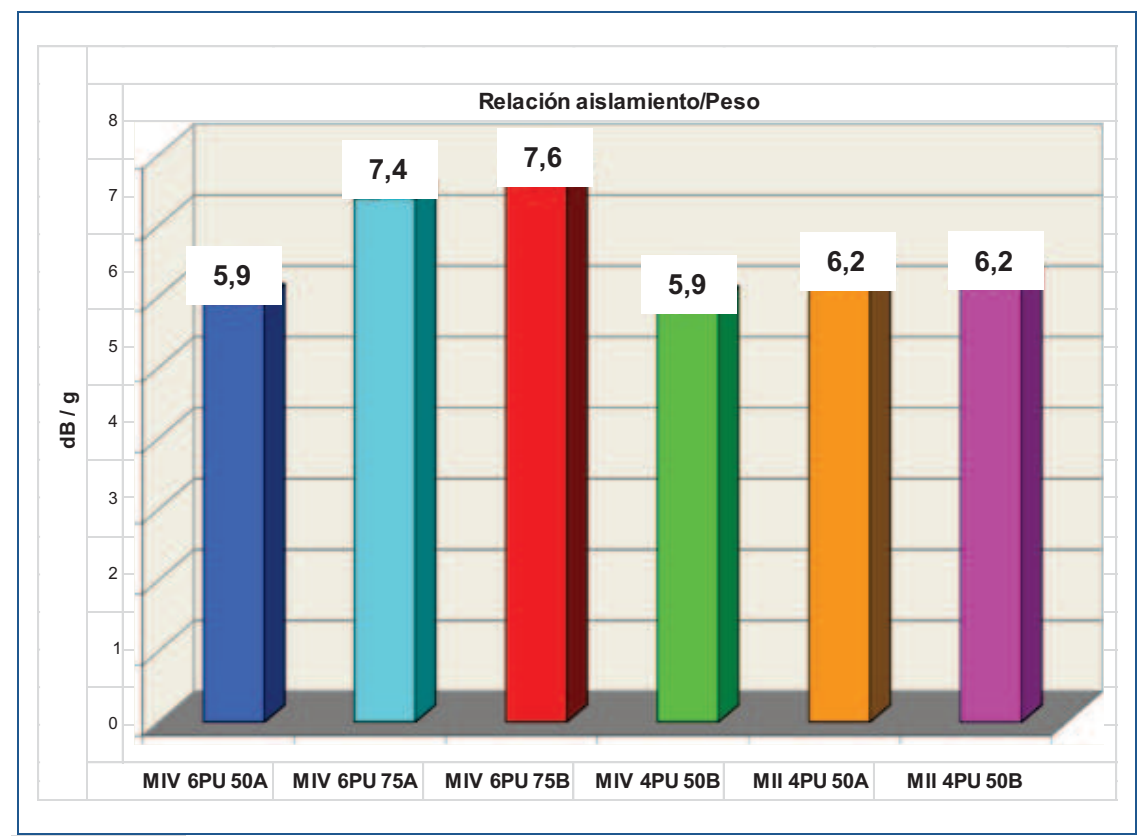

Figura 5.17. Relación Aislamiento acústico a ruido aéreo / Peso

\subsubsection{2.- Características mecánicas}

\subsubsection{1.- Resistencias a flexión y compresión}

Se han ensayado todas las probetas a flexión y compresión tanto a 7 días como a 28 días, con los resultados de las Tablas 5.15 y 5.16 
Fabricación y caracterización de morteros con aditivos

Tabla 5.15 Resistencia a la flexión y compresión a 7 días. Morteros con aditivos

\begin{tabular}{|l|c|c|c|c|c|c|}
\hline & Sin aditivo & Aditivo L & Aditivo P & Sin aditivo & Aditivo L & Aditivo P \\
\hline M II-4R & 2,25 & 2,94 & 2,84 & 7,61 & 6,78 & 8,17 \\
\hline M IV-4R & 2,65 & 2,47 & 3,20 & 8,33 & 6,83 & 8,08 \\
\hline M IV-6R & 1,03 & 2,89 & 2,73 & 3,81 & 7,15 & 7,51 \\
\hline M II-4PU50A & 1,80 & 2,01 & 2,50 & 6,54 & 4,29 & 6,94 \\
\hline M II-4PU50B & 1,75 & 2,07 & 0,89 & 4,94 & 4,98 & 2,80 \\
\hline M IV-4PU50B & 1,36 & 1,66 & 1,51 & 3,60 & 5,14 & 4,03 \\
\hline M IV-6PU50A & 1,11 & 1,10 & 1,30 & 4,02 & 3,11 & 3,92 \\
\hline M IV-6PU75A & 1,01 & 0,56 & 0,89 & 3,87 & 1,57 & 1,87 \\
\hline M IV-6PU75B & 0,69 & 0,52 & 0,47 & 2,88 & 1,28 & 1,81 \\
\hline
\end{tabular}

Tabla 5.16. Resistencia a la flexión y compresión a 28 días. Morteros con aditivos

\section{Mortero \\ Resistencia a flexión Mpa Resistencia a compresión Mpa}

\begin{tabular}{|l|c|c|c|c|c|c|} 
& Sin aditivo & Aditivo L & Aditivo P & Sin aditivo & Aditivo L & Aditivo P \\
\hline M II-4R & 3,38 & 2,67 & 2,53 & 11,67 & 13,15 & 12,23 \\
\hline M IV-4R & 3,79 & 2,70 & 3,19 & 9,36 & 11,30 & 14,50 \\
\hline M IV-6R & 1,30 & 2,98 & 2,64 & 6,01 & 13,21 & 15,09 \\
\hline M II-4PU50A & 1,92 & 2,31 & 2,70 & 7,01 & 6,23 & 8,88 \\
\hline M II-4PU50B & 2,23 & 2,12 & 1,78 & 6,39 & 5,55 & 4,96 \\
\hline M IV-4PU50B & 2,25 & 2,83 & 2,57 & 7,30 & 9,48 & 7,40 \\
\hline M IV-6PU50A & 1,39 & 1,80 & 2,18 & 5,01 & 5,12 & 6,75 \\
\hline M IV-6PU75A & 1,15 & 1,05 & 1,32 & 4,03 & 2,47 & 3,86 \\
\hline M IV-6PU75B & 0,72 & 0,85 & 0,65 & 3,01 & 2,40 & 2,23 \\
\hline
\end{tabular}

En las Figuras 5.18 y 5.19 se comparan las resistencias a flexión y compresión a los 28 días de los morteros con aditivos y de sus homólogos sin aditivos. 


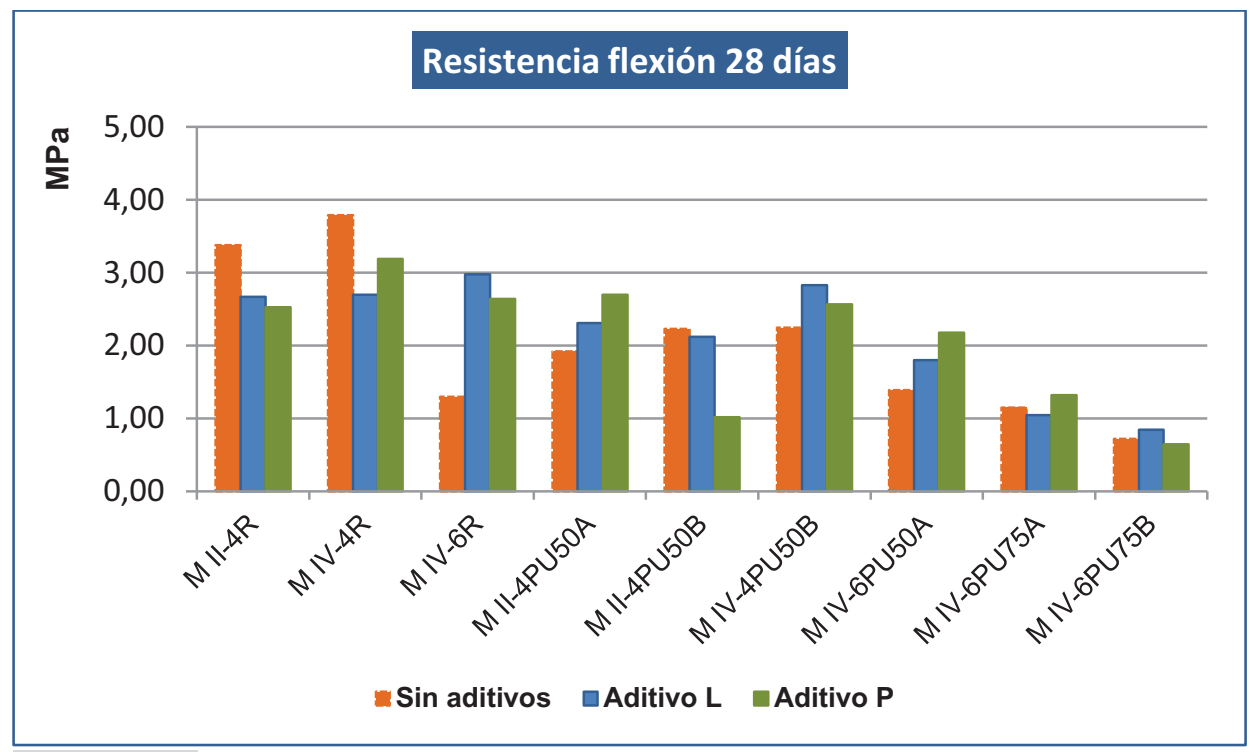

Figura 5.18. Resistencia a flexión 28 días. Comparativa morteros con y sin aditivos

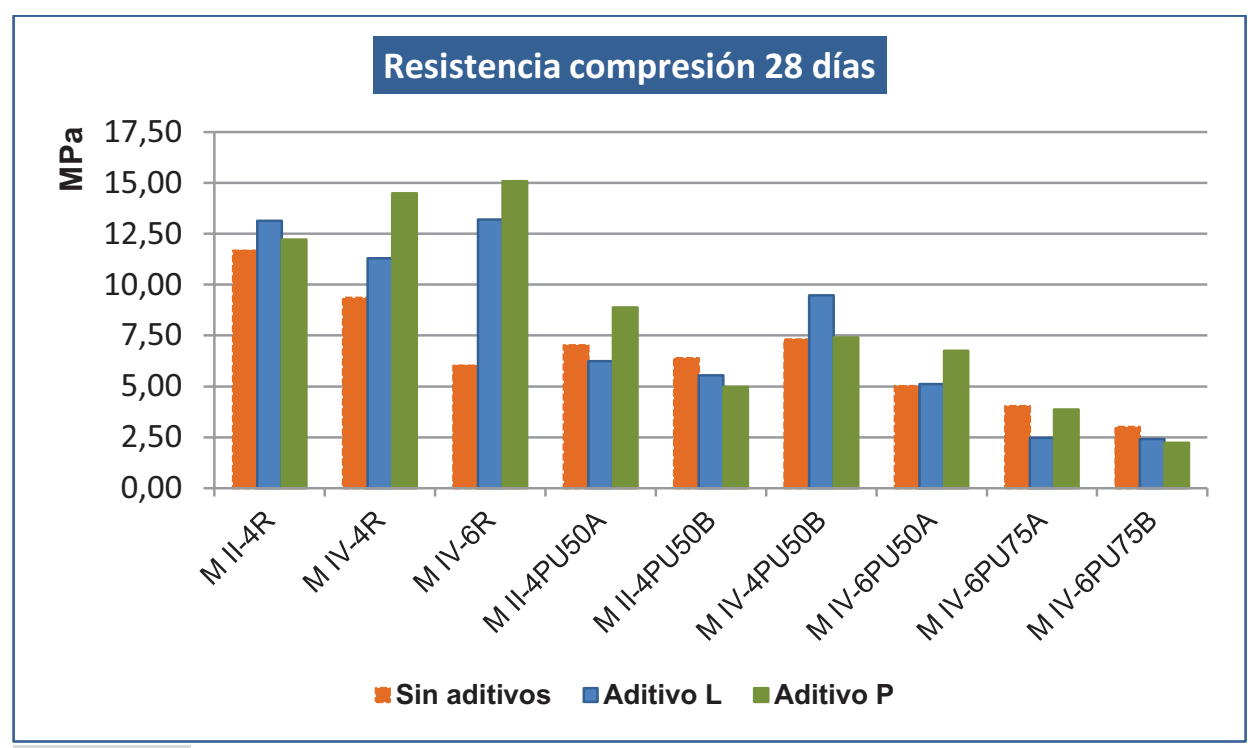

Figura 5.19. Resistencia a compresión 28 días. Comparativa morteros con y sin aditivos

En general, la resistencia a flexión mejora ligeramente con el empleo de aditivos en los morteros con agregados de PUR. Sin embargo en los morteros de referencia disminuyen las resistencias, a excepción del mortero M IV-6R, que incrementa considerablemente la resistencia a los 28 
días, por lo que no se pueden sacar unas conclusiones claras de estos resultados.

Los aditivos aumentan la resistencia a compresión a los 28 días en todos los morteros de referencia, debido a que al disminuir la cantidad de agua disminuye la porosidad, y en algunos casos se incrementa la cantidad de cemento (Tabla 5.17).

\begin{tabular}{|c|c|c|c|}
\hline \multirow[t]{2}{*}{ Mortero } & \multicolumn{3}{|c|}{ kg cemento por $\mathrm{m}^{3}$ de mortero } \\
\hline & Sin aditivos & Aditivo L & Aditivo $\mathrm{P}$ \\
\hline M II-4R & 356,3 & 327,0 & 342,8 \\
\hline M IV-4R & 360,8 & 342,0 & 361,2 \\
\hline M IV-6R & 248,6 & 259,2 & 289,7 \\
\hline M II-4PU50A & 467,4 & 381,2 & 425,7 \\
\hline M II-4PU50B & 450,4 & 325,1 & 369,2 \\
\hline M IV-4PU50B & 473,3 & 410,7 & 415,0 \\
\hline M IV-6PU50A & 328,7 & 310,0 & 354,8 \\
\hline M IV-6PU75A & 343,3 & 320,6 & 393,2 \\
\hline M IV-6PU75B & 287,7 & 297,8 & 324,8 \\
\hline
\end{tabular}

En los morteros con agregados de PUR la incorporación de aditivos apenas modifica la resistencia a compresión, pues en unos casos el aumento de porosidad se ve compensado con el aumento de cemento y en otros la menor porosidad conlleva un mejor comportamiento a compresión, por lo que la disminución de la relación agua-cemento es poco significativa, dando lugar incluso a morteros menos densos y probablemente con parecida porosidad, sin producirse mejora en las características mecánicas.

Para poder evaluar los efectos en las resistencias finales de los morteros con amplio período de trabajabilidad (aptdo. 5.3.1.2.-), se han realizado ensayos mecánicos a tres meses y se han comparado con los resultados obtenidos a los 28 días (Figura 5.20). El incremento general de resistencias a los tres meses en los morteros con sustitución del $50 \%$, es, en muchos casos, superior al $100 \%$. Esto lleva a pensar que los morteros con un cierto grado de sustitución de arena por PUR, pueden necesitar un aditivo acelerador de fraguado, con el objeto de alcanzar las resistencias finales en el entorno de los 28 días. 


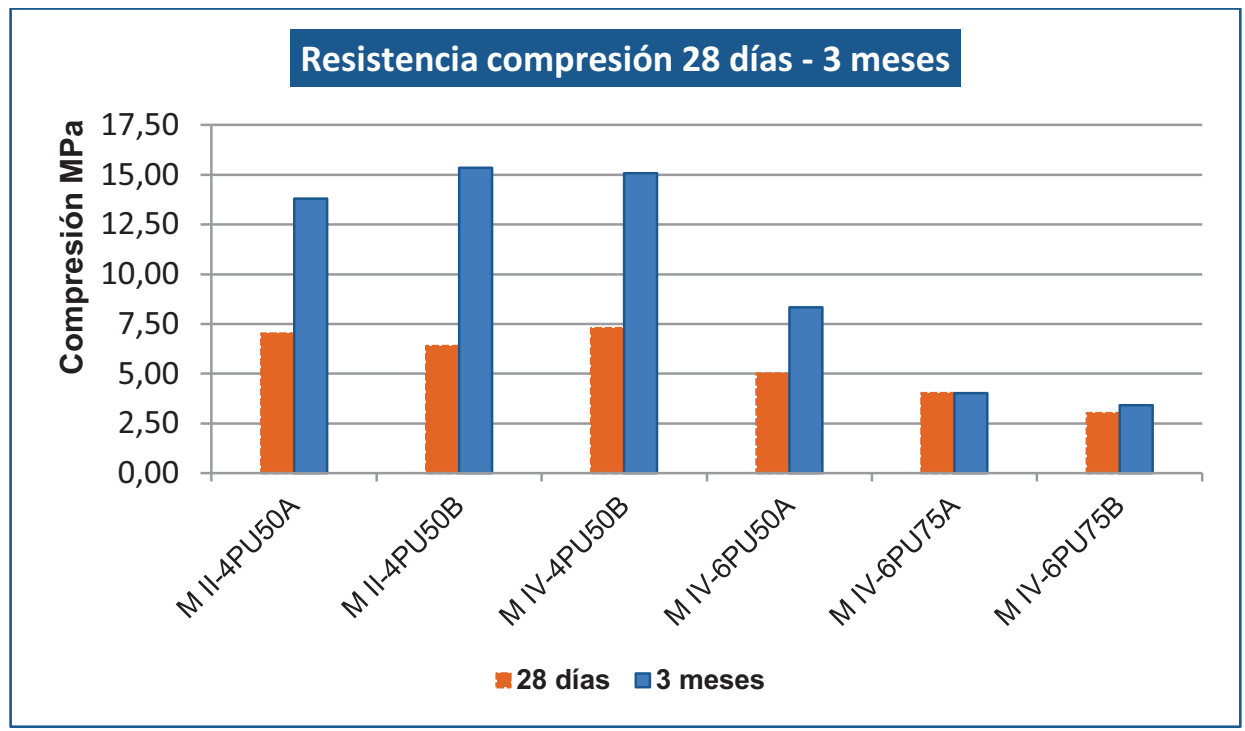

Figura 5.20. Resistencia a compresión a los 28 días y a los 3 meses.

Por último y completando el estudio de deformabilidad iniciado en el apartado 4.3.2.2.2 se han representado las curvas de tensión-deformación en los morteros seleccionados, rompiendo las muestras a compresión a los 3 meses, tal y como representa la Figura 5.20.

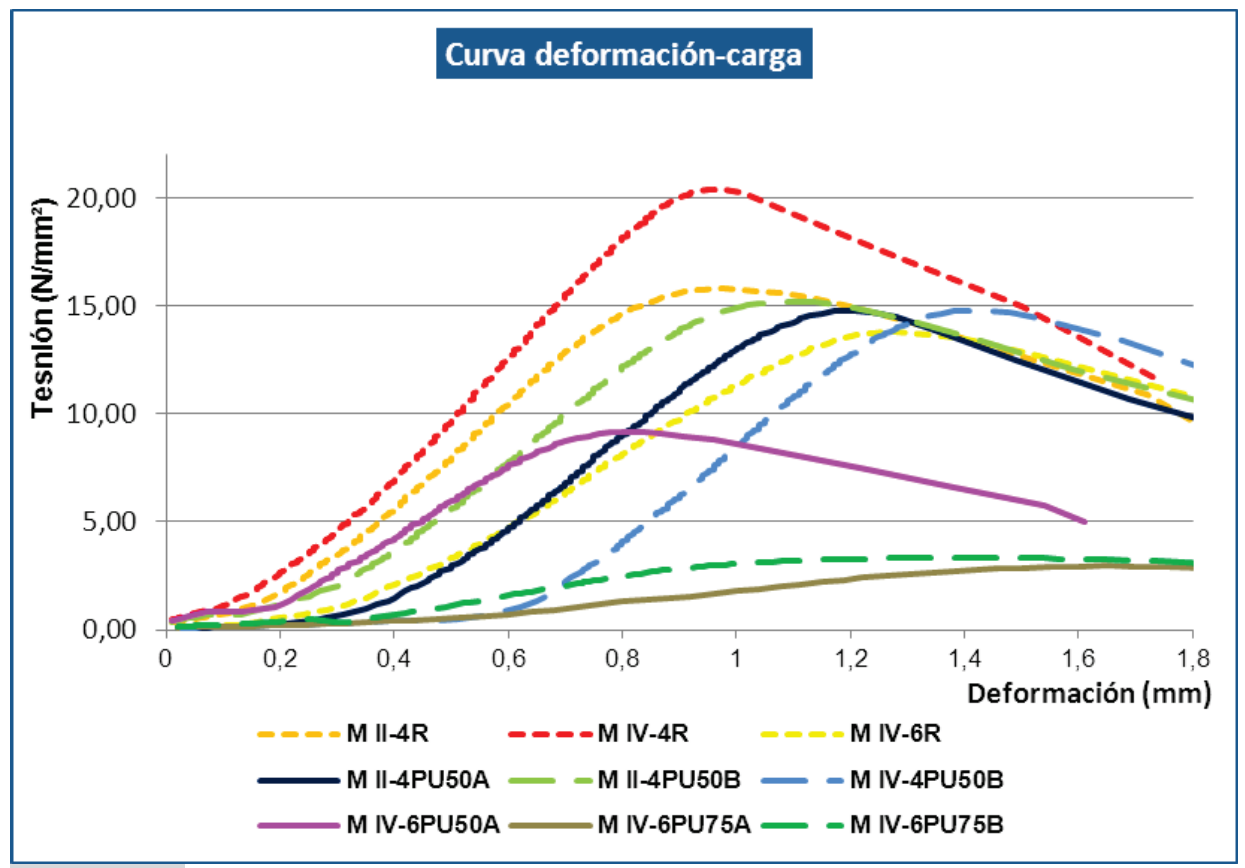

Figura 5.21. Curva tensión-deformación 
En los morteros con agregados de PUR se confirma en general que a igualdad de deformaciones acusan más tensión aquellos morteros sin sustitución de arena por PUR, lo que indica que los morteros con agregados de PUR de hasta el $75 \%$ pueden soportar mejor las deformaciones inducidas por elementos constructivos ajenos al mortero, como son las particiones, fachadas, etc., confinadas entre forjados.

\subsubsection{2.- Resistencia a la adhesión}

Una de las principales aptitudes de un mortero es su adherencia, entendida como la resistencia del mortero a despegarse del soporte, es decir la capacidad de resistir las tensiones normales y tangenciales en la interfase mortero-soporte.

Los resultados de la resistencia a la adhesión en las probetas con aditivo látex no mejoran la adherencia al soporte, a pesar de que una de las indicaciones del aditivo es precisamente mejorar esa propiedad. Por otro lado, la adherencia de las probetas con agregado de PUR resulta suficiente, aunque siempre menor que las probetas de referencia.

En la Tabla 5.18 se indican los resultados de las adherencias en distintos tipos de probetas.

Tabla 5.18. Resistencia a la adhesión de los morteros

\begin{tabular}{|c|c|c|}
\hline Mortero & Base cerámica & Base hormigón \\
\hline & \multicolumn{2}{|c|}{$\mathrm{N} / \mathrm{m} \mathrm{m}^{2}$} \\
\hline M II-4R & 0,46 & 0,08 \\
\hline M IV-4R & 0,49 & 0,38 \\
\hline M IV-6R & 0,41 & 0,13 \\
\hline M II-4PU50A/L & 0,14 & 0,07 \\
\hline M II-4PU50B/L & 0,09 & 0,10 \\
\hline M IV-4PU50B/L & 0,18 & 0,27 \\
\hline M IV-6PU50A/L & 0,16 & 0,33 \\
\hline M IV-6PU75A/L & 0,12 & 0,22 \\
\hline M IV-6PU75B/L & 0,11 & 0,11 \\
\hline
\end{tabular}

\subsubsection{3.- Resistencia a la abrasión}

Dentro de las aplicaciones del mortero de cemento está su empleo para el revestimiento de paramentos verticales y horizontales, sentado de fábricas 
de albañilería y base para la colocación de solados, bien solados cerámicos, pétreos, de madera o plásticos, adheridos, bien ciertos tipos de pavimento flotante.

La dureza a la abrasión no es una característica fundamental para los morteros de revestimiento de paramentos y juntas, pues salvo usos muy específicos, el mortero en general, no está expuesto al desgaste por efecto de la abrasión.

El que se emplea como solera-base para la colocación de un pavimento tampoco se encuentra, en principio, expuesto a desgaste por abrasión, pues en la vida útil del mortero su superficie estará protegida por el solado. Sin embargo, para poder colocar el solado sobre la solera de mortero, es necesario que ésta tenga la resistencia y grado de humedad determinado, que solamente se consiguen con el paso del tiempo. Durante este período tiempo en que el mortero alcanza la resistencia y grado de humedad óptimos, la solera está expuesta a degradación por abrasión, ya que la dinámica de los trabajos en obra no permite clausurar indefinidamente el paso por las estancias con la solera ejecutada.

Por este motivo es necesario conocer la dureza a la abrasión

No existe norma UNE sobre el método de este ensayo para morteros, por lo que ha sido necesario adaptar la norma UNE-EN 14157, que describe el procedimiento para evaluar el comportamiento de la piedra natural sometida a desgaste por abrasión, según el procedimiento operatorio del capítulo 2.

Para la determinación de la resistencia a la abrasión, dentro de los tres métodos que recoge la norma, se ha escogido el del disco de abrasión ancho.

La resistencia a la abrasión de las probetas de referencia (Tabla 5.19) es ligeramente inferior a la resistencia patrón "Mármol de Boulonnaise", cuya medida de huella, una vez calibrada la máquina, es de $20 \mathrm{~mm}$. La resistencia de los morteros de cemento II con sustitución del $50 \%$ por PUR, presentan una dureza algo inferior a sus homólogos de referencia. Los morteros de cemento IV con sustitución del $50 \%$ por PUR, presentan una dureza inferior en un $25 \%$ a sus homólogos de referencia. Finalmente los morteros con sustitución del $75 \%$, sufren pérdidas de resistencia 
superiores al $30 \%$, con especial incidencia en la muestra M IV-6PU75A, en que la medida de la huella aumenta hasta un $40 \%$.

Tabla 5.19. Resistencia a la abrasión

\begin{tabular}{|l|c|c|}
\multicolumn{1}{|c|}{ Mortero } & Resistencia a la abrasión & $\begin{array}{c}\text { Variación con mortero de } \\
\text { referencia }\end{array}$ \\
\hline M II-4R & $\mathrm{mm}$ & $\%$ \\
\hline M IV-4R & 25,4 & --- \\
\hline M IV-6R & 23,4 & --- \\
\hline M II-4PU50A & 26,3 & --- \\
\hline M II-4PU50B & 28,8 & $-13,4$ \\
\hline M IV-4PU50B & 25,7 & $-1,2$ \\
\hline M IV-6PU50A & 29,1 & $-24,4$ \\
\hline M IV-6PU75A & 33,2 & $-26,2$ \\
\hline M IV-6PU75B & 37,5 & $-42,6$ \\
\hline
\end{tabular}

De estos resultados se puede extraer que la resistencia a la abrasión de los morteros con sustitución del $50 \%$ de arena por PUR es relativamente alta y suficiente para su empleo en obra como morteros de albañilería y revestimiento vertical, ya que en esos casos no están expuestos a desgaste por abrasión.

Los morteros con sustitución del $75 \%$ de arena por PUR presentan una resistencia menor, lo que puede hacerlos no aptos para su colocación como material de base de nivelación para solados, exclusivamente en la fase que transcurre desde su puesta en obra hasta la colocación del correspondiente revestimiento, ya sea de pavimento flotante o de pavimento pegado. En todo caso, y en esta fase de la ejecución de la obra, se deberían proteger exteriormente de la abrasión mediante la colocación de film plástico, fieltros o cartones. Estos materiales, colocados tanto en juntas de fábricas como en revestimiento de paredes o techos, pueden ser aptos si no están expuestos a abrasión "excesiva". Una protección exterior de los morteros, como puede ser una capa de terminación con mortero rico en cemento, un revestimiento cerámico o similar o una pintura, evitarían la abrasión superficial de estos mortero más blandos.

\subsubsection{4.- Capacidad de deformación}

En las gráficas de tensión-deformación del apartado 4.3.2.2.2 se ha comprobado que la capacidad de deformación de los morteros con 
agregado de PUR es superior a la de sus homólogos sin agregados, y que a mayor cantidad de agregado de PUR, mayor capacidad de deformación.

Para contrastar esta capacidad de deformación de los morteros, se han realizado una serie de ensayos que han consistido en medir la deformación y recuperación de los morteros sometidos a ciclos de carga-descarga, de acuerdo con el ensayo expuesto en el capítulo 2.

En las Figuras 5.22 a 5.30 se muestran gráficas de la deformación que han sufrido las probetas en los sucesivos ciclos. La medición se ha realizado desde la pletina metálica hasta la cara inferior de las probetas es decir sobre un espesor total de la probeta de $75 \mathrm{~mm}$. Superpuesta y con trazo más fino se ha representado la gráfica de los ciclos de carga, en la que se observa cómo en cada ciclo aumenta la carga aplicada, hasta estabilizarse en los últimos cuatro ciclos. Las deformaciones van paralelas a la aplicación de la carga descarga pero con una ligera tendencia a aumentar, incluso en los últimos ciclos en que la carga máxima no sufre incremento.

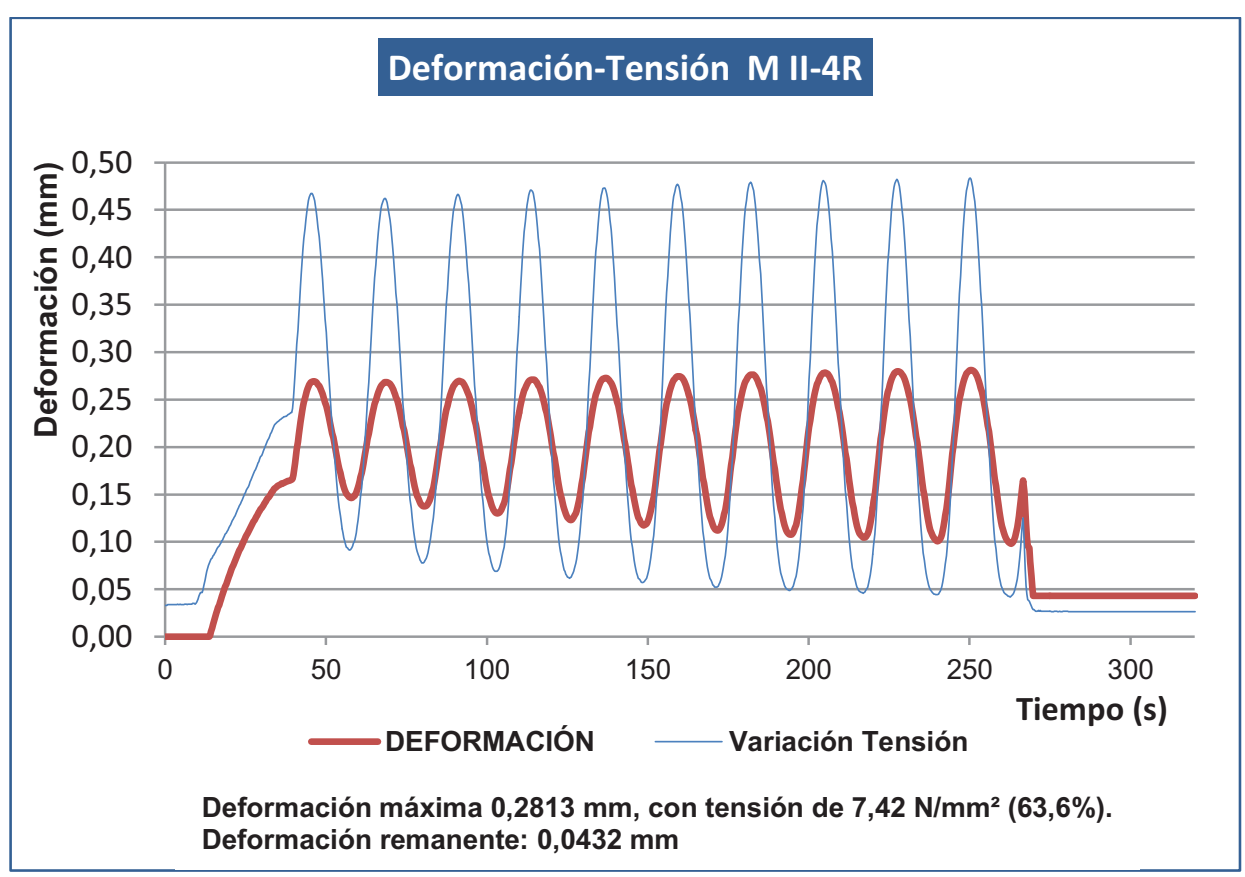

Figura 5.22. Gráfica ciclos tensión-deformación M II-4R 


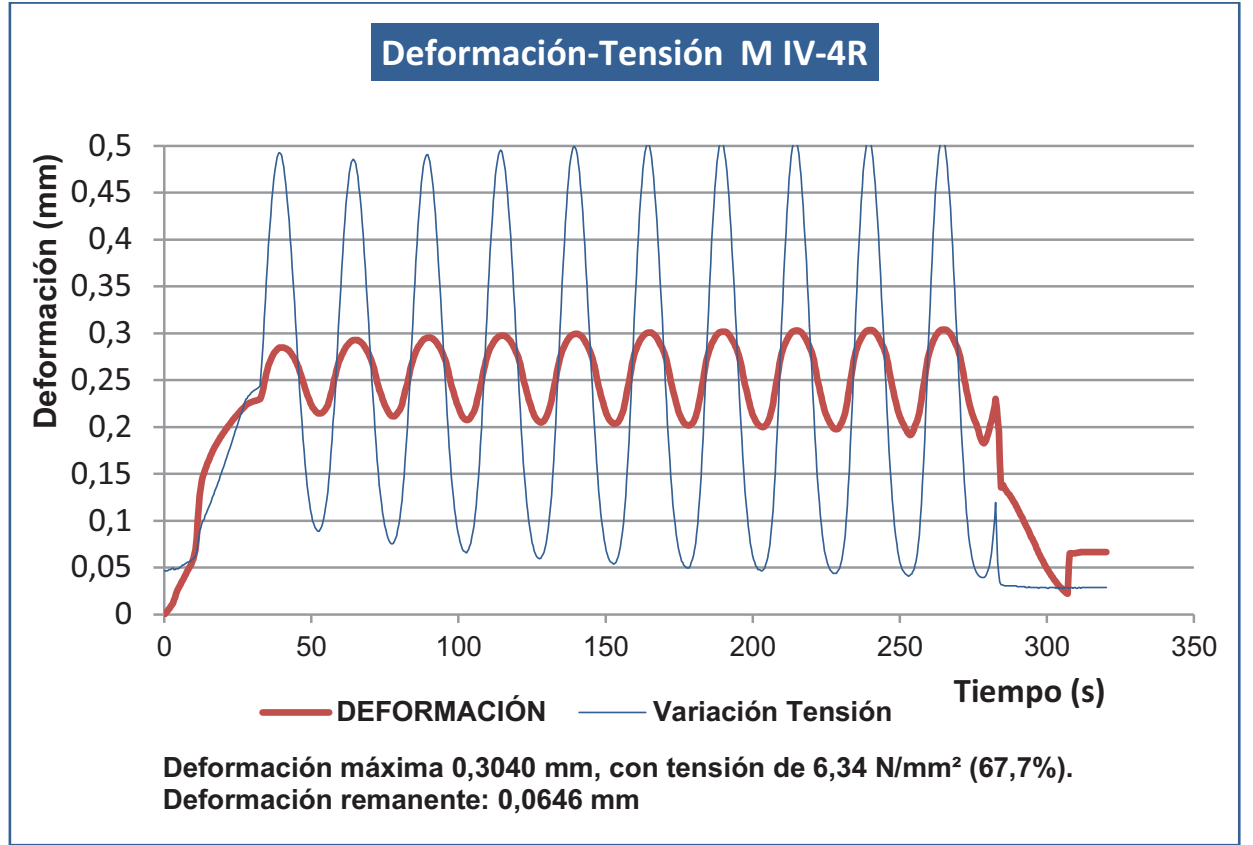

Figura 5.23. Gráfica ciclos tensión-deformación M IV-4R

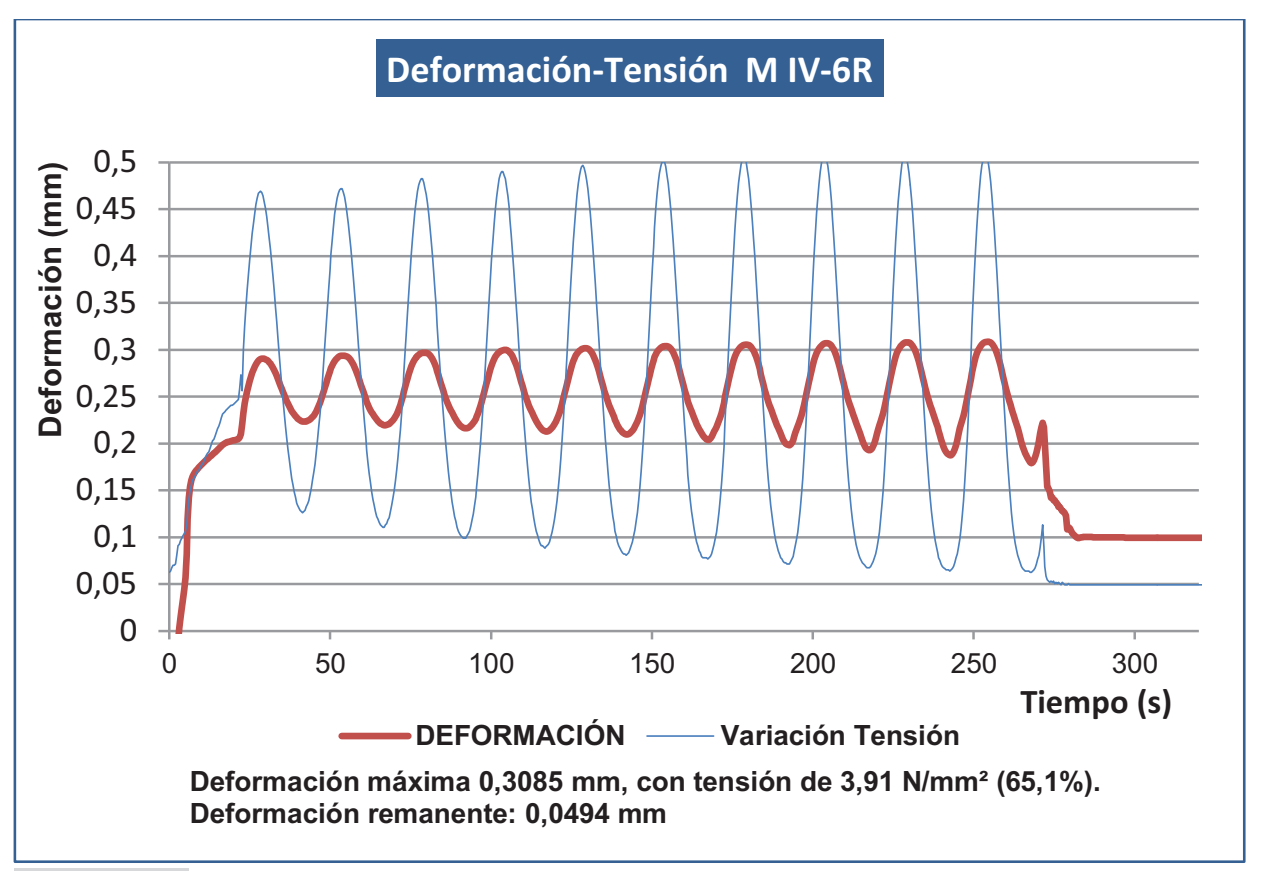

Figura 5.24. Gráfica ciclos tensión-deformación M IV-6R 


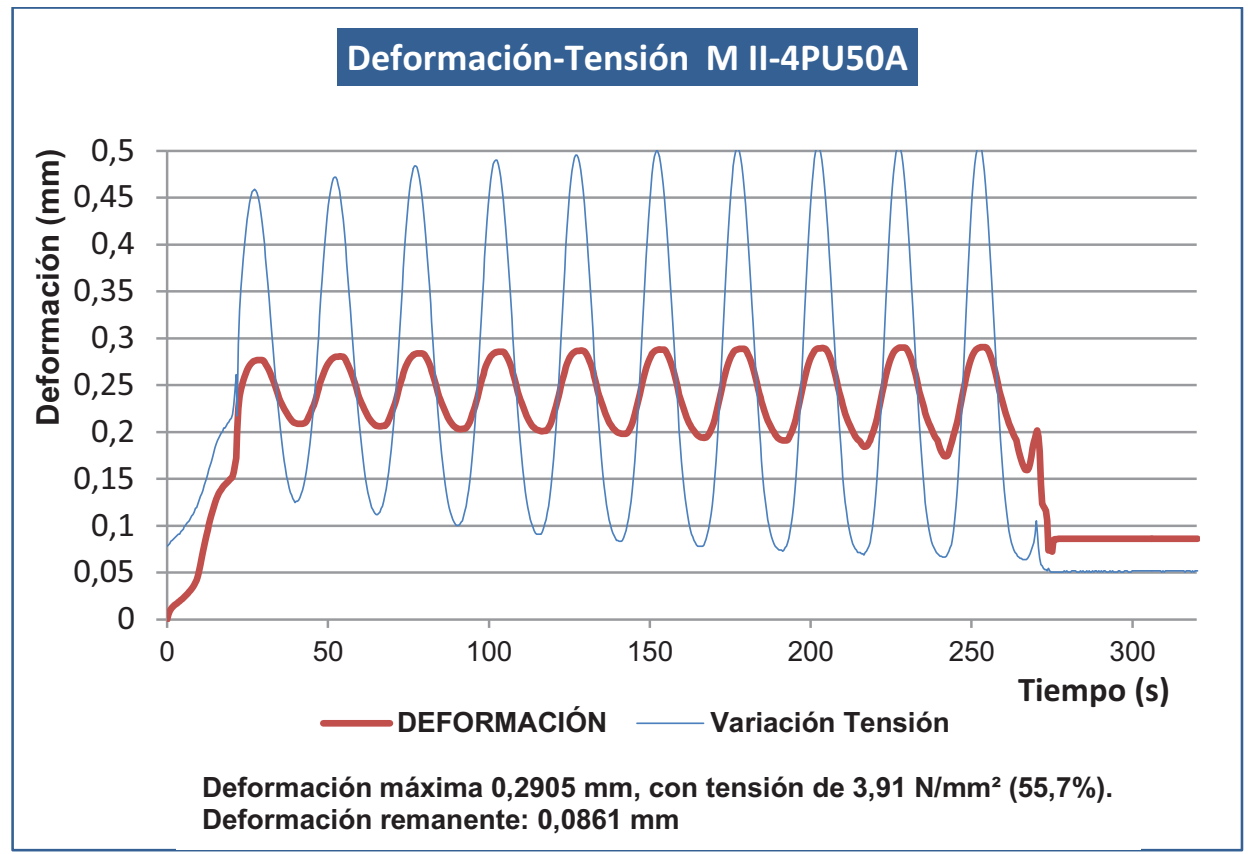

Figura 5.25. Gráfica ciclos tensión-deformación M II-4PU50A

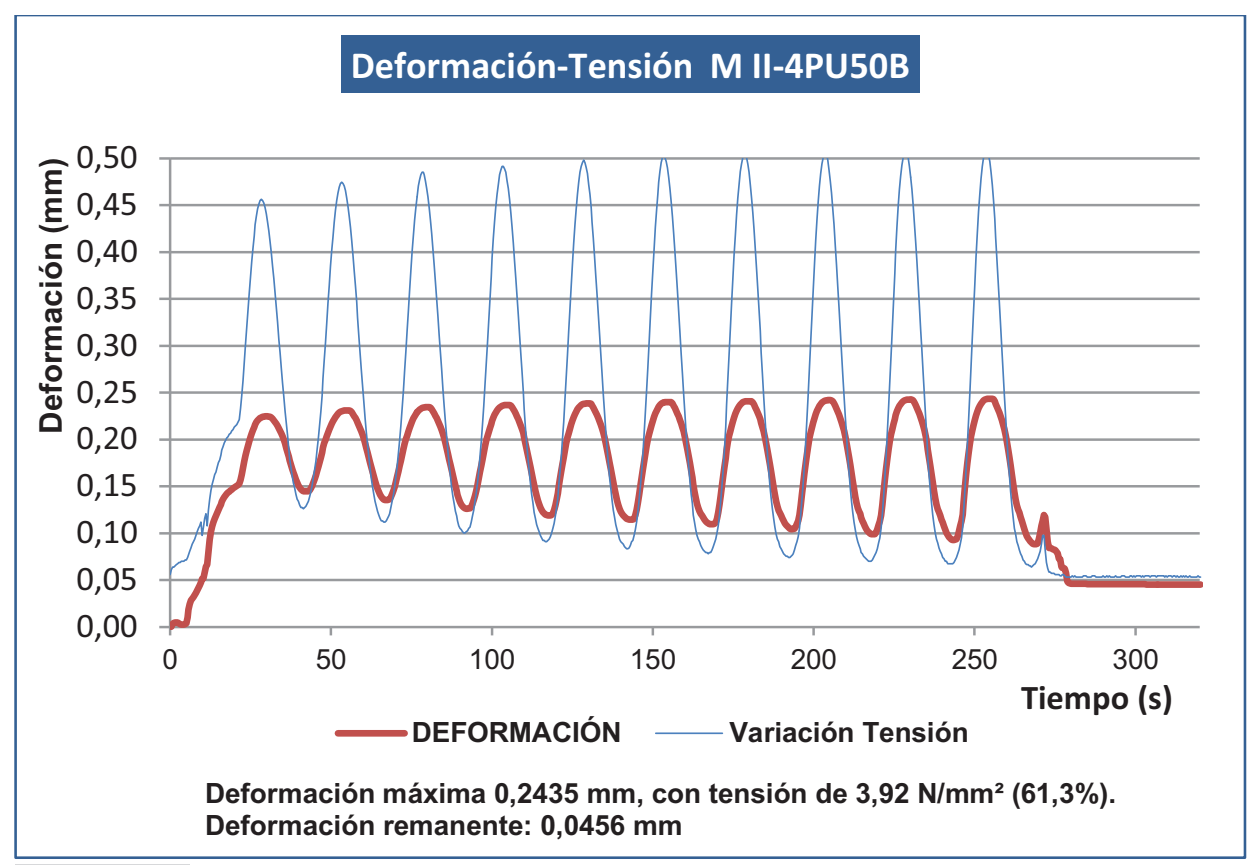

Figura 5.26. Gráfica ciclos tensión-deformación M II-4PU50B 


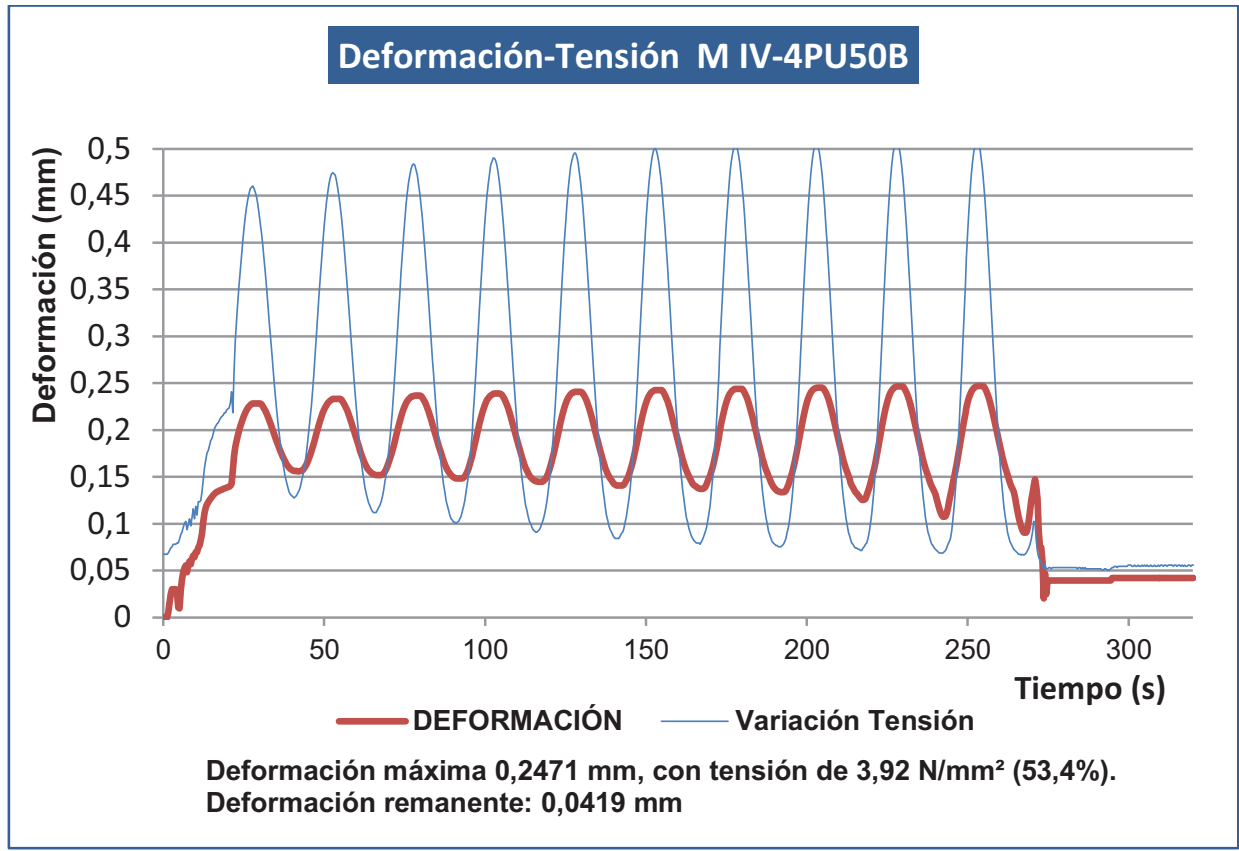

Figura 5.27. Gráfica ciclos tensión-deformación M IV-4PU50B

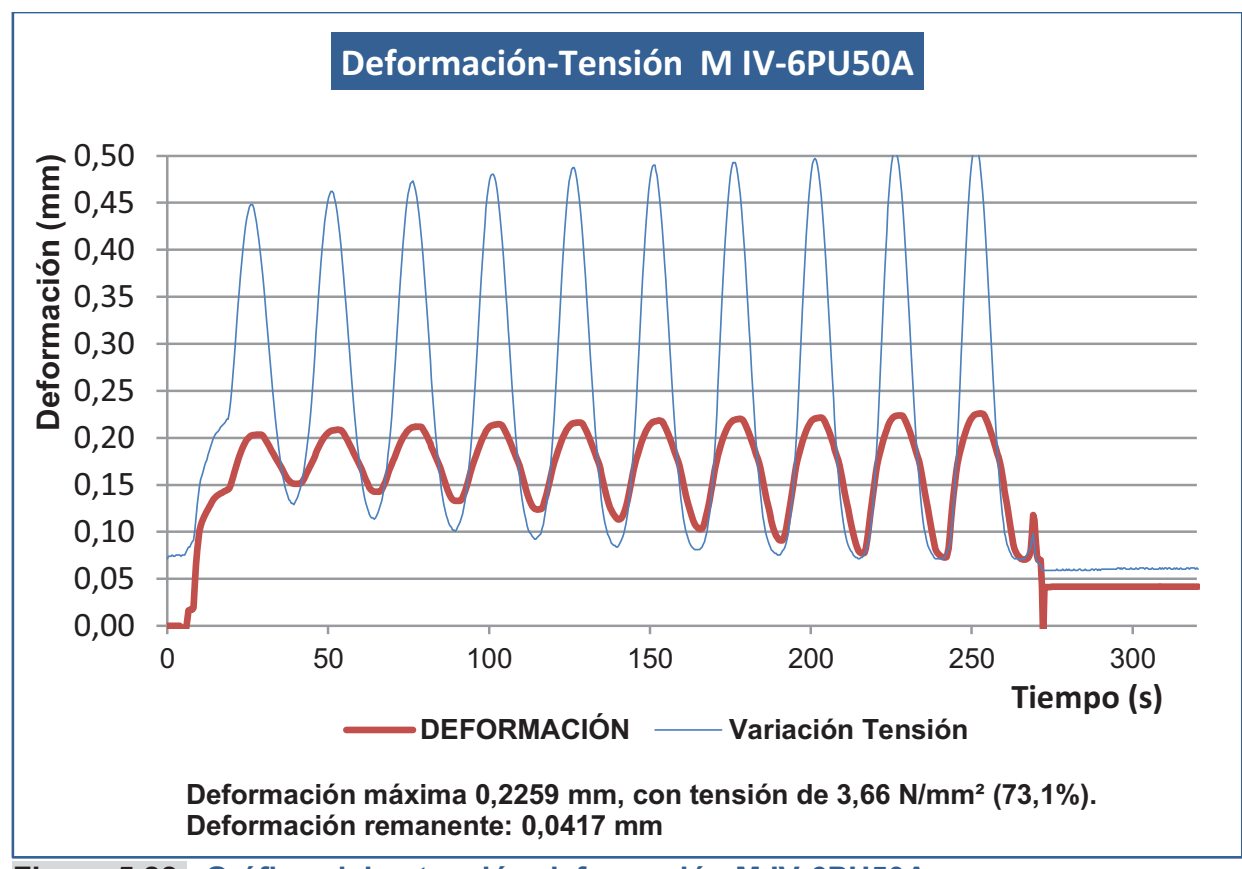

Figura 5.28. Gráfica ciclos tensión-deformación M IV-6PU50A 


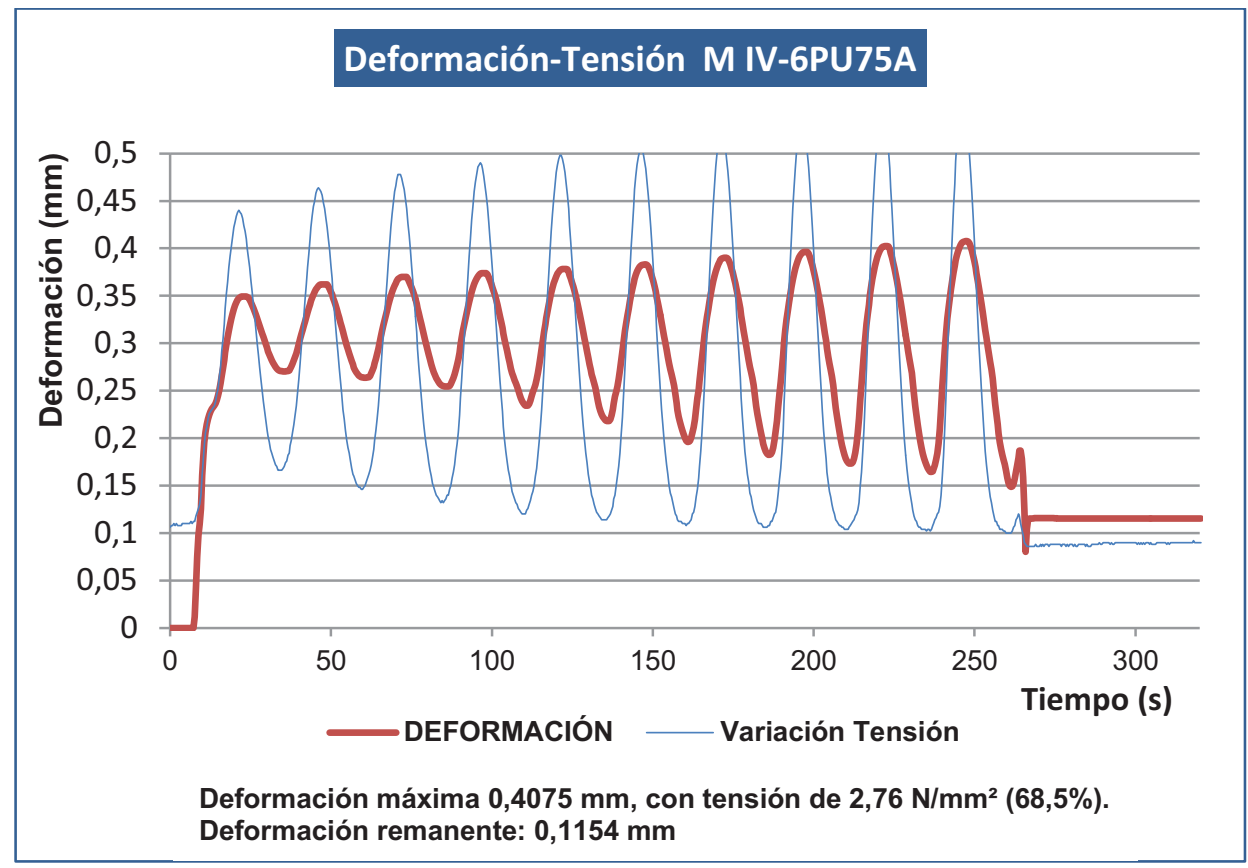

Figura 5.29. Gráfica ciclos tensión-deformación M IV-6PU75A

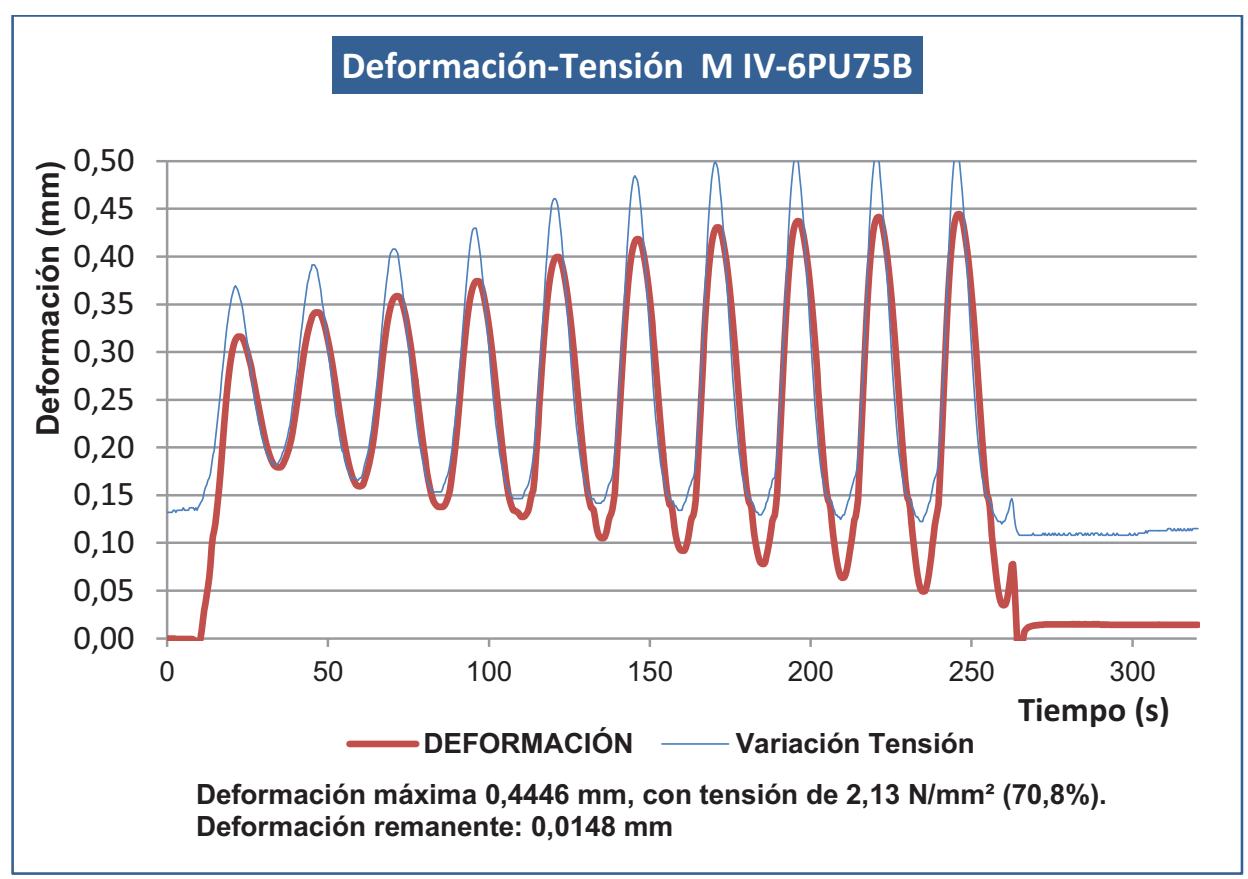

Figura 5.30. Gráfica ciclos tensión-deformación M IV-6PU75B

La Tabla 5.20 contiene las deformaciones máximas y remanentes y la diferencia entre la deformación máxima y remanente. También se indica el 
porcentaje de la tensión aplicada sobre la máxima de rotura en cada probeta. Se ha calculado la relación entre la deformación máxima y el porcentaje de tensión aplicado, lo que ha permitido establecer la posible capacidad de deformación de cada mortero.

Tabla 5.20. Deformabilidad

\begin{tabular}{|l|c|c|c|c|c|}
\hline \multicolumn{5}{|c}{ Mortero } & \multicolumn{3}{c}{$\begin{array}{c}\text { Tensión } \\
\text { s/rotura \% }\end{array}$} & $\begin{array}{c}\text { Deformación } \\
\text { máxima } \\
\text { s/tensión \% }\end{array}$ \\
\hline M II-4R & 0,2813 & 0,0432 & 0,2381 & 63,6 & 0,44 \\
\hline M IV-4R & 0,3040 & 0,0646 & 0,2394 & 67,7 & 0,45 \\
\hline M IV-6R & 0,3085 & 0,0494 & 0,2591 & 65,1 & 0,47 \\
\hline M II-4PU50A & 0,2905 & 0,0861 & 0,2044 & 55,7 & 0,52 \\
\hline M II-4PU50B & 0,2435 & 0,0456 & 0,1979 & 61,3 & 0,40 \\
\hline M IV-4PU50B & 0,2471 & 0,0419 & 0,2052 & 53,4 & 0,46 \\
\hline M IV-6PU50A & 0,2259 & 0,0417 & 0,1842 & 73,1 & 0,31 \\
\hline M IV-6PU75A & 0,4075 & 0,1154 & 0,2921 & 68,5 & 0,59 \\
\hline M IV-6PU75B & 0,4446 & 0,0148 & 0,4298 & 70,8 & 0,63 \\
\hline
\end{tabular}

De la Tabla 5.20 se puede extraer que la capacidad de deformación en un estado de confinamiento, es similar en los morteros con agregado hasta un $50 \%$ de PUR que en los morteros de referencia. Por otro lado, la "deformabilidad" de los morteros con agregado del $75 \%$ de PUR es muy superior a sus homólogos de referencia.

Con estos datos podemos concluir que los morteros con agregado de hasta un $75 \%$ de PUR tienen una muy buena capacidad de adaptación en estados obligados de deformación por confinamiento (elementos verticales entre forjados como fachadas, particiones interiores, etc.), o en situaciones obligadas de deformación por cambios térmicos (fachadas expuestas a sol de poniente), lo que evita que lleguen a la rotura por flexión o aplastamiento. Estas situaciones pueden ser causa de fisuración o rotura en los morteros convencionales. 
6

O

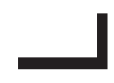

$\supset$

1

$1-$

口

$\varangle$

U

Durabilidad 



\section{Capítulo 6.- Durabilidad}

Uno de los principales objetivos del presente trabajo de investigación consiste en estudiar la viabilidad a largo plazo de los morteros con agregado de PUR como material de construcción, por lo que se debe conocer la aptitud para su puesta en obra y los efectos producidos por el paso del tiempo en las distintas condiciones ambientales o de uso que soportan los morteros de albañilería.

Los ensayos de durabilidad que a continuación se relacionan, también llamados de envejecimiento acelerado, no se han completado en todos los casos con los morteros modificados con aditivos, pues con el empleo de los aditivos se ha pretendido únicamente determinar las mejoras de las propiedades en las condiciones de amasado y en las resistencias mecánicas finales.

Los ensayos de durabilidad llevados a cabo según los procedimientos operatorios del apartado 2.4, son los siguientes:

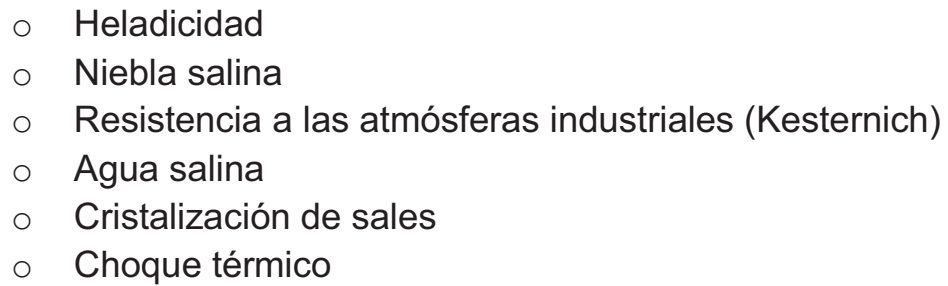

\section{1.- Resultados obtenidos}

\subsection{1.- Heladicidad}

El comportamiento frente a la helada evalúa la resistencia de los morteros colocados en el exterior, al tiempo que nos muestra el grado de cohesión interna de las partículas que componen el mortero.

No existe norma UNE sobre el método de este ensayo para morteros, por lo que ha sido necesario adaptar la norma UNE-EN 12371, que describe el procedimiento para evaluar el comportamiento de la piedra natural sometida a ciclos de hielo/deshielo. El número de ciclos a los que se 
somete el material depende del objetivo del ensayo, bien sea ensayo de identificación, bien ensayo tecnológico. La diferencia estriba en que en el ensayo tecnológico se evalúa el comportamiento a partir de las normas del producto, mientras que en el ensayo de identificación se evalúa el producto en función del número de ciclos prescrito por el cliente.

Los ciclos de hielo/deshielo para el ensayo se han calculado con las normas aplicables a la piedra natural, que señalan 56 ciclos para el ensayo de identificación, para baldosas de pavimentación, de acuerdo con UNE 22202-1:2011 144 y 59 ciclos para una exposición de 40 años en Burgos capital, según UNE 22203:2011, ${ }^{145}$ para aplacados de fachadas. Se optó por los 56 ciclos de hielo/deshielo, que pertenecen a la serie de ciclos de la norma UNE-EN 12371 y que se consideran suficientes.

Los resultados de los ensayos mecánicos después de los ciclos de hielodeshielo se indican en la Tabla 6.1.

Tabla 6.1. Ensayo de ciclos hielo-deshielo. Resistencias mecánicas a los 28 días

\begin{tabular}{|l|c|c|c|c|}
\multicolumn{1}{|c}{ Mortero } & \multicolumn{3}{c}{ Resistencia a flexión Mpa } & \multicolumn{2}{c|}{ Mesistencia a compresión } \\
& Antes & Después & Antes & Después \\
\hline M II-4PU50A & 1,92 & 3,64 & 7,01 & 15,32 \\
\hline M II-4PU50B & 2,23 & 2,98 & 6,39 & 15,06 \\
\hline M IV-4PU50B & 2,25 & 2,77 & 7,30 & 12,48 \\
\hline M IV-6PU50A & 1,39 & 2,45 & 5,01 & 8,39 \\
\hline M IV-6PU75A & 1,15 & 0,63 & 4,03 & 4,00 \\
\hline M IV-6PU75B & 0,72 & 0,11 & 3,01 & 1,82 \\
\hline
\end{tabular}

Las resistencias mecánicas de los morteros modificados con polímero se siguen desarrollando y aumentando con el tiempo, más allá de los primeros 28 días. Como los ensayos de heladicidad se han realizado durante 56 días (56 ciclos de hielo-deshielo), la edad final de las probetas en el momento de la rotura es de 3 meses aproximadamente, lo que en definitiva justifica la mejora en las propiedades mecánicas a flexión y compresión.

Por este motivo y con el fin de realizar un análisis comparativo más adecuado, se han representado los resultados de resistencia a compresión

\footnotetext{
144 Norma Española UNE 22202-1. Productos de piedra natural. Construcción de pavimentos con piedra natural. Parte 1: Baldosas para pavimentación de suelos y escaleras. 2011

${ }^{145}$ Norma Española UNE-EN 22203. Productos de piedra natural. Construcción de aplacados de fachadas con piedra natural. 2011
} 
obtenidos a los 3 meses (probetas patrón y probetas después del ensayo de heladicidad). (Figura 6.1).

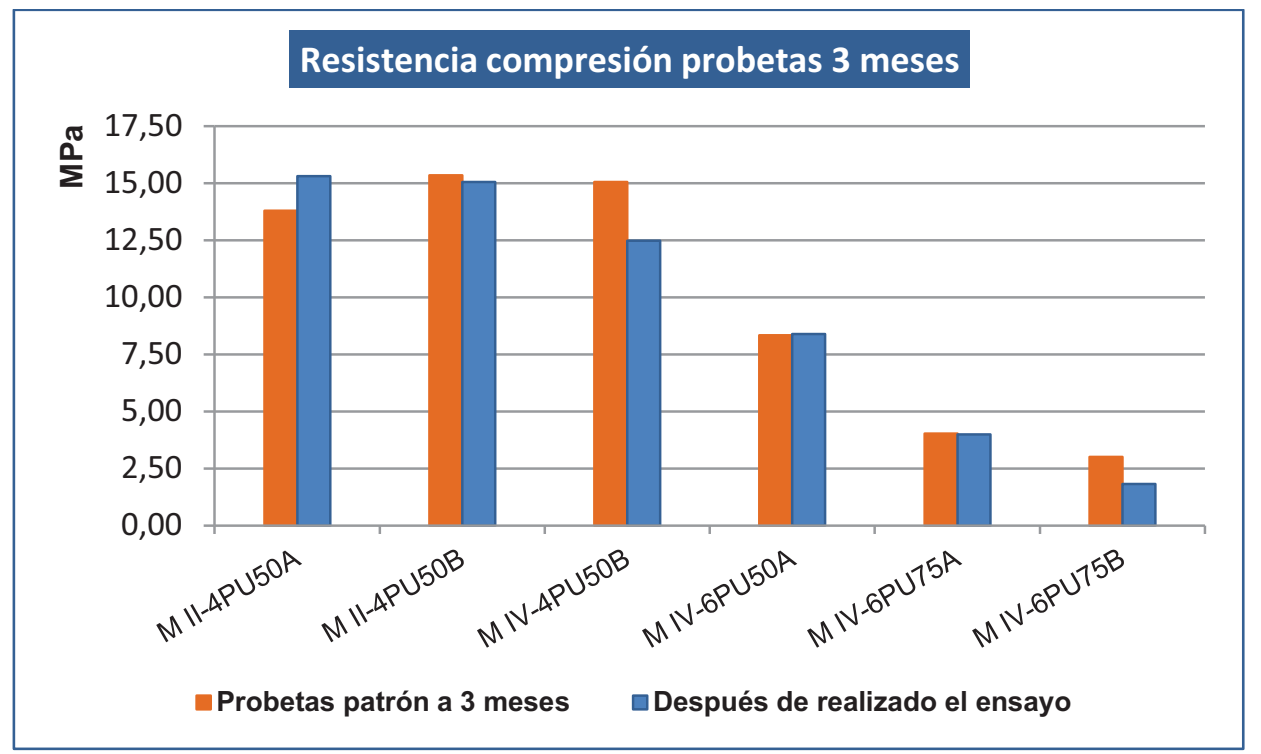

Figura 6.1. Ensayo de heladicidad. Resistencia a compresión a 3 meses.

En todos los casos la resistencia a la helada después de los 56 ciclos no sufre variaciones importantes, excepto en la mezcla M IV-6PU75B. Por ello se puede considerar que los morteros ensayados con agregados de espuma son, en general, resistentes a la helada.

El aspecto visual de las probetas indica que no se han producido deterioros importantes en las mismas, salvo un ligero deterioro en las probetas de $M$ IV-6PU75A y 75B (Tabla 6.2 y Figura 6.2).

Tabla 6.2. Deterioro de las probetas después de los ciclos hielo-deshielo

\begin{tabular}{|c|c|}
\hline Mortero & Inspección visual \\
\hline & Estado de la probeta \\
\hline M II-4PU50A & Daños mínimos (1) \\
\hline M II-4PU50B & Daños mínimos (1) \\
\hline M IV-4PU50B & Daños mínimos (1) \\
\hline M IV-6PU50A & Daños mínimos (1) \\
\hline M IV-6PU75A & Rotura de pequeños fragmentos (2) \\
\hline M IV-6PU75B & Rotura de pequeños fragmentos (2) \\
\hline
\end{tabular}




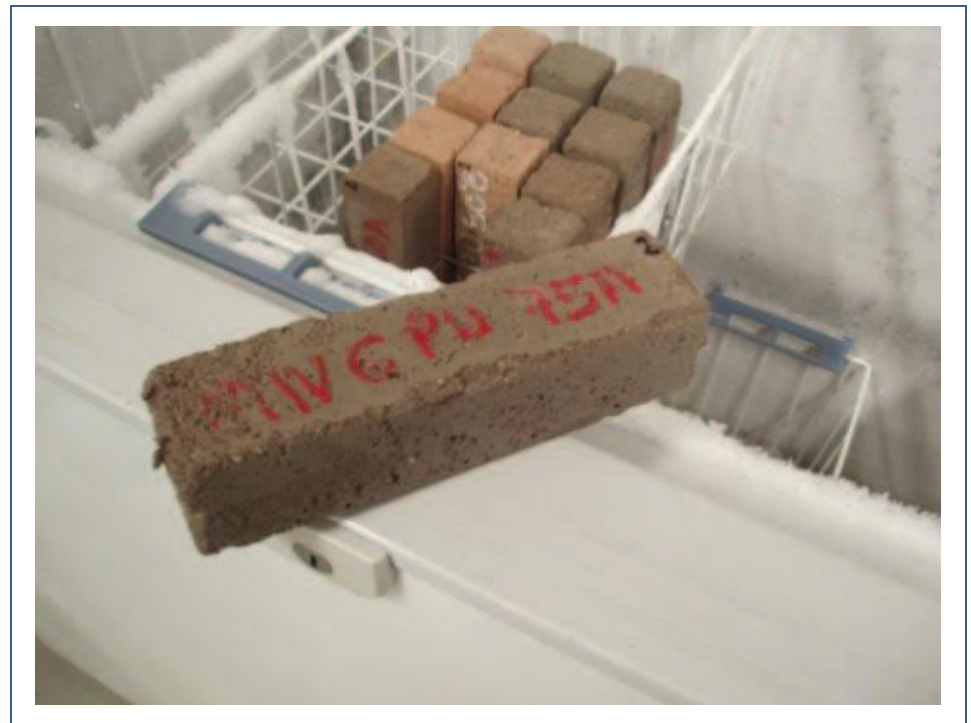

Figura 6.2. Daños mínimos de la muestra M IV-6PU75A

\subsection{2.- Niebla salina}

La utilización de morteros en zonas próximas al mar, o en localidades con industrias que emiten a la atmósfera cantidades importantes de humos cargados con gases, da lugar al depósito de sales en el interior del mortero, por fenómenos de absorción.

Es sabido que estas sales al cristalizar sufren un aumento de volumen que crea tensiones en el interior del mortero que pueden acortar sensiblemente la vida útil del material. Por ello es necesario conocer el comportamiento de los morteros expuestos a esas atmósferas. Para comprobar los efectos de las atmósferas marinas sobre la durabilidad, se realiza el ensayo denominado "resistencia al envejecimiento por niebla salina".

Los ensayos de durabilidad de los morteros no están normalizados, por lo que es necesario recurrir a ensayos que evalúan la modificación de ciertas características en materiales de similar uso, motivo por el cual se ha adaptado el ensayo de la norma UNE-EN 14147:2003, de aplicación a la piedra natural.

El resultado de la variación de peso nos indica que en todos los casos hay aumento de peso, debido normalmente al depósito de las sales en el interior de los poros (Figura 6.3), produciéndose en general, un incremento mayor en los materiales con mayor cantidad de poros. 


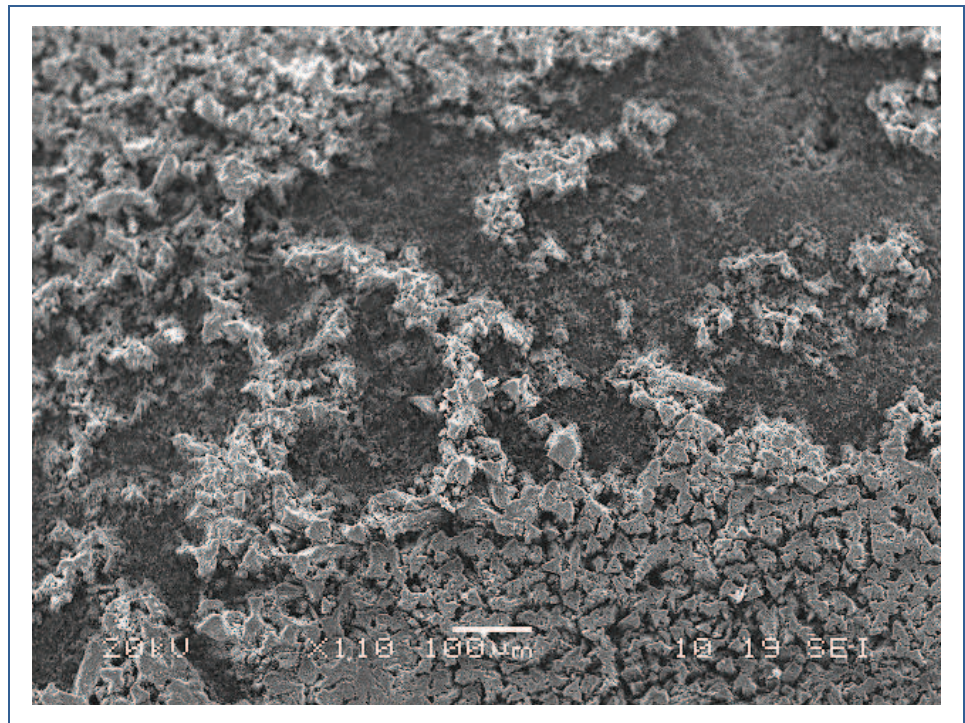

Figura 6.3. Deposición de sales. Ensayo de niebla salina.

Solamente el mortero M IV-6PU75B ha incrementado su peso en menor proporción que su homólogo y que el correspondiente con el $50 \%$ de agregado, lo que puede indicar que, habiéndose depositado una cantidad de sales similar al $75 \mathrm{~A}$, se ha producido una pérdida de materia por efecto de las tensiones producidas por la cristalización de sales. (Tabla 6.3 y Figura 6.4).

Tabla 6.3. Envejecimiento acelerado niebla salina. Variación de masa

\begin{tabular}{|l|c|c|c|c|c|}
\multicolumn{1}{|c|}{ Mortero } & \multicolumn{3}{|c|}{ Masa de la probeta en gramos } & $\begin{array}{c}\text { Peso } \\
\text { cemento }\end{array}$ & $\begin{array}{c}\text { Peso } \\
\text { espuma }\end{array}$ \\
\hline & Antes & Después & Variación $\%$ & \multicolumn{3}{c|}{ kg } \\
\hline M II-4PU50A & 418,78 & 433,74 & 3,57 & 467,4 & 30,3 \\
\hline M II-4PU50B & 412,15 & 432,82 & 5,02 & 450,4 & 38,5 \\
\hline M IV-4PU50B & 400,09 & 419,60 & 4,88 & 473,3 & 40,5 \\
\hline M IV-6PU50A & 394,01 & 424,21 & 7,66 & 328,7 & 32,0 \\
\hline M IV-6PU75A & 273,87 & 290,75 & 6,16 & 343,3 & 50,1 \\
\hline M IV-6PU75B & 233,66 & 256,74 & 9,88 & 287,7 & 55,3 \\
\hline
\end{tabular}




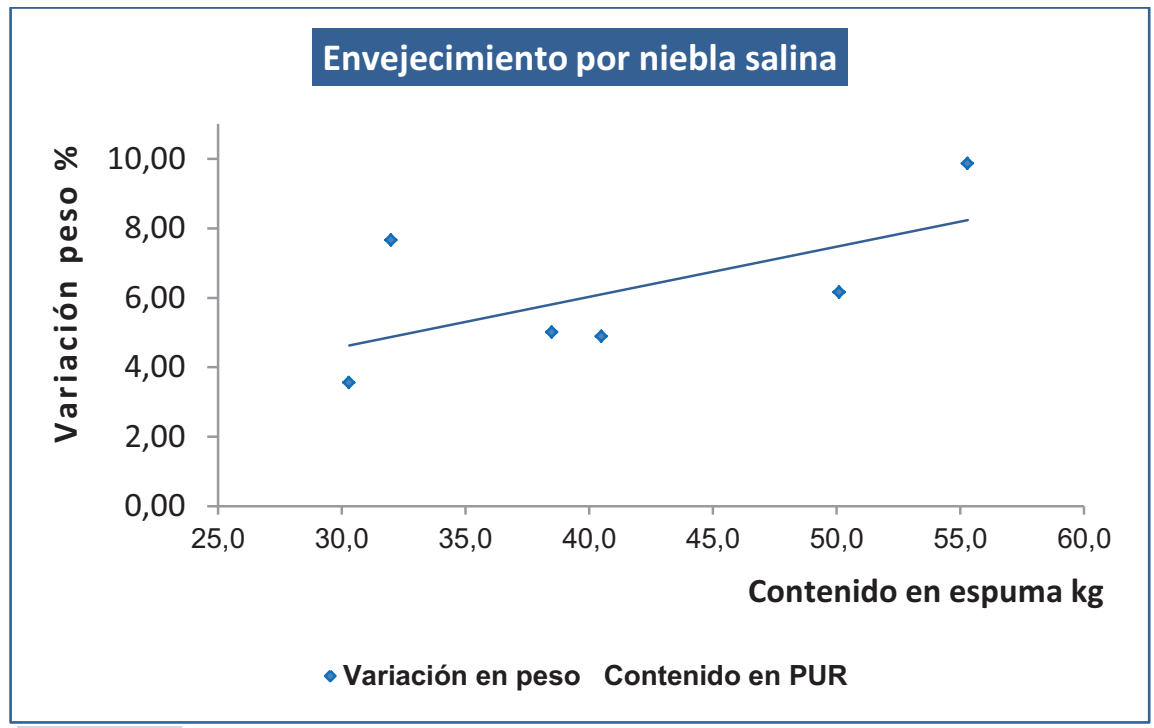

Figura 6.4. Relación entre el contenido de PUR y la variación de peso después del ensayo de niebla salina.

Los morteros sometidos a envejecimiento acelerado por niebla salina aumentan en general sus resistencias mecánicas una vez realizado el ensayo (Tabla 6.4). El motivo vuelve a ser la edad de las probetas, por lo que se realiza la comparativa de nuevo con morteros de edades similares (3 meses), con y sin envejecimiento (Figura 6.5).

Tabla 6.4. Envejecimiento acelerado en agua salina. Resistencias mecánicas

\begin{tabular}{|l|c|c|c|c|}
\multicolumn{1}{|c}{ Mortero } & \multicolumn{3}{c}{ Resistencia a flexión Mpa } & \multicolumn{2}{c|}{ Resistencia a compresión } \\
& Antes & Después & Antes & Después \\
\hline M II-4PU50A & 1,92 & 4,13 & 7,01 & 16,36 \\
\hline M II-4PU50B & 2,23 & 4,08 & 6,39 & 16,82 \\
\hline M IV-4PU50B & 2,25 & 3,38 & 7,30 & 15,48 \\
\hline M IV-6PU50A & 1,39 & 2,53 & 5,01 & 11,20 \\
\hline M IV-6PU75A & 1,15 & 0,82 & 4,03 & 3,25 \\
\hline M IV-6PU75B & 0,72 & 0,42 & 3,01 & 1,35 \\
\hline
\end{tabular}




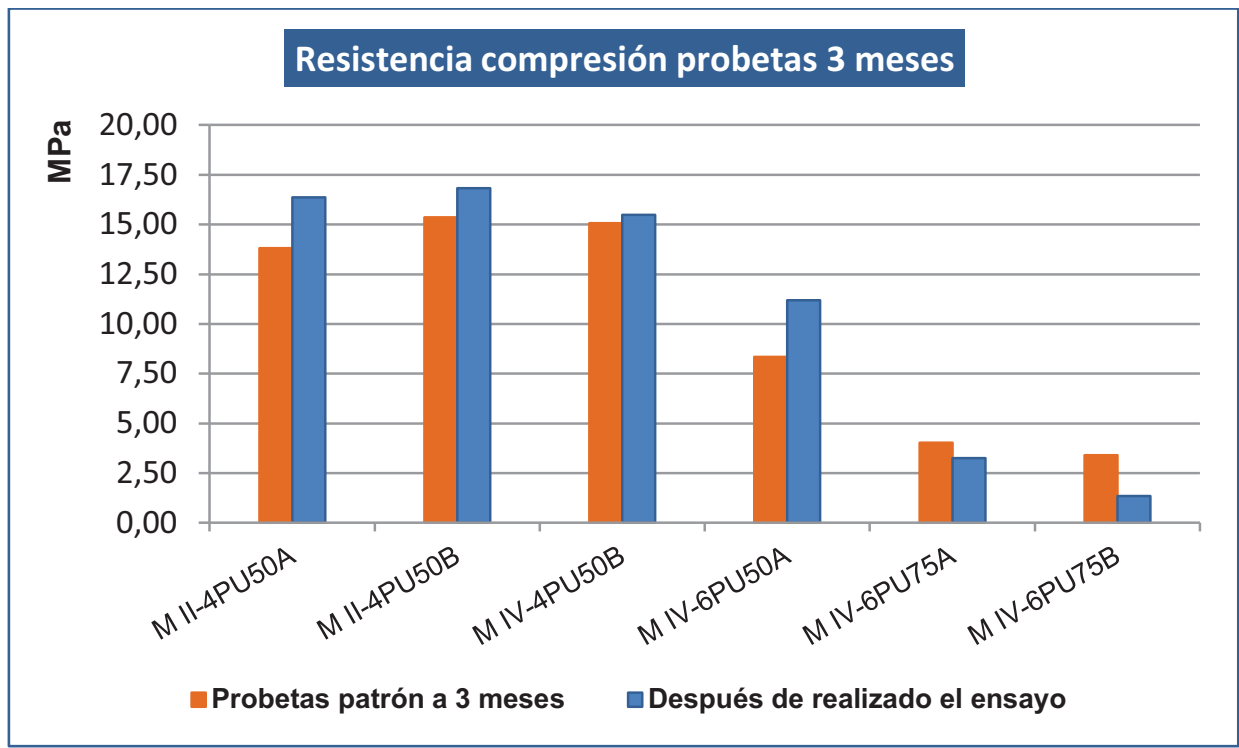

Figura 6.5. Envejecimiento acelerado por niebla salina. Resistencia a compresión a 3 meses.

La significativa disminución de resistencia del M IV-6PU75B, puede confirmar que se ha producido una cierta desagregación del mortero por efecto de las tensiones creadas en la cristalización de sales, lo que ha derivado en pérdida de materia.

\subsection{3.- Comportamiento frente al dióxido de azufre (Kesternich)}

Un ensayo complementario de durabilidad es el comportamiento frente al dióxido de azufre con humedad condensada. Este análisis sirve para conocer el comportamiento de los materiales que recubren elementos metálicos, como puede ser el caso de algunos tipos de morteros de cemento armados con malla de alambre de acero, o incluso morteros reforzados con fibras metálicas. Además complementa los ensayos de envejecimiento por la acción atmosférica, en este caso las atmósferas ácidas producidas por los gases de combustibles fósiles.

$\mathrm{El} \mathrm{SO} \mathrm{S}_{2}$ puede llegar a reaccionar con la cal libre de la matriz cementicia, y con las espumas de poliuretano si al reaccionar con el vapor de agua degenera en ácido sulfúrico (lluvia ácida).

El ensayo al dióxido de azufre con condensación general de humedad, norma UNE-EN ISO 6988:1985, no es específico de ningún material 
concreto, pero es perfectamente válido para los morteros colocados en exteriores.

La norma ISO 6988 coincide con la norma Alemana DIN 50018 "ensayo de corrosión en atmósferas húmedas saturadas con adición de dióxido de azufre", que se denomina Ensayo Kesternich DIN 50018. Este ensayo simula un clima alterno de vapor de agua condensado, con adición de dióxido de azufre; la norma ISO 6988, admite como método para realizar el ensayo, la exposición continua de las muestras, o una exposición en el interior de la cámara de 8 horas (clima alterno).

Con una simple inspección visual no se ha apreciado ningún signo relevante de degradación después del ensayo, lo que parece indicar que la atmósfera sulfurosa no afecta ni al cemento ni a los residuos de PUR. En el microscopio electrónico se puede ver la deposición de sales en la superficie (Figura 6.6), lo que provoca en general un ligero aumento de peso en la probeta (Tabla 6.5). Solamente en el caso del mortero M IV-6PU75B, se constata una casi inapreciable pérdida de peso.

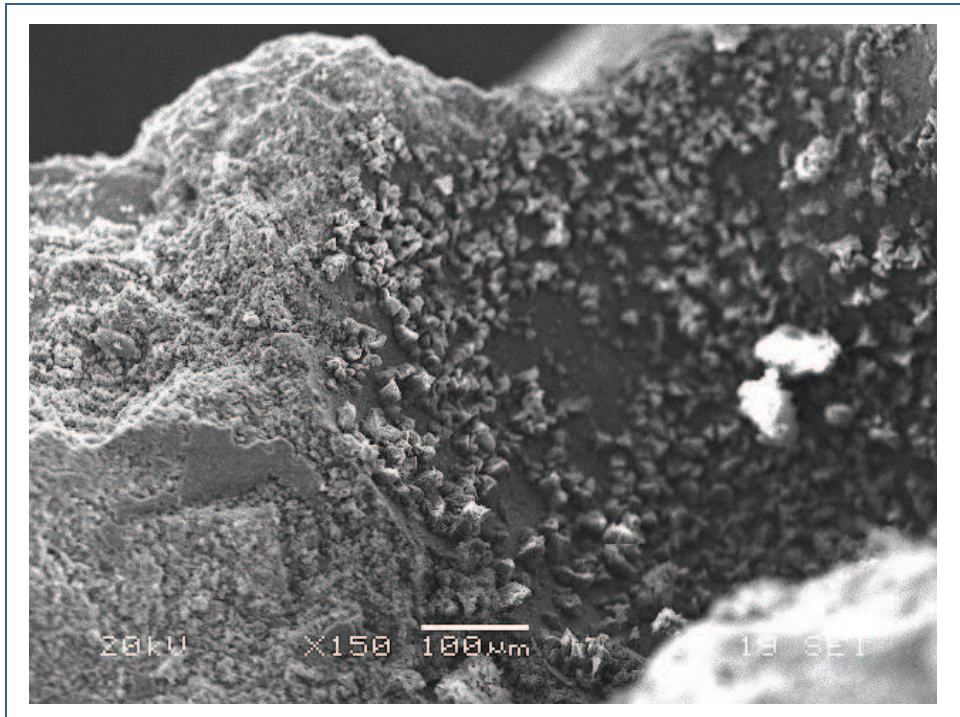

Figura 6.6. Deposición de sales. Ensayo Kesternich. 
Tabla 6.5. Ensayo al dióxido de azufre con condensación general de humedad. Variación de masa

\begin{tabular}{|l|c|c|c|}
\hline \multirow{2}{*}{ Mortero } & \multicolumn{3}{c|}{ Masa de la probeta en gramos } \\
\hline & Antes & Después & $\%$ \\
\hline M II-4PU50A & 422,67 & 429,02 & 1,50 \\
\hline M II-4PU50B & 418,09 & 430,36 & 2,93 \\
\hline M IV-4PU50B & 393,99 & 394,36 & 0,09 \\
\hline M IV-6PU50A & 398,55 & 414,83 & 4,08 \\
\hline M IV-6PU75A & 274,53 & 282,09 & 2,75 \\
\hline M IV-6PU75B & 243,88 & 243,68 & $-0,08$ \\
\hline
\end{tabular}

Los resultados mecánicos, después del ensayo no muestran pérdidas de resistencias mecánicas en las probetas a los tres meses, manteniéndose el incremento de las resistencias si las comparamos con las homólogas de referencia a los 28 días (Tabla 6.6) y a tres meses (Figura 6.7).

Tabla 6.6. Ensayo al dióxido de azufre con condensación general de humedad. Resistencias mecánicas a los 28 días

\begin{tabular}{|c|c|c|c|c|}
\hline \multirow[t]{2}{*}{ Mortero } & \multicolumn{2}{|c|}{ Resistencia a flexión Mpa } & \multicolumn{2}{|c|}{$\begin{array}{l}\text { Resistencia a compresión } \\
\text { Мpa }\end{array}$} \\
\hline & Antes & Después & Antes & Después \\
\hline M II-4PU50A & 1,92 & 2,27 & 7,01 & 13,91 \\
\hline M II-4PU50B & 2,23 & 2,26 & 6,39 & 13,28 \\
\hline M IV-4PU50B & 2,25 & 1,78 & 7,30 & 13,02 \\
\hline M IV-6PU50A & 1,39 & 1,88 & 5,01 & 9,79 \\
\hline M IV-6PU75A & 1,15 & 0,96 & 4,03 & 4,06 \\
\hline M IV-6PU75B & 0,72 & 0,67 & 3,01 & 2,70 \\
\hline
\end{tabular}




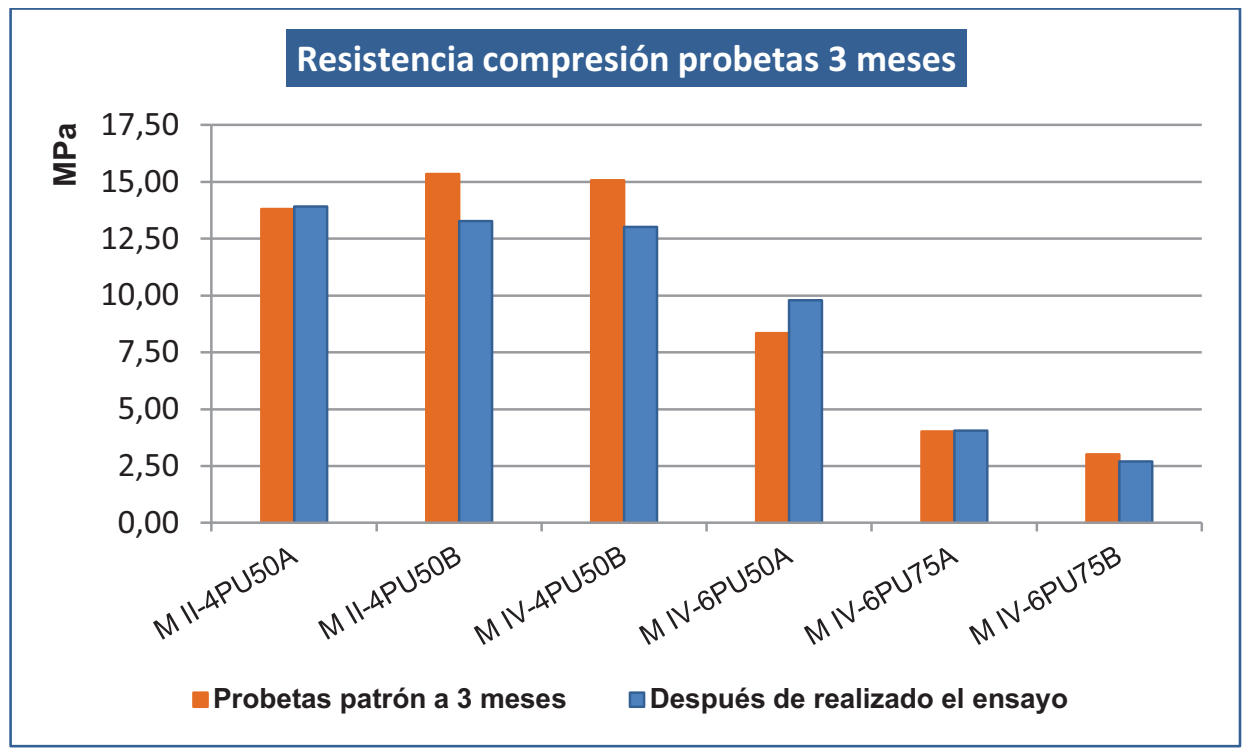

Figura 6.7. Ensayo al dióxido de azufre con condensación general de humedad. Resistencia a compresión a 3 meses.

\subsection{4.- Agua salina}

El ensayo de inmersión en agua salina permite determinar la expansión o hinchamiento de los conglomerados y aunque no es un ensayo específico de los morteros informa sobre la estabilidad de los agregados de espuma.

No existe norma UNE específica para la realización del ensayo, por lo que se emplea el procedimiento de ensayo de la Norma Americana ASTM D$4792 / 99$.

La Tabla 6.7 muestra un aumento de peso en todos los casos, que es mayor en los morteros con PUR "B". Este incremento también es más acusado en los morteros con sustitución del $75 \%$ de espuma. La ganancia en peso se puede deber a una reacción del cemento o del agregado con la sal disuelta en agua.

Teniendo en cuenta que la cantidad de cemento por $\mathrm{m}^{3}$ de mortero es mayor en los morteros con sustitución del $50 \%$ de PUR que en los morteros con sustitución del $75 \%$, y siendo éstos últimos los que más peso han ganado, podemos concluir que la razón del aumento de peso radica en el contenido en espuma (Figura 6.8), ya sea por una reacción de las espumas con la sal de la solución salina o por una mayor capacidad de retención de las sales por parte de las espumas. 
Tabla 6.7. Envejecimiento acelerado en agua salina. Variación de masa

\begin{tabular}{|c|c|c|c|c|c|}
\hline Mortero & \multicolumn{3}{|c|}{ Masa de la probeta en gramos } & $\begin{array}{c}\text { Peso } \\
\text { cemento }\end{array}$ & $\begin{array}{c}\text { Peso } \\
\text { espuma }\end{array}$ \\
\hline & Antes & Después & Variación \% & \multicolumn{2}{|c|}{ kg } \\
\hline M II-4PU50A & 418,78 & 431,73 & 3,09 & 467,4 & 30,3 \\
\hline M II-4PU50B & 412,15 & 427,64 & 3,76 & 450,4 & 38,5 \\
\hline M IV-4PU50B & 400,09 & 430,36 & 7,57 & 473,3 & 40,5 \\
\hline M IV-6PU50A & 394,01 & 416,72 & 5,76 & 328,7 & 32,0 \\
\hline M IV-6PU75A & 273,87 & 297,22 & 8,53 & 343,3 & 50,1 \\
\hline M IV-6PU75B & 233,66 & 259,33 & 10,99 & 287,7 & 55,3 \\
\hline
\end{tabular}

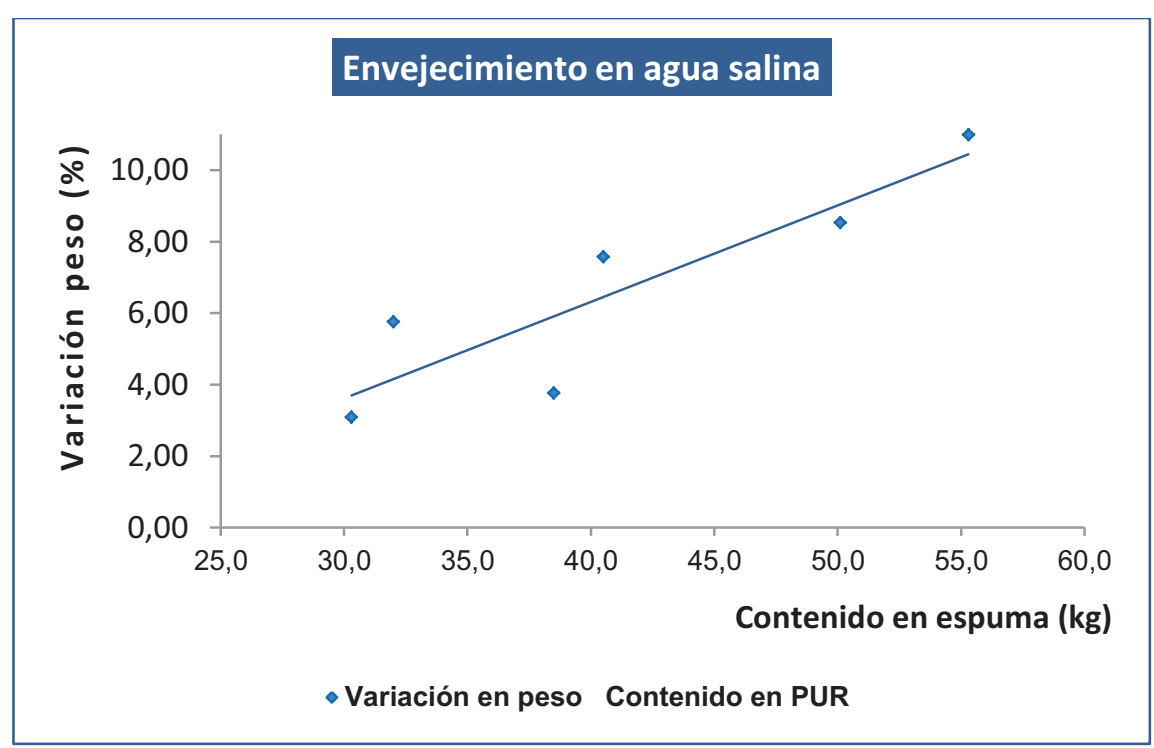

Figura 6.8. Relación entre el contenido de PUR y la variación de peso después del ensayo de agua salina.

Los morteros ensayados a envejecimiento acelerado en agua salina aumentan en general sus resistencias mecánicas una vez realizado el ensayo (Tabla 6.8). El motivo vuelve a ser la edad de las probetas, por lo que se realiza la comparativa nuevamente con morteros de edades similares (3 meses), con y sin envejecimiento (Figura 6.9). 
Tabla 6.8. Envejecimiento acelerado en agua salina. Resistencias mecánicas

\begin{tabular}{|l|c|c|c|c|}
\multicolumn{1}{|c}{ Mortero } & \multicolumn{3}{c|}{ Resistencia a flexión Mpa } & \multicolumn{2}{c|}{ Mesistencia a compresión } \\
\hline & Antes & Después & Antes & Después \\
\hline M II-4PU50A & 1,92 & 3,47 & 7,01 & 17,49 \\
\hline M II-4PU50B & 2,23 & 3,70 & 6,39 & 16,05 \\
\hline M IV-4PU50B & 2,25 & 2,34 & 7,30 & 16,28 \\
\hline M IV-6PU50A & 1,39 & 2,23 & 5,01 & 12,38 \\
\hline M IV-6PU75A & 1,15 & 1,32 & 4,03 & 5,20 \\
\hline M IV-6PU75B & 0,72 & 1,23 & 3,01 & 4,05 \\
\hline
\end{tabular}

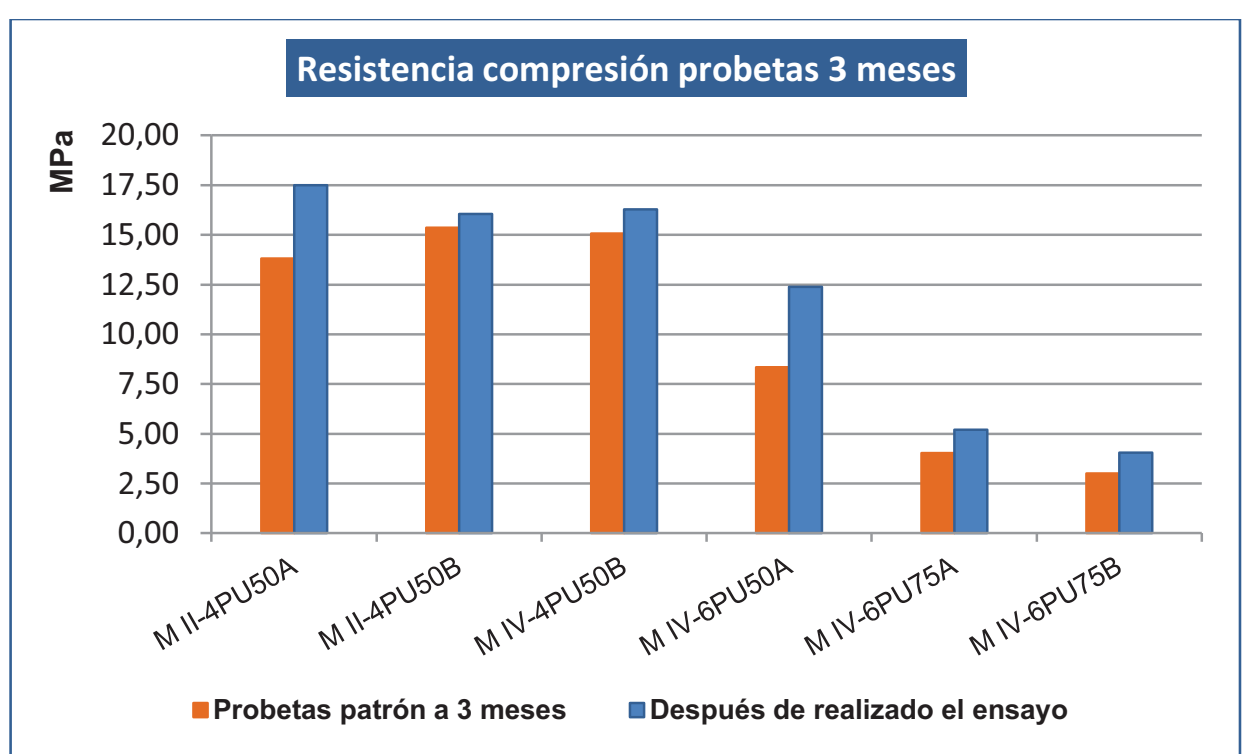

Figura 6.9. Envejecimiento acelerado en agua salina. Resistencia a compresión a 3 meses.

\subsection{5.- Cristalización de sales}

Los morteros de cemento pueden sufrir alteraciones por la tensión que produce la cristalización de sales solubles en su interior. Estas sales disueltas pueden provenir de los propios materiales que conforman el producto, como son las arenas de playa, arenas contaminadas, aguas duras, aditivos o cementos con álcalis. En otros casos proceden de los materiales en contacto con el mortero, como son las piezas cerámicas y conglomerados de cemento, que habitualmente contienen cierta cantidad de sales solubles en su interior. Finalmente, las condiciones ambientales, como son las atmósferas industriales y la humedad del terreno, pueden 
aportar sales solubles que se depositan en el interior del mortero por efectos de capilaridad.

La cristalización de estas sales solubles en el interior del mortero produce un aumento de volumen, que deriva en la creación de tensiones en el seno del mortero y conlleva la degradación del mismo, bien por efecto de la intensidad de la tensión, bien por efecto de fatiga.

Un mortero colocado en el exterior está expuesto a estos fenómenos, que acortan la vida útil del mortero y en consecuencia, su durabilidad.

Para realizar el ensayo de comportamiento frente a la cristalización de sales se ha utilizado la norma UNE-EN 12370 de aplicación a la piedra natural, puesto que no existe una norma UNE que indique el procedimiento para la realización de los ensayos en los morteros. La analogía entre el comportamiento de una piedra natural y el mortero de cemento se considera justificación suficiente para utilizar este método.

El estado de las probetas después de realizado el ensayo muestra importantes deterioros en los morteros con menores resistencias mecánicas, por lo que los resultados de los ensayos en esas probetas (Tabla 6.9) arrojan importante pérdida de masa y degradación excesiva de las probetas (Figura 6.10). Sin embargo en los morteros con resistencias mayores la degradación es ligera y se produce un aumento de peso, debido al peso de las sales cristalizadas en el interior de los poros.

Tabla 6.9. Resistencia a la cristalización de las sales. Variación de masa

\begin{tabular}{|l|c|c|c|c|}
\multicolumn{2}{c}{ Mortero } & \multicolumn{2}{c}{ Masa de la probeta en gramos } & $\begin{array}{c}\text { Estado de la } \\
\text { probeta }\end{array}$ \\
\hline & Antes & Después & $\%$ & Degradación \\
\hline M II-4PU50A & 426,30 & 432,10 & 1,36 & Ligera \\
\hline M II-4PU50B & 419,75 & 428,90 & 2,18 & Ligera \\
\hline M IV-4PU50B & 393,65 & 410,25 & 4,22 & Ligera \\
\hline M IV-6PU50A & 400,20 & 380,35 & $-4,96$ & Excesiva \\
\hline M IV-6PU75A & 273,15 & 250,65 & $-8,24$ & Excesiva \\
\hline M IV-6PU75B & 240,30 & 228,75 & $-4,81$ & Excesiva \\
\hline
\end{tabular}




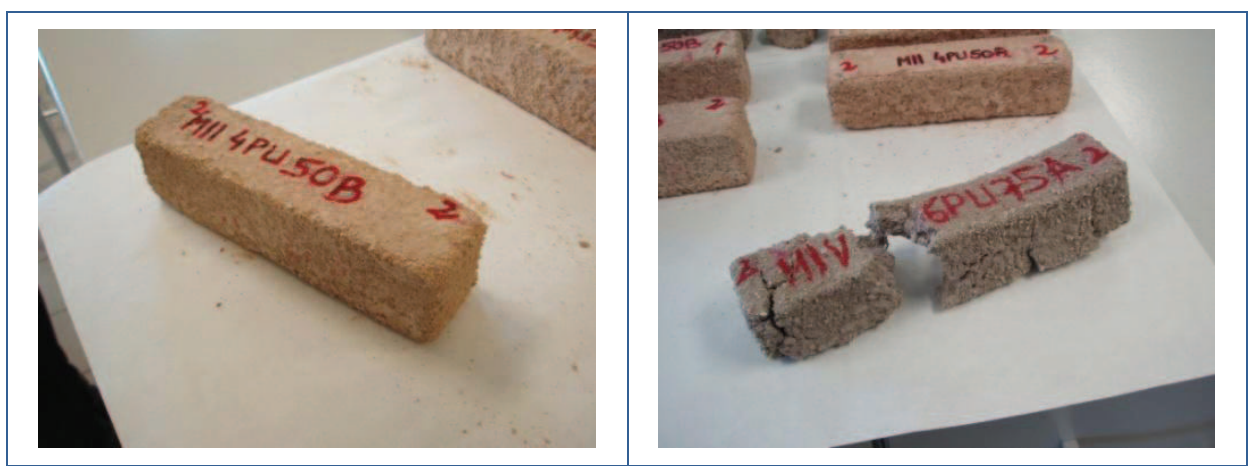

Figura 6.10. Degradación ligera (M II-4PU50B) y excesiva (M IV-6PU75A)

\subsection{6.- Choque térmico}

Todos los morteros colocados en el exterior están sometidos a ciclos continuos de humedad-sequedad debidos a los cambios climatológicos. Un mortero a pleno sol un día de verano, puede alcanzar sin problema los $50^{\circ} \mathrm{C}$ de temperatura; una tormenta de verano llega a mojar el mortero y puede hacer que su temperatura baje bruscamente $30^{\circ} \mathrm{C} \circ 40^{\circ} \mathrm{C}$ en la superficie expuesta al agua. Estas bruscas variaciones de temperatura crean tensiones en el interior del mortero, y especialmente en zonas muy próximas del mismo, debido a la diferencia de temperatura entre la cara expuesta y la cara interior.

Los procesos de cambios bruscos de temperatura se ocurren innumerables veces en la vida útil de los materiales de revestimiento colocados en el exterior, por ello se realiza un ensayo en el que se mide la resistencia al envejecimiento por choque térmico. Ante la falta de normativa para aplicación a los morteros se ha adaptado el ensayo de la norma UNE-EN 14066, específico de la piedra natural.

La variación de masa en las probetas, después de realizado el ensayo (Tabla 6.10), no muestra modificaciones reseñables, por lo que se puede concluir que no se ha producido deterioro en las muestras que provoque desagregación del mortero. 
Tabla 6.10. Envejecimiento acelerado por choque térmico. Variación de masa

\begin{tabular}{|l|c|c|c|}
\multicolumn{2}{|c}{ Mortero } & \multicolumn{3}{c|}{ Masa de la probeta en gramos } \\
\hline M II-4PU50A & Antes & Después & $\%$ \\
\hline M II-4PU50B & 421,12 & 413,30 & $-1,86$ \\
\hline M IV-4PU50B & 422,62 & 416,44 & $-1,46$ \\
\hline M IV-6PU50A & 392,14 & 395,26 & 0,80 \\
\hline M IV-6PU75A & 271,20 & 270,46 & $-0,28$ \\
\hline M IV-6PU75B & 238,62 & 235,86 & $-1,16$ \\
\hline
\end{tabular}

Los resultados de resistencia se muestran en la Tabla 6.11. En ambos se observa un aumento de las resistencias mecánicas en los morteros con $50 \%$ de agregado de PUR, y en este caso también se registra un aumento de las resistencias de los que contienen el $75 \%$ de agregado. El motivo del aumento de resistencias podría ser el mismo que en los casos anteriores. El mortero tiene una edad de 3 meses y el efecto del choque térmico no es relevante, por lo que las resistencias se mantienen similares a las obtenidas en morteros a 3 meses (Figura 6.11), salvo el mortero M IV6PU75A.

Tabla 6.11. Ensayo de choque térmico. Resistencias mecánicas

\begin{tabular}{|l|c|c|c|c|}
\multicolumn{1}{|c}{ Mortero } & \multicolumn{3}{c}{ Resistencia a flexión Mpa } & \multicolumn{2}{c|}{$\begin{array}{c}\text { Resistencia a compresión } \\
\text { Mpa }\end{array}$} \\
\hline M II-4PU50A & Antes & Después & Antes & Después \\
\hline M II-4PU50B & 1,92 & 2,82 & 7,01 & 15,93 \\
\hline M IV-4PU50B & 2,23 & 3,19 & 6,39 & 15,44 \\
\hline M IV-6PU50A & 2,25 & 2,45 & 7,30 & 14,97 \\
\hline M IV-6PU75A & 1,39 & 1,97 & 5,01 & 12,74 \\
\hline M IV-6PU75B & 1,15 & 1,30 & 4,03 & 6,80 \\
\hline
\end{tabular}




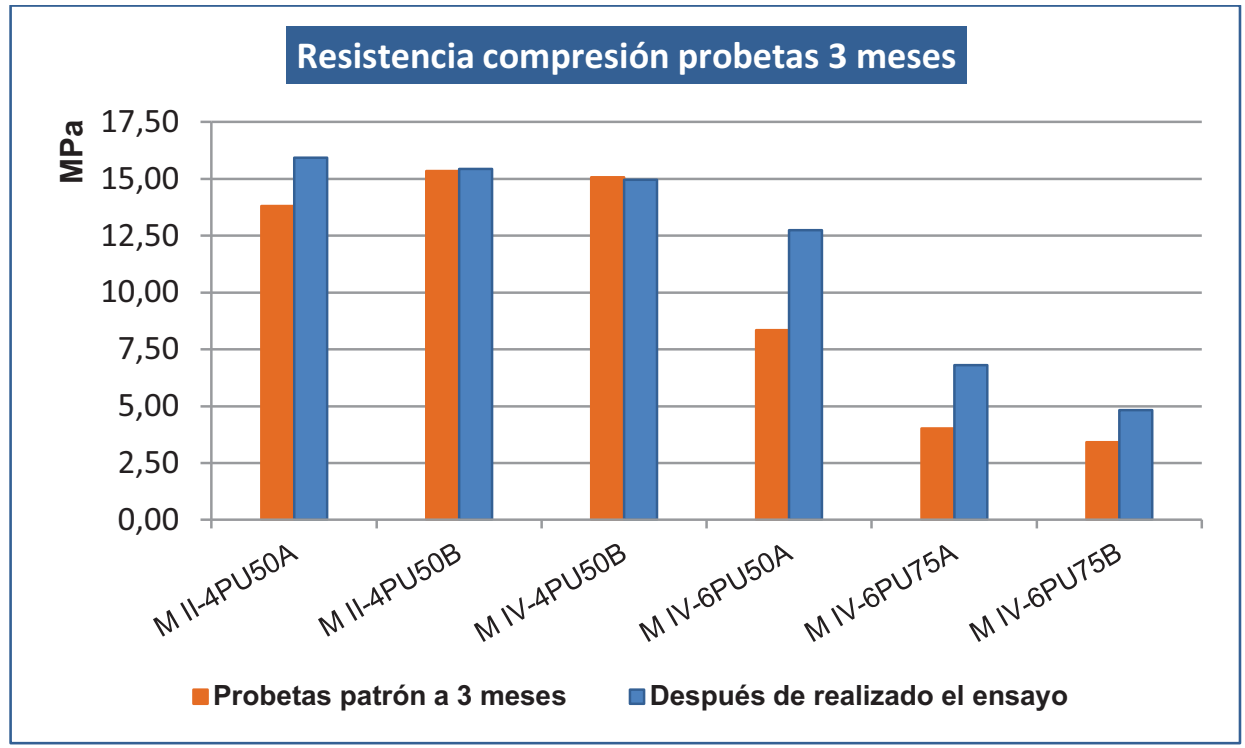

Figura 6.11. Ensayo de choque térmico. Resistencia a compresión a 3 meses.

\subsection{7.- Envejecimiento acelerado (materiales poliméricos)}

Hasta ahora se han caracterizado los morteros de cemento con agregado de PUR, por los métodos y ensayos específicos de los morteros para albañilería; los áridos para morteros que contempla la norma EN 13139, define los mismos como materiales de origen mineral o en todo caso inorgánico, por lo que en los ensayos de caracterización no se incluyen ciertos ensayos que puedan alterar la naturaleza y comportamiento de otros tipos de compuestos.

Por este motivo se ha creído necesario completar la caracterización de los morteros con los agregados PUR, con la realización de dos ensayos específicos de durabilidad de materiales poliméricos celulares. Se trata de ensayos de envejecimiento acelerado descritos en la norma UNE-EN ISO 2440 , donde se somete a las muestras de poliuretano a calor seco y calor húmedo, comprobando las alteraciones que sufre el poliuretano inmerso en la matriz cementosa, pues en esas condiciones se pueden producir reacciones de oxidación o hidrólisis.

Como en la inmensa mayoría de los ensayos de durabilidad, se ha obtenido un incremento general de las resistencias a flexión y compresión en los morteros con sustitución del $50 \%$ de arena, y una ligera a moderada 
reducción de la resistencia en los morteros con sustitución del 75\% (Tablas 6.12 y 6.13$)$.

Tabla 6.12. Envejecimiento acelerado (materiales poliméricos). Calor seco. Resistencias mecánicas

Mortero Resistencia a flexión Mpa Resistencia a compresión Mpa

\begin{tabular}{|l|c|c|c|c|c|c|} 
& Antes & Después & $\begin{array}{c}\text { Variación } \\
\%\end{array}$ & Antes & Después & $\begin{array}{c}\text { Variación } \\
\%\end{array}$ \\
\hline M II-4PU50A & 1,92 & 3,70 & $-92,71$ & 7,01 & 14,36 & $-104,85$ \\
\hline M II-4PU50B & 2,23 & 3,74 & $-67,71$ & 6,39 & 12,60 & $-97,18$ \\
\hline M IV-4PU50B & 2,25 & 2,94 & $-30,67$ & 7,30 & 12,30 & $-68,49$ \\
\hline M IV-6PU50A & 1,39 & 2,53 & $-82,01$ & 5,01 & 6,16 & $-22,95$ \\
\hline M IV-6PU75A & 1,15 & 1,17 & $-1,74$ & 4,03 & 3,45 & 14,39 \\
\hline M IV-6PU75B & 0,72 & 0,74 & $-2,78$ & 3,01 & 2,66 & 11,63 \\
\hline
\end{tabular}

Tabla 6.13. Envejecimiento acelerado (materiales poliméricos). Calor húmedo. Resistencias mecánicas

Mortero Resistencia a flexión Mpa Resistencia a compresión Mpa

\begin{tabular}{|l|c|c|c|c|c|c|}
\hline & Antes & Después & $\begin{array}{c}\text { Variación } \\
\%\end{array}$ & Antes & Después & $\begin{array}{c}\text { Variación } \\
\%\end{array}$ \\
\hline M II-4PU50A & 1,92 & 2,39 & $-24,48$ & 7,01 & 9,09 & $-29,67$ \\
\hline M II-4PU50B & 2,23 & 2,53 & $-13,45$ & 6,39 & 9,19 & $-43,82$ \\
\hline M IV-4PU50B & 2,25 & 2,30 & $-2,22$ & 7,30 & 8,58 & $-17,53$ \\
\hline M IV-6PU50A & 1,39 & 2,07 & $-48,92$ & 5,01 & 7,30 & $-45,71$ \\
\hline M IV-6PU75A & 1,15 & 0,87 & 24,35 & 4,03 & 2,71 & 32,75 \\
\hline M IV-6PU75B & 0,72 & 0,68 & 5,56 & 3,01 & 1,92 & 36,21 \\
\hline
\end{tabular}

Si comparamos las resistencias mecánicas a 3 meses de los morteros seleccionados, edad aproximada de la finalización de estos ensayos, con los resultados obtenidos en los ensayos de calor seco y húmedo, comprobamos que la resistencia a compresión es similar en las probetas sometidas al ensayo de calor seco, e inferior en las sometidas al de calor húmedo (Figuras 6.12 y 6.13 ). 


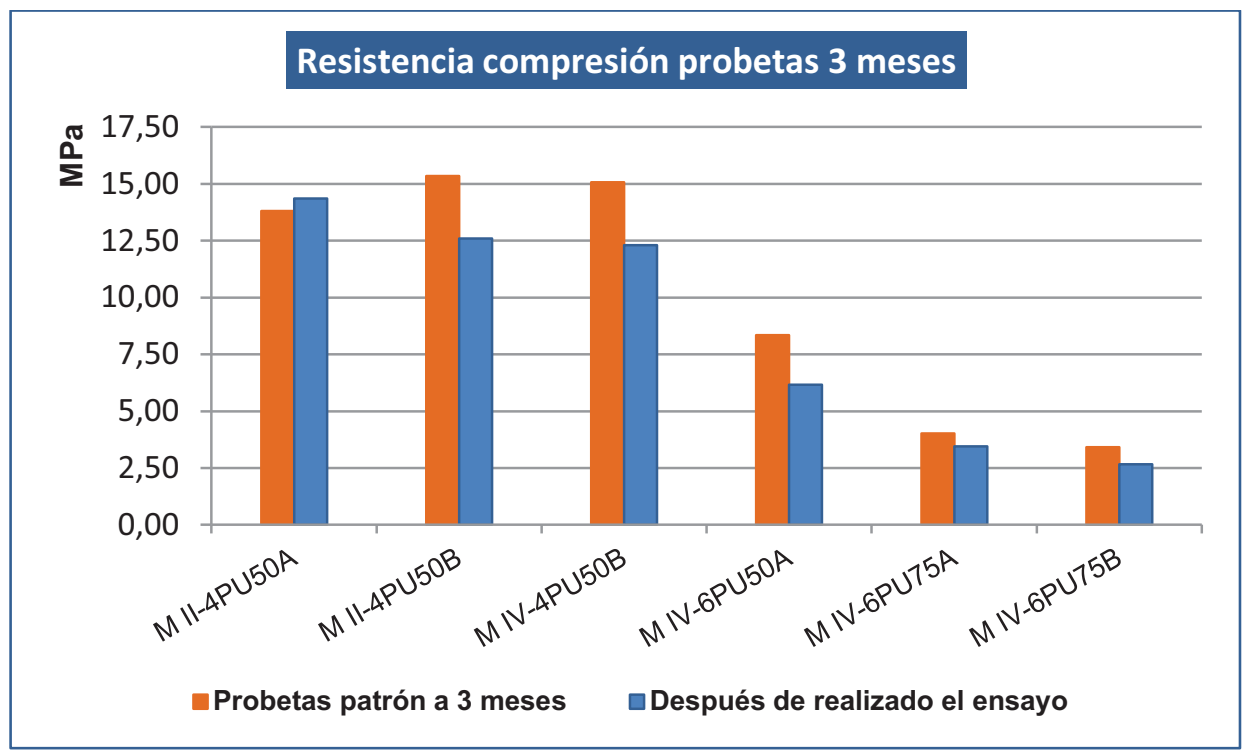

Figura 6.12. Envejecimiento acelerado (materiales poliméricos). Calor seco. Resistencia a compresión a 3 meses.

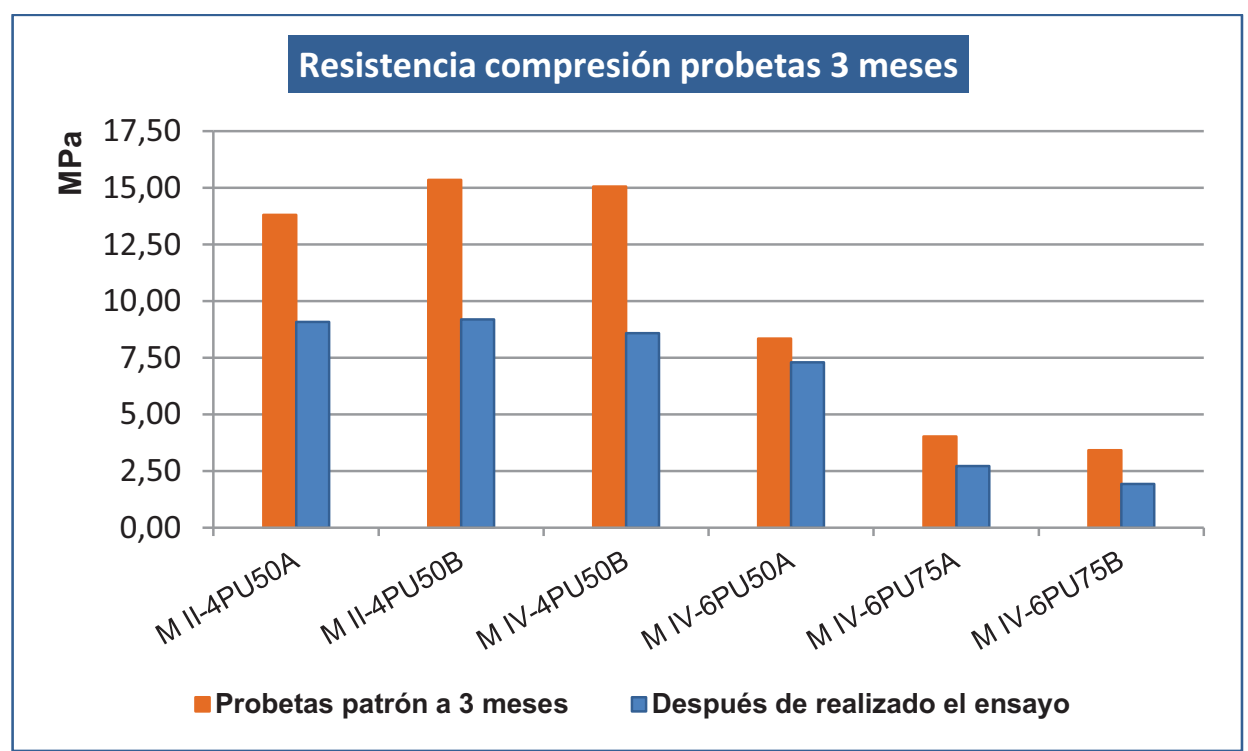

Figura 6.13. Envejecimiento acelerado (materiales poliméricos). Calor húmedo. Resistencia a compresión a 3 meses.

Finalmente resulta interesante comparar los efectos del ensayo de calor seco y calor húmedo. La Figura 6.14 representa las resistencias a compresión después de realizados ambos ensayos. La gráfica indica que el calor húmedo afecta directamente a los dos tipos de espumas, produciéndose una merma en la resistencia a compresión, superior en 
muchos casos al $20 \%$ con respecto a los resultados del ensayo de calor seco, excepto en el mortero M IV-6PU50A.

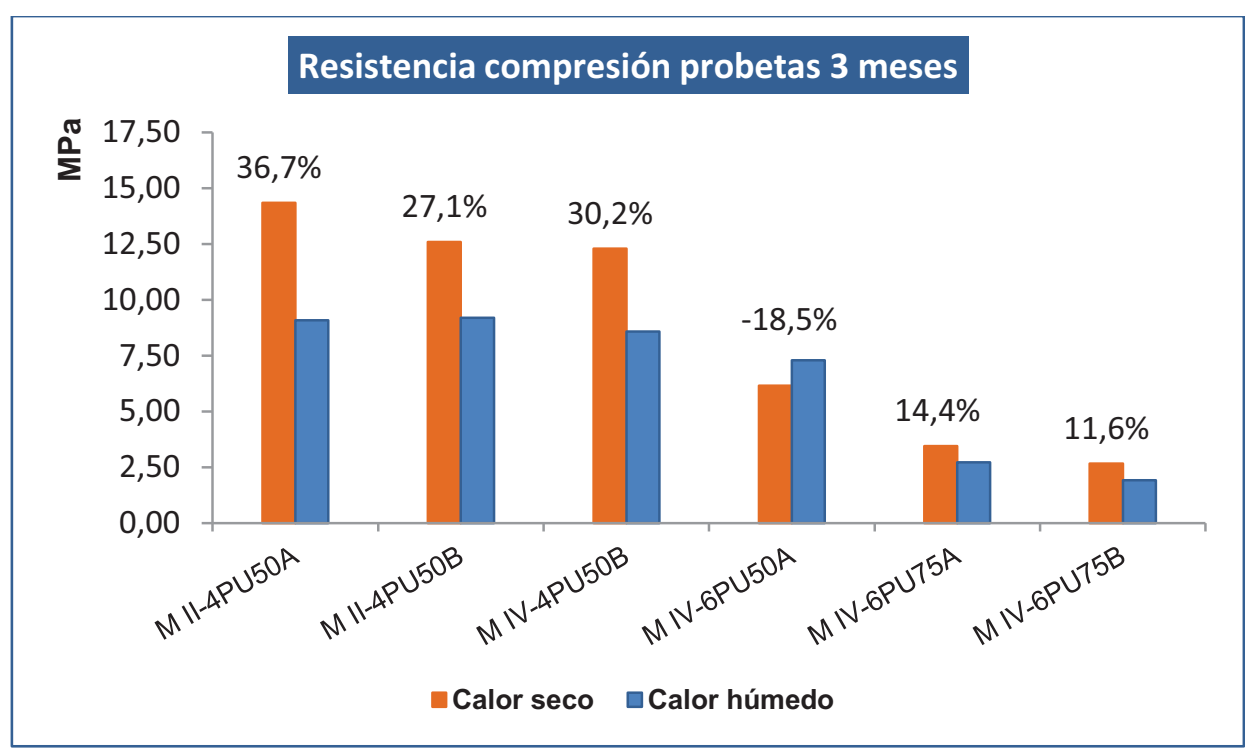

Figura 6.14. Envejecimiento acelerado (materiales poliméricos). Calor seco Calor húmedo. Resistencia a compresión a 3 meses. Diferencia porcentual seco/húmedo 


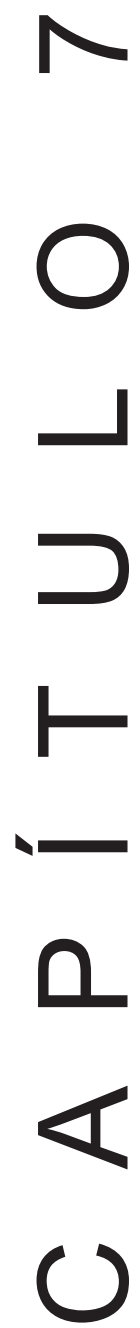

0

Aplicación y puesta en obra 



\section{Capítulo 7.- Aplicación y puesta en obra}

Los morteros de albañilería confeccionados tienen un uso como morteros para asiento de fábricas y morteros de revestimiento, por lo que la primera aplicación y puesta en obra ha sido como mortero de juntas y de enfoscado. Además se ha realizado una aplicación como capa de nivelación de suelos para tapar tubos y como base para el pavimento.

Para la puesta en obra de los morteros se ha construido una casetaalmacén de forma rectangular y dimensiones exteriores en planta de 4,25 $\mathrm{m}$ por $2,70 \mathrm{~m}$ y altura media de 2,25 $\mathrm{m}$. Los muros cortos tienen una orientación norte-sur y los muros largos una orientación este-oeste. La cubierta es a un agua.

La caseta se ha levantado en el complejo de la "Cúpula de la Energía", en la localidad de Garray, provincia de Soria. Altitud: 1011 metros. La construcción de este conjunto de edificios se está llevando a cabo por la UTE Vías-Zarzuela, dentro del Proyecto "CONPOL" de investigación CDTIMEC (Centro de Desarrollo Tecnológico Industrial - Ministerio Educación y Ciencia), llevado a cabo entre nuestro equipo de investigación de la UBU y la empresa VIAS S.A.

Se ha realizado una solera de hormigón ligeramente armado sobre la que han asentado los muros. Se han empleado dos tipos de ladrillo. Para los dos muros más largos se utilizó un ladrillo con perforaciones en testa, de dimensiones $24 \mathrm{~cm}$ de soga, $11,5 \mathrm{~cm}$ de tizón y $9,5 \mathrm{~cm}$ de grueso y colocado a tabicón (espesor 9,5 cm). Los dos muros cortos se han ejecutado con ladrillo de dimensiones $24 \mathrm{~cm}$ de soga, $11 \mathrm{~cm}$ de tizón y 10 $\mathrm{cm}$ de grueso y colocado a medio pie (espesor $11 \mathrm{~cm}$ ).

El uso final de la caseta será de almacén de pequeños productos y productos peligrosos hasta que se termine la obra (tiempo estimado 2 años).

Se han contratado dos albañiles de nombres Fausto y Luis, que han replanteado la construcción y han ejecutado la solera de hormigón armado sobre la que se han asentado los muros de cerramiento. Estas dos personas han realizado todos los trabajos de manipulación de materiales y puesta en obra de los mismos. 
Para confeccionar las mezclas se ha empleado una hormigonera de 50 litros de capacidad. Las cantidades de cada material se han pesado en obra, para lo que se ha instalado en obra la balanza de precisión que habitualmente se emplea en los laboratorios de materiales de la EPS de la UBU. Se han pesado los materiales en cubos o seras de plástico, señalando en los recipientes el equivalente en volumen del peso especificado, por lo que las segundas y posteriores amasadas de cada dosificación se han realizado en volumen. Incluso la cantidad de arena de cada amasada, una vez hecha la primera pesada, se ha contabilizado con el número de paladas equivalente, a fin de simular una puesta en obra "típica" de un mortero prescrito y realizado "in situ".

Las unidades de obra no ejecutadas con las mezclas de agregado de PUR, se han completado con morteros de cemento y dosificaciones tradicionales, de acuerdo con el buen hacer de los dos operarios.

En todos los casos, las consistencias de las mezclas han sido obtenidas con las dosificaciones prescritas en la investigación realizada, pero con ligeras correcciones indicadas por los operarios en aras a facilitar su puesta en obra.

\section{1.- Amasado en obra}

El amasado en obra se ha efectuado de la siguiente forma:

- Pesado de la arena en un recipiente de plástico e introducción en la hormigonera.

- Pesado del PUR, en una caja de cartón e introducción en la hormigonera, con precaución para impedir que el viento disperse la espuma al ambiente. Es conveniente que la manipulación del PUR se realice con mascarilla, pues el bajo peso de las partículas puede provocar que éstas se introduzcan en las vías respiratorias al flotar en el ambiente.

- Amasado previo de arena y PUR con adición de agua, aproximadamente el $50 \%$ del agua total prevista para los 50 I de mortero. La duración de este amasado es de aproximadamente 2 minutos, dando lugar a una mezcla bastante homogénea. 
- Pesaje del cemento, introducción en la hormigonera y añadido del resto de agua hasta completar la dosificación. Amasado durante 2 minutos.

\section{2.- Aplicación en obra}

La aplicación de las distintas mezclas se ha realizado entre las 10,30 horas y las 16,30 horas de los días 26 y 27 de junio de 2012. En los dos días el cielo se ha mantenido despejado, con temperaturas que han oscilado entre los $26^{\circ} \mathrm{C}$ a primera hora de la mañana y los $33^{\circ} \mathrm{C}$ a primeras horas de la tarde. Por las noches la temperatura no ha bajado de $15^{\circ} \mathrm{C}$. Las altas temperaturas se han mantenido los 2 días posteriores. Los 3 siguientes días las temperaturas han ido descendiendo del orden de 4-5 grados diarios.

El mortero aplicado se ha regado a las 6 horas, a las 24 horas y a las 48 horas desde su puesta en obra, excepto la mezcla M IV-6PU75B, que no se ha podido regar a las 6 horas, debido a la presencia de un velo de agua en la superficie, por lo que se ha regado a las 24 horas y a las 48 horas desde su puesta en obra.

\subsection{1.- Mortero M II-4PU50A}

Se ha empleado esta dosificación como mortero de enfoscado exterior en el muro corto que mira al norte. Las dimensiones de ese muro son de 2,70 metros de longitud por 2,25 metros de altura media, con un grueso de 11 $\mathrm{cm}$. El ladrillo con un canto de superficie rugosa y el otro canto con superficie lisa, se ha colocado indistintamente con la cara rugosa al interior $o$ al exterior. El mortero de enfoscado exterior se ha ejecutado en dos capas de espesor medio cada una de ellas de $0,6 \mathrm{~cm}$, con un espesor total de $1,2 \mathrm{~cm}$. El acabado del mortero se ha realizado con llana, y se ha bruñido, también con llana, una porción del muro. Antes de aplicar el mortero, se ha procedido a humedecer la fábrica de ladrillo.

\subsection{2.- Mortero M II-4PU50B}

Esta mezcla se ha utilizado como mortero de enfoscado interior en el muro corto que mira a la cara sur. Las dimensiones de ese muro son de 2,52 metros de longitud por 2,25 metros de altura media, con un grueso de 11 
$\mathrm{cm}$. El ladrillo tiene un canto con superficie rugosa y el canto contrario con superficie lisa y se ha colocado indistintamente con la cara rugosa al interior o al exterior. El mortero de enfoscado exterior se ha ejecutado en dos capas de espesor medio cada una de ellas de $0,6 \mathrm{~cm}$, con un espesor total de $1,2 \mathrm{~cm}$. El acabado del mortero ha sido con llana, y se ha bruñido con llana una porción del muro. Previamente se ha humedecido el ladrillo.

\subsection{3.- Mortero M IV-4PU50B}

Se ha colocado este mortero en la ejecución de las juntas del muro corto al norte. Las dimensiones exteriores del muro son de 2,70 metros de longitud por 2,25 metros de altura media y un grueso de $11 \mathrm{~cm}$. El espesor medio de junta entre ladrillos ha sido de $1,2 \mathrm{~cm}$, aunque en algunas zonas de remates se ha aumentado el espesor. Previamente a su colocación, el ladrillo se ha humedecido introduciéndolo en un barril con agua apenas unos segundos, para impedir su saturación.

Este muro se ha revestido posteriormente en su parte exterior con enfoscado de mortero de cemento.

\subsection{4.- Mortero M IV-6PU50A}

Esta dosificación se ha empleado en el asiento del ladrillo del muro largo que mira al oeste. Las dimensiones exteriores del muro son de 4,25 metros de longitud por 2,50 metros de altura, con un grueso de 9,5 cm. El espesor medio de junta entre ladrillos ha sido de $1,2 \mathrm{~cm}$. En algunas zonas de remates se ha aumentado el espesor de la junta. Previamente a la colocación del ladrillo, se ha humedecido con agua.

El muro quedará sin revestir (visto) en su cara exterior.

\subsection{5.- Mortero M IV-6PU75A}

Se ha colocado como mortero en capa de nivelación de suelos en el interior (para tapado de tubos y solera previa al pavimento). Las dimensiones de la capa de nivelación han sido de 2,52 metros de longitud por una anchura de 1,25 metros y $6 \mathrm{~cm}$ de espesor. 


\subsection{6.- Mortero M IV-6PU75B}

Esta mezcla se ha utilizado como capa de nivelación de suelos en el interior (para tapado de tubos y solera previa al pavimento). Las dimensiones de la capa de nivelación son de 2,52 metros de longitud por una anchura de 1,25 metros. La solera tiene un espesor de $6 \mathrm{~cm}$.

\section{3.- Puesta en obra de los morteros}

\subsection{1.- Ejecución de enfoscado de exteriores}

Enfoscado de exteriores. M II-4PU50A

- El operario que aplica el mortero indica que se trata de un mortero más "gelatinoso" que los morteros convencionales. De fácil aplicación y sin apreciarse descuelgues.

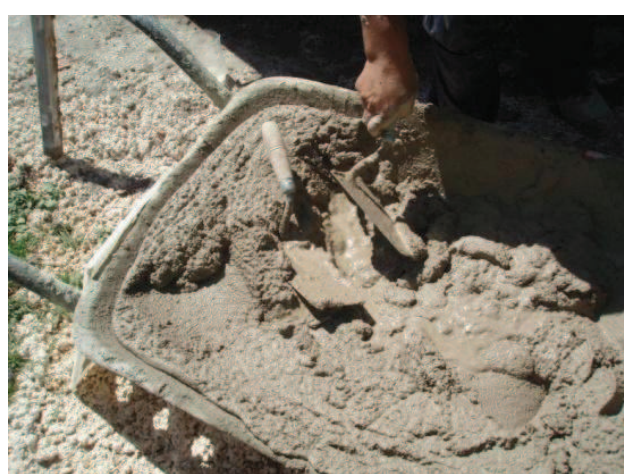

Aspecto de la amasada

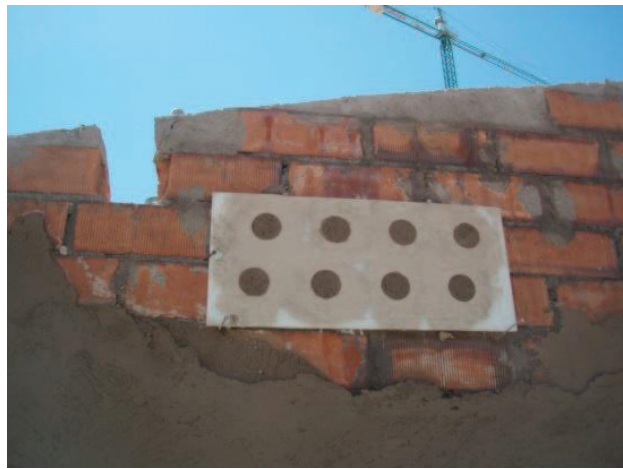

Plantilla y mortero para el ensayo de adhesión

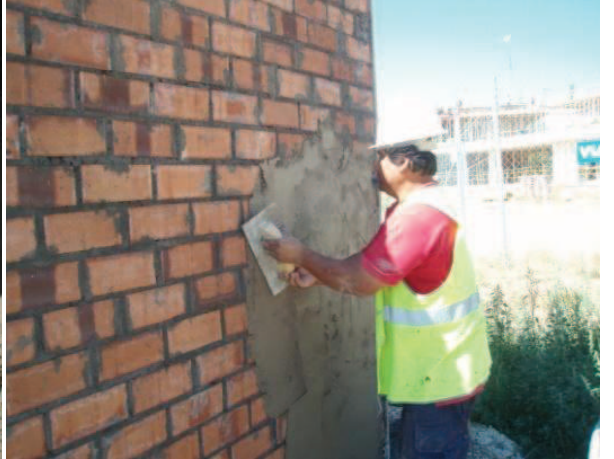

Aplicación del enfoscado en la primera capa

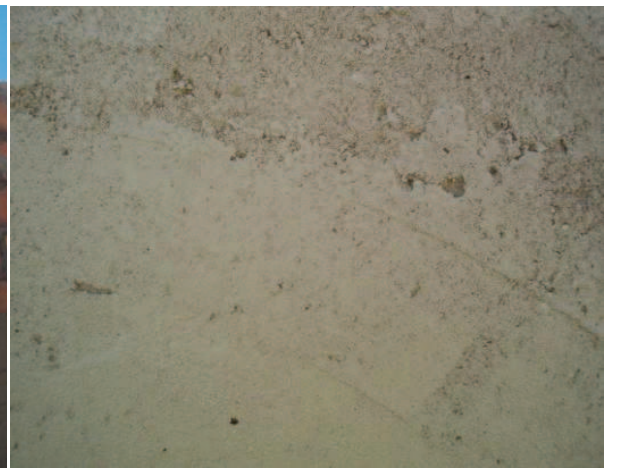

Enfoscado. Bruñido parcial 


\subsection{2.- Ejecución de enfoscado de interior}

\section{Enfoscado de interior. M II-4PU50B}

- El operario que aplica el mortero explica que se maneja como un mortero similar a los morteros convencionales. De fácil aplicación y sin apreciarse descuelgues.

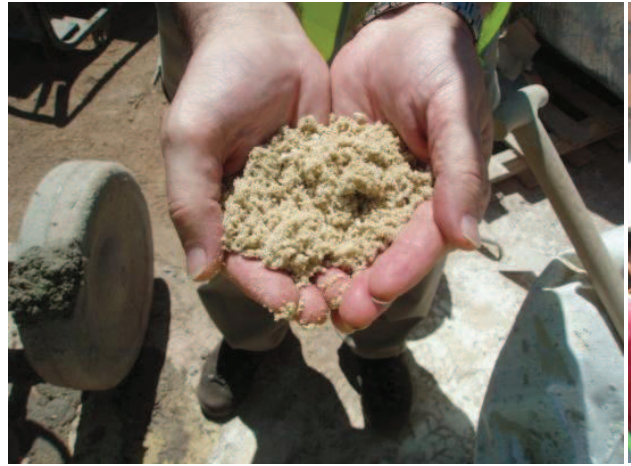

Aspecto del amasado previo de arena y PUR

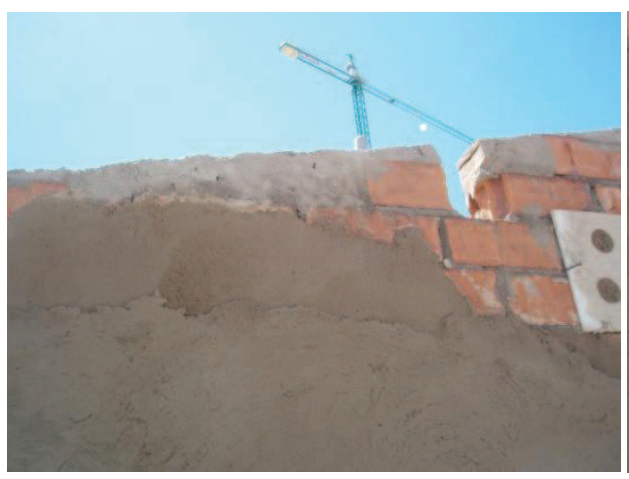

Se aprecian las dos capas de enfoscado

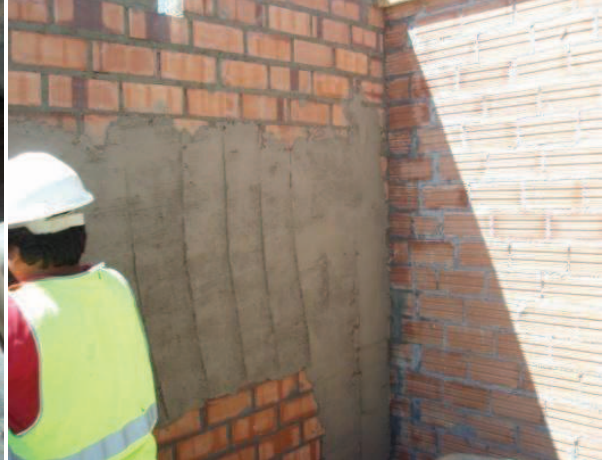

Aplicación primera capa de enfoscado

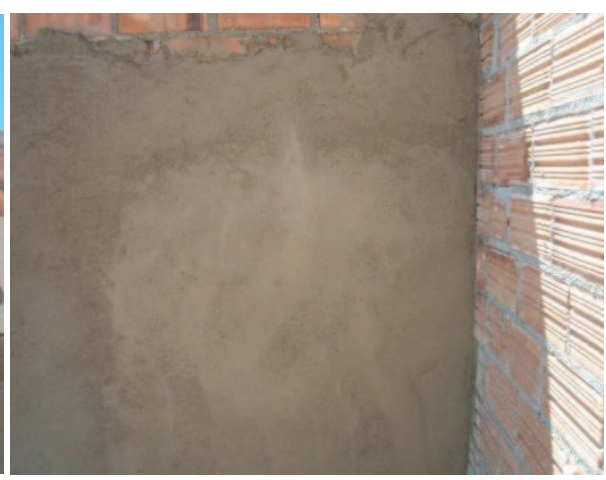

Enfoscado. Bruñido parcial del paramento

\subsection{3.- Ejecución de muro con juntas para revestir}

\section{Juntas de fábrica para revestir M IV-4PU50B.}

- Según opinión de los operarios que manipularon el mortero, su comportamiento y plasticidad resulta similar a los morteros convencionales, no produciéndose aplastamiento del mortero durante su compactación, con pequeños golpes sobre el ladrillo, ni produciéndose pérdida de agua durante esa compactación. 


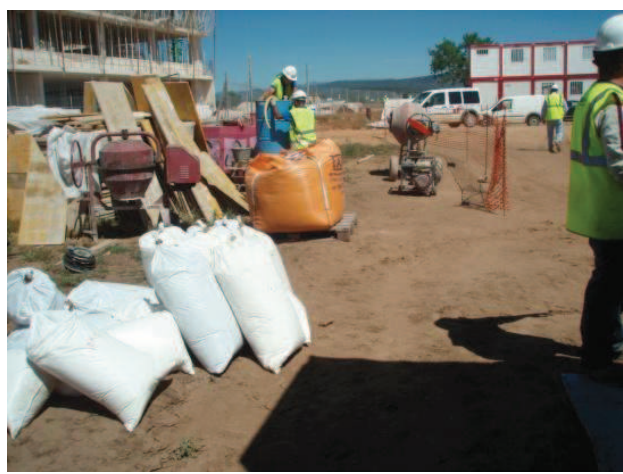

Acopio del PUR en sacos

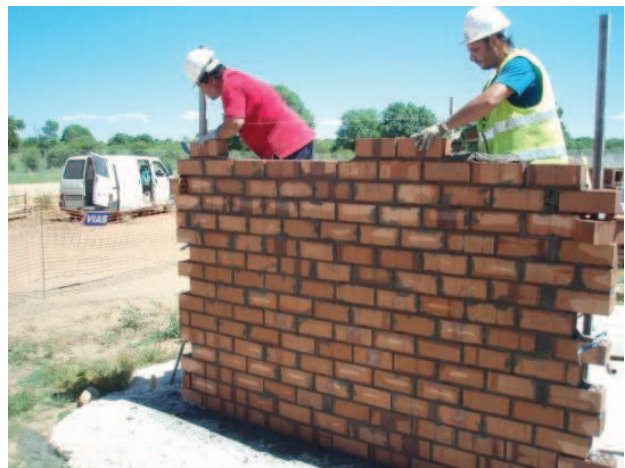

Ejecución del muro de 1/2 pie

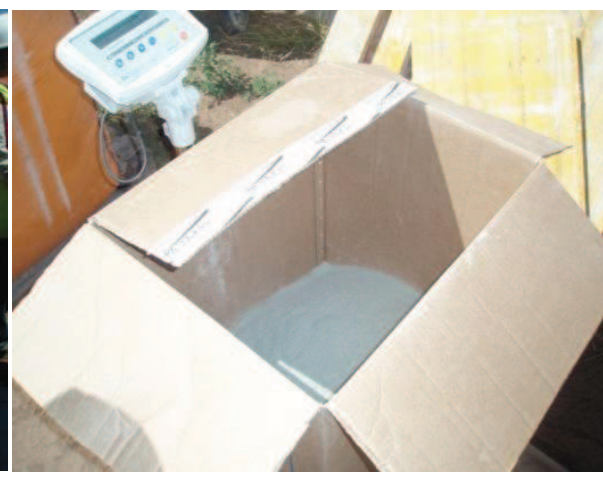

Pesaje del PUR en caja de cartón

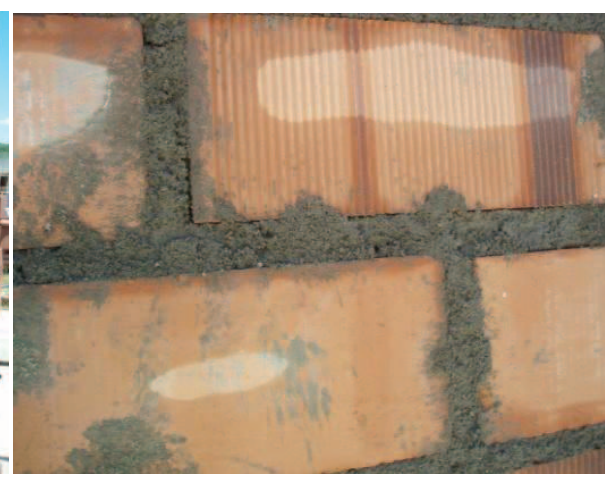

Aspecto del mortero colocado en juntas

\subsection{4.- Ejecución de muro con juntas vistas}

\section{Juntas de fábrica vistas. M IV-6PU50A}

- La opinión de los operarios que manipularon el mortero, fue que su comportamiento y plasticidad resultó similar a los morteros convencionales, produciéndose un ligerísimo aplastamiento del mortero durante su compactación, con pequeños golpes sobre el ladrillo. Se observó una ligera pérdida de agua en el proceso de compactación, pero que apenas dejó mancha en el ladrillo. 


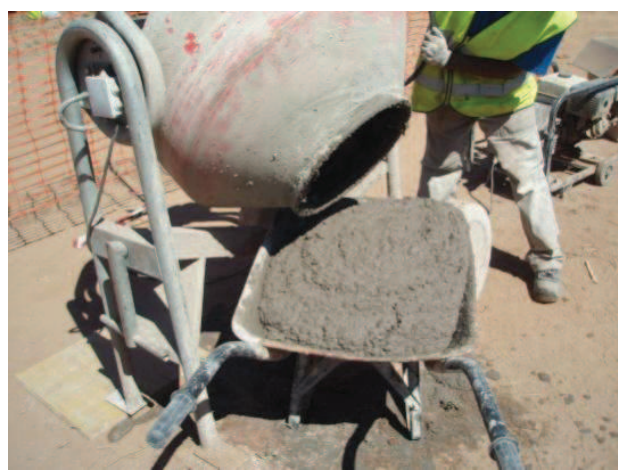

Vertido del mortero en la carretilla

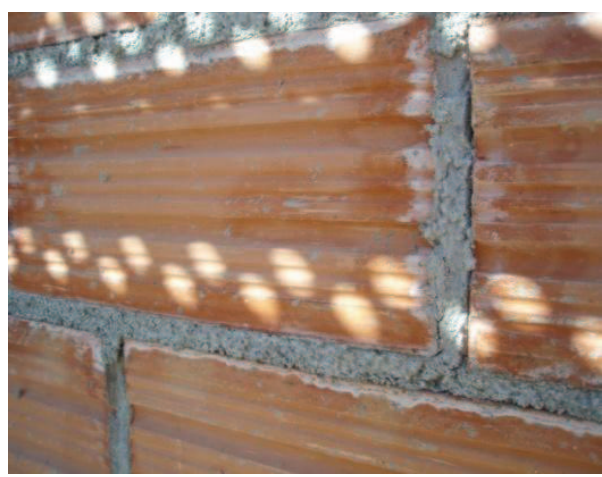

Aspecto del mortero colocado en juntas

\subsection{5.- Ejecución de solera de interior}

\subsubsection{1.- Mortero M IV-6PU75A}

\section{Solera capa de nivelación interior. M IV-6PU75A}

- Los operarios que manipularon el mortero, indicaron que se trataba de un mortero más "gelatinoso" que los morteros convencionales, de fácil aplicación en obra, si bien en la fase de compactación con regla no aparecían burbujas de aire y por el contrario el mortero se desplazaba como un líquido ligeramente viscoso. Se aprecia que el peso de la carretilla es menor que con los morteros tradicionales.

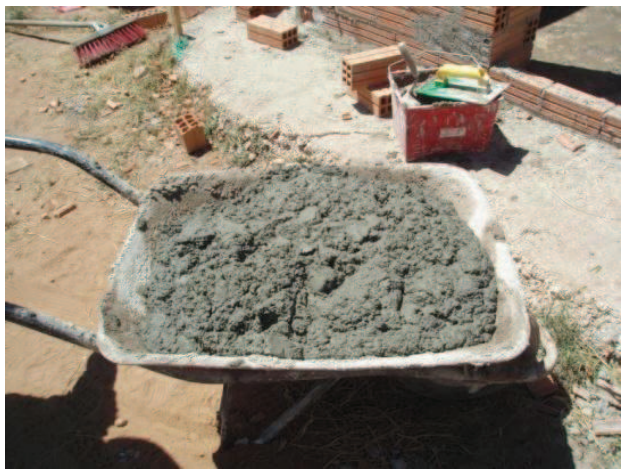

Aspecto del mortero en la carretilla

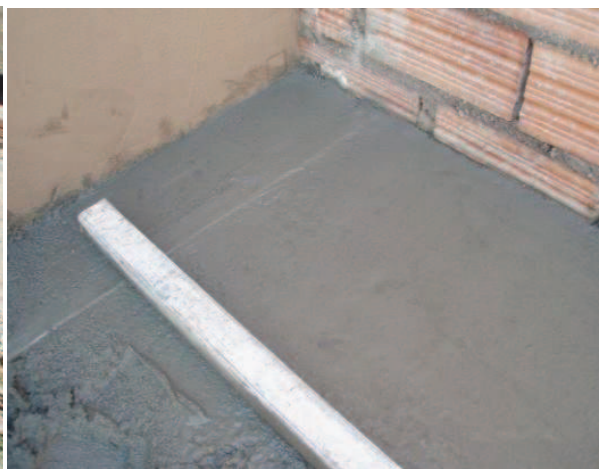

Colocación de la capa con regla 


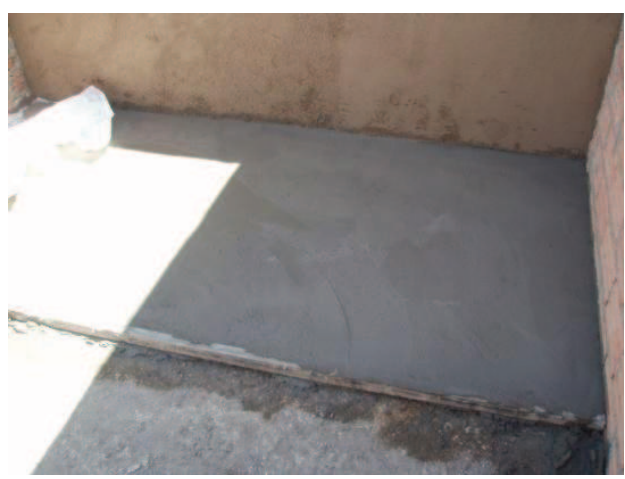

Terminación de la solera de base

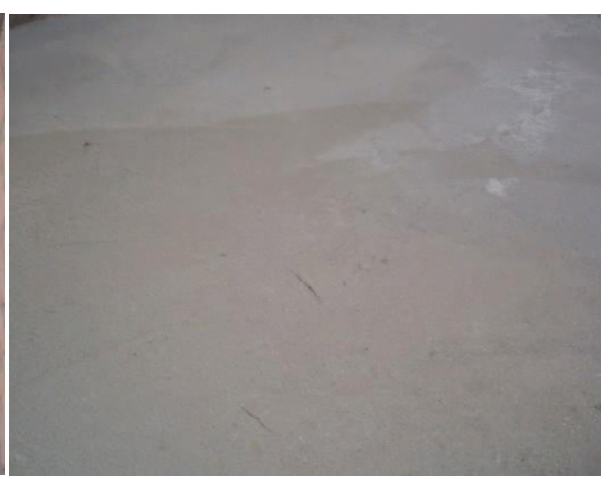

Fisuras por retracción a las 2 horas

\subsubsection{2.- Mortero M IV-6PU75B}

\section{Solera capa de nivelación interior. M IV-6PU75A.}

- Según opinión de los operarios que manipularon el mortero, se trata de un mortero muy "gelatinoso" de muy fácil aplicación en obra; no aparecen burbujas de aire y su manipulación era como la de un mortero autonivelante. El peso de la carretilla era menor que con los morteros tradicionales.

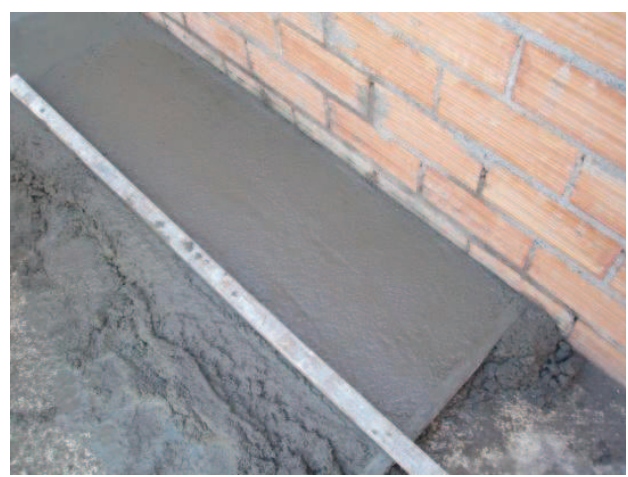

Compactado del mortero con regla

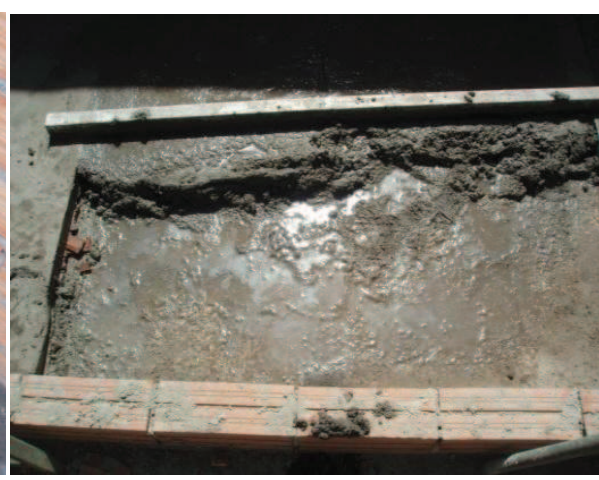

Mínima pérdida de agua del mortero 


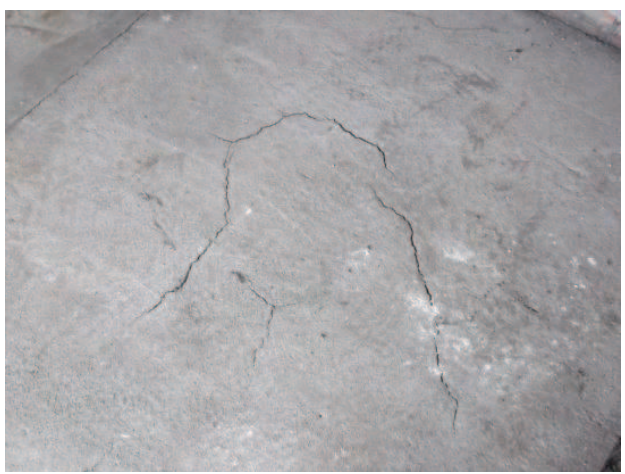

Fisuras por retracción a las 24 horas

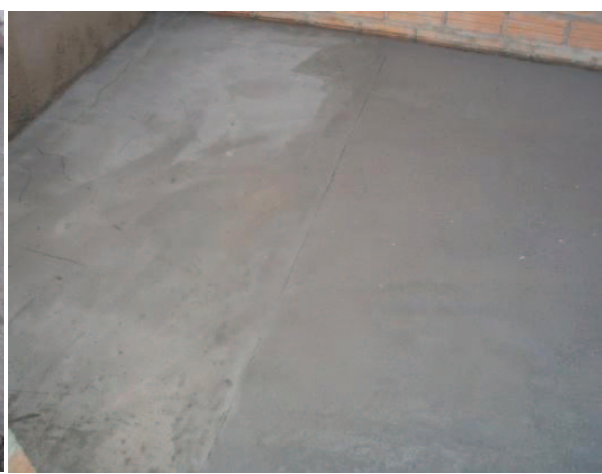

Aspecto general de la solera

\subsection{6.- Chapado de baldosa cerámica}

\section{Chapado de baldosa cerámica sobre enfoscado. M II-4PU50B}

- Se ha colocado una baldosa cerámica de absorción media-alta sobre el enfoscado interior de mortero M II-4PU50B. Se ha utilizado un cemento cola gris para interiores "Weber Col. Gris", adecuado para soportes y baldosas de media-alta absorción. Se ha aplicado con llana dentada de $8 \times 8 \mathrm{~mm}$ de acuerdo con las instrucciones del fabricante. No se ha humedecido el soporte.

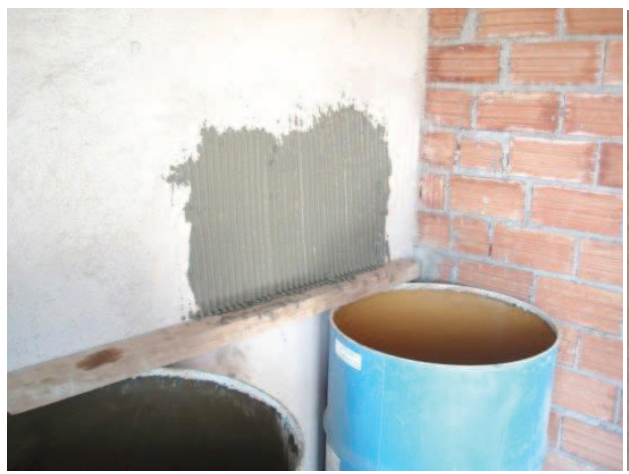

Extendido del cemento cola

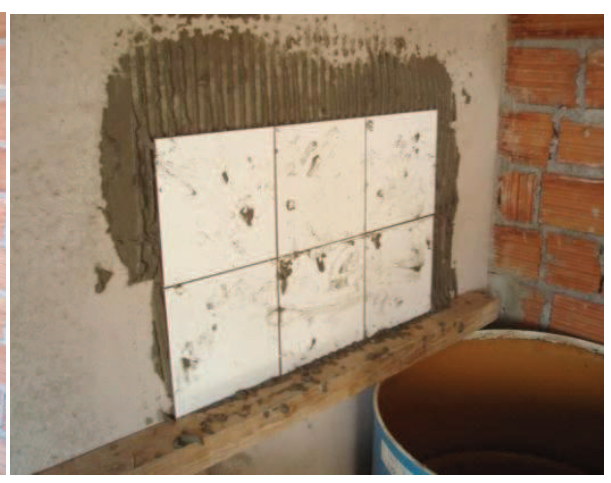

Chapado de baldosa cerámica 


\subsection{7.- Solado con baldosa cerámica}

Solado con baldosa cerámica sobre capa de nivelación. M IV-6PU75A y M IV-6PU75B

- Se ha solado con baldosa cerámica de absorción media-alta sobre las soleras de nivelación de los morteros M IV-6PU75A y M IV-6PU75B. Se ha utilizado un cemento cola gris para interiores "Weber Col. Gris", adecuado para soportes y baldosas de media-alta absorción. Se ha aplicado con llana dentada de $8 \times 8 \mathrm{~mm}$ de acuerdo con las instrucciones del fabricante. Previamente se han limpiado de polvo las superficies de las soleras. No se ha humedecido el soporte.

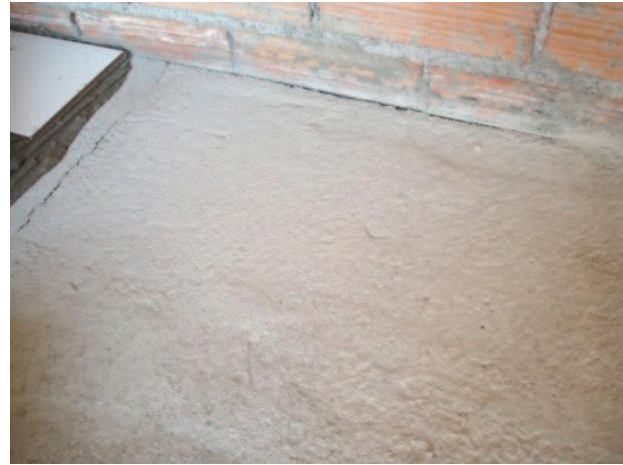

Soporte barrido y limpio

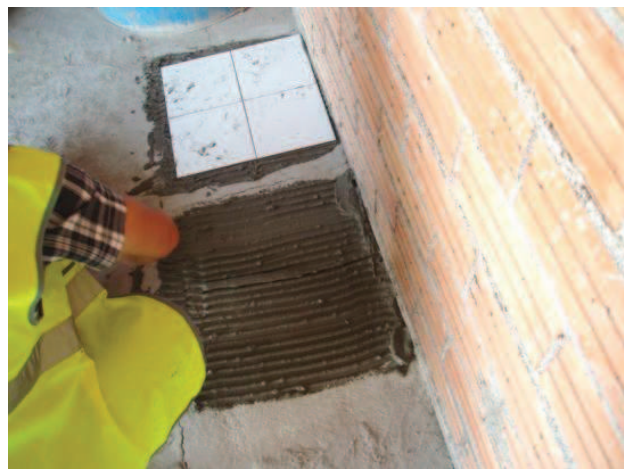

Extendido con llana dentada

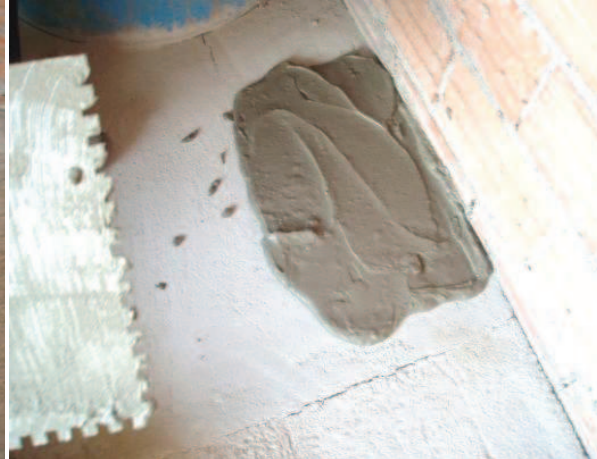

Extendido previo del cemento cola

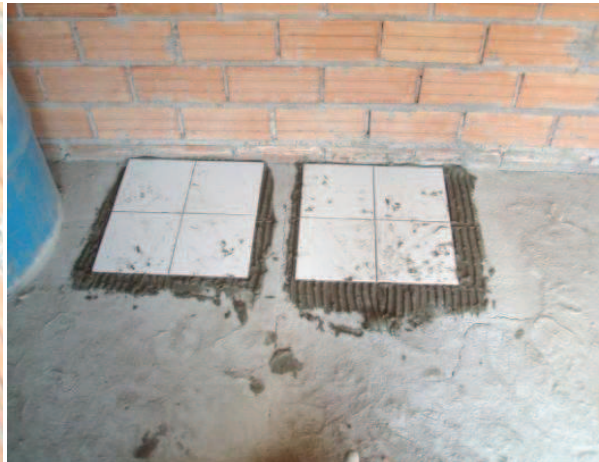

Solado en las dos soleras 


\subsection{8.- Revestimiento con pintura epoxi}

Aplicación de pintura-revestimiento epoxi sobre capa de nivelación. M IV-6PU75A y M IV-6PU75B

- Sobre las soleras de nivelación de los morteros M IV-6PU75A y M IV6PU75B, se ha aplicado una pintura de acabado de suelos de resina epoxi 2 componentes "C-Floor E225 SAT, recubrimiento epoxi satinado para pavimentos" de la casa CIN-Corporaçao industrial do norte S.A. Se ha barrido y limpiado el soporte pero no se ha fratasado ni granallado. Tampoco se ha aplicado una mano de sellador recomendada por el fabricante. Se ha extendido una mano con rodillo en lugar de las dos manos que recomienda el fabricante, pues se trata exclusivamente del conocimiento del comportamiento de la solera en lo referente a la adherencia de la resina. La humedad de ambos soportes era del 3,05\%, siendo la exigida por el fabricante del 3\%. La temperatura interior del recinto era de $26^{\circ} \mathrm{C}$, estando comprendida entre los $10^{\circ} \mathrm{C}$ y $40^{\circ} \mathrm{C}$ recomendados por el fabricante.

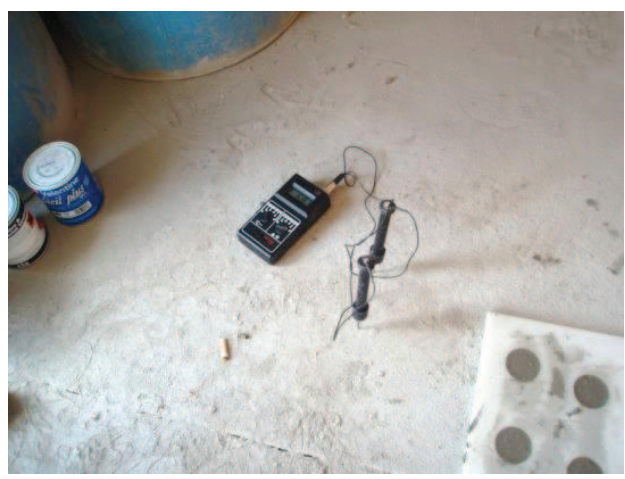

Medición de la humedad

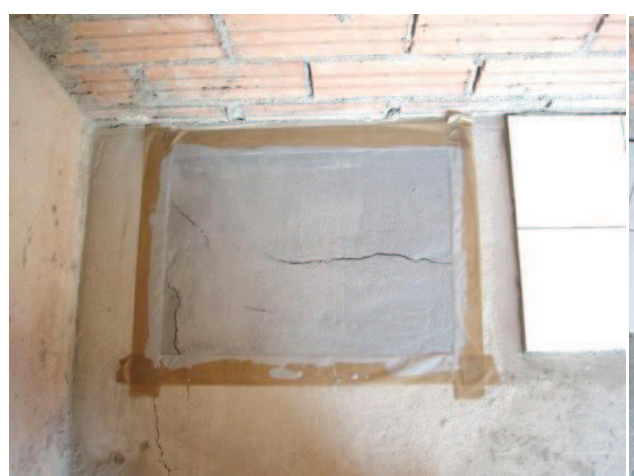

Aplicación de resinas en M IV-6PU75A

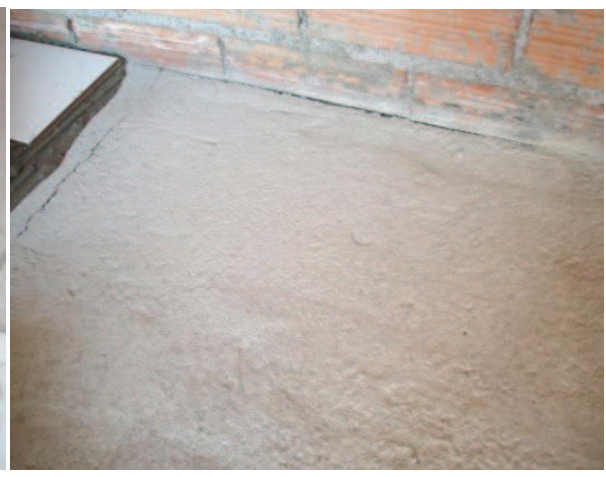

Solera barrida y limpia

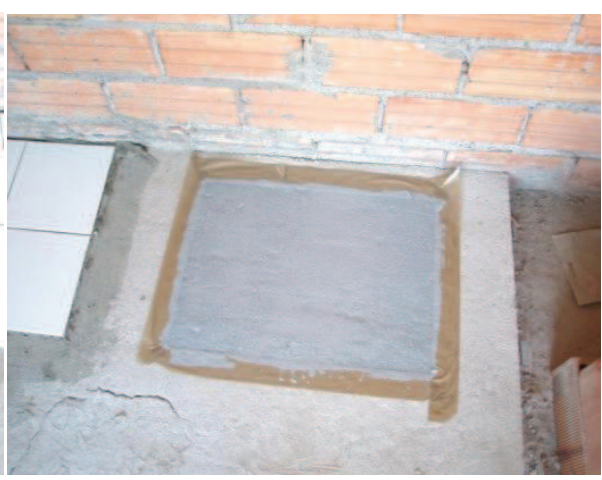

Aplicación de resinas en M IV-6PU75A 


\subsection{9.- Aplicación de pintura plástica}

\section{Pintado de paramento exterior sobre enfoscado. M II-4PU50A}

- Se ha pintado una porción del muro norte, en su cara exterior enfoscada con mortero M II-4PU50A, sobre la superficie ligeramente bruñida. La pintura utilizada ha sido pintura plástica al agua. No se ha imprimado el soporte. Se ha aplicado una mano sin diluir. No se han aplicado más manos pues el objeto de la prueba ha sido conocer la idoneidad del enfoscado para recibir un acabado tradicional, en base a una buena adherencia.

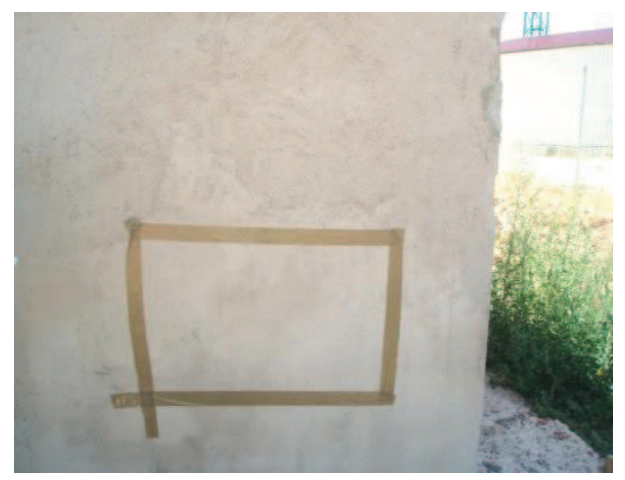

Zona enfoscado bruñido

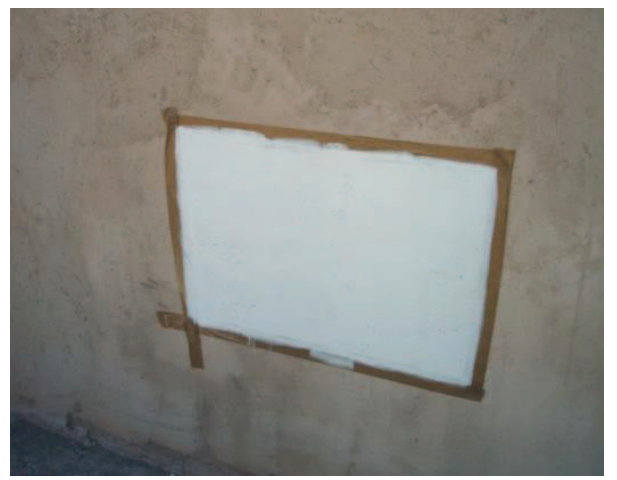

Pintura sobre enfoscado

\section{4.- Resultados de ensayos de muestras recogidas en obra}

\subsection{1.- Ensayos mecánicos}

Se han tomado muestras en obra de los morteros de solado y revestimiento para realizar los ensayos mecánicos de resistencia a flexión y a compresión. Las probetas de dimensiones $(4 \times 4 \times 16) \mathrm{cm}^{3}$ se han confeccionado con el mortero vertido en la parte media de la carretilla. Los moldes con las probetas se han cubierto con un vidrio y se han conservado las primeras horas en una caseta de obra y, posteriormente, se han trasladado a Burgos, a la cámara húmeda del laboratorio. Se han desmoldado a las 48 horas y se han curado hasta los 28 días en la cámara.

Los valores de los ensayos de flexión y compresión a 28 días se muestran en la Tabla 7.1, indicando por una parte los resultados de las series confeccionadas en laboratorio y por otro los resultados de las muestras recogidas del mortero amasado en obra. 
Tabla 7.1. Resistencia a la flexión y compresión a 28 días. Morteros puestos en obra

\begin{tabular}{|l|c|c|c|c|}
\multicolumn{2}{|c}{ Mortero } & \multicolumn{2}{c}{$\begin{array}{c}\text { Resistencia a flexión } \\
\text { Mpa }\end{array}$} & \multicolumn{2}{c|}{$\begin{array}{c}\text { Resistencia a compresión } \\
\text { Mpa }\end{array}$} \\
\hline M II-4PU50A & Laboratorio & Obra & Laboratorio & Obra \\
\hline M II-4PU50B & 1,92 & 2,78 & 7,01 & 9,46 \\
\hline M IV-6PU75A & 2,23 & 2,41 & 6,39 & $\mathbf{8 , 4 3}$ \\
\hline M IV-6PU75B & 1,15 & 1,10 & 4,03 & 2,84 \\
\hline
\end{tabular}

Los resultados sobre las muestras recogidas en obra indican un aumento de la resistencia a compresión en las probetas con cemento del tipo II y sustitución del $50 \%$ de árido, y una disminución en las probetas con cemento tipo IV y una sustitución del $75 \%$ de arena por PUR. La diferencia en los resultados de obra con respecto a laboratorio se puede deber a la variación de la relación agua cemento, ya que la cantidad de agua del mortero en obra ha sido función de la plasticidad requerida por los operarios. Otro factor a tener en cuenta, que puede haber influido en los resultados, es la compactación que no ha sido posible realizarla convenientemente en los morteros con un $75 \%$ de espuma. En cualquier caso, se han obtenido resultados aceptables, que deberán contrastarse con las resistencias a largo plazo.

\subsection{2.- Ensayos de adherencia de los morteros puestos en obra}

Se han llevado a cabo ensayos de adherencia en los morteros aplicados como revestimientos, tanto exterior como interior. La placa se ha mantenido en obra 18 días, hasta asegurar que su retirada no suponía esfuerzos significativos sobre el mortero. Posteriormente se han efectuado las mediciones de adhesión de acuerdo con la norma UNE EN 1015-12, que se muestran en la Tabla 7.2.

Tabla 7.2. Resistencia a la adhesión. Morteros puestos en obra

\begin{tabular}{|l|c|c|}
\multicolumn{1}{|c}{ Mortero } & \multicolumn{2}{c|}{$\begin{array}{c}\text { Resistencia a la adhesión } \\
\text { N/m m } \mathbf{m}^{2}\end{array}$} \\
\hline M II-4PU50A & Laboratorio & Obra \\
\hline M II-4PU50B & 0,24 & 0,18 \\
\hline
\end{tabular}

Los valores obtenidos indican una adherencia similar en obra que en laboratorio. Estos resultados sólo son estimativos, pues el ladrillo utilizado 
en el laboratorio es diferente al empleado en obra, especialmente en lo relativo a la rugosidad superficial. Las condiciones de obra han sido distintas y la mecánica empleada para la toma de las muestras, en paño vertical y compactada por los operarios, difiere de la utilizada en el laboratorio. Sin embargo los resultados indican que con una técnica tradicional de puesta en obra la adherencia de los morteros es elevada.

\section{5.- Resultados de ensayos sobre unidades de obra}

No ha sido posible evaluar la durabilidad de los morteros puestos en obra, pues solamente han transcurrido 3 meses desde la aplicación de los morteros y la finalización de este Trabajo. Sin embargo se han podido estudiar ciertos aspectos relativos al comportamiento de los morteros como revestimiento propiamente dicho o como base para un posterior revestimiento tradicional, con material cerámico o pintura.

\subsection{1.- Ensayos organolépticos}

Los ensayos organolépticos del mortero puesto en obra han consistido en la apreciación visual de los morteros de revestimiento y base de nivelación y de uno de los morteros de juntas.

\subsubsection{1.- Resultados iniciales}

No se han apreciado modificaciones en la textura de los morteros de enfoscado, M II-4PU50A y M II-4PU50B; tampoco se ha observado fisuración por retracción plástica.

Los morteros colocados en solados muestran una fisuración inicial por retracción plástica importante a las pocas horas de su colocación. Los factores más determinantes que han influido en la fisuración por retracción han sido los siguientes:

- Espesor de $6 \mathrm{~cm}$ de la capa de mortero. Para espesores de este tipo y morteros de solado, se recomienda la utilización de áridos de mayor tamaño, generalmente de tamaños hasta $8-10 \mathrm{~mm}$, lo que daría lugar a la confección de hormigones de árido fino. 
- Riqueza en conglomerante. Valores que oscilan entre los $288 \mathrm{~kg}$ del M VI-6PU75B y los $343 \mathrm{~kg}$ del mortero M IV-6PU75A. En principio no parecen dosificaciones excesivamente altas, si bien para este tipo de mortero-hormigón, de base de nivelación, se recomiendan dosificaciones de $1 / 8$ o $1 / 10$, lo que supone un contenido del orden de $200 \mathrm{~kg}$ de cemento por $\mathrm{m}^{3}$ de mortero.

- Retracción de secado intensa. Las condiciones ambientales han sido de escasa humedad y temperaturas por encima de los $30^{\circ} \mathrm{C}$. Además, una parte de la solera ha estado expuesta al sol durante más de una hora.

\subsubsection{2.- Resultados a los 28 días}

La caseta (Figuras 7.1 y 7.2 ) se ha utilizado desde el octavo día para almacén de productos en barriles y también como zona de estancia de algunos operarios, por lo que el tránsito dentro de la caseta se puede considerar como importante y quizás similar al que pueda sufrir una solera de nivelación en un edificio en construcción, teniendo en cuenta que la ejecución de las soleras de nivelación se corresponde con la fase final de la obra.

La estancia de los operarios en el interior de la caseta en posición sentada, hace que la abrasión del suelo por movimiento del calzado tenga cierta importancia. A consecuencia de ello, los morteros de solado M IV-6PU75A y $B$, han sufrido una ligera abrasión superficial, más importante en el mortero con PUR B, que también ha estado más expuesto a la abrasión. No se han observado signos de erosión en los morteros de revestimiento. 


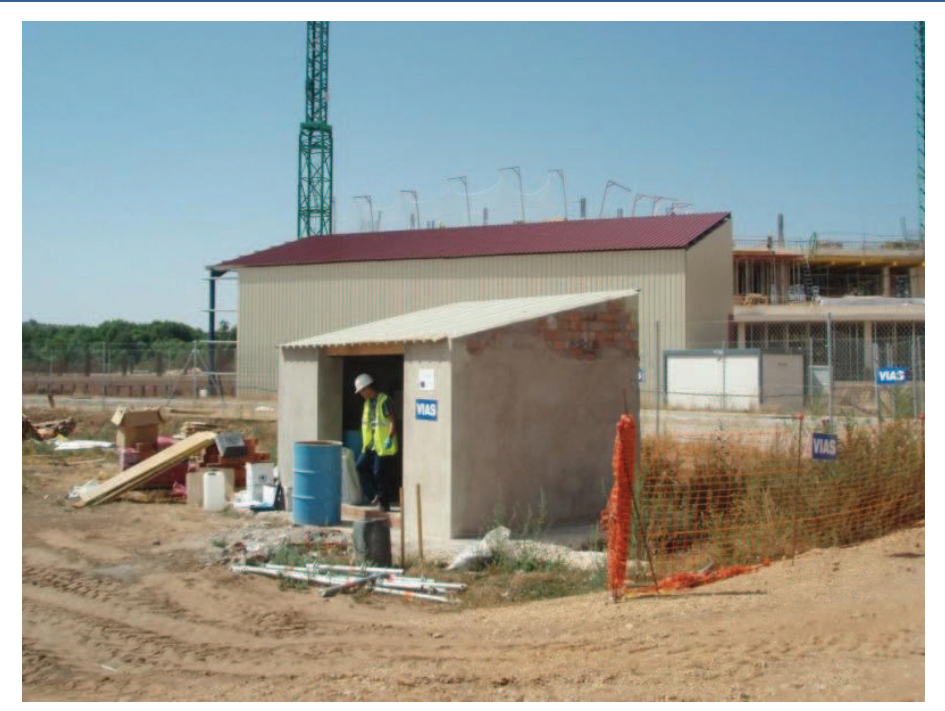

Figura 7.1. Uso de la caseta como almacén y estancia

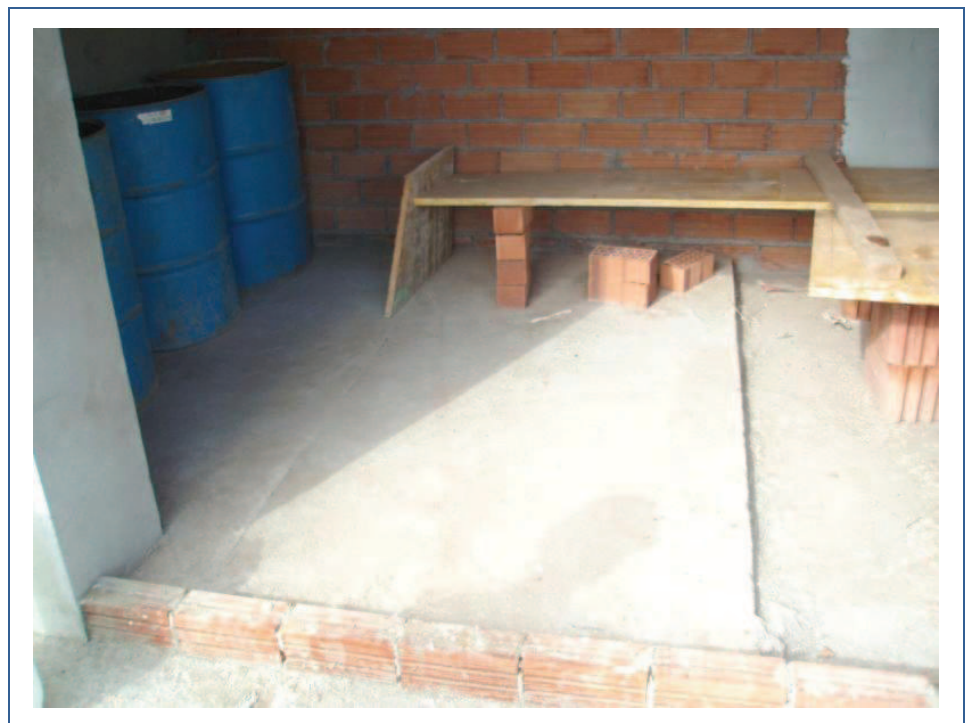

Figura 7.2. Interior de la caseta

La observación directa de los morteros puestos en obra, no difiere demasiado con el aspecto del mortero a las pocas horas de colocado. Las fisuras por retracción de los morteros colocados como solados han aumentado muy ligeramente en anchura y longitud (Figura 7.3), no habiendo aparecido nueva fisuración superficial. 


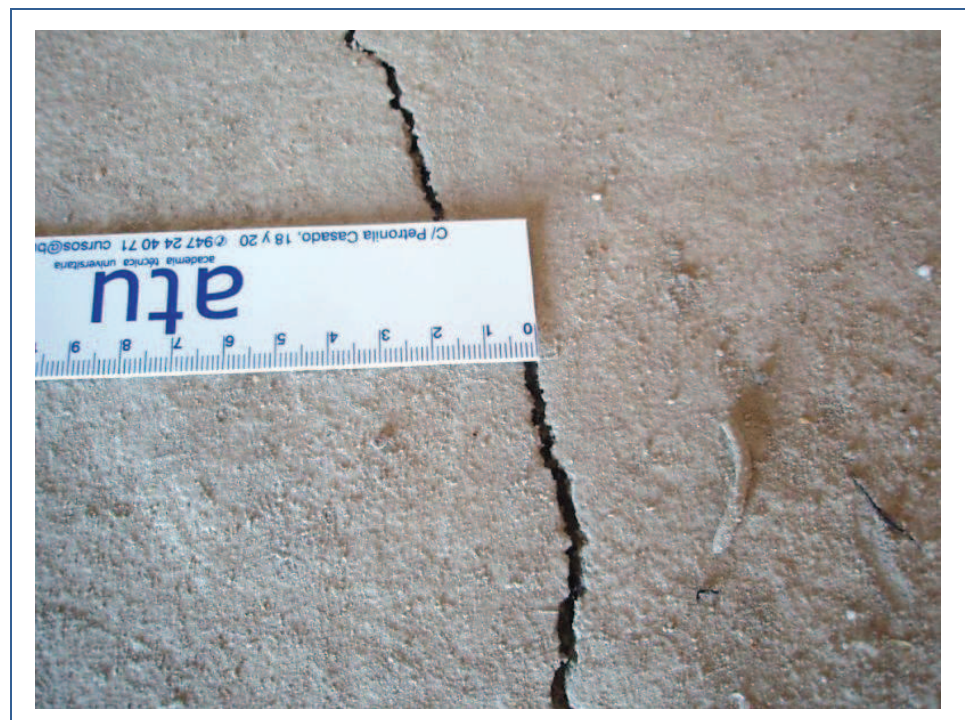

Figura 7.3. Anchura de fisura $2,5 \mathrm{~mm}$. Mortero en solado $\mathrm{M}$ IV-6PU75A

Se ha apreciado un importante descenso en el mortero de nivelación de suelo M IV-6PU75B, del orden de $4 \mathrm{~mm}$ con respecto al suelo de M IV6PU75A (Figura 7.4).

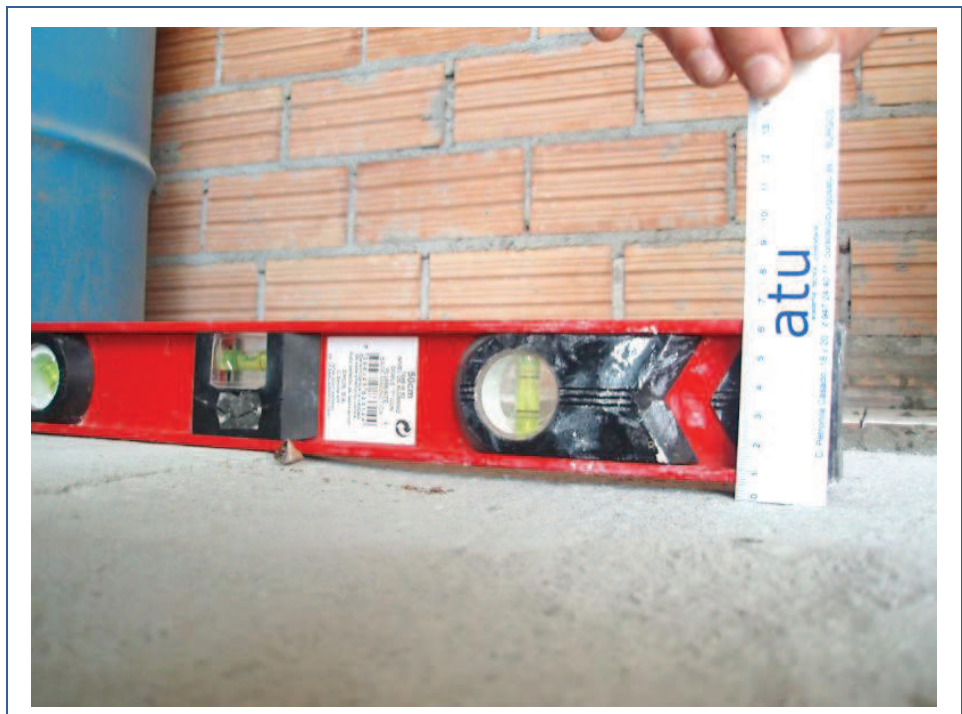

Figura 7.4. Descenso de $4 \mathrm{~mm}$ de la solera realizada con M IV6PU75B

El motivo de la disminución del espesor de la solera se puede deber al aplastamiento del mortero por una débil consistencia, que se pudo intuir 
después de compactado el mortero con la regla, ya que apareció una lechada superficial de cierto espesor, que posteriormente se ha secado. No parece que la causa del aplastamiento haya sido el tránsito y uso de la caseta ya que, una vez barrido el suelo, no han aparecido marcas o hundimientos localizados en el suelo (Figura 7.5).

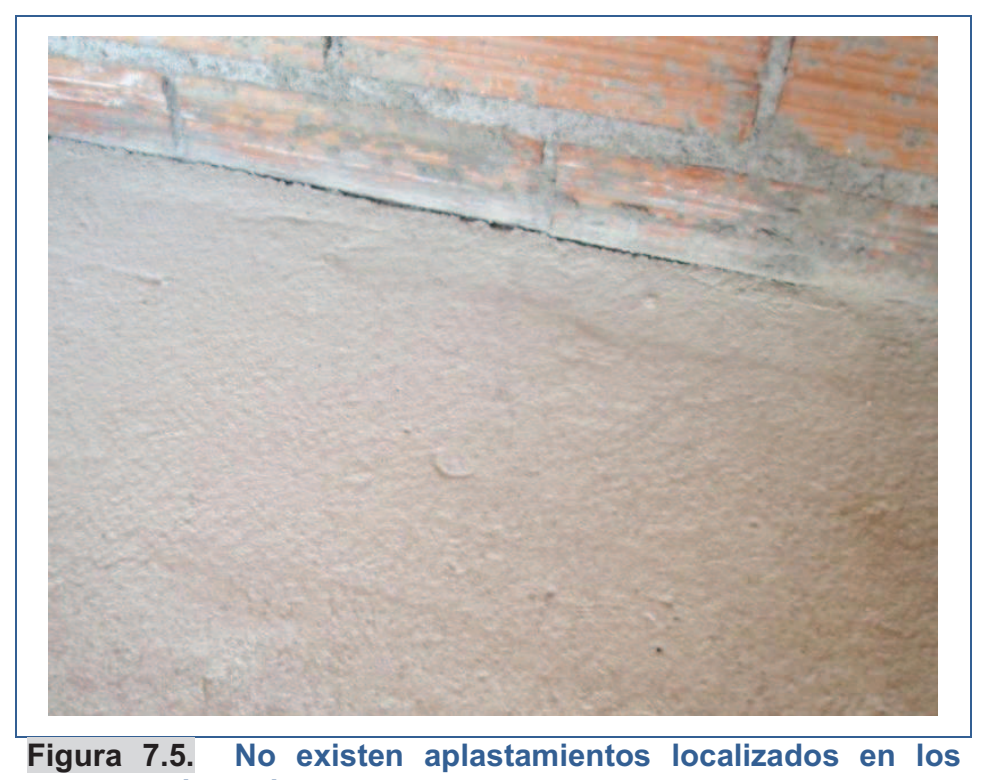
morteros de suelo

\subsection{2.- Pruebas de aptitud}

Para comprobar la idoneidad de los morteros a los 28 días de su puesta en obra, se han realizado las siguientes pruebas de aptitud

- Colocación de baldosa cerámica con adhesivo sobre el enfoscado interior y sobre las soleras de base para pavimento interior

- Comprobación de la adhesión del mortero de base de nivelación a la solera de hormigón

- Aplicación de pintura plástica en paramento enfoscado exterior

- Aplicación de pintura de revestimiento-acabado de las soleras de mortero 
- Estimación de la resistencia a la penetración con la introducción de un clavo en los morteros de juntas y de soleras

\subsubsection{1.- Adhesión de baldosa cerámica}

Para evaluar la aptitud del mortero de enfoscado interior como base de revestimientos tradicionales, se extrajo un testigo del muro de cerramiento de la caseta con una baldosa colocada 28 días antes (Figura 7.6).

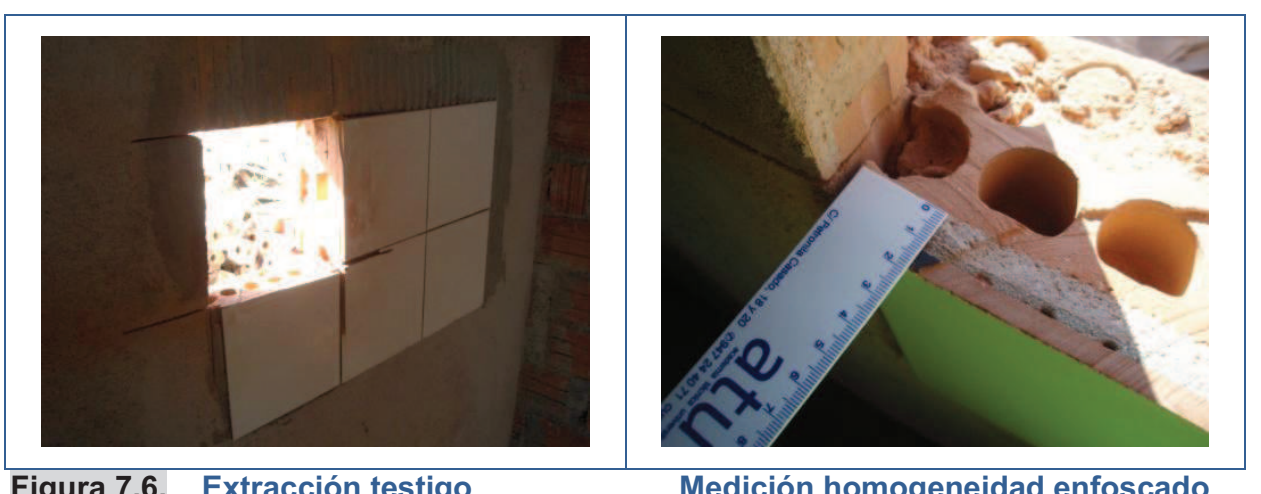

Figura 7.6. Extracción testigo

Medición homogeneidad enfoscado

En la extracción del testigo se comprobó la homogeneidad y continuidad del enfoscado (M II-4PU50B), en capa de 1 a 1,2 cm. Posteriormente se despegó una baldosa apalancando con una uña. Debido a la buena adherencia, la baldosa partió en dos trozos. En la Figura 7.7 se puede apreciar la buena adherencia del adhesivo al enfoscado, ya que el fallo en la adherencia se produjo en la interfase adhesivo-baldosa.

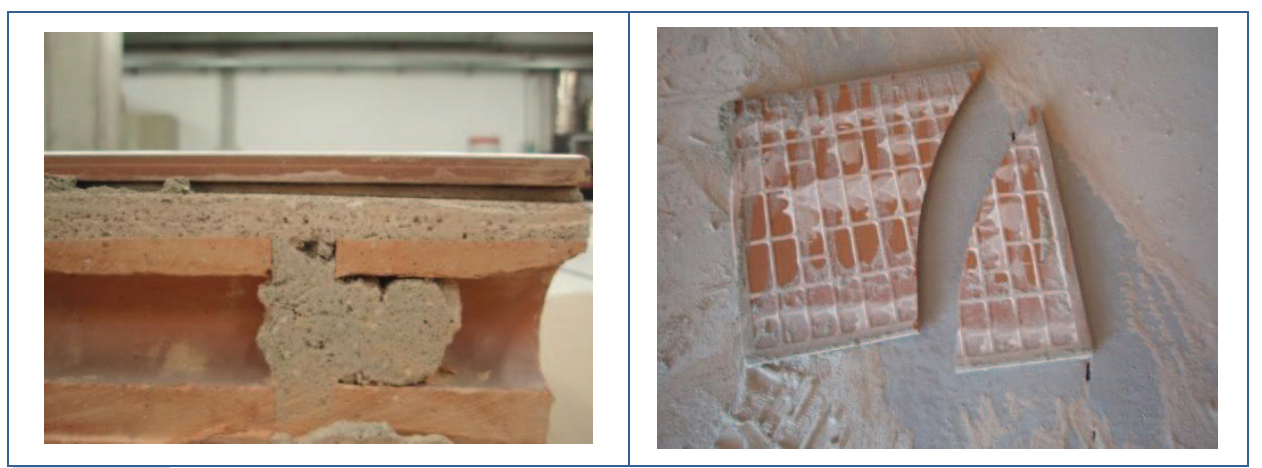

Figura 7.7. Buena adhesión del mortero a fábrica y adhesivo 
Una vez en laboratorio se ha comprobado la distribución homogénea del mortero y la buena adhesión del mortero de enfoscado, tanto al adhesivo como a la fábrica de ladrillo (Figura 7.8).

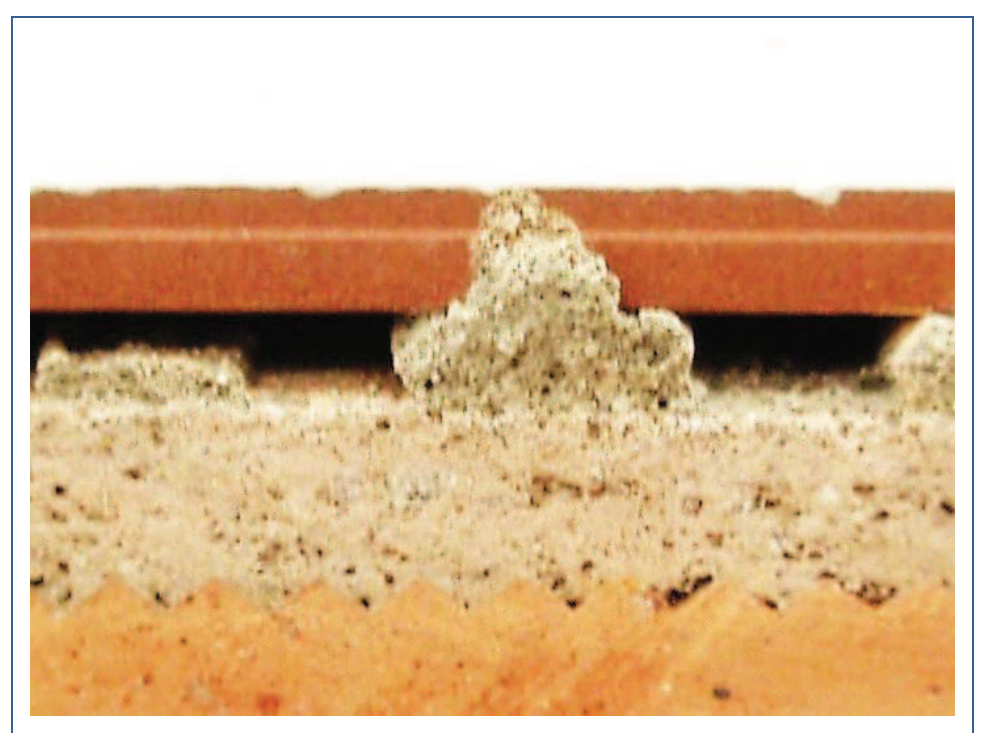

Figura 7.8. Distribución homogénea del mortero sobre la superficie del ladrillo

De igual forma se ha determinado la adherencia del adhesivo sobre la solera de los morteros M IV-6PU75A y B, con la misma técnica que en el apartado 7.5.2.1., con los siguientes resultados (Figura 7.9). 


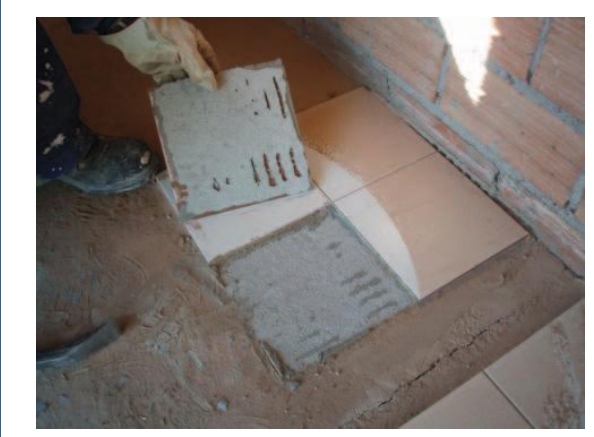

M IV-6PU75A

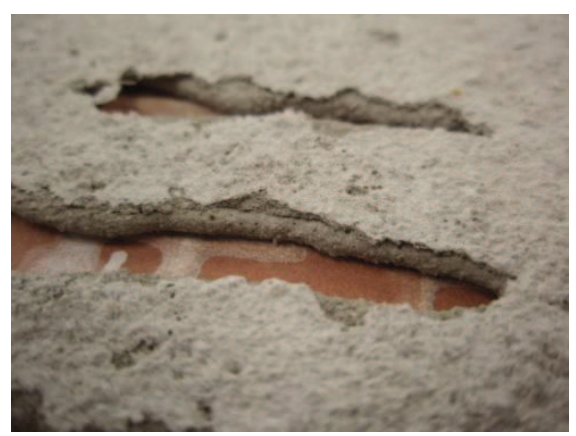

Figura 7.9.

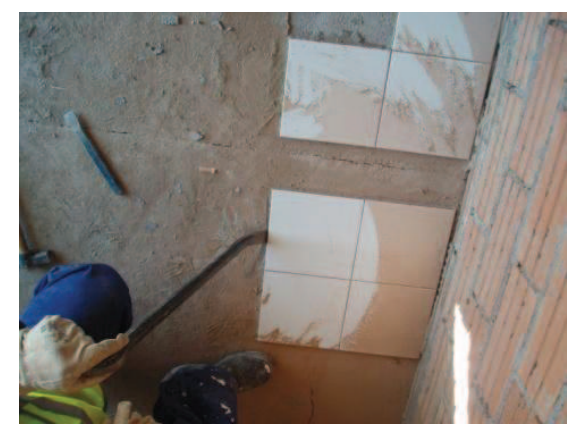

M IV-6PU75B

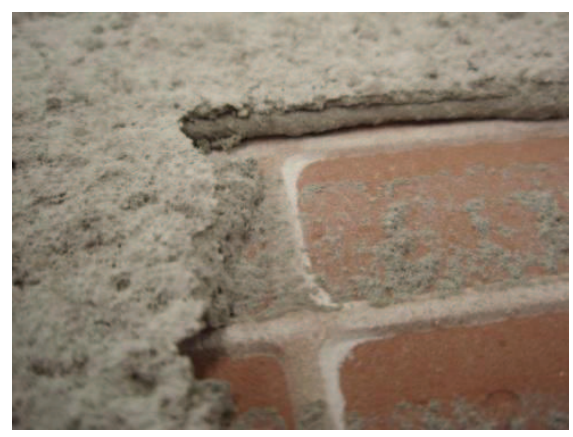

Buena adhesión del adhesivo al mortero de solera

\subsubsection{2.- Adhesión sobre soporte de hormigón}

Se ha extraído un testigo en obra del mortero M IV-6PU75B para conocer el grado de adherencia de la solera de mortero (Figura 7.10).
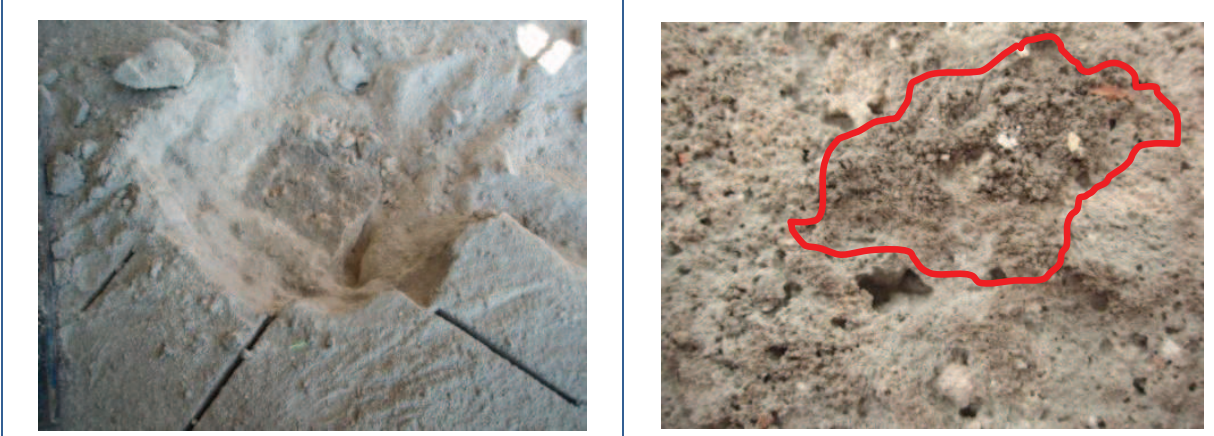

Figura 7.10.

Testigo y plano de contacto solera de hormigón-mortero

Se puede comprobar parte de la capa superficial de la solera de hormigón, de color más oscuro, adherida al mortero, lo que demuestra una buena adherencia entre ambos materiales. 


\subsubsection{3.- Pintura plástica sobre paramento enfoscado exterior}

Las características organolépticas del paño de pintura sobre enfoscado exterior en el mortero M II-4PU50A, no muestran que haya degradación de la pintura, abombamientos o fisuración superficial, si bien es necesario evaluar esta aptitud a más largo plazo.

\subsubsection{4.- Pintura de acabado sobre soleras}

La aplicación directa de pintura de acabado superficial de las soleras, con resina epoxi de dos componentes, indica una buena aptitud de las soleras para recibir este tipo de acabados. La extracción de un testigo de la solera de la caseta de obra, realizado apalancando en un plano cercano al de contacto entre resina y mortero, muestra que se ha mantenido la resina completamente adherida al soporte, habiendo roto éste en un plano alejado del de contacto entre los materiales (Figura 7.11).

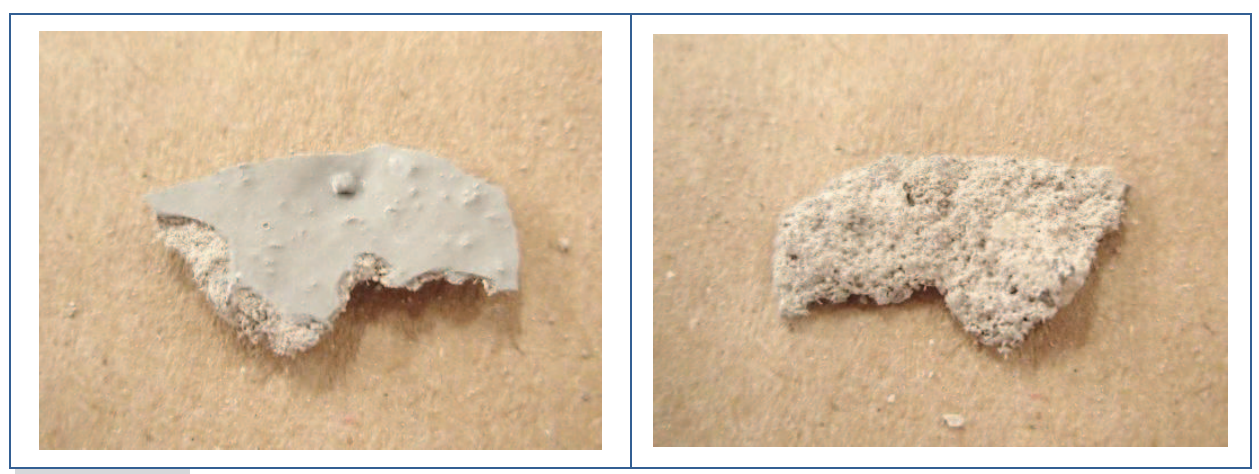

Figura 7.11. Adherencia entre revestimiento epoxi y mortero M IV-6PU75B

\subsubsection{5.- Resistencia a la penetración}

Se ha clavado por golpeo una punta de acero en el mortero de juntas ( $M$ IV-4PU50B y M IV-6PU50A) y en el mortero de solera de nivelación (M IV6PU75A y M IV-6PU75B) (Figura 7.12).

La prueba ha consistido en la hinca con martillo tradicional. No se ha medido la penetración con un número determinado de golpes, sino simplemente la resistencia que se apreció al golpear con el martillo. Posteriormente se extrajo el clavo. 


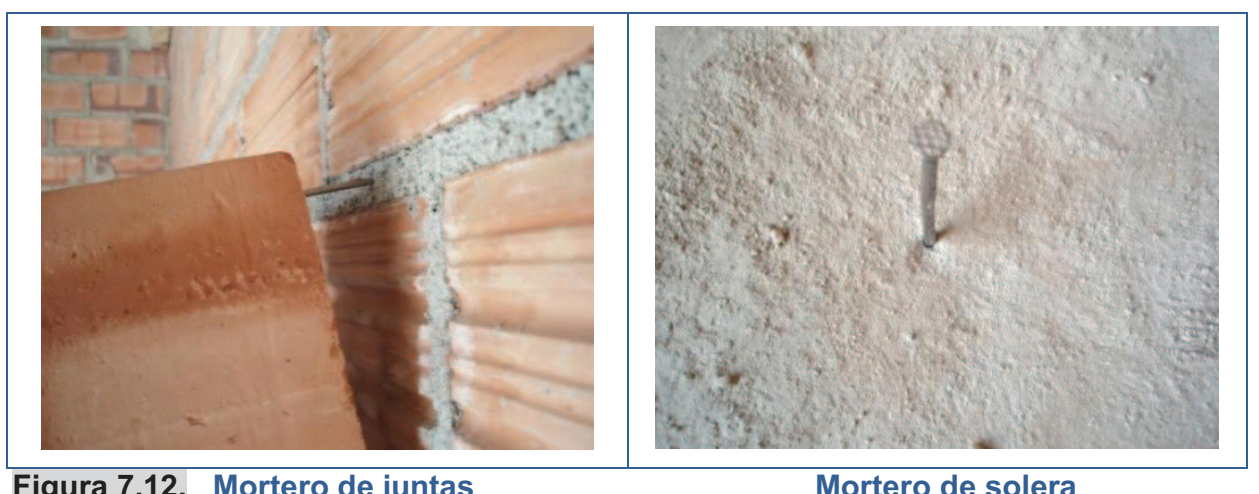

Figura 7.12. Mortero de juntas

Mortero de solera

La resistencia a la penetración apreciada al golpear con el martillo en los morteros de juntas ha resultado importante, llegando a doblarse el clavo de acero. Posteriormente se han sacado los clavos ofreciendo cierta resistencia. La resistencia a la penetración de las soleras ha sido menor. El mortero M IV-6PU75A ha ofrecido bastante más resistencia que el M IV$6 \mathrm{PU75B}$, en el que el clavo ha penetrado con cierta facilidad. La extracción posterior de los clavos ha sido dificultosa en ambos morteros.

\subsubsection{6.- Dureza superficial}

Con carácter meramente informativo, se ha evaluado la dureza superficial de los enfoscados y solera de nivelación, tomando como base la dureza superficial obtenida en el enfoscado de referencia colocado en la obra. Se ha empleado el método de "Dureza Shore C" para medidas en obra, de acuerdo con la Norma UNE $102039^{1}$, que aunque es de aplicación a yesos y escayolas, puede servir como un parámetro válido para estimar la dureza relativa de los morteros aligerados.

Los resultados se muestran en la Tabla 7.3, en la que se puede comprobar que la dureza superficial de enfoscados es similar en los morteros con agregado del $50 \%$ de PUR que en el de referencia. Los morteros con agregado del $75 \%$ tienen una dureza superficial inferior al de referencia, si bien mejoran sensiblemente con el revestimiento de resinas epoxídicas.

\footnotetext{
${ }^{1}$ Norma Española UNE 102-039 85. Yesos y escayolas de construcción. Determinación de la dureza Shore C y de la dureza Brinell. 1985
} 
Tabla 7.3. Dureza Shore C

\section{Mortero}

\begin{tabular}{|l|c|c|c|} 
& Sin acabado & $\begin{array}{c}\text { Acabado Pintura } \\
\text { plás tica }\end{array}$ & $\begin{array}{c}\text { Reves tim iento } \\
\text { Epoxi }\end{array}$ \\
\hline M IV-4R & 85,00 & -- & -- \\
\hline M II-4PU50A & 84,90 & 94,80 & -- \\
\hline M II-4PU50B & 87,00 & -- & -- \\
\hline M IV-6PU75A & 63,40 & -- & 78,60 \\
\hline M IV-6PU75B & 46,20 & -- & 74,40 \\
\hline
\end{tabular}



$\infty$

O

-

$\supset$

$\vdash$

$-$

口

$\varangle$

0

Estudio económico 



\section{Capítulo 8.- Estudio económico}

Hasta ahora hemos estudiado la aptitud y durabilidad de los morteros fabricados con agregados de PUR, tanto a escala de laboratorio como en su puesta en obra.

Aunque la aportación a la sostenibilidad por el reciclaje de materiales y a la mejora en la gestión de ciertos residuos, son por sí mismas propiedades que podrían influir de forma determinante en el empleo de estos materiales, se debe realizar un estudio económico que complete el conjunto de cualidades que nos permitan la elección de este material de construcción frente a sus competidores.

Aunque el estudio económico, en el sentido más amplio de la expresión, abarca tanto la valoración cuantitativa como cuantitativa del producto, resulta difícil llegar a evaluar numéricamente el material como compendio de todas sus propiedades. Por tanto, en este capítulo nos ceñiremos a realizar una valoración cuantitativa, es decir, el coste del mortero puesto en obra con el empleo de los medios habituales y una estimación de la reducción de la carga que soportan las estructuras, que es función de la cantidad y densidad de los materiales empleados, en este caso morteros de menor densidad que los convencionales.

El estudio económico se ciñe exclusivamente a las 6 dosificaciones puestas en obra y a las 3 dosificaciones homólogas que han servido de referencia.

\section{1.- Valoración cuantitativa de los morteros con agregados de PUR}

El precio final de un mortero de cemento, ya colocado en obra y apto para su uso lo componen tres factores: el coste de las materias primas, el coste de la confección de la mezcla y el coste de la puesta en obra del mortero

De estos tres factores, solamente se ha realizado una valoración del coste de las materias primas a pie de obra ya que, como se ha 
comprobado en las pruebas de puesta en obra, tanto la confección de la mezcla como el rendimiento en la colocación en obra de los morteros, ha sido independiente del contenido de agregado.

En los casos en que el mortero se suministra mezclado en obra, se unifica el precio de las materias primas y el precio de la fabricación de la mezcla. Pero debido a que en la dosificación de los morteros con agregados de PUR se han empleado como referencia los morteros tradicionales prescritos, el estudio económico se ha realizado con el precio de los morteros tradicionales confeccionados en obra, es decir, con mezcla de las materias primas en obra.

Dado que el transporte de las materias primas es un componente determinante en el precio final, se ha establecido una distancia máxima de $20 \mathrm{~km}$ desde el centro de suministro de la arena y el lugar de ubicación de la construcción, ya que normalmente existen suficientes canteras de árido repartidas por la geografía española.

La limitación de distancia del lugar de suministro del árido también incluye al agregado PUR, de modo que se han realizado distintas simulaciones de precio final del mortero en función de las posibles ubicaciones de industrias que pudieran generar residuos de espuma rígida de poliuretano, considerando una distancia máxima de $200 \mathrm{~km}$.

\subsection{1.- Precios unitarios de los materiales a pie de obra}

Los precios de los materiales a pie de obra se han consultado en diversas empresas de suministro de materiales de construcción de Burgos capital. Estos precios han sido contrastados con otras empresas del sector de la construcción.

El precio unitario de los materiales a pie de obra se compone del precio de adquisición del material en origen y del precio de transporte hasta la obra para el árido y la espuma, ya que el cemento se compra a empresas de suministro y almacenamiento de materiales, que venden sus productos a pie de obra. El agua se encuentra directamente en la obra, pues las construcciones precisan de acometida de agua municipal. 
Todos los materiales llegan listos para su empleo, excepto la espuma, que bien en origen, bien en obra, necesitará de una trituración al tamaño adecuado a su uso. Así pues, al transporte de la espuma hasta obra habrá que añadir el precio de la trituración, que se ha calculado consultando diferentes empresas de alquiler de maquinaria para trituración. Se ha estimado un rendimiento en la molturación de 0,8 tn/hora y un coste total de trituración por tn de $29,393 € €^{146}$ que se añadirá al precio en origen.

Los precios estimados para el transporte de los áridos se indican en la Tabla 8.1.

Tabla 8.1. Precio transporte árido por tn y km

\begin{tabular}{|l|c|c|}
\hline \multicolumn{2}{|c|}{ Precio transporte en $€$} \\
\hline & km ida y vuelta & tn.km ida y vuelta \\
\hline $\begin{array}{l}\text { Camión trailer. } \\
\text { Capacidad 38 tn Arena }\end{array}$ & 4,940 & 0,130 \\
\hline $\begin{array}{l}\text { Camión trailer remolque 75 } \mathrm{m}^{3} . \\
\text { Capacidad 3,360 tn PUR A }\end{array}$ & 6,420 & 1,191 \\
\hline $\begin{array}{l}\text { Camión trailer remolque 75 } \mathrm{m}^{3} . \\
\text { Capacidad 4,425 tn PUR B }\end{array}$ & 6,420 & 1,451 \\
\hline
\end{tabular}

En la Tabla 8.2 se establecen los precios de los materiales en origen, lo que incluye el tratamiento del poliuretano, consistente en la trituración de la espuma que se realizará en el punto de producción del residuo.

Tabla 8.2. Precio materia prima en origen

\begin{tabular}{|l|c|c|c|}
\multicolumn{1}{|c|}{ Material } & \multicolumn{3}{|c|}{ Precio $€$} \\
\hline CEM II/B L 32,5 R & tn & Manipulación & tn origen \\
\hline CEM IV/B (V) 32,5 N & 96,810 & -- & 96,810 \\
\hline Arena & 85,420 & -- & 85,420 \\
\hline PUR A & 12,150 & -- & 12,150 \\
\hline PUR B & 0,000 & 29,393 & 29,393 \\
\hline Agua & 0,000 & 29,393 & 29,393 \\
\hline
\end{tabular}

146 Gutiérrez González, S. Tesis Doctoral. "Yesos aligerados fabricados a partir de reisduos de espumas de poliuretano y polvo de poliamida". Universidad de Burgos. España. 2012 
En la Tabla 8.3 se muestran los precios unitarios por tonelada de los materiales puestos a pie de obra, en función de la distancia de procedencia del agregado PUR.

Tabla 8.3. Precio materia prima puesta en obra por tn

\begin{tabular}{|l|c|c|c|}
\hline \multicolumn{3}{|c|}{ Material } & \multicolumn{3}{|c|}{ Precio $€$} \\
\hline & tn origen & transporte & tn obra \\
\hline CEM II/B L 32,5 R & 96,810 & incluido & 96,810 \\
\hline CEM IV/B (V) 32,5 N & 85,420 & incluido & 85,420 \\
\hline Arena (hasta 20 km) & 12,150 & 2,600 & 14,750 \\
\hline PUR A (hasta 20 km) & 29,393 & 23,820 & 53,213 \\
\hline PUR A (hasta 50 km) & 29,393 & 59,550 & 88,943 \\
\hline PUR A (hasta 100 km) & 29,393 & 119,100 & 148,493 \\
\hline PUR A (hasta 150 km) & 29,393 & 178,650 & 208,043 \\
\hline PUR A (hasta 200 km) & 29,393 & 238,200 & 267,593 \\
\hline PUR B (hasta 20 km) & 29,393 & 29,020 & 58,413 \\
\hline PUR B (hasta 50 km) & 29,393 & 58,040 & 87,433 \\
\hline PUR B (hasta 100 km) & 29,393 & 145,100 & 174,493 \\
\hline PUR B (hasta 150 km) & 29,393 & 217,650 & 247,043 \\
\hline PUR B (hasta 200 km) & 29,393 & 290,200 & 319,593 \\
\hline Agua & 1,270 & incluido & 1,270 \\
\hline
\end{tabular}

\subsection{2.- Precio del mortero previo al amasado}

Se ha realizado una composición del precio del metro cúbico de cada tipo de mortero antes del amasado, función de la distancia de procedencia del agregado PUR. Los resultados obtenidos se muestran en las Tablas 8.4 a 8.10 . 
Tabla 8.4. Precio $\mathrm{m}^{3}$ morteros de referencia

\begin{tabular}{|c|c|c|c|c|}
\hline \multicolumn{5}{|c|}{ Mortero } \\
\hline & $\begin{array}{c}\text { Cantidad } \\
\operatorname{tn} / \mathrm{m}^{3}\end{array}$ & $\begin{array}{c}\text { Precio } \\
€ / \text { tn }\end{array}$ & $\underset{€ / m^{3}}{\text { Suma }}$ & \\
\hline \multicolumn{5}{|c|}{ M II-4R } \\
\hline Cemento & 0,3563 & 96,810 & 34,497 & \\
\hline Arena & 1,4254 & 14,750 & 21,024 & $M \|-4 R .-\epsilon / m^{3}$ \\
\hline Agua & 0,3183 & 1,270 & 0,404 & 55,926 \\
\hline \multicolumn{5}{|c|}{ M IV-4R } \\
\hline Cemento & 0,3608 & 85,420 & 30,821 & \\
\hline Arena & 1,4433 & 14,750 & 21,288 & $M I V-4 R .-\epsilon / m^{3}$ \\
\hline Agua & 0,3031 & 1,270 & 0,385 & 52,495 \\
\hline \multicolumn{5}{|c|}{ M IV-6R } \\
\hline Cemento & 0,2486 & 85,420 & 21,233 & \multirow[b]{2}{*}{ M IV-6R.- $€ / \mathrm{m}^{3}$} \\
\hline Arena & 1,4914 & 14,750 & 21,999 & \\
\hline Agua & 0,3162 & 1,270 & 0,402 & 43,633 \\
\hline
\end{tabular}

Tabla 8.5. Precio $\mathrm{m}^{3}$ mortero M II-4PU50A

\begin{tabular}{|c|c|c|c|c|c|}
\hline \multicolumn{6}{|l|}{ Mortero } \\
\hline M II-4PU50A & $\begin{array}{c}\text { Cantidad } \\
\operatorname{tn} / \mathrm{m}^{3}\end{array}$ & $\begin{array}{c}\text { Precio } \\
€ / \text { tn }\end{array}$ & $\underset{€ / m^{3}}{\text { Suma }}$ & & \\
\hline Cemento & 0,4674 & 96,810 & 45,246 & & \\
\hline Arena & 0,9347 & 14,750 & 13,788 & \multicolumn{2}{|c|}{ M II-4PU50A.- $€ / m^{3}$} \\
\hline PUR A (hasta 20 km) & 0,0303 & 53,213 & 1,612 & hasta $20 \mathrm{~km}$ & 61,144 \\
\hline PUR A (hasta 50 km) & 0,0303 & 88,943 & 2,694 & hasta $50 \mathrm{~km}$ & 62,226 \\
\hline PUR A (hasta 100 km) & 0,0303 & 148,493 & 4,497 & hasta $100 \mathrm{~km}$ & 64,030 \\
\hline PUR A (hasta 150 km) & 0,0303 & 208,043 & 6,301 & hasta $150 \mathrm{~km}$ & 65,833 \\
\hline PUR A (hasta 200 km) & 0,0303 & 267,593 & 8,104 & hasta $200 \mathrm{~km}$ & 67,637 \\
\hline Agua & 0,3926 & 1,270 & 0,499 & & \\
\hline
\end{tabular}


Tabla 8.6. Precio $\mathrm{m}^{3}$ mortero M II-4PU50B

\begin{tabular}{|c|c|c|c|c|c|}
\hline \multicolumn{6}{|l|}{ Mortero } \\
\hline M II-4PU50B & $\begin{array}{c}\text { Cantidad } \\
\operatorname{tn} / \mathrm{m}^{3}\end{array}$ & $\begin{array}{c}\text { Precio } \\
€ / \text { tn }\end{array}$ & $\begin{array}{c}\text { Suma } \\
€ / \mathrm{m}^{3}\end{array}$ & & \\
\hline Cemento & 0,4504 & 96,810 & 43,602 & & \\
\hline Arena & 0,9466 & 14,750 & 13,962 & \multicolumn{2}{|c|}{ M II-4PU50B.- $€ / m^{3}$} \\
\hline PUR B (hasta 20 km) & 0,0385 & 58,413 & 2,249 & hasta $20 \mathrm{~km}$ & 60,324 \\
\hline PUR B (hasta 50 km) & 0,0385 & 87,433 & 3,367 & hasta $50 \mathrm{~km}$ & 61,442 \\
\hline PUR B (hasta $100 \mathrm{~km}$ ) & 0,0385 & 174,493 & 6,719 & has ta $100 \mathrm{~km}$ & 64,794 \\
\hline PUR B (hasta $150 \mathrm{~km}$ ) & 0,0385 & 247,043 & 9,513 & hasta $150 \mathrm{~km}$ & 67,588 \\
\hline PUR B (hasta 200 km) & 0,0385 & 319,593 & 12,307 & has ta $200 \mathrm{~km}$ & 70,382 \\
\hline Agua & 0,4023 & 1,270 & 0,511 & & \\
\hline
\end{tabular}

Tabla 8.7. Precio $\mathrm{m}^{3}$ mortero M IV-4PU50B

\begin{tabular}{|c|c|c|c|c|c|}
\hline \multicolumn{6}{|l|}{ Mortero } \\
\hline M IV-4PU50B & $\begin{array}{c}\text { Cantidad } \\
\operatorname{tn} / \mathrm{m}^{3}\end{array}$ & $\begin{array}{c}\text { Precio } \\
€ / \text { tn }\end{array}$ & $\begin{array}{c}\text { Suma } \\
€ / m^{3}\end{array}$ & & \\
\hline Cemento & 0,4733 & 85,420 & 40,430 & & \\
\hline Arena & 0,9466 & 14,750 & 13,962 & \multicolumn{2}{|c|}{ M IV-4PU50B.- $€ / \mathrm{m}^{3}$} \\
\hline PUR B (hasta 20 km) & 0,0405 & 58,413 & 2,364 & hasta $20 \mathrm{~km}$ & 57,257 \\
\hline PUR B (hasta 50 km) & 0,0405 & 87,433 & 3,538 & hasta 50 km & 58,431 \\
\hline PUR B (hasta 100 km) & 0,0405 & 174,493 & 7,061 & has ta $100 \mathrm{~km}$ & 61,954 \\
\hline PUR B (hasta 150 km) & 0,0405 & 247,043 & 9,997 & has ta $150 \mathrm{~km}$ & 64,890 \\
\hline PUR B (hasta 200 km) & 0,0405 & 319,593 & 12,933 & has ta $200 \mathrm{~km}$ & 67,826 \\
\hline Agua & 0,3944 & 1,270 & 0,501 & & \\
\hline
\end{tabular}

Tabla 8.8. Precio $\mathrm{m}^{3}$ mortero M IV-6PU50A

\begin{tabular}{|c|c|c|c|c|c|}
\hline \multicolumn{6}{|l|}{ Mortero } \\
\hline M IV-6PU50A & $\begin{array}{c}\text { Cantidad } \\
\operatorname{tn} / \mathrm{m}^{3}\end{array}$ & $\begin{array}{c}\text { Precio } \\
€ / \text { tn }\end{array}$ & $\underset{€ / m^{3}}{\text { Suma }}$ & & \\
\hline Cemento & 0,3287 & 85,420 & 28,081 & & \\
\hline Arena & 0,9862 & 14,750 & 14,547 & \multicolumn{2}{|c|}{ M IV-6PU50A.- $€ / m^{3}$} \\
\hline PUR A (hasta 20 km) & 0,0320 & 53,213 & 1,704 & has ta $20 \mathrm{~km}$ & 44,842 \\
\hline PUR A (hasta 50 km) & 0,0320 & 88,943 & 2,848 & hasta $50 \mathrm{~km}$ & 45,986 \\
\hline PUR A (hasta $100 \mathrm{~km}$ ) & 0,0320 & 148,493 & 4,755 & hasta $100 \mathrm{~km}$ & 47,893 \\
\hline PUR A (hasta $150 \mathrm{~km}$ ) & 0,0320 & 208,043 & 6,661 & hasta $150 \mathrm{~km}$ & 49,799 \\
\hline PUR A (hasta $200 \mathrm{~km}$ ) & 0,0320 & 267,593 & 8,568 & hasta $200 \mathrm{~km}$ & 51,706 \\
\hline Agua & 0,4017 & 1,270 & 0,510 & & \\
\hline
\end{tabular}


Tabla 8.9. Precio $\mathrm{m}^{3}$ mortero M IV-6PU75A

\begin{tabular}{|c|c|c|c|c|c|}
\hline \multicolumn{6}{|l|}{ Mortero } \\
\hline M IV-6PU75A & $\begin{array}{c}\text { Cantidad } \\
\operatorname{tn} / \mathrm{m}^{3}\end{array}$ & $\begin{array}{c}\text { Precio } \\
€ / \text { tn }\end{array}$ & $\underset{€ / m^{3}}{\text { Suma }}$ & & \\
\hline Cemento & 0,3433 & 85,420 & 29,323 & & \\
\hline Arena & 0,5149 & 14,750 & 7,595 & \multicolumn{2}{|c|}{ M IV-6PU75A.- $€ / \mathrm{m}^{3}$} \\
\hline PUR A (hasta 20 km) & 0,0501 & 53,213 & 2,667 & hasta $20 \mathrm{~km}$ & 40,207 \\
\hline PUR A (hasta 50 km) & 0,0501 & 88,943 & 4,458 & hasta $50 \mathrm{~km}$ & 41,998 \\
\hline PUR A (hasta $100 \mathrm{~km}$ ) & 0,0501 & 148,493 & 7,442 & hasta $100 \mathrm{~km}$ & 44,982 \\
\hline PUR A (hasta $150 \mathrm{~km}$ ) & 0,0501 & 208,043 & 10,427 & hasta $150 \mathrm{~km}$ & 47,967 \\
\hline PUR A (hasta $200 \mathrm{~km}$ ) & 0,0501 & 267,593 & 13,411 & hasta $200 \mathrm{~km}$ & 50,951 \\
\hline Agua & 0,4902 & 1,270 & 0,623 & & \\
\hline
\end{tabular}

Tabla 8.10. Precio $\mathrm{m}^{3}$ mortero M IV-6PU75B

\begin{tabular}{|c|c|c|c|c|c|}
\hline \multicolumn{6}{|l|}{ Mortero } \\
\hline M IV-6PU75B & $\begin{array}{c}\text { Cantidad } \\
\operatorname{tn} / \mathrm{m}^{3}\end{array}$ & $\begin{array}{c}\text { Precio } \\
€ / \text { tn }\end{array}$ & $\underset{€ / m^{3}}{\text { Suma }}$ & & \\
\hline Cemento & 0,2877 & 85,420 & 24,577 & & \\
\hline Arena & 0,4316 & 14,750 & 6,366 & \multicolumn{2}{|c|}{ M IV-6PU75B.- $€ / m^{3}$} \\
\hline PUR B (hasta 20 km) & 0,0553 & 58,413 & 3,232 & hasta $20 \mathrm{~km}$ & 34,956 \\
\hline PUR B (hasta 50 km) & 0,0553 & 87,433 & 4,838 & hasta $50 \mathrm{~km}$ & 36,562 \\
\hline PUR B (hasta $100 \mathrm{~km}$ ) & 0,0553 & 174,493 & 9,656 & hasta $100 \mathrm{~km}$ & 41,379 \\
\hline PUR B (hasta $150 \mathrm{~km}$ ) & 0,0553 & 247,043 & 13,671 & hasta $150 \mathrm{~km}$ & 45,394 \\
\hline PUR B (hasta $200 \mathrm{~km}$ ) & 0,0553 & 319,593 & 17,686 & hasta $200 \mathrm{~km}$ & 49,409 \\
\hline Agua & 0,6146 & 1,270 & 0,780 & & \\
\hline
\end{tabular}

De la observación de las tablas se puede extraer lo siguiente:

- El precio final del mortero depende de la cantidad de cada componente, siendo la cantidad de cemento el factor más importante.

- La distancia del punto de suministro del agregado PUR es un factor determinante que llega incluso a multiplicar por 5 el precio de la espuma y a incrementar, en algunos casos, casi hasta un $50 \%$ el precio de las materias primas en obra. 
- Si la distancia del punto de suministro del agregado PUR a la obra es inferior de $20 \mathrm{~km}$, se obtienen morteros con árido reciclado cuyos precios resultan bastantes más bajos que sus homólogos de referencia, como es el caso del M IV-6PU75B, cuyo precio antes del amasado es casi un $15 \%$ menor.

- Si se evalúa el mortero sin considerar su resistencia a compresión, encontramos morteros con agregados de PUR más competitivos que sus homólogos de referencia.

En los cuadros comparativos de la Figuras 8.1 y 8.2 se representa el coste de los morteros con agregados de PUR y los morteros de referencia para una distancia media de $100 \mathrm{~km}$ y $20 \mathrm{~km}$ respectivamente, desde el punto de producción del residuo hasta la obra. En el mismo cuadro se indican las resistencias a compresión de los morteros a 28 días.

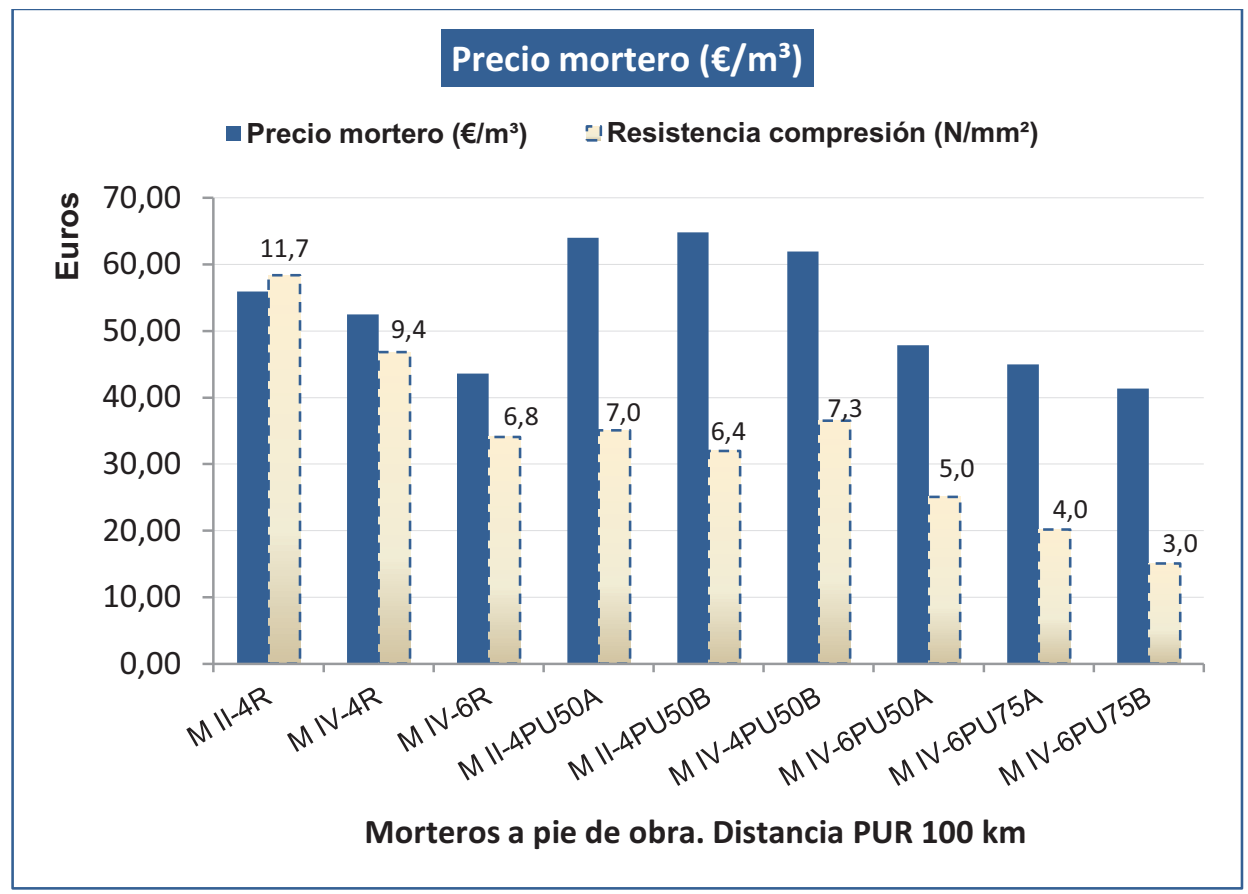

Figura 8.1. Precios comparativos de morteros a pie de obra. Distancia PUR 100 km 


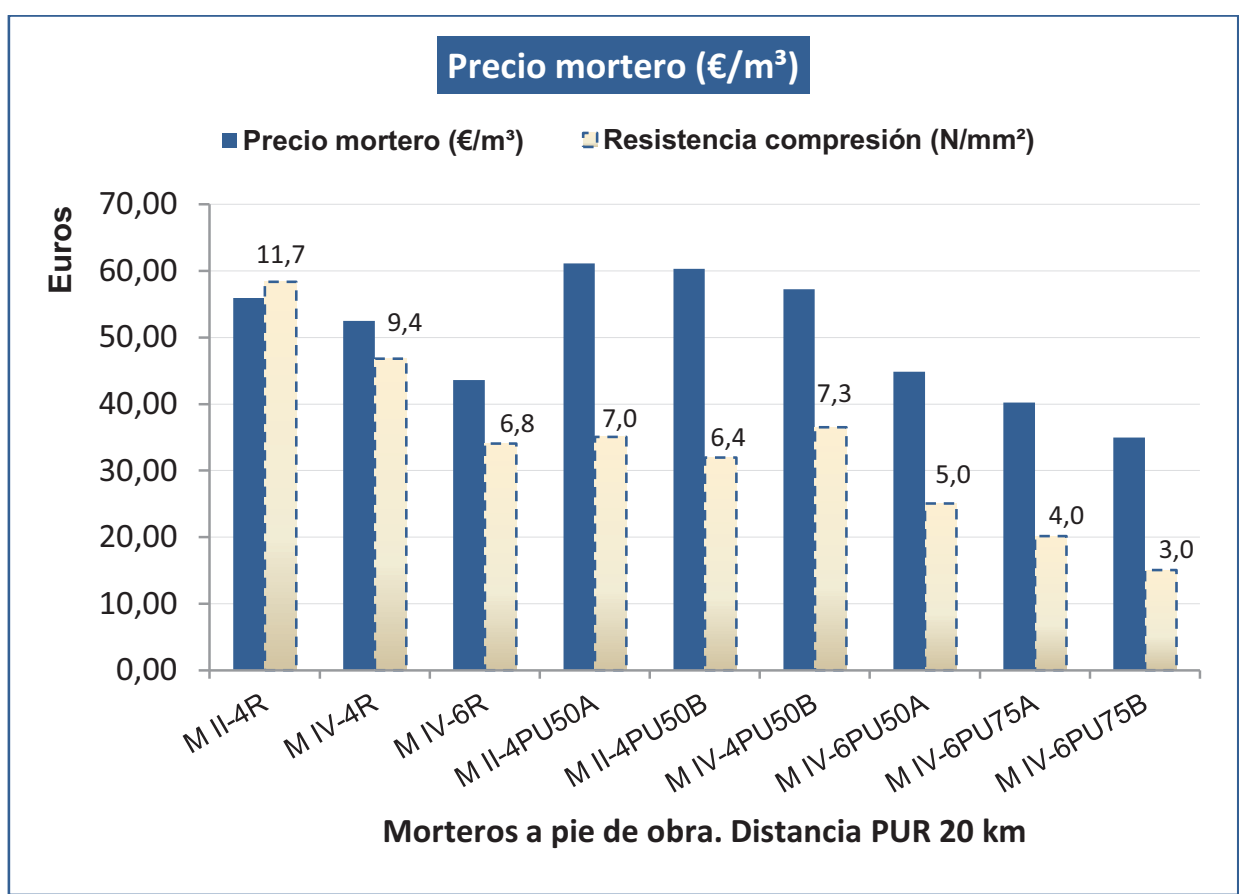

Figura 8.2. Precios comparativos de morteros a pie de obra. Distancia PUR $20 \mathrm{~km}$

\section{2.- Disminución del valor de las acciones permanentes sobre la estructura de los edificios}

Se ha realizado una simulación de la diferencia de peso de la totalidad del mortero que se utiliza en un "edificio tipo" de viviendas en la ciudad de Burgos, si se sustituye el mortero tradicional por el aligerado. La diferencia en el peso total dividida entre los metros cuadrados de forjado de la construcción nos indicará la disminución de las cargas, que repercutirá en la carga total de cálculo de forjados y demás elementos estructurales, incluida la cimentación.

El edificio objeto de la simulación es un edificio residencial privado situado en Burgos capital finalizado en el año 2007, que consta de planta de sótano para garaje, plantas bajas destinadas a portal y locales comerciales y pisos $1^{\circ}$ a $5^{\circ}$ que albergan un total de 36 apartamentos de un dormitorio y 44 viviendas de dos y tres dormitorios; el espacio bajo cubierta alberga 80 trasteros (Figura 8.3). 


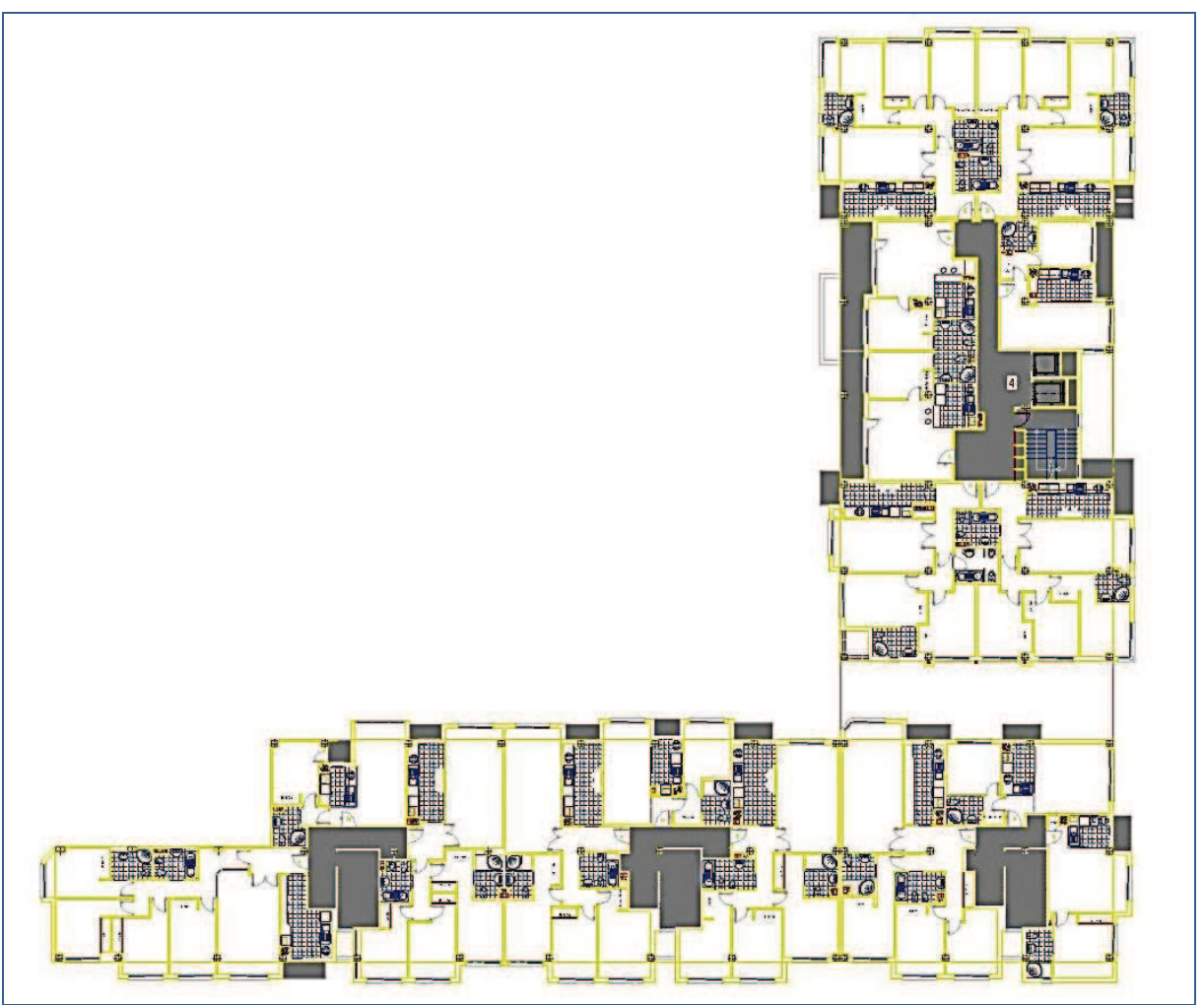

Figura 8.3. Plano de planta edificio objeto de simulación

Los principales materiales empleados en la construcción han sido: cimentación y estructura de hormigón armado; cerramientos de fachada de ladrillo cara vista y elementos prefabricados de hormigón; particiones interiores de ladrillo hueco o perforado de $24 \mathrm{~cm}$ de soga; alicatados de baldosa cerámica pegados sobre enfoscado de cemento; solados de madera y cerámicos sobre capa de nivelación de mortero de cemento de $6 \mathrm{~cm}$ de espesor. El resto de unidades de obra no intervienen de forma directa en la estimación del peso del mortero de cemento.

Para poder evaluar la disminución de cargas sobre el edificio, por el uso de morteros con espuma, se han realizado las mediciones de las unidades de obra con presencia determinante de mortero de cemento. Los morteros aligerados empleados en la simulación se han incluido en las mismas unidades que los utilizados en el Capítulo 7 de "aplicación y puesta en obra" 
La Tabla 8.11 muestra los metros cúbicos de mortero puestos en obra en el edificio, con expresión de las distintas unidades en las que es necesaria una cantidad significativa de mortero.

Tabla 8.11. Volumen de mortero empleado en edificio tipo

\begin{tabular}{|c|c|c|c|}
\hline Unidad de obra & Medición & $\begin{array}{c}\text { Cantidad/ } \\
\text { unidad }\end{array}$ & Mortero total \\
\hline & $\mathrm{m}^{2}$ & $\mathrm{~m}^{3}$ & $\mathrm{~m}^{3}$ \\
\hline $1 / 2$ pie L.P. V. $5 \mathrm{~cm}$ fachada & $1.812,10$ & 0,032620 & 59,110 \\
\hline $1 / 2$ pie L.P. N.V. $7 \mathrm{~cm}$ & $3.420,75$ & 0,025789 & 88,217 \\
\hline Tabicón L.H.D. 9 cm & $10.196,85$ & 0,016484 & 168,080 \\
\hline Tabique L.H.D. 7 cm & $6.196,59$ & 0,012821 & 79,443 \\
\hline Tabique L.H.D. $4 \mathrm{~cm}$ & $1.632,12$ & 0,007326 & 11,957 \\
\hline $1 / 2$ pie L.H.D. $11,5 \mathrm{~cm}$ & $1.632,12$ & 0,021425 & 34,967 \\
\hline Enfosc. B.V. cámaras & $1.812,10$ & 0,010000 & 18,121 \\
\hline Enfosc. Maest. Exterior (pint) & 239,62 & 0,015000 & 3,594 \\
\hline Enfosc. Maest. Interior (alicat) & $6.051,46$ & 0,015000 & 90,772 \\
\hline Capa nivelación suelos $6 \mathrm{~cm}$ & $6.094,55$ & 0,060000 & 365,673 \\
\hline
\end{tabular}

En las Tablas 8.12 y 8.13 se ha calculado el peso total de mortero en el edificio, empleando mortero tradicional y aligerado respectivamente.

Tabla 8.12. Peso total del mortero de referencia en edificio tipo

\begin{tabular}{|c|c|c|c|c|}
\hline Unidad de obra & $\begin{array}{c}\text { Mortero } \\
\text { total }\end{array}$ & $\begin{array}{c}\text { Tipo } \\
\text { mortero }\end{array}$ & Densidad & Peso \\
\hline & $\mathbf{m}^{3}$ & & $\mathrm{~kg} / \mathrm{m}^{3}$ & kg \\
\hline $1 / 2$ pie L.P. V. $5 \mathrm{~cm}$ fachada & 59,110 & II $1 / 6$ & 1.900 & 112.309 \\
\hline $1 / 2$ pie L.P. N.V. $7 \mathrm{~cm}$ & 88,217 & II 1/6 & 1.900 & 167.612 \\
\hline Tabicón L.H.D. 9 cm & 168,080 & II $1 / 6$ & 1.900 & 319.352 \\
\hline Tabique L.H.D. 7 cm & 79,443 & II 1/6 & 1.900 & 150.942 \\
\hline Tabique L.H.D. 4 cm & 11,957 & II 1/6 & 1.900 & 22.718 \\
\hline $1 / 2$ pie L.H.D. $11,5 \mathrm{~cm}$ & 34,967 & II 1/6 & 1.900 & 66.438 \\
\hline Enfosc. B.V. cámaras & 18,121 & II 1/6 & 1.900 & 34.430 \\
\hline Enfosc. Maest. Exterior (pint) & 3,594 & II $1 / 4$ & 1.980 & 7.117 \\
\hline Enfosc. Maest. Interior (alic) & 90,772 & II 1/4 & 1.980 & 179.728 \\
\hline \multirow[t]{2}{*}{ Capa nivelación suelos $6 \mathrm{~cm}$} & 365,673 & II 1/6 & 1.900 & 694.779 \\
\hline & & & TOTAL & 1.755 .425 \\
\hline
\end{tabular}


Tabla 8.13. Peso total del mortero con agregado PUR en edificio tipo

\begin{tabular}{|c|c|c|c|c|}
\hline Unidad de obra & $\begin{array}{c}\text { Mortero } \\
\text { total }\end{array}$ & Tipo mortero & Densidad & Peso \\
\hline Mortero tradicional & $\mathbf{m}^{3}$ & & $\mathrm{~kg} / \mathrm{m}^{3}$ & kg \\
\hline $1 / 2$ pie L.P. V. $5 \mathrm{~cm}$ fachada & 59,110 & M IV-4PU50B & 1.610 & 95.168 \\
\hline $1 / 2$ pie L.P. N.V. $7 \mathrm{~cm}$ & 88,217 & M IV-4PU50B & 1.610 & 142.029 \\
\hline Tabicón L.H.D. 9 cm & 168,080 & M IV-6PU50A & 1.312 & 220.521 \\
\hline Tabique L.H.D. 7 cm & 79,443 & M IV-6PU50A & 1.312 & 104.230 \\
\hline Tabique L.H.D. 4 cm & 11,957 & M IV-6PU50A & 1.312 & 15.687 \\
\hline 1/2 pie L.H.D. $11,5 \mathrm{~cm}$ & 34,967 & M IV-6PU50A & 1.312 & 45.877 \\
\hline Enfosc. B.V. cámaras & 18,121 & M IV-6PU50A & 1.312 & 23.775 \\
\hline Enfosc. Maest. Exterior (pint) & 3,594 & M II-4PU50B & 1.629 & 5.855 \\
\hline Enfosc. Maest. Interior (alic) & 90,772 & M II-4PU50A & 1.339 & 121.544 \\
\hline \multirow[t]{2}{*}{ Capa nivelación suelos 6 cm } & 365,673 & M IV-6PU75A & 987 & 360.919 \\
\hline & & & TOTAL & 1.135 .604 \\
\hline
\end{tabular}

La diferencia entre el peso total del mortero de referencia y el mortero con agregado de PUR es de $\mathbf{6 1 9 . 8 2 1} \mathbf{~ k g}$. La medición de los metros cuadrados de forjado, excluido el forjado del techo del sótano, situado bajo una plaza pública, es de $11.324 \mathrm{~m}^{2}$, por lo que la disminución de cargas sobre el forjado es de $54,74 \mathrm{~kg} / \mathrm{m}^{2}$, es decir $0,54 \mathrm{kN} / \mathrm{m}^{2}$

El Código Técnico de la Edificación (CTE) en su documento básico de seguridad estructural SE-AE Acciones en la edificación, ${ }^{147}$ determina las acciones sobre los edificios para el cumplimiento de los requisitos de seguridad estructural, considerando unas acciones permanentes y unas acciones variables, que para un edificio de viviendas de configuración estándar situado en la provincia de Burgos son las siguientes:

Acciones permanentes:

- Peso propio elementos estructurales

$3,0 \mathrm{kN} / \mathrm{m}^{2}$

- Peso propio tabiquería

$1,0 \mathrm{kN} / \mathrm{m}^{2}$

- Peso propio solados

$1,0 \mathrm{kN} / \mathrm{m}^{2}$

- Suma acciones permanentes

$5,0 \mathrm{kN} / \mathrm{m}^{2}$

147 Código Técnico de la Edificación (CTE). Documento Básico de Seguridad estructural, Acciones en la edificación (DB-SE AE). RD 314-2006 de 17 de marzo. BOE $n^{\circ} 74$ de 28/03. 2006 
Acciones variables:

- Sobrecarga de uso

$2,0 \mathrm{kN} / \mathrm{m}^{2}$

- Suma acciones variables

$2,0 \mathrm{kN} / \mathrm{m}^{2}$

Carga total de cálculo de los forjados

$7,0 \mathrm{kN} / \mathrm{m}^{2}$

La disminución de $0,54 \mathrm{kN} / \mathrm{m}^{2}$ en las cargas sobre forjado, por efecto del empleo de morteros aligerados con PUR en cerramientos, particiones y solados, supone una reducción en la carga total de cálculo de los forjados del $\mathbf{7 , 7 1 \%}$, con la consiguiente reducción del coste de la estructura y cimentación. 

の

0

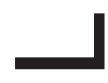

$\supset$

$\vdash$

$-$

0

$\longrightarrow$

0

Conclusiones finales

Líneas de investigación de futuro 



\section{Capítulo 9.- Conclusiones finales. Líneas de investigación de futuro}

\section{1.- Conclusiones finales}

El trabajo de investigación realizado en esta Tesis Doctoral demuestra la viabilidad de la fabricación y puesta en obra de los morteros aligerados con agregados de PUR, que se resume en las siguientes conclusiones:

1. Los residuos de espuma rígida de poliuretano, previamente triturados, pueden sustituir parcialmente a la arena en los morteros de cemento, obteniendo mezclas "manejables", homogéneas y plásticas en estado fresco

2. La densidad aparente de las mezclas en estado endurecido, es significativamente menor en los morteros con agregados de PUR que en los morteros de referencia, alcanzándose densidades por debajo de $1,30 \mathrm{~kg} / \mathrm{l}$, por lo que en muchos casos se pueden considerar como materiales ligeros.

3. La caracterización microestructural del mortero endurecido muestra una buena cohesión entre todos los componentes y una distribución homogénea de los materiales y poros.

4. Las prestaciones mecánicas de estos morteros reciclados son inferiores a las de los morteros de referencia, pero suficientes para el cumplimiento de las especificaciones de las normas EN para su utilización en obra, tanto como morteros para albañilería como morteros para revoco y enlucido.

5. Los ensayos de durabilidad realizados indican, en todo caso, que las pérdidas de resistencia son similares en los morteros con espuma y en sus homólogos de referencia.

6. Los morteros con agregados de PUR tienen una permeabilidad al vapor superior a los morteros de referencia debido a su elevada porosidad, por lo que su empleo en cerramientos de fachada facilita la difusión de vapor y en consecuencia mejora el comportamiento de la fachada frente a las condensaciones intersticiales. 
7. Los morteros ligeros ensayados muestran una mejor adaptación frente a estados obligados de deformación (estados de confinamiento) que los morteros de referencia, al tratarse de morteros más deformables, lo que previene la fisuración en los morteros de juntas, pudiéndose incluso llegar a eliminar las juntas de movimiento en algunos tipos de fábricas.

8. Se ha comprobado que las mezclas confeccionadas con los dos tipos de aditivos no ofrecen mejora sustancial en las características de los morteros con agregados de PUR.

9. Se ha contrastado la viabilidad de estos materiales para su aplicación in situ, comprobando que las condiciones de amasado y puesta en obra son similares a las de los morteros de referencia y que son aptos como soporte para revestimientos y acabados tradicionales.

10. La reutilización de los residuos de espumas de poliuretano produce un beneficio medioambiental importante, pues el volumen de mortero que se emplea en un edificio implica un gran volumen de residuos reciclados. El reciclaje es un valor añadido frente a la posible recuperación energética, y en mayor medida frente a la eliminación en vertederos.

11. Los morteros obtenidos presentan un precio muy competitivo con respecto a sus homólogos de referencia llegando a ser, en algunos casos, claramente inferior. La disminución en las cargas permanentes sobre la estructura implicaría el proyecto de una estructura más ligera y en consecuencia de menor coste, que en todo caso se podría evaluar cuantitativamente.

\section{2.- Líneas de investigación de futuro}

En esta investigación no se ha profundizado en el conocimiento de algunas características importantes de los morteros ni en dosificaciones con árido algo más grueso que pueda dar lugar a la obtención de hormigones no estructurales. Por ello se proponen las siguientes líneas de investigación para el futuro. 
1. Analizar con mayor intensidad el comportamiento frente al fuego del mortero con agregado de PUR, en las dos vertientes de resistencia y reacción al fuego, con el objeto de obtener una clasificación normativa de este tipo de morteros.

2. La mejora en el aislamiento térmico que proporciona el empleo de morteros aligerados es evidente, pero no se ha evaluado. Sería preciso cuantificar los valores de conductividad térmica de estos materiales para calcular la mejora en las transmitancias térmicas en las unidades de obra de que forman parte, y poder estimar el ahorro energético.

3. Al tratarse de morteros menos rígidos que los convencionales, es muy posible que mejoren el confort acústico en el interior de los recintos. Por ello se propone profundizar en el conocimiento de la absorción acústica.

4. La fabricación de hormigones no estructurales con gravas finas o gravillas y con sustitución total de la arena por PUR, podría ser utilizado en capas de nivelación sobre forjados o en la formación de pendientes para cubiertas planas o inclinadas.

5. Las industrias que emplean conformados de espuma rígida de poliuretano, fabrican sus productos con acabados plásticos o de fibras. La utilización de los residuos de estos materiales compuestos, previamente triturados, podrían proporcionar morteros igualmente viables.

6. Sería interesante investigar en cómo reciclar este tipo de morteros que incluyen poliuretano, una vez que su ciclo de vida útil haya terminado, transformando así un proceso lineal en un proceso cíclico. La demolición de las edificaciones debe realizarse con separación de las unidades de obra que contengan mortero con agregados de PUR. Es posible que una trituración adecuada del residuo, que incluya materiales cerámicos o pétreos, pueda nuevamente ser utilizada como sustitución total o parcial del árido de morteros y hormigones no estructurales. 